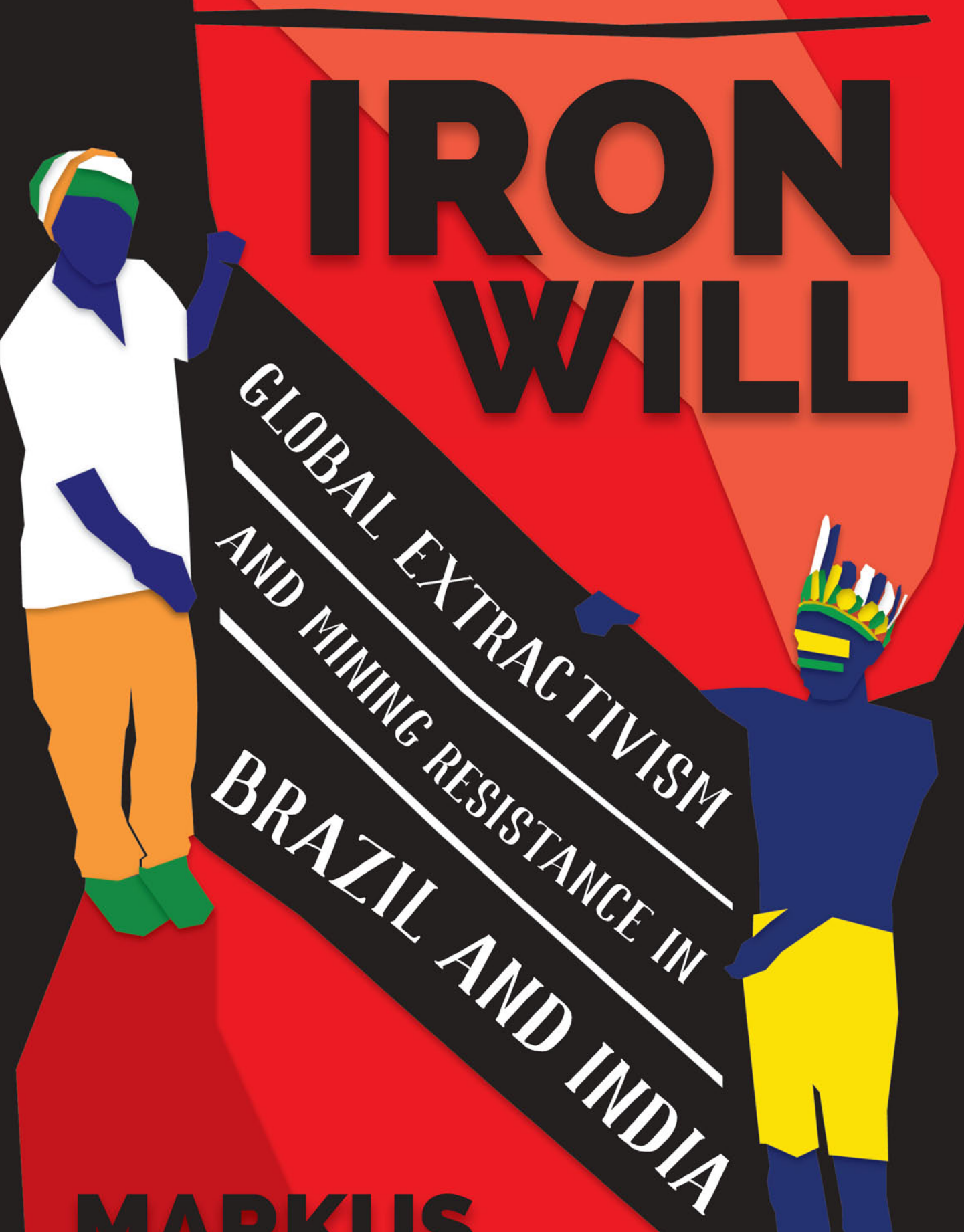


Iron Will 


\title{
Iron Will
}

\author{
Global Extractivism and \\ Mining Resistance \\ in Brazil and India
}

Markus Kröger

University of Michigan Press

Ann Arbor 
Copyright (C) 2020 by Markus Kröger

All rights reserved

\section{cc)creative}

This work is licensed under a Creative Commons Attribution-NonCommercialNoDerivatives 4.0 International License. Note to users: A Creative Commons license is only valid when it is applied by the person or entity that holds rights to the licensed work. Works may contain components (e.g., photographs, illustrations, or quotations) to which the rightsholder in the work cannot apply the license. It is ultimately your responsibility to independently evaluate the copyright status of any work or component part of a work you use, in light of your intended use. To view a copy of this license, visit http://creativecommons.org/licenses/by-nc-nd/4.0/.

Published in the United States of America by the University of Michigan Press

Manufactured in the United States of America

Printed on acid-free paper

First published November 2020

A CIP catalog record for this book is available from the British Library.

Library of Congress Cataloging-in-Publication data has been applied for.

ISBN 978-0-472-13212-6 (hardcover : alk. paper)

ISBN 978-0-472-12711-5 (e-book)

ISBN 978-0-472-90239-2 (OA)

http://dx.doi.org/10.3998/mpub.11533186 
To Otso and Jenni 


\section{Contents}

Preface $\quad$ ix

Acknowledgments $\quad \mathrm{xv}$

Introduction 1

Part I. Theorizing the Impacts of Resistance to Extractivism 25

Chapter 1. Resistance and Investment Outcomes 27

Chapter 2. Theory of Investment Politics and Spatial Changes 47

Part II. Political Dynamics and Contexts $\quad 67$

Chapter 3. Nonarmed Resistance 69

Chapter 4. Armed Conflicts 105

Part III. Peaceful Resistance Strategies 139

Chapter 5. Protesting by Mass Social Movements 141

Chapter 6. Using a Broad Set of Strategies 153

Chapter 7. Global and National Coalitions 189

Conclusion: Resisting the Global Political Economy of Extractivism 202

Epilogue $\quad 233$

Methodological Appendix $\quad 235$

Notes $\quad 245$

$\begin{array}{ll}\text { Abbreviations } & 271\end{array}$

References 273

Index 287

Digital materials related to this title can be found on the Fulcrum platform via the following citable URL: https://doi.org/10.3998/mpub.11533186 


\section{Preface}

The sun shone and gusts of hot air hit my face while I motorcycled down the road, alternately passing through patches of rice paddies and forests. I was somewhere I had been before, but something was different. It took a minute to put my finger on it: the previously ever-present dust floating in the air of eastern Goa's hilly mining areas was gone. In India's largest iron ore exporting state, mining had abruptly ceased. This seemed incongruous to the normal course of extractive ventures as there was still plenty of ore in the ground, and global iron ore prices and demand were at record highs. I had traveled to Goa to understand how and why the mining had been stopped. I was on this long ride with scholar Sebastian Rodrigues, an advocate of socio-environmental justice, and we traveled these winding roads to meet another key activist, Ramesh Gauns, in the town of Bicholim. The residents of this town, as in many other towns and villages around the world, had seen their lives deeply disrupted by a sudden and aggressive increase in mining activities in the 2000s. Mines, both legal and illegal, had surrounded their neighborhoods with little warning and certainly no free, prior, or informed consent — churning away forests, hills, and rice paddies, and turning their rivers into muddy flows of silt. At the height of the mining crisis it seemed like these communities would end up ground away, cast aside in favor of the ore buried in their very foundations. Yet the mining had been stopped.

From the tranquil rice fields in Bicholim we could see the hilltops of the Western Ghats mountains, stripped of their forests. The scars of mining operations were visible, brown open-pit mining areas, a visceral reminder of the scale of the destruction and turmoil. Now the hilltops were still; a few short months ago there was simply the traffic of trucks and the noise of mining excavators, but today birdsongs could be heard once again. This seemed to be something of a miracle, but I quickly figured out that this was 
not a stand-alone case. In my travels across the iron ore mining areas and steel towns of India in 2013, I came across other places where birdsongs, the chatter of monkeys, and the conversations of citizens gathered at food stands were louder than extraction machines. In addition to the closures there was an even more unexpected finding, that new and purported to be important planned mining projects, which would have removed mountains in the Tamil Nadu, Odisha, Chhattisgarh, and Jharkhand states of India, had also been discontinued. Even more shocking, this was not a phenomenon limited to the hills of India, as I also encountered shuttered and discontinued mining and extraction projects in Brazil. The common factor between these geographically distant examples was that these outcomes were mostly the result of different types of resistance led by communities or local NGOs, or both. This book will tell the story of how varying sets of local resistance groups succeeded-despite seemingly insurmountable odds.

Between 2005 and 2015, a time period that came to be known as the commodities "supercycle," there was an unprecedented global boom in commodity prices. In many places the will to get rich through natural resource extraction did not meet the kind of fierce resistance that I witnessed in Brazil and India. This unprecedented will, coupled with a new level of industrial capacity to extract iron ore and other natural resources faster and in larger quantities than ever before, was happening simultaneously all around the world. The turn toward mining in Goa was part of a larger trend. When people affected by these mining operations tried to take a stand against the mines, they seldom managed to turn the boom to a bust. A more likely outcome was greater monetary compensation by sharing the spoils of extractivism. However, for the people who were affected on the ground level, even this compensation was typically just a fraction of the riches carried away by those in power who pocketed the mining profits from the sapped lands of local communities. The lived environments of these communities were turned into natural resources, trucked out, and shipped away, while their possibilities of returning to prior land uses and livelihoods were rendered virtually impossible. However, Goa was different. A strong willingness joined with a capacity and innovative strategies to resist this "extractivism" was forged and spread. Willing to stop the extraction at almost any cost, activists threw themselves into a fight against a powerful force.

The activists in Goa approached their resistance from multiple angles and expressed openly in writing, speeches, and through other tangible actions what they thought and felt about this irreversible transformation of their home regions. These concrete actions forged an iron will for resistance. The 
citizen-activists of Goa and several other parts of India formed mass social movements, campaigned, protested vehemently, networked with supporters around the world, and targeted state institutions to change the way those institutions treated mining. The results of this resistance were profound. Mining regulations were changed all around India, and the resistance led to massive discontinuations of mining operations and cancellation of irregular licenses in about half of the iron ore areas in the country. This iron will of resistance led to the discontinuation of practically all iron ore mining operations in Goa.

As fast, concrete, and actionable solutions to the worldwide lifethreatening climate, biodiversity, and other socio-environmental crises are urgently needed, I went to India to document how this kind of change had been possible in practice. My first trip was in 2010 and introduced me to the efforts being made on the ground to resist the mining. I went to southern Goa, visiting the tribal villages there, walking for several hours across the Western Ghats' rainforest-covered hills to the state of Karnataka with the locals, sleeping on the hard clay floor of huts in a remote village, deep in the forest and very seldom visited by outsiders. I covered this ground with the locals to understand what was being churned away and endangered by the spread of open-pit mines that I saw being gouged ever deeper into the hills. I returned in 2012-13 to speak with those activists who had put their lives on the line to stop the mining destruction. In addition, I used this trip to visit the devastated and targeted areas to get an intimate knowledge of the lived environments after the mining ceased. I was guided by seasoned activists, such as Rodrigues and Gauns, who were among those spearheading the resistance in Goa. These men had personally felt the collateral damages of mining such as air pollution and its negative health impacts. They were active in writing poetry about their love for nature that was being destroyed and for the villages the mining was turning to dust. This poetry deeply resonated with and inspired the citizenry, both in the affected areas and beyond. Rodrigues, who personally wrote over 1,000 blog posts between 2007 and 2010 that collectively got over 100,000 views, considered the following as important qualities for developing a successful activism:

Write with evidence, make no compromises, refuse [private] talks [with companies]. The most critical thing was to talk out first, before trying to organize people. I played very risky, put myself in front, had a confidence that I can defend myself, while some other person might not. I knew I had lot of support, and miners underestimated us. 
This quote encapsulates a key feature behind success of the resistance in Goa, which was the willingness to resist and act, choosing the right choice of strategies, and the avoidance of seeming potential allies who really did not work for the benefit of the locals in the long run. By "willingness," I mean that initial active agency is crucial to launch into any broader resistance effort.

Standing on a hilltop temple in Bicholim with Rodrigues, I could see how the adjacent hills' forests had been turned into mining areas. However, there was something visible beyond the expected green and brown contrast between the forest and the open mines. The hillsides were dotted with huge blue tarps: Why were these here? Rodrigues explained that the resistance had started to use satellite maps to detect the spread of mines and compare these with the official mining lease areas, which allowed them to accurately denounce irregularities. This "orbital" resistance had proved effective, and the miners were attempting to hide their actions from satellite observation by camouflaging the mines. The blue of the tarps blended with the green of the forest in the satellite images. This novel and evidence-based form of resistance using satellite maps was just one of many that were explained to me throughout the years that I spent in areas targeted by large-scale investment projects aimed at creating and extracting "natural resources."

My research has been mostly based around studying and understanding natural resource politics and large-scale resource extraction investment projects. This work is timely and important, as on a truly global scale, the investment in the extraction of natural resources has been significantly accelerating and expanding. This unprecedented expanse is driven by increasing global demand and the allure of higher profits during a period of buoyant prices for a range of industrial raw materials. Numerous governments around the world, both in the Global North and Global South, have pursued the expansion of natural resource extraction projects. These projects have been explicitly justified and rationalized as a vehicle for economic growth and development. Mining has been at the center of this global expansion of extractivism. I have been doing fieldwork to support my research in Brazil since 2004 and India since 2010, as both of these countries were key players as extraction sites in this resource boom. My aim was to gather material for a book that would compare these two globally crucial sources of raw materials, which were also among the world's largest democracies and rising powers during the 2000s. I have a long-standing interest in the phenomena of resistance and the conditions under which it forms, and what causes it to succeed or fail. This book reveals whether and how resistance influences local, national, and global extractive projects. This exploration of resistance in the face of extraction also engages with many other important political 
processes, such as democratic decision-making within these two rising powers of Brazil and India.

During my journeys through India and Brazil, I visited iron ore mining and steel towns, forests, and mountain ranges during both the boom and bust periods of the global commodity supercycle. This book is about what I learned and observed in these different places. I heard many stories of extraction and resistance, and in several key moments I was there to personally observe the events as they unfolded on the ground. I traveled with the key players and observed their meetings where important decisions were discussed and adopted by the resistance. I got to see processes in their entirety from the seed of the idea to the execution of organized efforts, protests, and networking events. I also observed how the industry and selected state institutions made decisions, and visited many mining areas to understand how extraction takes place. For example, I was welcomed to the Vale headquarters where the company directors gave me rare interviews, and was granted a coveted visit as an outsider to the world's largest iron ore mine in Carajás, seeing in practice how the mine was cutting away the Amazon rainforest deep inside the mining area. It is these practical encounters and living with extraction and resistance that compelled me and piqued my interest. What I saw and heard led me to understand that there were many layers, undertones, and unnoted, yet important, actions and consequences that needed to be documented. 


\section{Acknowledgments}

This research for this book has been funded by the Academy of Finland, "The Politics of Corporate Resource Exploitation: Social Movement Influence on Paper and Metal Industry Investments in Brazil and India" (grant number 251321, postdoctoral fellow project); the Academy of Finland, "Human Ecology, Land Conversion and the Global Resource Economy" (grant number 253680); and a Kone Foundation postdoctoral fellow project, "Contentious Agency and Corporate Resource Exploitation: A Qualitative Comparative Analysis of Social Movement Impacts on Paper and Steel Industry in Brazil and India." Many thanks to the Academy of Finland and the Kone Foundation for their support of this research. This book would not have been possible without their financial support.

A research project of this magnitude could not have been carried out without enormous assistance from a very large group of people. I am extremely grateful and indebted to the people who helped me in innumerable ways along this path. Hundreds of people in Brazil and India helped me to conduct the field research, offering their valuable time for interviews, helping me to move around, to make contacts, providing access to new sites, and helping with accommodation and everything else.

There are some people in my field sites who were particularly helpful, and I would like to give them extra recognition. In Brazil, during my time in Maranhão, I want to thank Divina, Regina, José Luis, Antonio, and others who helped me do fieldwork. In Pará, I am grateful to Ulisses Manacas, Adima, Leticia, Maria Raimunda, Gabriela, Cassia, Salete, Felício Pontes, Claudio Ferreira, and Pablo Carrasco for hosting or offering contacts and viewpoints, or both. Elsewhere in Brazil, I am indebted in many ways for the help and commentaries by Pertti Simula, Biancca Castro, Mariana Penna, Rodrigo Santos, Carlos Bittencourt, Maria Gomes, José Batista, and many others. 
It was important and inspiring to have discussions on this book's topics with and receive help from Ville-Veikko Hirvelä, Kai Vaara, Satu RantaTyrkkö, Juho Partanen, Pekka Pennanen, Bobby Banerjee, Carlos Santana, Samarendra Das, Felix Padel, Eduardo Gudynas, Heather Bedi, Anita Basu, Subash Mohapatra, and Sam Agarwal. In India there were also key people who deserve extra thanks. In Goa, I am extremely grateful to Sebastian Rodrigues and all the others who helped me there; in Karnataka, to Leo Saldanha and others; in Tamil Nadu, to Piyush Manush; in Odisha, Chhattisgarh, New Delhi, and Jharkhand, to Rabi Pradhan and Duskar Barik, as well as many others whose help was crucial.

The ideas for this book were presented in numerous conferences, where several people offered their helpful comments. For commentaries on parts of this book I would like to thank my fellow Brazilian Studies Association panelists Kathryn Hochstetler, Andréa Zhouri, Klemens Laschefski, and Marcos Pedlowski. From the International Studies Association panels, I owe thanks to Amy Below, Vinicius Rodrigues, Marieke de Hoon, Mark Axelrod, Surupa Gupta, and Moises Arce. From the British Association of South Asian Studies and Swedish South Asian Studies Network panels I would like to thank Alf Nilsen, Patrik Oskarsson, and Kenneth Nielsen. From the World-Ecology Research Network conference, I was very happy to have constructive discussions with Jason W. Moore, Ossi Ollinaho, Joshua Eichen, Andrew Pragacz, and Marcus Taylor, among many others. From the Food Sovereignty and International Critical Agrarian Studies conferences organized by the International Institute of Social Studies in The Hague, Cornell, and elsewhere, I am grateful to discussions with Jun Borras, Alfredo Fradejas, Tania Li, Larry Lohmann, Joan Martinez Alier, Natalia Mamonova, Ben McKay, Sara Mingorría, and Henry Bernstein. From the International Sociological Association conferences, I would like to thank Peter Evans, Chris Chase-Dunn, Michael Levien, and James Goodman for fruitful discussions. From the BRICS Agrarian Studies Conferences, I am grateful to comments by Gustavo Oliveira, Sérgio Sauer, and others. From the International Rural Studies Association conference panel on mining, I would like to thank JoAnne Everingham and Sandra Franco. From the Development Days conferences in Helsinki, I would like to thank Neera Chandroke, Dinah Rajak, and all others who commented on my presentations.

I am deeply grateful to the many comments, edits, and proofreads I received from my colleagues in Finland. At the University of Helsinki, from Development Studies, I want to thank Barry Gills, Anja Nygren, Franklin Obeng-Odoom, Lauri Siitonen, Maria Ehrnström-Fuentes, and Gutu Wayessa; from Anthropology, Timo Kaartinen and Sarah Green; from 
World Politics and Political Science, Teivo Teivainen, Pertti Ahonen, Jussi Pakkasvirta, and Juri Mykkänen. Thanks also to my colleagues on our working group on Power and Ecology for our inspiring debates, including Tero Toivanen, Tuomas Tammisto, Otto Bruun, Mira Käkönen, Jenni Mölkänen, Johanna Järvelä, Maija Lassila, Anu Lounela, and Liina-Maija Quist. The language and contents of this book were greatly improved through their close and careful reading by Nely Keinänen, Marie-Louise Karttunen, and Sanna Komi. I also owe thanks for the editing contributions made by Sarra Kepponen and by Janne Salovaara for his help with the figures and cover design. I am especially deeply grateful to Sophia Hagolani-Albov for going through the manuscript in detail and helping me with all the different aspects of editing, proofing, figure development, and formatting to get this book completed. I am also grateful for the overall developmental commentaries given by Audra Wolfe and Tara Mendola.

Thanks to all the editors who worked on the book production at the University of Michigan Press. Special thanks to Senior Acquisitions Editor Elizabeth Demers for her enthusiastic and supportive feedback on this book project starting from our first exchanges. I am also thankful for the careful editorial help by Danielle Coty and Haley Winkle, as well as for Production Editor Mary K. Hashman and John Raymond for going through and copyediting the final manuscript in detail. I would also like to thank everyone else at the Press for helping with the publication of this book.

Finally, I am extremely grateful for all the support and help offered by my wife, Jenni Munne, throughout this research process, in innumerable ways. She helped me in crucial moments as a life partner, travel companion, field assistant, and transcriber. She offered insightful views and motivation to continue on long roads, pursuing higher goals. 


\section{Introduction}

This book explores how resistance to destructive extractive projects can succeed in keeping minerals in the ground even in very difficult circumstances. It demonstrates the importance of tackling the pressing global sustainability crises at the points of production, through a curbing of resource flow, which serves to affect the whole commodity chain. I explain how the use of five key strategies by local and larger-scale resistance is essential in addressing the global crises, mine by mine, based on a systematic comparison of these investment politics in Brazil and India as they took place during the recent commodity boom.

What I share herein is the result of many years of research on how resistance can successfully discontinue extractive operations. My formative visits to Goa, introduced in the preface, play a central role in this narrative because they offer important lessons on what strategies and tactics local communities and people may consider when facing the thrust of extractivism. ${ }^{1}$ I will compare the strategies and outcomes in Goa to other, less successful and far more complicated attempts at resistance, to understand how best to forge the will to resist. Radical actions and concrete solutions are needed if we are to alter the currently rapid pace of resource depletion and the related severe problems that are being created around the world. I attempt to offer some examples of lived experiences of these actions and potential solutions and strategies for future resistance efforts.

The aim of this book is to study what is effective in keeping minerals in the ground, and more broadly, giving effective governance power for locals to impede the transformation of their lived environments into simply a platform for destructive natural resource extraction, and which strategies do not support this. ${ }^{2}$ The first part of the book provides a general theory on how to study the resistance to extractivism. This provides tools for detailed analy- 
sis of investment politics and extractivism, including their resistance, across varying contexts. I will introduce five key strategies that are being used in differing combinations by a variety of types of resistance groups, which have targeted extractive operations. I compare these five strategies, which are intended to promote and support peaceful resistance to extractivism, with other, less successful or peaceful strategy choices. The second part of the book looks at how different contexts and contingencies influence the effectiveness of the strategies, and which of them are more likely to be used in different contexts. The third part of the book provides more detailed political ethnographic accounts that examine how these strategies functioned in different combinations within the specific contexts of resistance.

\section{Extractivism}

Generally, this book explains how the so-called commodity paradigm unfolded after its start around the mid-2000s and how the will to extract at an accelerating pace and the opposing will to resist reshaped entire nations and regions. By "commodity paradigm," investors and scholars looking at the unprecedented and widespread rise in a range of commodity prices during the latter half of 2000s were referring to the possibility that the world might be experiencing a paradigm shift in relation to the valuation of global trade. The paradigm of the twentieth century, where commodity prices were falling while the value of industrial goods and services was increasing, could possibly be changing back to the situation at the turn of the twentieth century, when resource exporting yielded comparatively more than after that. ${ }^{3}$ However, in comparison to the prior period of high commodity prices (approximately 1900), the commodity paradigm that started in mid-2000s had novel features; raw material production costs were increasing globally while prices were not coming down substantially, even after a global economic slowdown in 2008 (Kröger 2015a). I came to learn that these market tendencies were not directed by an invisible and impersonal hand, but rather caused to a large degree by politics, by personal and group efforts on the ground, which influenced extraction prices and impeded wanton expansion all around (Kröger 2019).

Extractivism has both political causes and effects, this being the politics that enfolds through environmental changes. The rapid shifts from acceleration of and a resistance to extractivism have resulted in the imprisonment of key politicians at one end and the creation of new global activists at the other. During the late 2000s, extractivism became the dominant political- 
economic model of many governments around the globe. This extractivist turn created grave sustainability challenges with global impacts. Mining at the breakneck pace that extractivism demands induces socio-environmental havoc, including increased air pollution, soil and water pollution, and severe social and health problems that all increase steadily as unchecked mining activity increases.

I adopt the term "extractivism" to describe this accelerated natural resource extraction. This term has been quite important in the social sciences and has been a key term in recent years to explain how Latin American countries molded their whole economies as export-oriented (neo-)extractivist economies (Burchardt and Dietz 2014; Gudynas 2015; McKay 2017). The term thus serves a broader political/economic analysis of important and contemporary social change processes (Ye et al. 2020). In Latin American (neo-)extractivism, financial remuneration for the megacorporations prevails over the strengthening of the rights of citizens or environmental protection. While this is true of any sector that is engaged in extractivist practices, it is particularly true for the massively important export mining sector (Chomsky 2016; Gudynas 2012, 2016; Petras and Veltmeyer 2014; Valdivia 2015). Mining expansion and conflicts illustrate the tension between belief in growth based on resource exploitation and demands that this extraction be curbed because it is either socio-environmentally unethical and unsustainable (see Zhouri and Valencio 2014) or developmentally misguided (see Evans 2010; Marques 2007, 2012), or both (see Bunker 1985, 2003). In this book I lift the concept of extractivism out of its Latin American context and use it as a lens through which to analyze the mining supercycle in India. Additionally, I will broaden the analytical power of extractivism by exploring in detail the social, physical, and symbolic dimensions and dynamics of the term. Research on extractivism as a concept that opens up in more detail and accuracy current key global transformations than prior concepts is growing. Jingzhong Ye, Jan Douwe van der Ploeg, Sergio Schneider, and Teodor Shanin (2020: 158) provide several hypotheses on how to think of the world through extractivism, arguing that extractivism is a patterning and structuring process that "explores the world for already existing, but still hidden wealth and then exploits it till it is exhausted," without producing wealth. They argue that extractivism has been turning from isolated local practices to macro-policies of entire nations (something that the debate on neo-extractivism started to point toward, see Svampa 2019), and has become evermore a hallmark of contemporary global capitalist development. They also suggest that many scholars of resistance are myopic to the currently existing forms of resistance to global capitalism, as this phenom- 
enon has changed into a much more unproductive one, and has other novelties that affect the forms of resistance. Exploring contemporary resistance in the global political economy through focus on resistance to extractivism, as in this book, can thus shed light on the real-world politics of today.

It is important to note that when using the term "extractivism," I refer not only to the mining sector but also to other forms of natural resource exploitation, for example, agroextractivism and forestry extractivism. Extractivism, which derives from the Latin extrahere, and refers to the action of "pulling or drawing out," has a negative connotation and is typically used to refer to large-scale or destructive forms of extraction. Extractivism would not be used to describe sustainable or balanced forms of making use of natural resources (Jalbert et al. 2017; Lang and Mokrani 2013; Willow 2018; Ye et al. 2020). There are many economic theories that study natural resources as "endowments," which can have both positive and negative developmental outcomes depending on the kind of politics through which these resources are extracted, instead of tying a country to a fate due to its having these endowments (Nugent and Robinson 2010; Watts 2004). Extractive behavior can take many forms, and, by extension, extractivism as a broader term is not one-dimensional. Rather, extractivism serves as a manifestation of the global market forces that seek ever-more profitable venues in which to invest. There is a long history to this process, with the past 5,000 years having seen several phases of capital imperialist expansions, wherein extracting resources by power elites in ever-more distant places has been a key feature of an expanding world system (Frank and Gills 1993). The past five centuries have greatly accelerated this process through the simultaneous conquest of the Americas and the linking of these new lands and other regions into a global system dominated and steered primarily by a capitalist world-ecology (Moore 2015). This world-ecology is inherently extractivist, as it relies on creating "cheap natures" and appropriating nature as a frontier-expanding process. Global extractivisms (of different types and sectors) are manifestations of this broader world-systemic process. As such, the extractivist boom, whose key years for iron ore were between 2007 and 2014, also called the "commodity supercycle" and "commodity paradigm," was affected by the key changes in the capitalist world-system (a world-ecology), such as the 2008 financial crisis, which led to abnormally high land and commodity prices, and thus also to land and resource grabbing (Bebbington and Bury 2013; Edelman, Oya, and Borras 2013; Moore 2015).

In comparison to the analyses focusing on the economic or material aspects, a key analytical distinction I want to make is that extractivism is not only a physical process but it also takes place, in a parallel way, in social 
and symbolic spaces. Extractivism entails a type of mind-set, ideology, and practice that seeks to primarily take from nature without giving back. In this extractivist thrust, the world is seen primarily as a series of objects and resources to be exploited, instead of a web of life composed of human and nonhuman living beings. The reciprocal and balanced, nonanthropocentric "lived environments" (see Taylor 2015) typical of many indigenous people and traditional populations (where one sees that one has to also give back to the nature if one takes something) are hidden by the ideological work, justifying framings, symbolic violence, and (de)legitimizing practices that are inherent to and produce extractivisms. As I will discuss, the locals facing these extractivist processes can and have used resistance actions in all the spheres on which global extractivism relies, including physical blocking of extraction, symbolic acts to revalue lives that are undervalued, the broadening of modern and Western understandings of what exists, and social actions to create networks and groups of resistance to counter the power of extractive capital.

To analyze the resistance to extractivism, I combine the more general theories of political economy and world-ecology with movement literature, as this unification can deliver particularly fruitful and powerful explanations of causalities. The goal is a nuanced theoretical framework that can capture detailed particularities, but present and analyze them in a general form. Resistance to expansion pressure is defined as those responses where people do not select a strategy of (loose or tight) incorporation into the business (e.g., by working at the mine, transporting ore, selling goods, or services locally) or conflict avoidance (e.g., by silently fleeing from the site of convulsion), but where they fight (violently or nonviolently, visibly or silently) to defend their autonomy, to retain or increase their control over physical, social, and symbolic space. This conceptualization of resistance and power relations draws on Scott (2009) and Bourdieu (1991). I focus on public and visible politics, on collective action in investment politics, and thus do not discuss at length "weapons of the weak" (see Scott 2009) inside family or organization hierarchies.

The dynamics of contention approach (McAdam, Tarrow, and Tilly 2001, 2008) and the study of investment politics (McAdam and Boudet 2012) make it clear that movements should not be studied alone, but as parts of larger political economic dynamics, where attention is also paid to the actions of targets and third parties (Luders 2010). In the study of movement outcomes, the analysis has usually focused on political outcomes (Amenta et al. 2010). There is, however, a budding scholarship studying the influence of movements on investment and economic outcomes (e.g., Bor- 
ras and Franco 2013; Bosi, Giugni, and Uba 2016; King 2008; King and Soule 2007; McAdam and Boudet 2012; Sherman 2011; Soule 2009; Vasi 2009), demanding further analysis of the causalities between protest and business within the dynamics of contention (McAdam, Tarrow, and Tilly 2001, 2008). The two key gaps that Giugni and Grasso (2015) identify in the study of (environmental) social movements are the interplay between the local and global and the movements' impacts. The detailed study of all the major iron ore mining regions of Brazil and India is an excellent platform to fill in the above theoretical and empirical gaps in knowledge.

\section{Brazil and India}

I chose Brazil and India for exploring the phenomenon of and resistance to extractivism because they are both globally prominent but underresearched centers of new investment and conflict that illustrate unexplored dimensions and new actors in the global political economy and world-ecology. In this book, I explain how the Indian resistance succeeded, against all odds, to discontinue half of the iron ore production in India. Through the detailed analysis of a large database of ethnographic and other data that I have collected over the course of my fieldwork, this book sheds new light to crucial questions whose ramifications and importance are much broader than simply mining. One key question that underpins the book is, how do social movements influence the economy? Which strategies work to resist undesired extraction projects, and which do not? This book analyzes how communities resist extractivism as an ideology and policy used by corporations and governments to turn environments into sites of natural resource extraction, for the purposes of contributing to global production, the everexpanding national production, and commodity markets.

I demonstrate how extractivism lies at the heart of the means by which political and corporate elites stay in power. During 2007-14, iron ore mining became a fast road to political power in both India and Brazil. Yet the people living at or near the extraction zones have revolted against these extractivist state policies, with varying degrees of success. In India, these resistance efforts were so successful that "resource nationalism" became the top risk in 2013 for mining companies (Ernst and Young 2013) and forced the country to curb exports. A political cascade effect of resistance at the point of production has the potential to disrupt commodity markets across the globe.

Extraction zones, such as mines, are often focal points for social resistance 
to extractivist imperatives. This book is the first to trace successful local resistance and evaluate the unsuccessful local resistance to extractivism in India and Brazil, looking specifically at an understudied locus of economic and environmental exploitation in the Global South-iron ore mines. I analyze all the major iron ore mines and expansion projects in these two globally crucial exporting countries through a multisited political ethnography to uncover how global mining processes operate in practice. I detail instances of resistance to extractivism itself, and analyze the outcomes of varying strategies of resistance in different geopolitical contexts. The book thus answers two central questions: how to solve pressing global overproduction and sustainability dilemmas, and what successful local resistance looks like.

The global commodity boom has meant not only a fiercely increasing resource exploitation but also a regulatory mobilization across the Global South. These mobilizations have led to the emergence of new subjectivities, including different types of social movements that include nongovernmental organizations (NGOs) and armed revolutionary groups. Although territorial changes and modifications in investment pace and style have also occurred, I show how, from a movement perspective, a political identity change toward a willingness to resist extractivism has fostered deeper democracy, which has been an important outcome of conflicts.

Although there is a growing literature on global environmental governance, including works that compare particular resource sectors in India and Brazil, ${ }^{4}$ the cases and analysis provided in this book make an original contribution to scholarship. ${ }^{5}$ Truly comparative studies that are well grounded in theory and build on a broad literature have been a rarity in the study of environmental politics (Steinberg and VanDeveer 2012). To address this issue, I detail various local conflicts and cover new cases from varied analytical perspectives. In order to understand global political economy and ecology, it is important to look at domestic- and local-level policy-making (Schreurs 2003). The regulation of extractive investments arises not only from government strategies but also from the comparative strength and strategies of resistance groups and their relations to the state and corporations. Yet in the existing literature the role of these other factors remains relatively unexplored (as noted, e.g., by Dalton, Recchia, and Rohrschneider 2003; Dryzek et al. 2003; McAdam and Boudet 2012). I aim to unveil these dynamics.

I will introduce and systematically apply a new theory of investment politics that explains when, how, and why investment politics arrive at certain outcomes. ${ }^{6}$ This framework is particularly useful for analyzing environmental politics, but can also be applied in other fields. Besides providing a way to systematically analyze several political games, which might or might not 
be used by different actors, the theory presents tools for the study of deeply material and symbolic processes, such as extractivism and its resistance. I also present a theory of physical, social, and symbolic spaces as interrelated and internally distinguished loci for changing power relations. These two theories can be applied individually or in concert. They provide complementary and thus supportive takes on complex social processes. The explanatory power of these theories is demonstrated throughout the book.

Iron ore is a globally crucial, yet understudied, bulk commodity, which has become central to not just natural resource politics but politics in general in India and Brazil. The steel-iron ore complex is also one of the most polluting and impactful sectors in terms of global warming, climate change, and socio-environmental disasters. Yet it has remained in the shadows while most media and policy attention has been placed on hydrocarbons and other minerals. Iron ore is Brazil's most important export commodity and hugely important for India as well, supporting the decision to focus exclusively on this mineral in this analysis. ${ }^{7}$ Focus on iron ore, which generates the bulk of mining politics and economy, also rules out the problem of mineral specificity in the analysis. Typical analyses lump different types of minerals and metals together, which creates analytical problems, since for example gold, uranium, coal, iron ore, sand, and bauxite mining have very different conflict and political economic dynamics, due to their differing extraction styles, volumes, and production processes. As an example of how mineral specificity affects conflict dynamics, gold tends to create more conflicts due to its high pollution through mercury and cyanide use than other minerals (Özkaynak et al. 2015). Furthermore, focusing on one mineral made it feasible to cover all the major extraction and project sites, which is important for the analysis to be comprehensive, instead of relying on a sampling method that has to be well justified and still results in the problematic presence of what are called logical remainders, that is, unobserved cases. All the iron ore mining project areas in India and the main iron ore extraction and new project areas of Brazil through 2015 are included in my analysis and their locations are presented on the maps below.

India and Brazil provide a mix of similarity and disparity in contexts, state and government structures and actions, extraction models, local political dynamics, and resistance strategies through which these gaps in the literature can be addressed. Both India and Brazil are large countries that were experiencing transitional or consolidating democracies during the 2005-15 period. ${ }^{8}$ The countries share institutional qualities, for example, they rank comparably in the World Bank's World Governance Indicators in the categories that interest global extractive capital. These categories were cited in a report by the International Council on Mining and Metals (2013), a prom- 


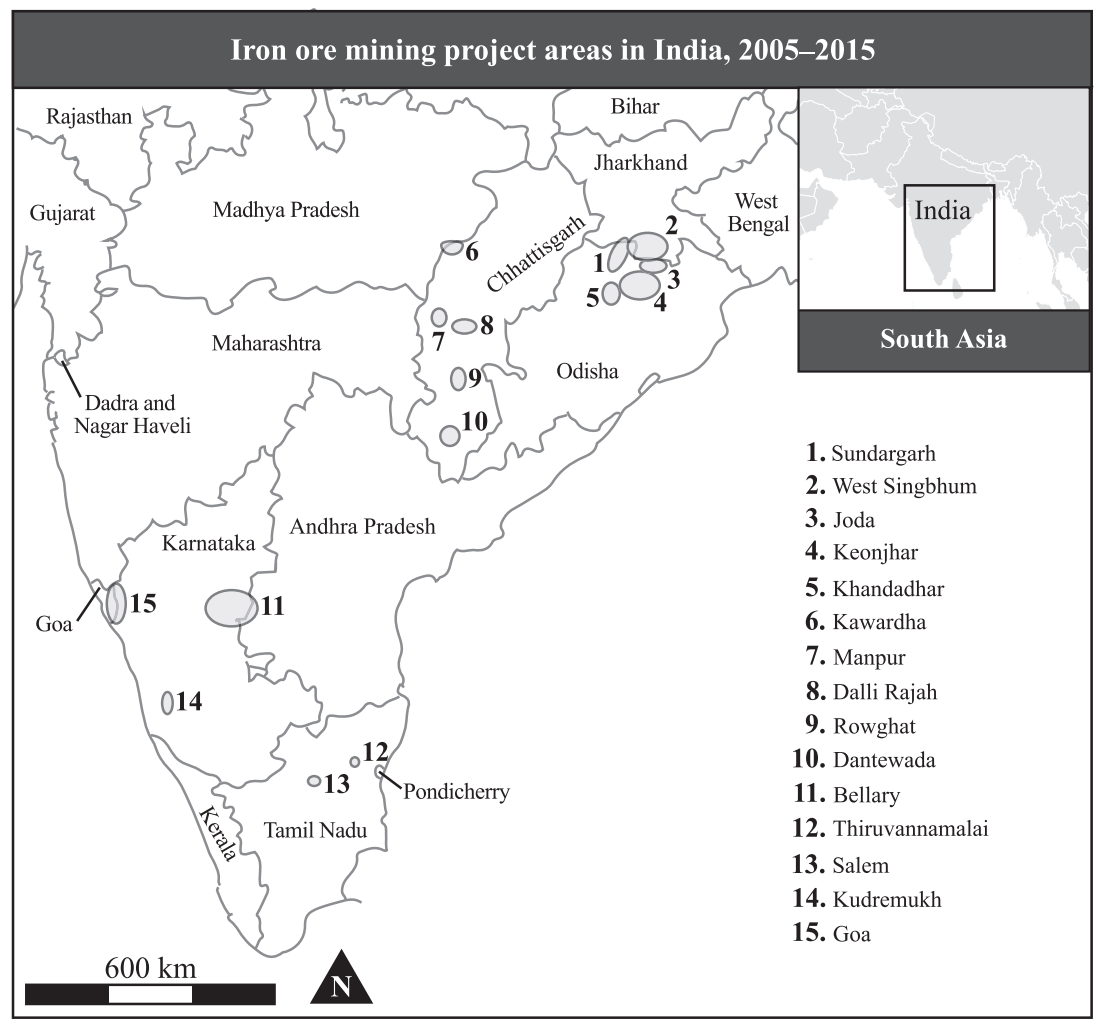

Map I. India's iron mining areas and projects. The size of the circles on the map represents the approximate extensions of the mining case areas.

ining lobby and interest group, illustrating that these factors are not random or theoretical, but significant in the real world for extractive business. ${ }^{9}$ This research setting of close affinity and slight differences allows for consideration of how their respective political systems do or do not influence extractive politics. The analysis focuses on the period between 2005 and 2015, when Brazil generally outperformed other BRICs countries (Brazil, Russia, India, and China) in the World Governance Indicators categories. Brazil's higher ranking could be argued to offer better political opportunity structures for mobilization and would thus be a more permissive context for movements to achieve their goals. However, from the resistance viewpoint, the mining politics in Brazil have led to comparatively less favorable outcomes than in India. This suggests that state or other contextual factors related to governance cannot solely explain how and why resistance can impact extraction.

Brazil's production of iron ore is booming, but Indian production has 


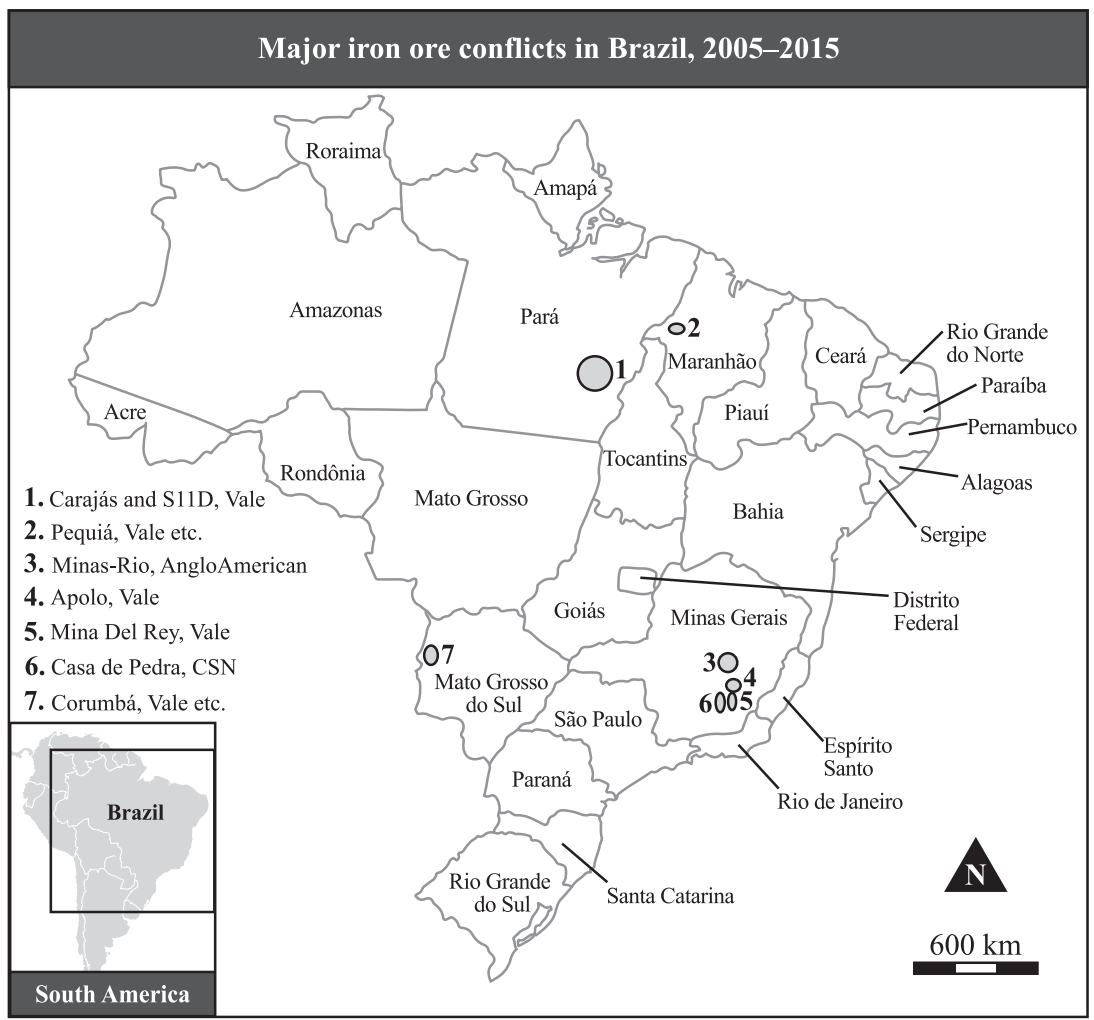

Map 2. Major iron mining conflicts in Brazil that are part of the data used in this book. The size of the mining areas is estimated based on my fieldwork between 2005 and 2015.

wound down dramatically since 2012. Both tendencies are hard to reverse, and this book explains why. ${ }^{10}$ This difference can be understood only by examining the role of new activist groups and progressive state actors in steering production, in India even more so than in Brazil. This is a story that has not been told explicitly although it has major theoretical and practical implications. In order to understand these new political dynamics, it is crucial to see how the new commodity paradigm is increasingly coproduced by grassroots groups, which can steer political economy at the point of commodity production. Between 2003 and 2010 global mining costs rose by 32 percent and may rise by a further 40 percent between 2014 and 2024; the conventionally listed causes are the increasing costs of energy and production (due to dwindling of world-class deposits), and tightening royalties and regulations (Carvalho et al. 2014, 225). I will show with my analysis how 
resistance can also affect these costs. The struggles studied in this book are essentially connected with capitalism's major reliance on producing what Moore (2014) calls "cheap natures." The conventionally listed causes for the end of "cheap natures" do not take into consideration that, for example, it is estimated that half of the world's population will have very limited access to water by 2030 , while practically all mines already have severe water-userelated problems or conflicts (see Carvalho et al. 2014). Grassroots actions, what could be termed "politics from below," will be an increasingly salient causal factor for explaining the investment politics of the future (see Borras and Franco 2013).

A particularly important parcel of the politics from below is the activism that surges from the actual physical locations of (would-be) resource extraction and tries to influence the outbound flow of resources by cutting off or regulating this process. Understanding the impact of these "upstream" strategies to choke off and regulate access to resources at the point of extraction is critical for the global governance of climate change and other urgent socioenvironmental challenges. Leaving such bulky and deeply emission-related minerals as iron ore in the ground is essential to effectively curb "carbon mobilization," the key proximate cause of climate change (Bridge 2010, 830). Thus far, however, most policy and scholarly focus has been on downstream strategies to impact consumption and adaptation, which have resulted only in modest reductions in emissions and other damages (Bridge 2010). Therefore, I focus on upstream strategies that carry untapped potential for addressing current global crises, mine by mine, conflict by conflict. Rising global powers, including, but not limited to, Brazil, India, China, Russia, South Africa, and Indonesia, are where the most research and attention should be placed, as they are the key to understanding the extractivist boom.

\section{Mining Booms and Busts}

The mining literature, specifically, needs further studies on conflicts, resistance, and their relation to investment outcomes. Rather than studies that specifically address resistance to mining projects, there has been a focus on social and economic issues, including the financial compensation for populations displaced by mining operations, the working conditions in mines, and the relation of mining investment to development (Banerjee 2000; Bebbington et al. 2008; Evans, Goodman, and Lansbury 2002; Poteete 2009). A burgeoning literature studies mining conflicts and their management, and I will be contributing most directly to this literature, challenging some 
findings and providing a framework to analyze how different investment outcomes are reached (a topic that has received very little attention). There are a few recent and impressive contributions that utilize large data sets to look for correlations. For example, Haslam and Tanimoune (2016) offer a large quantitative analysis of mining conflict determinants in Latin America, based on 640 cases, including many from Brazil (although not discussing these in detail or qualitatively). In these studies, the central focus has been on correlations between the causes, consequences, and character of mining conflicts (e.g., Özkaynak et al. 2012, 2015); more studies are needed on the causalities. The current theoretical frameworks have found it challenging to explain causalities in investment politics. For example, Özkaynak et al. $(2015,49)$ utilized statistical analyses to explore possible correlations between almost 350 mining cases around the world, and yet they could not discover "when a disruptive project will be stopped." Most of the political science studies of mining protests have focused on the use of political process theory to explain how liberal mining expansion has changed the intensity and style of extraction-based mobilizations, while making some notes on broad-level consequences (e.g., Arce 2014); specific linking of particular struggles with their respective outcomes is still needed. Grievances and mobilization have received substantial attention, for example, Conde (2017) reviews over 200 publications on how and why communities resist mining globally, but this does not include the first-person ethnographic observation on which I built my data set. These prior studies identify several gaps, which this book will address. Haslam and Tanimoune (2016) suggest that case studies and qualitative approaches need to adopt hypothesis testing, better case selection, comparative approaches, and variance across dependent variables. This book does just that and will also address the key gaps that Conde (2017) identified in the mining literature. These include the state's role in shaping resistance, the study of violence in conflicts, and cross-continental analyses of resistance upsurge causalities.

Brazilian mining has thus far received far less coverage than the rest of Latin America. For example, Brazil is not included in Bebbington and Bury (2013), which highlights resistance to mining in the Andes, and is also not discussed in detail in Deonandan and Dougherty (2017), which focuses on the push side of mineral extraction. The most up-to-date analysis on iron ore mining in Brazil is in Portuguese. Beatriz Saes (2018) uses the case of Brazil's iron ore exports to discuss ecologically unequal trade, from the perspective of ecological economics. Saes provides compelling evidence on the socioecologically negative consequences of mining, and how the current form of Brazilian iron exporting leads to maldevelopment; with the analytical focus 
on economics, not on politics, conflicts, or resistance. Two of the rare books in English that discuss mining and development in Brazil are Mining and the State in Brazilian Development by Gail Triner (2011) and Globalization and the Race for Natural Resources by Stephen Bunker and Paul Ciccantell (2005). However, neither discusses resistance or social movements. Triner offers a national historical explanation of why the iron ore sector has been focused on export, and the consequences of this for state formation. Both Triner and Bunker and Ciccantell provide important details on the relation between technologies of extraction, capital markets, and the state-thus providing the basis for a global geopolitical view and a world-ecology of iron ore (which should still be written). Bunker and Ciccantell focus on explaining how the building of the Carajás iron ore mine in the Eastern Amazon reflects the general working dynamics of the capitalist world-system. The book's main aim is to build neo-Marxist theorizing, a "new historical materialism," and thus less value is given to political dynamics than to the role of materiality and economic scale in explaining why the race for resources has intensified in recent globalization. Although I use somewhat similar theorizing, I reach opposite conclusions: namely, in terms of political economic dynamics and political relations, resistance movements have a larger role in defining investment outcomes than has been acknowledged in prior theorizing.

While Brazil remains underresearched from the perspective of iron ore mining, there is even less research done into the Indian mining sector in general, with the iron ore sector scarcely discussed. The most comprehensive literature review on mining conflicts in India is provided by Bisht and Gerber (2017). They provide a preliminary overview of 100 conflict cases that shows how mining expansion has led to a growing number of ecological distribution conflicts, but do not study the politics or causalities in detail. They call for more fieldwork on various forms of mobilization and protests to generate deeper understanding on what constitutes successful resistance. Also a few other mining studies mention iron tangentially, these all telling a bleak story of correlations between mineral-rich locations and severe land conflicts and impoverishment, making the study of resistance potential essential to developmental agendas. ${ }^{11}$

Yet iron deserves more attention as it stands as a key ingredient in the process of nation building. In fact, access to abundant iron ore has been a necessary condition for a nation to become a global power (Bunker and Ciccantell 2005). Yet, the 2007-14 global boom-bust cycle of iron ore has not been studied before this book. I shall show how both Brazilian and Indian miners have been able to produce cheap iron ore, costing much less than the 
officially assumed costs of mining. Iron's importance in industrialization has necessitated low prices and abundant quantities, while rising demand and a major global shift in the iron pricing system have introduced greater flexibility to the trade, contributing to a conflictive iron ore boom-bust cycle between 2007 and 2014. ${ }^{12}$

The phenomenal rise of steel (an alloy composed of iron and carbon) demand in China since approximately 2005 placed considerable pressure on potential extraction sites around the globe, particularly in new resource frontiers like India and Brazil. The global boom led miners to push for a major relaxation of the already-lax regulations, while the resistance demanded greater regulation. The extraction pace has been unrelenting, and left very little for the locals, the state, or future resource-users. For example, during the iron ore boom Goa captured, via royalties, only 0.3 percent of the value of depleted ore (Basu 2014). Eastern India's national state-owned steel producers are also running out of existing local supplies of iron ore and have thus engaged in what critics call a violent forest land grab at the expense of mostly indigenous peoples (Chhattisgarh Bachao Andolan 2014) ${ }^{13}$ Meanwhile, less violent, but just as destructive from an environmental perspective, expansion occurred in Western India, particularly in Goa and Karnataka's Bellary region.

In India, a civil society countermovement against land grabbers won a moratorium on illegal mining in 2010 and, as a result of subsequent measures by the Indian government to retain output for domestic steel mills, exports were slashed in half by $2012 .{ }^{14}$ Illegal gains from resource theft have been under government investigation since mining-critical civil society organizations started pressuring the state to intervene in 2009-10. In Goa, in September 2012, the Justice MB Shah Commission report on illegal iron ore mining quantified the total extraction value of ore from illegal encroachments outside of leases between 2006 and 2010 at Rs 35,000 crore (about 6.32 billion US dollars), with the commission demanding that mine owners pay that sum to the state. ${ }^{15}$ The commission concluded that if Goa continues such large-scale export of iron ore, representing over 60 percent ( 45 million tons) of India's annual export, the resource will be depleted in nine years. In 2007, India's production of iron ore as a percentage of the reserve base (over 5 percent) was the highest in the world, while Brazil's was the second highest (over 3 percent) (Mishra 2010). Meanwhile, activists in Goa and elsewhere explained to federal-level politicians that while India was focused on exporting its ore, China and the United States have a policy of building an iron reserve. With this information the activists highlighted to decisionmakers that iron is a crucial strategic mineral whose control will be essential 
for building global power and, particularly as domestic and global reserves dwindle, it can be used for world political control.

The iron ore boom became a fast road to power; especially for those who were on the leading edge of accessing the mineral deposits (e.g., by being a leading corporation or politician). Essentially, participating in extractivist mining was the way to accumulate economic and political power. Mining mafias formed in Goa, Karnataka, and elsewhere, and were linked to the national politics of India. Mining mafia refers to groups of individuals in positions of power, where the mixing and abuse of political and economic power and elite networks for gaining illegal access to mineral resources, and maximizing profits in the shortest amount of time by underpayment of royalties, briberies of officials, threats, and violence against resistance to them, and other criminal acts. High-level informants knowledgeable about the mining mafia told me that the "BJP [Bharatiya Janata Party] was funded in India largely by the Bellary Mafia," which consisted of several state ministers of the BJP. ${ }^{16}$ This suggests that illegal mining yields have been a key source of political-party funding, illuminating many of the claims I heard. A Supreme Court insider asserted in an interview that "mining has turned into the most important part of politics in India today." 17

In August 2015, following the 2015 amendments to the Mines and Minerals (Regulation and Development) Act of 1957 that dropped export duties from 30 percent to 10 percent for iron ore below 58.0 percent grade, a Vedanta mine reopened in Goa. ${ }^{18}$ It was remarkable that only one mine in Goa reopened, of all the numerous mines that had been operating there, which suggests that the resistance has had long-lasting impacts. In 2018, following a petition by the Goa Foundation, an environmental NGO, India's Supreme Court cancelled all eighty-eight iron ore mining leases in Goa, which meant the closure of all the mines. ${ }^{19}$ Once the resistance managed to stop extraction during the boom, time and world politics became its allies. As the boom waned, prices dropped significantly, and the Chinese buyers that had previously purchased the low-grade Goan ore had, during the three years the mines were closed, modified their steel mills to use average-grade iron ore from Australia. For these two reasons and the greater regulatory demands now imposed by the resistance, the 2015 Indian amendments to the Mines and Minerals Act do not have such dramatic impacts as it would have had if the resistance (and subsequent progressive government and judicial orders) had not kept the mines closed since 2011. This upstream stoppage has meant that downstream buyers have already incurred significant sunk costs in steering away from Indian ore, considered too risky a supply, thereby demonstrating how upstream resistance can outweigh even the 
impact of future government policies, as global buyers refashion their supply chains and technologies based on current political conditions.

Resistance was very effective in India, leading to authorities restricting illegal mining, as well as impacting legal mining. ${ }^{20}$ The fall of exports continued, showing that the closure of mines has been hard to reverse. Between April 2014 and March 2015 India exported only 16.5 million tons of iron ore ${ }^{21}$ thereby demonstrating the dramatic global impacts of local upstream struggles targeted at points of production. Importantly, these outcomes were reached during the mining boom, not after mineral prices slumped in 2014. By 2016, mining companies were stuck with huge debts due to boom period overinvestment and low prices, forcing production in large quantities or shutting down or selling mines-so, in retrospect, the resistance efforts against extractivism appear to have been a benediction for a sounder governance of the sector, including the management of investments. Based on the Brazilian and Indian iron ore booms, local resistance can cause a bust, or at least strongly influence not only ongoing extractivism but also the possibilities for future booms. However, at the local level, this "busting of booms" has not taken place in all parts of India or Brazil, for which reason much more detailed analysis is needed. It is therefore crucial to look at the political dynamics at the point of production, in operating and projected extraction zones.

\section{Hypothesis: Five Key Resistance Strategies}

The hypothesis explored in this book revolves around five key strategies that I think can generally explain when and how extractivist booms are busted by resistance. I will introduce the strategies here and then discuss each in further detail. These strategies will be identified and highlighted within the examples of resistance presented in this book:

(a) organizing and politicizing a mass social movement;

(b) campaigning by nonmodernist framing;

(c) protesting peacefully and physically so that this is noted, for example by blocking important resource export routes;

(d) networking; and

(e) (co)producing the state while retaining autonomy, by changing the rules or power relations through embedding in electoral, institutional, or judicial politics, or combinations of these. 
I will use the following shorthand when referring to these strategies: (a) movement-building; (b) campaigning; (c) protesting; (d) networking; and (e) state embedding.

The findings suggest that these are generalizable strategies that activists from impacted populations can implement to slow down and even discontinue extractivist ventures and investments they consider harmful. The strategies apply both across industry-specific lines and in different political systems. I have come to identify these strategies through the work I did in India and Brazil. These are all peaceful strategies, not based on using arms to get what the resistance wants or being prepared to inflict violence on the targets or third parties. I also studied the role of armed resistance, to see what difference the use of violence made. Additionally, in my prior research, I found a highly similar strategy set was used simultaneously by movements from different parts of the world in tree-plantation-caused conflicts. When food sovereignty movements implemented a set of strategies very similar to the above, they managed to considerably slow down industrial plantation expansion, and even block greenfield projects and contract the size of existing plantations (Kröger 2013a, 2014). Having seen and identified similar strategies in action in two distinct, but still extractive, sectors led me to expand on these findings in this book. I was able to explore the generalizability of the findings by studying them within a different commodity and economic sector (iron ore), and two large countries, which had both similar and diverging contexts and political systems (Brazil and India). In addition, I study how these five key peaceful strategies function differently in nonarmed and armed conflict contexts. I draw substantiated, well-grounded, and comprehensive conclusions based on the successes and failures in extractivist resistance over a several year period, which I have studied and personally observed in India and Brazil.

There are good reasons for separating different resistance strategies. Strategy (a), organizing and politicizing, refers particularly to grassroots mass social movement organizations, not resistance by NGOs. I can thus study the impact of both and see whether it is necessary to have the kind of mass social movement organization as the 1.5 million-member Brazilian Landless Workers' Movement (MST) to make a difference. This allows one to study whether and in which ways political and economic outcomes are linked to organizational structures.

I detail strategy (b) as campaigning using nonmodernist antimining framing. One could argue that all campaigns against investments are disruptive challenges. However, there are crucial differences in the degree and depth of 
how frames challenge the established order. The campaigns most radically critical of extractivism fundamentally challenge the modernist and anthropocentric notions of life, nature, and ethics. This nonmodernist framing also explains why most of the struggles I witnessed were about avoiding, stopping, and reversing mining. The locals saw that their ways of life would change drastically with mining. Mining and the ways in which it is enacted would serve as a proxy for establishing Western and modern ways of life. Mining was seen as having irreversible effects through its westernizing or modernizing of lived experiences, places, worlds, and even the way politics is done. The disaggregation of strategy (b) allows us to systematically study when and how resistance has made a difference by using or not using a nonmodernist framing of extractivism, which I will discuss in more detail in chapter 1.

It is sometimes assumed that social movements would always by definition include protesting (c) and networking (d), but this is not necessarily so and subsequently these two are disaggregated as specific strategies. Resistance groups, or social movements, do not, in fact, always protest across the board in all the different cases where they are involved, or even against the same company or investment model (Kröger 2013a). Some movements, even massive, named, formal organizations, are limited to a locale or against one specific investment, and only later start to network (d) with groups in other locations or with national or global networks. Some local resistance groups are not networked at all.

In Latin America, civil society has largely shied away from interacting with the state due to the perception that this would harm movement autonomy and integrity, and corrupt civil society. This attitude only began to change in the 1990s (Hellman 1992; Kröger 2011). There are still movements that avoid almost all politics, which would mean interacting with state institutions, and many do this out of the justified fear of (their leaders especially) becoming co-opted into "clientelistic" or proextractivist, reformist politics and abandon the more radical means and goals. Therefore, it is essential to analyze whether resistance actors can and have retained autonomy, even when they have interacted with the state.

State-society relations and synergies have been studied extensively under the rubric of embeddedness, and these studies emphasize that there is a delicate balance between embedding and autonomy (Evans 1995; Evans and Heller 2015). While these studies focus on how the state should embed the civil society to foster development, I focus on how the resistance has embedded, coproduced, or even produced the state, and thus influenced the outcomes. I show how resistance can be constitutive in establishing new political opportunities, while retaining autonomy. Embedding includes 
establishing deeper interpersonal ties between state and civil society actors. It can be assumed based on prior experiences that the resistance will not be effective even if it manages to establish deep interpersonal ties with the upper echelons of the state, or coproduces new rules and power relations within the state, if it loses its autonomy in this process, becoming a pawn in a game where it no longer sets the key goals. Retaining autonomy can thus be considered essential for the resistance to succeed in not only mildly steering extractivism but in actually discontinuing extractive operations. For this reason, both the maintenance of autonomy and state interactions can be hypothesized as being important. I thus study their mutual presence, and whether this has affected the outcomes. Furthermore, engaging with the state can be superficial or deep, ranging from pleas to powerholders to intervene to actually becoming a part of the processes whereby the resistance constitutes new state structures, rules, capacities, or institutions, and I thus specify different degrees of state embedding. For example, coproducing new state institutions is a higher-level result than the establishment of interpersonal ties. Through the state embedding strategy (e) the resistance can become involved in crafting new rules or power relations within electoral, institutional and structural, and judicial politics, through which important policy decisions are reached.

If all or some of the above five key strategies (a-e) are lumped together under "social movement action," important differences cannot be analyzed, which becomes crucial particularly when studying the reasons for the outcomes of investment politics at the project level. After disaggregating strategies in enough detail (while maintaining comparability), it becomes possible to pinpoint when resistance has an impact, when it has none, and, perhaps most importantly, why. However, while resistance may be using one or several of the above stances, which are clearly challenging extractivism, it may also be using strategies that are less clearly confrontational. I also study the role of these less confrontational strategies, by analyzing which kind of outcomes are related to the participation in private politics initiatives of companies (e.g., corporate social responsibility), where an agreement is reached. In addition, I will analyze how armed revolutionary resistance and the threat of using arms influences investment outcomes; these were two distinct strategies related to contexts of armed conflicts, and one or the other was used in quite a few of the Indian cases. This will be an important contribution, as the relative weight and relations between peaceful and armed resistance are rarely studied.

I am especially interested in the outcomes of resistance in place-based investment politics. I compare four political outcomes across the cases: 
- The transnational spread of resistance.

- The national spread of political and economic outcomes from this locality.

- The locally enduring and strong resistance capacities and willingness created.

- Armed revolutionary agency created and spread across states by the conflict experience of the resistance.

The three economic outcomes compared are the following:

- All mines (or all projects, or both) are discontinued.

- Some mines are closed or expansion extension and volume are significantly curtailed or there is a very major impact on extraction style (e.g., a nonmechanized, worker-controlled mine), or combinations of these.

- Expansion is slowed down.

The findings illustrate that the five key strategies do play an important role, but the context, policy, and sector in question affect the outcomes that these strategies produce. This book is part of a broader comparison. My prior research dealt with forestry extractivism, looking at the politics around industrial tree plantations such as eucalyptus pulpwood monocultures (Kröger 2013a). There was large-scale resistance against the expansion of these plantations, which managed in achieving its goals most successfully when using a strategy set similar to the five key strategies identified above. The findings of Iron Will show how the causal relation of the five key strategies with iron ore mining politics is even more drastic than with pulp investment expansion in Brazil, as it was the sufficient and ultimate cause for discontinuations of extractive operations in India. In Brazil, the results were mixed, suggesting a harder polity context for resistance than in India. Interestingly, even a subset of these key strategies did lead to several projects being blocked even in Brazil, illustrating that not all of them are necessary for resistance to have major economic outcomes. I explore the reasons for these anomalies by a systematic comparison across all cases. This reveals that participation in the private political initiatives of companies (i.e., "stakeholder dialogues" and similar schemes), where an agreement is reached, seem to have cut down or even defaulted the impact of using the five key strategies. Overall, my research suggests that simply engaging in private politics can seriously hinder the effects of other resistance strategies. ${ }^{22}$

Importantly, the sufficient (but not necessary) condition for reaching 
iron ore mine closures or blocking projects in India has been the use of all the five key strategies in concert. This means that not all of these have been necessary in India, but when all of them have been used, this has been sufficient. I identify several cases where just some of these strategies were used, with quite surprising effects, such as project blockings.

\section{Chapter Guide: Complementary Analyses of Causalities}

To explain how and when resistance influences extractive investment, this book is divided into three parts. Part I builds the conceptual frameworks that are required for the kind of detailed analysis of investment politics that will follow. The major theories developed stem from the literature on agrarian political economy and political ecology, world-ecology, and contentious politics. In chapter 1, I situate Iron Will in the literature, and explain the theoretical roots of the concepts that I develop and utilize. Chapter 2 provides two conceptual frameworks to analyze investment politics and spatial causalities, which are helpful not only for comparative politics, but can be applied more generally. Part I and the methodological appendix provide a detailed discussion of what needs to be considered when assessing complex causalities that explain political and economic outcomes in investment politics and environmental conflicts. Table 1 in the methodological appendix summarizes the basic data on the iron mining cases in Brazil and India. I compared twenty-three cases of mining politics. Seven were in Brazil and sixteen were in India. Sixteen cases were in existing mine areas (eleven in India, five in Brazil); seven were greenfield project areas (five in India, two in Brazil).

Part II examines the hypothesis by looking at the contextual and political system differences, and how these have shaped extractive politics, including resistance styles and their impacts. This contextual approach is helpful in highlighting how resistance is formed in and forms different political settings. Chapter 3 compares several nonarmed conflict settings, starting with an analysis of the setting in Western India (Karnataka and Goa) of consolidating democracy. I then study the state of Minas Gerais in Brazil, which provides fruitful examples of how urban, middle-class, and NGObased resistance to the expansion of extractivism in old, established, and traditionally promining regions are currently rising and how they function in such settings. The last section of chapter 3 studies the setting of the Eastern Amazon in Brazil, where a globally significant commodity frontier is expanded forcefully. In the Eastern Amazon, the resistance did not resort 
to taking up arms, contrary to what a significant part of the resistance to iron ore mining has done in India's Chattisgarh and Jharkhand states, which are studied in chapter 4. This discrepancy provides a fruitful comparison, since both locales are cast as the key national resource frontiers, and are thus forcefully opened by the governments. Building on the work of chapter 3, chapter 4 argues that neither mobilization style nor the outcomes of resistance can be explained without considering the role of armed conflict. The chapter includes an analysis of subregional variations in armed resistance agency targeting extractivism.

In part III, I explore in detail different peaceful resistance strategies, by regional political ethnographies focusing on nonarmed-conflict contexts. Part III is a detailed comparison of how different peaceful resistance strategies function, and what have been the outcomes of their use, separately or in groups of two or more strategies used in the same case. I also delineate subcategories (tactics) for some of these strategies, which advocacy practitioners might find useful. The effects and particularities of different combinations of strategies are explored in differing contexts, through ethnographies of resistance cases. Chapter 5 analyzes the impact of mass social movements and collective protest on extractivist imperatives. For example, I explain how the Salem activists in Tamil Nadu were able to resist mining successfully, by deploying a narrow strategy that focused primarily on mass protest. This chapter highlights the importance of collective protest in extractivist resistance. Chapter 6 uses the cases in Odisha and Goa to explore in detail the resistance benefits when using all the five key strategies in concert. Chapter 7 analyzes the role of national and global coalition-building. I explain how global resistance to extractivism is not spearheaded by actors from the Global North, but rather it is based on mobilization surging at the points of production in the Global South, on which new transnational resistance coalitions can be built.

The conclusion addresses the ways to best tackle and start to solve the dire sustainability problems caused by global extractivism as informed by the rich assortment of cases discussed in the book. The contributions of Iron Will to a series of themes, disciplines, and research agendas are discussed. I then turn to avenues for future research.

I have discussed in this introduction the need to study extractivism and its resistance and explained how the study of iron ore mining politics in Brazil and India can deliver on several fronts. I explained how I came to write this book and introduced the key contemporary debates. There are many extremely interesting theoretical developments ongoing in the field of social movement studies, world-ecology, political ecology, and compara- 
tive politics that this book will unite. I welcome the reader to join for the rest of the book on a journey that explores how some of the most pressing sustainability issues that our planet faces have started to be tackled by largely unknown local movements. I suggest several ways for studying this groundswell in more detail and show how this can be done. Quotes from extremely inspiring, yet seldom heard-of social and environmental thinkers and ethnographic accounts reveal the real-world politics on which the building of steel-based societies relies.

In Brazil and India local resistance efforts were able to shut down destructive mining operations and projects even in very difficult circumstances. I observed and assert that these efforts consistently had more success in shutting down mining projects if the resistance adopted the five key strategies, which I explore in detail in this book. These findings applied across the many different contexts and political systems that I encountered in my field research. However, there were contexts where resource conflicts were increasingly violent and armed, and in these conflicts special strategies were required. I hope that the worlds that are brought into focus and a heightened visibility in the rest of the book will be helpful in reflecting on the possibilities of change. 


\section{Theorizing the Impacts of Resistance to Extractivism}

Part I is divided into two chapters that in tandem provide a robust exploration of the theoretical backgrounds and aspects of the topics of extractivism and its resistance covered in this book. In addition, these chapters offer a set of theoretical tools for broader social scientific inquiry. The first chapter canvasses the key theories for the study of environmental politics and positions Iron Will in the academic literatures to which it contributes. Chapter 1 also explains how to mobilize for sustainable and post-Cartesian worlds, and why the relations of state, government, and civil society actors should be studied in detail to understand when and where this can happen. The second chapter presents two novel theories premised on the concepts and ideas introduced in the first chapter. These two chapters create theoretical frameworks on investment politics and spatial causalities (between social, symbolic, and physical spaces) that will be used in analyzing the role of resistance, and particularly strategies in resisting extractivism. 


\section{Resistance and Investment Outcomes}

When I first arrived in Goa in 2010, traveling from the state of Maharashtra also in India, where I had come to spend time in the vipassana meditation centers in Igatpuri and Mumbai before getting to know the mining conflicts, it was like arriving to another country. Everything around was a deep verdant green and there was an air of affluence. It was the monsoon season and the beach towns were empty of tourists. The insistent rains kept pouring over roofs, while I had long and lingering discussions with activists, such as Sebastian Rodrigues. Sebastian had traveled to Finland a few months earlier to share the mining problems of Goa with a European audience. When speaking with him, I learned that we both had an interest in the study of resistance movements and in the meditation technique taught by S. N. Goenka in India. These two connections inspired me to travel to India to learn more. In India, my learning curve was steep - especially regarding how to think about and conceptualize resistance efforts. I spent time reading in the moments I was alone, from Mahatma Gandhi to B. R. Ambedkar, which gave me new ideas to complement what I had learned in the academic arena, during my time at the University of California, Berkeley and the University of Helsinki. While Goa had several resemblances to Brazil, this was different from what I had learned in my years living there and other places around South America. This experience in India deepened my other knowledges, which were gleaned from the countryside and passing time among people living in rural areas, such as members of organized peasant movements, observing their lives. I will be starting each chapter with a narrative glimpse into my personal experiences and the process of doing the field research. These ethnographic vignettes serve as a second narrative that floats on top of the book. These brief stories will describe the sights, sounds, smells, colors, mood, and sensations of being in place on the ground as a witness to the events at the core of this book. 


\section{Positioning Iron Will}

Prior research on social movements has focused on studies where cases are selected based on the dependent variable and subsequently tend to focus on success rather than failure (McAdam and Boudet 2012). However, while this strategy lends itself to exploration of some movements, this positioning does not provide a full picture of responses to and actors in broader politics (Giugni, Bosi, and Uba 2013). Unlike typical social movement studies, this book is primarily concerned with understanding investment politics. It draws its primary material from a study that includes all the major iron ore projects in Brazil and India, not only the cases of resistance to those projects. This fuller spectrum of cases, some more and some less contentious, gives a better grounding to answer questions about both causes and outcomes. Using this data, I will be able to address the trajectory and outcome of specific forms of activism, as my database includes a larger set of different types of activism than is typically used in most comparative studies. Another factor that sets this book apart from the existing research is that I broaden and unite the study of armed resistance and peaceful movements - an approach called for by McAdam, Tarrow, and Tilly (2001). Armed resistance is not homogenous, and it comes in many forms, as does its subcategory, armed revolutionary agency. To highlight these potential differences, I will briefly explain the different motivations and ends in two instances of armed resistance. Take for the first example the Zapatistas, in Chiapas, Mexico, an armed group that was quite vocal about the presence of their arms. However, they did not use these arms primarily for violent ends; rather, they used them as an overt signal that made explicit there was a real possibility for armed resistance. For the second example, in Indian armed resistance the resistance actions rely on the actual use of arms to incite a Maoist revolution (Banerjee 2013; Choudhary 2012), or to secede from the state to form an ethnically separated region (Karlsson 2011). I will further distinguish such nuances in the types of actions used as different resistance strategies to address extractivism. To understand these nuances is a necessary step in examining these strategies because the type of action, in the specific context, might result in different political and economic outcomes.

The theory building of this book is a continuation of recent work in agrarian political economy and critical agrarian studies that combines Polanyian and Marxist theories, which address the role of land in value creation with a detailed analysis of the roles played by resistance and other political dynamics (e.g., Kröger 2013a; Levien 2015). In line with what Marx called "primitive accumulation," which is a situation where capital accumulates via 
a process of predatory capitalism, dispossession and resistance may follow. Polanyi (2001), in turn, saw the rise of the "organic society," which consists of progressive, regulation-creating state and civil society actors. For Polanyi, these entities work in conjunction as an almost automatic defense mechanism of the society, which serves as a protective barrier against destruction by the overcommodification of nature, human life, and money. In this theory, Polanyi focused on the macro level and successful cases of civil movements. In this book my Polanyian observation serves primarily as a macro-level concept to illustrate how Brazilian and Indian resistance, or at least a significant portion of these resistance efforts, has yielded a remarkable process, which unified many actors across the civil society and the progressive parts of the state in their attempt to respond to the problem of free-market mining. In addition to this macro lens, I will also contribute to Polanyian theorizing by explaining in detail how and when resistance happens within a specific context, and what forms this resistance takes.

There are spatial dimensions that distinguish the dynamics of resistance to global extractivism from social movements that are not so place based or directed at resource extraction. These spatial interactions between capital and resistance need to be considered when theorizing the resistance and alternatives to extractivism. An emblematic case is the MST, which uses the direct action of land occupation to boost settlement creation. These efforts, which are very strong at the main iron extraction site in Carajás, Brazil, are in direct conflict with the growth of iron ore exports. Some of these new land reform settlements, and the contentious actors inhabiting them, are in strategic locations from the perspective of the iron ore export industry. For instance, one key point of resistance action is the railroad, owned by the Vale Corporation, which runs from the Carajás mine through the Palmares II settlement of the MST in the Parauebebas municipality in Pará. The MST settlers and indigenous groups operating in their own traditional and functional territories have blocked the railroad several times, reportedly causing millions of dollars' worth of losses to the company through delays in iron exports. In these spaces, placed literally in the way of capital movement, the potential for mobilization has been successfully tapped by activists and used as a platform for globalizing the struggle through deliberate networking with other place-based groups. Iron ore extraction, in this sense, has served as the very fuel used to forge transnational coalitions that extend far beyond the starting point at the extraction site where the initial resistance ignited.

There have been many recent calls for a united resistance front against the dominant global system, and especially central in these calls has been the goal of uniting environmental and labor rights concerns. My analysis and 
data address a dire need in the study of the potential of such counterhegemonic globalization (Evans 2014) through the inclusion of cases that allow the assessment of how new networks of trade unions and environmental movements break old boundaries in extractivism. These data can provide new insights on the shift toward a Polanyian countermovement by way of an alliance between progressive trade unions and environmentalists against global capitalism. One of the clearest examples, but by no means the only one, is the case of the anti-Vale transnational resistance movement. Within the case examples herein there are multiple instances when workers' movements embraced environmentalism, but there are also cases in which trade unions were hostile toward environmentalist stances or citizen concerns, or both. This latter stance reflects the more typical framing of resource conflicts as representations of economic growth against the environment. The role of both stances to environmentalism by trade unions will be explored in the case material. These cases show that labor unions have been key players in many ways. Often the role of labor unions is simplified, in that they are characterized as only useful for generating strikes for better salaries or change in the style of investment. However, in my cases labor unions were also active in blocking the expansion of established brownfield mines (in Congonhas and Mariana in Minas Gerais in Brazil), or markedly slowing down the expansion of these mines (in Carajás and Maranhão in Brazil, and Dalli Rajhara in Chhattisgarh, India).

A large part of conflict resolution and management literatures miss the opportunity to reflect upon the question of which actors are actually served by the resolution of a conflict, and which are not. I investigate mining politics through an analytical lens where contention and conflict are not automatically assumed as a negative externality. Rather, they are respected as an instrumental part of political dynamics, and moreover as potentially able to have a positive impact on future democracy and development. This approach differs from the several studies on "resource curses," which see conflicts in a negative light, and developmental failures as somehow flowing naturally from a country having ample natural resources. Instead, in the line of Watts (2004), which criticizes such approaches for their simplistic understanding of the many politics involved in defining the developmental and political outcomes in resource-rich contexts, I aim to provide a much more detailed explanation on the politics behind extractivist investments and their outcomes. Conflicts are instrumental in addressing unequal power relations and forwarding change in unethical circumstances. This is a normal process in politics and not a pathology to be cured. Whereas the study of power inequalities has been adapted in prior studies on political ecology, Iron Will 
further widens the parameters of inquiry in political ecology and addresses key gaps in this field. Political ecology has historically had a marked preference for studying informal and unorganized politics from the viewpoint of the underdog. This is perhaps because the field "grew out of a desire to understand marginalization and contestations" (Wolford and Keene 2015, 573). In addition, political ecologists typically focus on the level of individuals, households, communities, groups broadly defined, or organizations, yet they do not regularly study social movements. A reason for this could be the very limited interaction between sociology and political ecology (Wolford and Keene 2015). This book departs from these two biases of prior political ecologies, instead looking in detail at organized politics and social movements. Thus, I can contribute new answers to the core aim of political ecology, which is to understand how the mechanisms of accumulation and extraction "shape, and are themselves shaped by, unequal locations within, access to and control over the environment" (Wolford and Keene 2015, 573, italics in the original). Questions like these serve to open up the power relations in environmental politics.

A substantial body of literature can be found on the mobilizations in India of lower castes and other marginal populations, such as the Adivasis, which is a collective term for indigenous peoples of the Indian subcontinent (e.g., Ganguly 2015; Guha 1989; Guha and Martinez-Alier 1997; Nilsen 2012; Omvedt 1993; Shah 2010). ${ }^{1}$ There is a growing number of studies on environmentalism as it is enacted by these groups, and these studies provide important insights for use in global comparison. In line with the "environmentalism of the poor," which is characteristic of the Global South, Guha and Martinez-Alier (1997) offer evidence that Indian protest politics have been particularly marked by the enmeshed position of those defending both social and environmental justice. Mining struggles in both Brazil and India underline the point made by the aforementioned authors. Engaged activistscholarship, such as ecofeminism (Mies and Shiva 2014), has been strongly present in India, of which Shiva (1991) is an important early exemplar. The key argument is that, due to India's specific setting, environmental struggles are often struggles for survival. The comparisons I make with Brazil provide new insights for both the study of Brazil and India. The particularities of the Indian struggles (i.e., there is nowhere else for the displaced to go, after so many displacements by land grabs) might explain a part of the differences in mobilization in comparison to Brazil, where resource frontier expansion is still an option-not only for the capitalists, rich, and middle-class peasants, but even for many of the poor (Kröger 2015b). Putting the Latin American and South Asian literatures in discussion with each other, especially in light 
of the concrete cases I observed, is thus fruitful, and an exercise that needs to be done.

In overall explanations of Indian politics, social movements have not been in the limelight, something that the recent rise in movement scholarship is trying to rectify. ${ }^{2}$ What are especially needed are detailed studies on the relation between different strategies and their political economic outcomes. As Baviskar $(2014,51)$ notes, "Only the rare study attributes agency and dynamism to villagers. And if it does so, collective action is shown as a mysterious, spontaneous phenomenon, with little attention to the mobilization of resources and the transformation of consciousness." This is a shortcoming, which is directly addressed through my study of and on the key mobilizing strategies. I will contribute to the growing literature on environmental/land-based movements in India, which includes for example the work of Temper $(2014)$ and Levien $(2015,2018)$. The cases presented in this book serve to expand the scale and scope of this scholarship, and thus also challenge and corroborate some of the existing claims, based on other cases, such as the resistance against free-trade zones and bauxite mines.

Globally, new conceptual frameworks are needed to accommodate complex realities and social actors, which vary from case to case. Recent ethnographic inquiries into mining conflicts, inspired by Bruno Latour, have been adamant to highlight that the classic actor categories and analytical concepts are too rigid and thus do not represent the reality of cleavage lines in places such as Papua New Guinea (e.g., Golub 2014) or Peru (Li 2015). In my study, I understand social actors as being formed by conjoined strategies, mechanisms, and processes, instead of as ontologically "existing" actors. This holds especially true when applied to social constructions, which include particular social movements.

This book adds to the existing scholarship on world-ecology. Worldecology scholarship suggests that any study of environmental politics should begin with an explicit discussion of what the authors and the people in the studied area understand by the key concepts of "nature" and the "environment." There is a helpful recent scholarship that looks for conceptualizations of these concepts that transcend nature-society dualism, and I will build on these, as they are in line with the local conceptualizations of the indigenous and other populations that I encountered in the fieldwork for this study. In line with this intention, I suggest that the concepts of lived environments (see Taylor 2015) and historic natures (see Moore 2015) are helpful for providing a post-Cartesian analysis. ${ }^{3}$ These concepts also help to avoid the trap of flat ontological thinking where sentient beings are equalized with all sorts of "things"; I find it is essential to distinguish the existence of different types 
of beings. This includes sentient beings and human beings among the other types of beings that exist in the world. While the production of "nature" is not the key focus of this book, I will refer to political ontology (Blaser 2009; de la Cadena 2015) and world-ecology and their importance as complementary post-Cartesian approaches when suggesting avenues for future research on the politics of extractivism.

Another key factor to be opened and explored is the definition and understanding of indigeneity, which is one of the central themes in the study of extractivism. In this book, I follow the understanding of Ingold (2000) on indigeneity, according to which, lived practices, skills, and daily tasks, as well as dwelling in particular natures, constitute specific lived environments. The primordial or green primitivist view of indigeneity, which assumes all tribal people are "noble savages," is dated, as demonstrated for example by Karlsson's (2011) study of the heavy extraction of minerals and timber by Northeast India's indigenous inhabitants. There are many varieties of lived environments in India, especially in terms of the form of dwelling. The sustainable dwellers are typically Adivasi people, but not exclusivelyancestry or genes do not automatically make one an environmentalist, as the political ecological critique of the romanticizing of "local communities" has aptly noted. However, it is still the case that those who are irreversibly transforming forest areas by ordering the digging of open-pit mines are typically upper-caste people, or from the upper classes-although many prominent environmentalists also come from these castes and classes. The latter groups' dwellings are not place based-as capitalist mine owners, they often live in the cities - and their connection with the mining areas (previous Adivasi dwelling areas) usually lasts only as long as the ore does. ${ }^{4}$

The politics surrounding indigeneity is, in many cases, a key dynamic in explaining the outcomes of extractivism. Watts's (2004) study on Nigerian oil politics exhibits how the politics of indigeneity do not necessarily rely on any preexisting historical continuity of ethnicity, and can lead to very violent, unequal, and racist dynamics. This can occur both within the created ethnic group and in its relations to other groups. Li (2015) has made a similar claim in the case of Peru's mining conflicts, pointing out that indigenous-led protests have also been held in favor of mining companies. For this reason, $\mathrm{Li} \mathrm{(2015)}$ argues that the classic cleavage lines (e.g., the corporate-community clash) and sociological categories (e.g., indigenous) might not describe the conflict dynamics of extractivism very well.

The theory presented herein offers a response to classic theories of human emancipation and the class theories of Marx (1887), both of which have had trouble in encompassing the complexities presented by societies, especially in 
the Global South. The understanding of resistance in this book ties together many threads, including the emancipatory theories of the Frankfurt school, which looked at, among other theories, emancipation as a cultural phenomenon (Gunderson 2015); the Freirean view of freedom as a pedagogical process (Freire 2000); and autonomist tendencies, which see emancipation as the rejection of work and control. The classic Marxist theories, in contrast, are based on the empirics of an industrial working class and emancipation arising from exploited labor. Although post-Marxist and feminist literature have fruitfully criticized the classic theories (e.g., Mies and Shiva 2014), a look at the resistance to extractivism embraces socio-ecological conflicts on a much wider, more likely, and currently unfolding scope, which problematizes paid labor, male-dominated working classes, and other Western-based emancipation views. Although there are classic dimensions included in the theory proposed here, the conceptual toolbox also allows the explanation of how, for example, not only the mine worker but also a social movement with ecological dimensions can usher in emancipation, thus broadening the circle of agency in classic theories. Resistance to extractivism challenges prior classic theories of emancipation, offering both a challenge and a possibility for theoretical renewal. This broadening takes place by including advances in contentious politics theorizing; Indian and Brazilian movement scholarship; the study of mining; general natural resources and environmental conflicts; world-ecology and land-grabbing resistance literature; and allowing the empirical reality of the studied cases to inform advances in the phenomena and unite them. The multifaceted resistance to extractivism, as conceptualized in this book, offers a nuanced explanatory tool for politics across contexts.

In my study of strategies for resistance, I work particularly with the strand of research that explores contentious politics. This type of politics could be called relational and seeks for organizing concepts beyond the structureagency debate. Relational scholarship, exemplified by Doug McAdam, Sidney Tarrow, and Charles Tilly's Dynamics of Contention (2001), demands a more dynamic framework. This has led scholars to study political opportunity structures more relationally, which explains how movements can create structures, opportunities, and political game rules for themselves, instead of waiting for them to "open up" from above. Bunce and Wolchik $(2011,16)$ observe how electoral politics "can be ideal sites for expanding opportunities for mobilization while lessening the familiar constraints on collective action." Agency is to be considered in conjunction with political process analysis because, as noted by Hadden $(2015,87)$, "political structures do influence the forms of action that groups use when they contest climate 
change. But the effect of this structure is not uniform, and some organizations systematically seem to ignore political opportunities. In other words, the results suggest that structure is important, but agency is real." This is a helpful notion, serving to suggest, for example, that armed resource conflict is not only a result of political structures but also of revolutionary agencypotentially ignoring political opportunities. Building on the relational approach, I introduce different arenas of politics as key sites to be studied, such as "electoral politics," which includes actors beyond just political parties (both of the government and the opposition) and elected politicians, but also extractivist corporate and resistance actors that engage in electoral politics. This relational and dynamic approach to studying investment politics will also be helpful in explaining their contours and trajectories better than structural arguments. In fact, explanatory frameworks relying overtly on contextual analysis have been unable to capture the unfolding conflict dynamics around iron ore mining in Brazil. ${ }^{5}$

\section{Mobilizing for Sustainable Worlds}

Extractivist projects that churn up the lived environments of local populations create grievances. There is potential for mobilization in all the iron ore project areas in Brazil and India, as there are people whose lived environments are being targeted. The mining areas in both India and Brazil are not empty voids; there are people that live within them, and thus there is the potential for mobilization against disruption of these environments. These areas contain social groups that often have very different developmental and political goals than the extractive industry. Polanyi emphasized that there are certain areas of life, and thresholds of society, that when broken lead to the rise of an "organic society" as a countermovement regulating capital. However, detailed research has shown that not all types of grievances are the same or have the same tendency to support mobilization efforts (Kröger 2013b). There is a particular need to identify the type of grievances and the kind of strategic actions that seem to work together to support resistance mobilization, which is not an automatic process. When examining and attempting to understand the micro level or when comparing multiple cases, automatic social self-defense cannot be assumed, and self-destruction remains a plausible alternative in the absence of resistance. The cognitive promotion of action by pinpointing a relative worsening of conditions, or lack thereof, explains the degree variance between cases where resistance does and does not take place. 
Local grievances can only be used as a starting point for developing a broader understanding of the myriad political dynamics at play in conflicts. After these grievances have been turned into budding activism, the resistance groups typically use one or more of what I have identified as the five key strategies to pursue peaceful resistance in a more concerted way. The strategies are (a) movement-building; (b) campaigning; (c) protesting; (d) networking; and (e) state embedding. These strategies of resistance support not only each other but also a peaceful mobilization process. The work of organizing and politicizing within a resistance group creates a social movement and is essential in fostering, for example, interpersonal trust between members. Trust is a key element in the acts of protest by these movements: the more militant and dangerous the act, the deeper the required trust between and among the members of the movement (Benson and Rochon 2004). Importantly, this applies across contexts and in both democratic and nondemocratic states, with higher trust levels correlating with more protests (Benson and Rochon 2004). Trust allows a rise in the intensity of participation, which means that a wider array of strategies become available. Notably, the act of staging and executing a protest often creates a positive feedback loop for trust levels. Protests can bind participants together through the shared experience; for example, within the Brazilian Landless Workers' Movement (MST) their land occupations have served as the most important sites of movement creation (Kröger 2011). In another example, while studying the presence of cognitive activation to recognize injustice in India's Dalit population, Davenport and Trivedi (2013) found that training in nonviolent resistance (for example, in the Ambedkarian Buddhist tradition, or the Gandhian Hinduist tradition known as satyagraha) was important in making people who rarely participated in activism much more aware of injustices, and thus more likely to protest. Likewise, exposure to other activists, or to oppression/oppressors, led to cognitive activation.

Campaigning through specific framing actions is closely related to boosting the will to resist. Reviewing the studies using the framing perspectivewhich has mostly focused on explaining political or economic outcomes, as I also do-Snow et al. $(2014,35)$ argue that for activists the framing of their core claims has "a decisive impact on building movements, winning positive outcomes, and shaping the overall trajectories of movement efforts." Normative struggles are key, that is, struggles whereby well-chosen words, phrases, images, banners, and other aids are used to communicate with their target audience to challenge the established order and depict mining, for example, as "socio-environmental havoc" or "criminal activity," or both, rather than "development." 
Besides the above framings, campaigning by nonmodernist framing has been an essential element in many mining struggles. The usage of nonmodernist concepts, for example, in Ausangate in Peru or Niamgiri in India, challenges the whole apparatus of modern politics by invoking the agency of nature, usually through a cosmology wherein nature is made holy, and the ontological invoking of extrahuman or non-Western beings, which are difficult to comprehend or even to describe by Western notions. Such framings stretch and redefine moral action and ethics. These nonmodernist framings, which do not put a monetary value on nature, are currently on the rise - or at least gaining more attention —in many parts of the world. In India, the Niamgiri mining project has been studied in these respects, but there are also many other cases, such as the National Mineral Development Corporation mines in southern Chhattisgarh, which the local Adivasis hold as holy, and several hills in Tamil Nadu. I study these cases here in the global context of such rising ontological conflicts across extractive settings. It is worth mentioning that my understanding of resistance "strategy" as a mechanism, which can have crucial impacts in shaping the political arena and thus influencing the investment outcomes, draws from broader global literatures and comparisons. I also visited Peru while writing this book, to witness the myriad mining conflicts there, where nonmodernist understandings and ontologies of mountains as something more than mere mountains, and something entirely different, are ubiquitous. In Cusco, Peru, local resistance has claimed that the mountain, identified as an earth-being (or earth-being that is also a mountain, Ausangate), is upset and angry about a proposed mining project (de la Cadena 2015), a framing that challenges the language and thus politics and ethics of "modernics," as Eduardo Gudynas has pointed out. ${ }^{6}$ Most framing in extractive conflicts is still anthropocentric, even when offered by resistance groups. This results in politics as usual, which can be effective, but also sometimes is not enough. Gudynas (2015) argues that politics that frame nature by its monetary value do not instigate the revision of the anthropocentric ethic. However, the surge of new, nonanthropocentric framing does, and will, change the way that political dynamics work. Gudynas (2015, 434, translation from Spanish by the author) writes:

The recuperation of other values in Nature, and particularly when its own rights are recognized, is not only an antidote to extractivisms, but an alternative to anthropocentric ethics. . . . any change in this spinal cord of values generates a cascade of modifications at many other levels. 
These notions are important, as during the course of field research I ran into such framings and understandings of the world and lived environments, which challenged mining in a way that goes far beyond the option of seeking compensation (which should not be seen as an option if we are looking for the kind of solutions that a real solving of the current crises would require).

Framing as a tool for boosting mobilization for sustainable worlds is then most efficient when it deals with morality and ethics, as this changes the whole political economy and ecology and the way political dynamics operate. I would thus refer to the nonanthropocentric symbolizations of mining as a "postCartesian mining politics." Post-Cartesian refers to understandings of nature that are not based on the nature/society dualism that is indicative of the thinking of the seventeenth-century French philosopher René Descartes. Descartes has been criticized, for example, by ecofeminism as establishing a frame of mind through which the rest of the world could be divided into nature and society, and thus it can be used as a source of wealth to be exploited and appropriated to advance the key goal of "enlightening" the mind of the white European elite men (the "society"), which was seen as the pinnacle of Enlightenment (Mies, Bennholdt-Thomsen, and von Werlhof 1988). Building on this criticism, worldecology has analyzed how capitalism is an ideological process that relies on the Cartesian dualism of separating nature from society. What is explicitly included in the conceptualization of "nature" has differed—especially in prior centuries. A prominent example of this was the framing and treating of most non-European peoples as part of "nature," who could be utilized as slaves or servants, whose life and labor could be extracted for free or at extremely low cost for the service of the "society" (Moore 2014). Post- or pre-Cartesian refers to such understandings that do not have this anthropocentrism, such as the biocentric views of Henry Thoreau, and the many indigenous cosmologies of Latin America, some of which have been enshrined in new constitutions that grant rights to nature, at least on paper (Gudynas 2009). Gudynas (2015, 434, author's translation from Spanish) finds that extractivists typically want to push moral and ethical discussions of this sort aside as weird and irrelevant, while for him this is "the fundamental question":

Many of the current problems originate in how values are understood, and any alternative would require changes in them. A suspension of ethics is what makes... [possible the] extractivist imposition. For this reason, conceptions such as Vivir Bien or the rights of Nature are without a doubt alternatives, but become substantial in promulgating ethical changes that open the door to other valuations, thus generating consequences on many levels. ${ }^{7}$ 
Framing that recognizes the rights of "extrahuman" nature seems to be an efficient way to change natural resource politics into post-Cartesian environmental politics. I share the view of Gudynas $(2015,434$, translation by the author from Spanish) that such a broadening of terms "opens alternative paths between us," paths that should result in making a break with "the bonds of anthropocentrisms and utilitarianisms." Political ontology (Blaser 2009; de la Cadena 2015; Escobar 2011) has also made these kinds of observations. In addition, environmental historians, such as Joan Martinez-Alier, aware of the novelty and deep impacts of pricing nature, have warned that the last thing resistance should do is put a monetary value on the environment. ${ }^{8}$ This is because then they are in great danger of losing their lived environments, the physical places that form the very basis of their existence and lifestyles and cosmologies, when these places are being mined or otherwise destroyed, as they are turned into money.

\section{Resistance and the State}

Besides organizing, campaigning, protesting, and networking, I argue that resistance is most likely to attain its goal when participating in and trying to change the rules of state-mediated political games, through which official policies are made, while also retaining its autonomy. There are three such key political games to challenge extractivism through legal and routine politics. The first is electoral politics, for example through targeted voting for politicians opposing mining or allying with politicians seeking mine closure. For example, the mayors of two important cities (Congonhas and Mariana in Brazil) were convinced to join the resistance. The second is institutional and structural politics, such as acquiring progressive state-actor led investigations via advocacy, successfully demanding that regulatory institutions intervene to uphold the rule of law, occupying key institutions, or crafting new institutions. For example, in India, resistance actions enabled the establishment of a new national commission to investigate mining irregularities and regulate them. The third is judicial politics, which could strengthen litigation in court against the project among other possible outcomes. As an example of coproducing new power relations within judicial politics, professional legal NGOs from Goa and Karnataka created new capacities for courts to uphold India's mining laws and ensured that this took place through their highquality litigation.

The above separation of key political games is a contribution to existing theorizing on state-society relations. In the study of environmental politics, 
the state has been conceived either as an actor or as an arena for governance (Duit 2014). This dual role of the state is incorporated into the theoretical framework that guides my analysis. This is especially pertinent as recent comparative scholarship on environmental governance has found ample evidence that the role of the state has not withered away (Duit 2014). As a matter of fact, a reasonable initial hypothesis in explaining the outcomes of investments would merely be a state-centric explanatory framework, wherein the analysis of the state as the most powerful actor in society would be sufficient. Yet, out in the field, I quickly came to notice that state-centered explanations cannot in practice explain when and how extractive operations expand or contract. To understand the nuance of these fluctuations in the size and scale of extractive practice a much more dynamic view of the state is required. This differs from a simple statement that the state does or does not matter. States do matter, this is not contested, but how they matter in today's world has changed.

To incorporate the analysis of the state as a dynamic arena as well as an actor, I unite two approaches. The first is the relational approach of state actor-ship (Evans 1995), which regards state and society as actors that can embed each other. The second is the dynamics of contention approach of state-mediated contentious politics by McAdam, Tarrow, and Tilly (2001), where the state is seen an arena. With this incorporated approach, I look at how the dialectics of supporting resistance to extractivism have or have not played out in different state-mediated political games in which the resistance has been a key player. It has been through the state that the resistance has managed to create greater political opportunities and thus to foster greater resistance elsewhere. In the tradition of the comparative institutional approach of Evans (1995), the goal is to explain the diverse outcomes with a focus on concrete variations across historical cases, whereby diverse states and state-society relations are created in different yet connected historical processes.

In the context of states such as Brazil and India the government is unlikely to act alone, and any political opportunities existing or latently available within federal or lower-level state structures are to be used and made functional by the resistance (Carter 2015; Hochstetler and Keck 2007; Kröger 2013a; Wolford 2010). The extractivist push and lobby are very strong in both Brazil and India, which renders their mining policies in dire need of a balancing or "checking" by civil society to secure the rule of law and to lower negative impacts. A geologist with decades of experience in directing mines around India told me in December 2012 that in India there are about 10,000 legal and 80,000 illegal mines. He believes there is a great need 
for a regulatory body, particularly now as the mining regulators often also work as mining consultants. ${ }^{9}$ The words of a coordinator of Mines, Minerals and Peoples (MMP, an important national umbrella NGO in India) summarize the message of a multitude of interviews that I conducted in India with the blunt statement that there is "no long-term government strategy on resources." Currently, the legal setting of mining is more than confusing with numerous contradictory rules, not all of which must be followed. It is very unclear what the de jure rights and responsibilities are in practice, as executive orders seem to supersede legislative and court power, varying case by case.

Individual state governments have not usually been on the forefront of resistance to extractivism. For example, prior research on Brazil's environmental governance has emphasized that the establishment of stricter environmental norms has almost always required a very active role by civil society. These societal actors must apply pressure to the state and actively support progressive state actors in establishing new rules (Hochstetler and Keck 2007; Kröger 2013a; Wolford 2010). A similar tendency can be seen in India (see, e.g., Shah 2010; Sisodia and Dalapati 2015; Tiwari 2016). It was the civil society, particularly the forest-dwelling communities' movements, that pushed for the Scheduled Tribes and Other Traditional Forest Dwellers (Recognition of Forest Rights) Act 2006 (FRA) (see, e.g.. Nayak 2015; Tiwari 2016). In some cases, my informants argued that the FRA only later, after its inception, became a key political opportunity structure for mobilization and for winning better outcomes for resistance. To study the FRA as a state-established opening of political opportunity would be a misinterpretation of the dynamics, which are more complex and dialectical in reality. New concepts are needed to explain these complex realities that a dichotomy would oversimplify.

In relation to the concept of state embedding by civil society, I first adhere to the notion that states and state actors can and should be approached and attempts should be made to steer and change the political trajectory by active citizens and social groups. Embedding the state means that first these groups will have created long-term and consistent ties with state actors, which will be helpful in negotiating policies and institutional designs. A further step up the ladder of state embedding is to start (co)producing the state, either by activating or redirecting latent state institutions, or by creating new institutions. When the actions initiated by civil society have led to continual negotiation of policies between state and civil society actors, creating consistency and new political opportunities in the political games through which policies are made, then state embedding by civil society has occurred. Both 
the creation of new and consistent connections to state actors and the (co) production of state institutions have been important tactics of resistance, having notable influence on the discontinuation of mining. By state (co-) production, I refer to the implanting of a desired policy, institution, political game rule, judicial decision, or other feature that can open up a political opportunity for the societal entity doing the embedding. ${ }^{10}$ In order to analyze the role of such actions across the varying cases, I will conceptualize state embedding by civil society actors as a specific strategy, with different substrategies (tactics), and observe what outcomes their usages have had. ${ }^{11}$

Most of the studies on state embedding in environmental governance argue that state embedding by civil society occurs when state agencies make space for civil society to act autonomously and guide policy (see, e.g., Sowers 2013; Teets 2014). Although this might be true in many cases, particularly in the authoritarian regimes on which Sowers and Teets base their theoretical claims and the well-studied advanced industrial democracies of the Global North (Schreurs 2003), the cases from Brazil and India do not fit into this explanation. Within these cases, more often than not, civil society groups have been the instigators of change. Khagram (2004), who has studied both authoritarian regimes and rising democracies, found that democratic institutions and the strength of social mobilization were equally important in defining investment project outcomes. O'Neill (2012), in her comparison of the role of political opportunities and environmental movements on policymaking across different regimes, found that there is typically a much greater leeway for mobilization to influence policies in the Global South.

This discussion offers one solution to the theoretical debate in movement scholarship on whether activists should avoid the state and try to retain autonomy at all costs (see Kröger 2013a). Given proper strategies to maintain the autonomy of the civil society group, isolation is not necessary, so state embeddedness can be pursued. Moreover, this state embeddedness can even be very helpful in ensuring movement autonomy in the face of capture attempts by other civil society actors, such as powerful corporations. ${ }^{12}$

As a result of the interaction during the embedding process, it is likely there will be a new state-society boundary-breaking set of social ties, where activists can help state actors do their jobs better, and also help protect the autonomy of the state from being taken captive by extractive interests. Reciprocally, the state actors will be helping the resistance-it might even be that they become pivotal in resistance after the initial civil society steps. Thus, in the process of resistance, both the state and civil societies can be transformed.

State embedding can take place in parallel and simultaneous political 
games: for example, depending on the local case, in electoral, institutional, or judicial politics; in just some of these; or in none. State embedding while retaining autonomy refers to a situation where social actors are not or do not become entrenched in the upper stratums of the state. Such entrenchment would make the use of contentious actions, such as disruptive protests, incongruous. Several cases in this study illustrate how embedding that retains autonomy can have as huge an impact: resistance actors are simultaneously entrenched while still retaining the ability to engage in contentious politics and avoid the movement's capture by the state.

Evans (1995) regarded the state of India as hugely inefficient in the steel and iron ore sector. Additionally, Brazil is also purported to have major problems in this sector. It was surprising to see for myself how little had changed since 1995 in India and Brazil in this sector-with the inefficiencies being exemplified by the Indian mining scams and the Brazilian tailings pond disasters. In general, Evans (1995) saw India as being somewhere between what he conceptualized as developmental and predatory states, while Brazil was decidedly closer to a "developmental" state. In an updated account Evans and Heller (2015) criticize the state of India strongly for its inability to deliver even basic services to its population, for example, healthcare or adequate food. The key reasons for this are regarded as stemming from the power of elites and the narrow linkages of the state-society, which are also too party based. They suggest that broad political mobilizations that challenge the power of the elites would be required for the otherwise promising federal state structures to be used successfully and more generally than in only a few states, such as Kerala and Tamil Nadu. The vast iron ore scams in India since the mid-2000s support this finding of inefficiency in handling state-owned resources. Yet the fact that a powerful, loose, and broad civil society-state actor-which I loosely characterize here as a sort of Polanyian "organic society" — has managed to prevent the slide toward becoming a predatory state, and made such powerful interventions, suggests that there is a huge potential for expanding the rule of law in India. In general, the recent mobilization wave has been impactful in attempting to influence large-scale investments in many cases in India (Levien 2018). Interestingly, in contrast Brazil seems to have experienced less desirable economic outcomes from the perspective of the resistance.

The cases mentioned here show how political opportunities (as consistent dimensions of politics) were not present for the use of the resistance, mostly because the governments of Brazil and India have been strongly proextractivist. Brazil especially has been, for five centuries, guided by it elites to a path that is dependent on the primary sector where "landed" elites 
still prominently prevail. Likewise, in India large areas are still treated, even today, as resource peripheries in a colonial-type fashion (globally and internally), at the cost of higher value-adding and possibly less socio-ecologically damaging industries and social structures. This particular quality of the states of India and Brazil partly explains why civil society has had to play a much more crucial role in these countries' environmental politics in comparison to many other countries, where the role of the state has been more marked and clearer in promoting greater regulatory standards. ${ }^{13}$

It is helpful to define the "government" as an important part of the "state," but not as its synonym. While I studied the extractivism of Brazil and India, there were new progressive state actors and institutions in both. These state institutions included a substantial part of the Public Prosecutor's Office (Ministério Público) and the Ministry of Agrarian Development in Brazil, and the Supreme Federal Court and its judges and lawyers in India. Thus, it would be misleading to say that a "state," with those institutions involved, would be driving extractivism and clamping down on resistance. Rather, it is much more precise to describe extractivism as being promoted by these countries' governments, not by the states themselves. Prior research on environmental movements has found that not even authoritarian states are monolithic central bureaucracies that would only follow government orders (Sowers 2013; Steinberg and VanDeveer 2012). The "state as an arena" approach is thus suited to explain the spectrum of politics more fully. I will discuss many cases in which, besides the government, civil society actors have successfully steered the state arena. For example, the working dynamics of electoral politics, as a specific game within the state, were transformed at the municipal level in Odisha's Keonjhar district in India. In Keonjhar, the tribes that resisted mining decided to demand that all political candidates (at the municipal, state, and federal levels) who came to hold rallies in their territory would sign a formal pledge to oppose mining. Such a memorandum of understanding has dramatically changed the informal rules of electoral politics, and consequently the outcomes of elections. I consider this type of action as a state embedding and coproduction by civil society (via electoral politics), whereby the state apparatus is changed by a resistance strategy. Once elected and chosen to be part of a government, the antimining politicians who signed the memorandum of understanding have found their range of actions regarding extractivist policies tightened within the limits preferred by the resistance. Although they have become new state and governmental actors, they have also created novel ties to civil society, and are bound by the new rules of the political games that have been formulated by the resistance. 
The state, from this viewpoint, is in constant flux and redetermination, which is an arena of struggle. In that struggle, as many scholars of global environmental governance have pointed out (e.g., Fuentes-George 2016; Khagram 2004; Kröger 2013a; Pellow 2007; Rodrigues 2003; Sawyer 2004; Sowers 2013; Teets 2014), some state agencies might be more receptive to civil society engagement than others and can be played against more hostile agencies. The same can be expected for engagement with federal versus state-level, municipal, and interstate agencies. Thus, within the cases I discuss, I will analyze the role of different scales of the state (international, federal, state, municipal, and local) in detail where relevant in explaining the outcomes. There are cases in which informants mentioned they had "played" some state levels or agencies against others. In other cases, I have other concrete evidence that this had happened even if it was not specifically articulated by the informants. I will explain how the resistance sees contentious, electoral, institutional, and judicial politics as alternative paths of state embedding, and discuss how the resistance sees, for example, the judicial game as an alternative to other opportunities, to be used only in particular circumstances.

A similar set of resistance strategies is unlikely to lead to similar outcomes across the widely varying polities of the world. Western, established industrial democracies and authoritarian regimes might have very different dynamics. It remains to be studied whether, how, and to which extent the strategies studied herein would be as important elsewhere. In consolidating democracies such as Brazil and India, during the period I observed them (2000-2015) the very processes of consolidating democracy or transitioning toward it, via grassroot mobilizations, created new state-society structures and relations. In contrast, Teets's (2014) character analysis of the budding Chinese civil society liberties illustrates how a single party-state still strongly defined what kind of civil society agency is allowed and in which arenas. Teets argues that the Chinese state directs this action in such a way that the supposed increased democracy might serve to consolidate authoritarianism, which is why she calls China's model of state-civil society relations "consultative authoritarianism." In comparison, as I demonstrate, Brazil and India (particularly in some of their regions) were transitioning toward democracy until 2015, particularly through the use of the five key resistance strategies. ${ }^{14}$

Lastly, in positioning this book among the literature to which it contributes, I would also like to relate the resistance to extractivism studied here to two classic and helpful notions about the state, by Max Weber and James Scott. Their work informs figure 1 in the following chapter, particularly in differentiating state-mediated and nonstate-mediated political games. I will 
detail, for example, cases in which large chunks of the territories disputed are not under state control, referring to Weber's (1968) classic definition of the state, which includes the monopoly of legitimate violence. Up to one-eighth of India's territory is under the control, or partial control, of Maoist guerrilla groups, which often also enjoy at least partial local legitimacy (Banerjee 2013). This suggests that the Indian state does not have dominance or hegemony in these areas. ${ }^{15}$ I will discuss cases where the Indian state is present in armed resource conflicts, trying to secure new natural resources for its stateowned enterprises, for which reason they first must try to win the monopoly or hegemony of violence, or both, in those would-be mining areas. The Indian state has found this very hard to do. Likewise, in Brazil there are large forest areas, on top of mineral resources or rich soils, where the state does not have de facto control over the use of the territory. In these spaces, where the state has not been able to secure the monopoly of legitimate violence, the use of land is controlled by elites, illegal land grabbers, or indigenous and other rural populations in lieu of the absent state. In this sense, the expansion of extractivism also includes cases in which the state-in Scott's (1998) conceptualization of state-building as a high-modernist project-simplifies territories and tries to extinguish nonstate space by and for the purposes of extractivism. Moreover, the largely tribal-populated forested hill areas in India that host a variety of resistance to extractivism are also considered as part of Scott's (2009) South Asian cases, where the resistance is attempting to avoid being incorporated under the state of India, and specifically looks for ways not to be governed by outsiders. ${ }^{16}$

In this chapter I have scrutinized the key concepts that lay the groundwork for my analysis, including the role and form of the "state" and the key strategies through which I analyze how peaceful resistance is formed. In addition, I discussed the causalities and noncausalities between extractive investments, grievances, and mobilization. Building on this foundation, the next chapter will offer a synthetizing framework that dynamically unites these concepts. 


\title{
Theory of Investment Politics and Spatial Changes
}

\begin{abstract}
In the midst of writing up my initial field research on mining conflicts in Brazil and India, Finland was caught in a major mining boom. A wellknown politician compared the illegalities in this Arctic mining thrust to the rampant expansion in the Congo. I packed my bags and traveled to Lapland to understand what was going on. To my deep surprise, I learned that the extractivism I had witnessed in the Global South was also here in the North, in the Arctic, and the similarities ran deep. Not only were the physical and social spaces transformed, but also the symbolic valuations were being changed by the irreversible transformation of forests and pristine lakes into toxic lagoons and open pits. State officers responsible for regulating mining were becoming mining lobbyists, and directors of environmental NGOs were recruited to establish promining stakeholder mechanisms. Most worryingly, in my many discussions with regulators, they saw no problem in themselves going over to the other side through what seemed to be a revolving door. A view of social power relations and how politics are shaped by such personal decisions was missing. Finding this extractivist expansion in the mind-sets and landscape-changing actions even in the Global North was helpful in developing a conceptual framework regarding the spatial dynamics in extractive politics and the political games that are used in investment politics. Finding extractivisms where one would least expect was formative for understanding the globality of the key transformations changing lives on this planet.
\end{abstract}

\section{Political Games and Agencies}

Investment and mining politics typically consist of clashes between corporations and resistance in largely state-mediated political moves to influence 


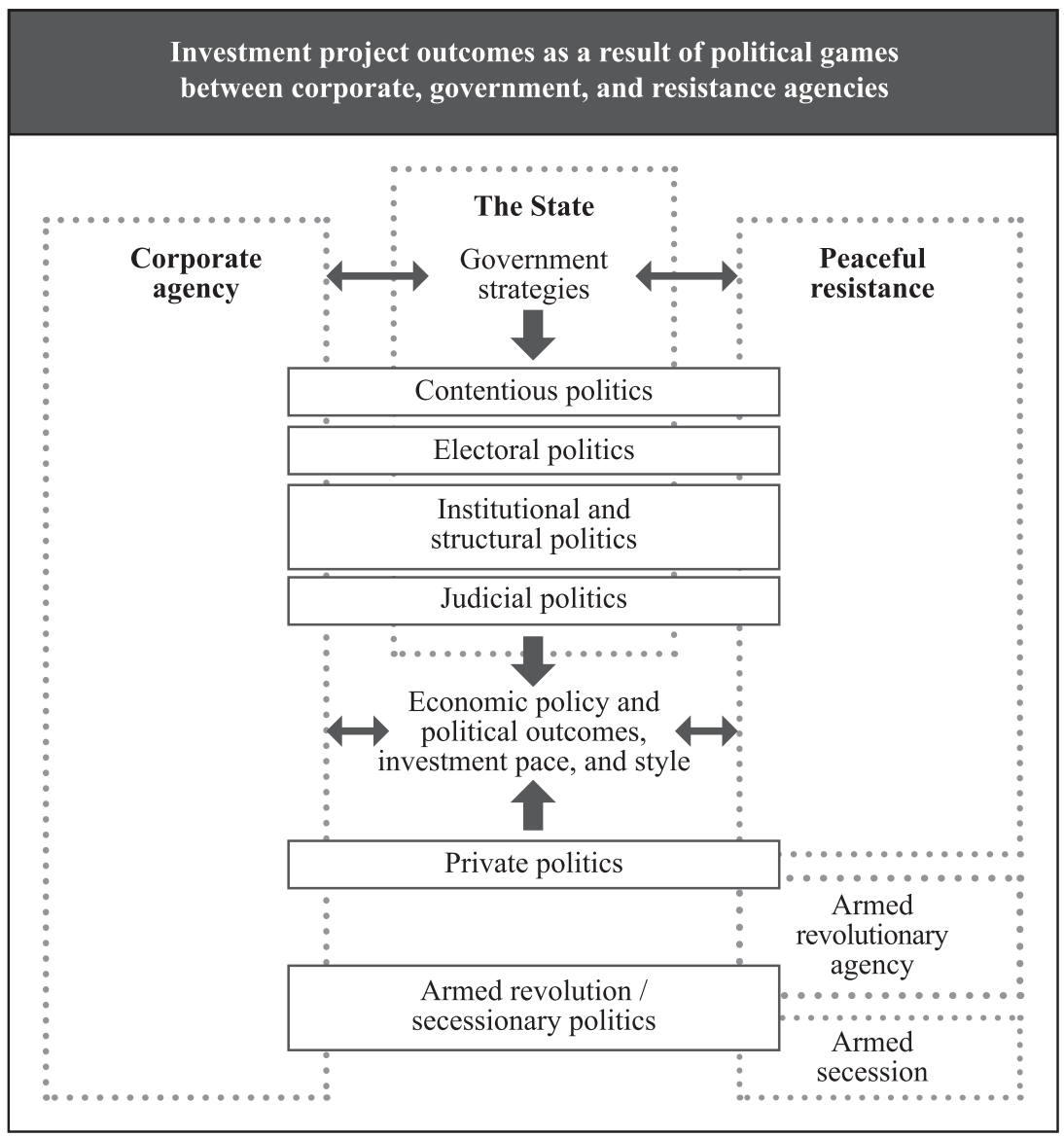

Fig. I. Different political actors and games through whose interactions the outcomes of investment politics are determined. Corporate, state, government, and resistance agencies of different types can try to influence economic and political outcomes either directly via specific strategies, or indirectly through statemediated or private politics, or, in some cases, through armed conflicts.

investment decisions. Figure 1 illustrates a general theoretical framework for the analysis of investment politics across differing contexts, agencies, and political games. This section discusses the framework I employed across all the local cases and used to explain the national and regional dynamics. While I employ this framework in relation to mining politics, it can also be used more generally. The figure builds loosely on Bourdieu's (1991) theory of fields, which examines the construction of social fields and an individual's reaction and response to interaction with those fields, and my prior theorizing on natural resource politics (Kröger 2013a). 
This figure shows the players that have agency (corporate entities, the state, and civil society) and the type of political interaction these players can engage in given their respective position. The central boxes and arrows in figure 1 illustrate the centrality of relationships within this framework. This figure is a summary of the potential interactions that can be accessed or utilized by different players within investment projects. In the central column the first four boxes-contentious politics, electoral politics, institutional and structural politics, and judicial politics-are descriptive of the types of games that strongly and mostly occur under the state, and thus the (re) mediation of state and governmental actors. The bottom two boxes capture the situations where corporate or resistance actors, or both, choose not to engage with the state and its institutionalized channels to pursue their goals. Rather, these types of political games rely on direct interaction between companies and their challengers. Peaceful resistance as a strategy can move between the state-mediated strategies or direct interaction through private or other nonstate politics, but it would not engage with armed revolution/ secessionary politics. Conversely, armed revolutionary/secession resistance, due to its nature, is not aiming to achieve its strategic goals through the largely state-controlled channels of interaction. Armed resistance of this type tries to either overthrow the existing state or create a new state, so these guerrilla groups do not typically see a point in trying to peacefully reform the existing state structures. Instead, they rely on armed actions of resistance, and direct interactions with corporations, such as asking for levies. The following paragraphs will provide more specific and detailed examples of scenarios that clarify the flow of information and action in different types of resistance situations.

The first more fleshed out example concerns the role of contentious politics, as this is an extremely important facet and field of investment politics that came up many times during my field research. What is "contentious" is defined by those who are in power and is always in reference to the "normal" and accepted opinions and political methods in the context in question. Thus, something considered contentious in an Indian context at a given point in time might be normalized in the Brazilian context and vice versa. Environmental politics and land conflicts where local people, companies, and state authorities clash in physical mobilizations, such as peaceful protests and land occupations, are situated within the field of contentious politics. Contentious politics may be a more or less institutionalized and normalized part of the political system. For example, the many land occupations in Brazil have become a normalized political act in the past three decades (Carter 2015; Wolford 2010). Nevertheless, the way incumbents, such as conservative politicians, elites, and companies, talk about the politi- 
cal tactics used by contesters in contentious politics often frames these acts as contentious or illegal, immoral, undevelopmental, backward, unacceptable, destructive, violent, chaotic, abusive, and so on. These social actors may demand, for example, "strong" action to punish perpetrators and stop such actions via police or paramilitary violence. Government actions also influence the political game of contentious politics, the dynamics of which are strongly steered by the state (McAdam, Tarrow, and Tilly 2001). Progressive governments, especially those embedded by contentious movements, to a considerable degree may remediate resource conflicts to the benefit of local underdog groups. For example, in the 2000s, the federal government of Luiz Inácio "Lula" da Silva (Workers' Party) in Brazil (2003-10) ordered the federal police and army to support communities against land grabbers in several resistance cases in the Amazon, and clamped down on illegal deforestation by the elites (Kröger 2013a, 2015b; Kröger and Lalander 2016), while the government of Jair Bolsonaro (2019-) in Brazil has quite the opposite stance and rhetoric in these respects. In this sense, the rules and actions within different political games are defined by the actions of state, civil society, and corporate actors.

Besides contentious politics, there may be, and typically are, other political games in which the outcomes are determined by the clash of incumbents and challengers. These are the less contentious and much more routinized games, represented by the next three boxes in figure 1: electoral, institutional and structural, and judicial politics. The political games that belong to this subset are the primary suggested means of political participation, usually by the conservative elites, in democratic political systems such as Brazil and India (at least during the period they are studied in detail in this book, until 2015). Yet there may be actors with antidemocratic tendencies seeking to curb even these routinized games. In conflict situations, electoral, institutional and structural, or judicial politics may also be framed as contentious and unacceptable by different reasonings. One example is when a general opinion or circumstance is curbed in deference to the interests of "the majority."

All the above-mentioned political games are remediated by the state. ${ }^{1}$ Private politics are not; these are represented by the fifth central box in figure 1. Private political tools and tactics consist of direct interactions between companies and their challengers, including corporate social responsibility, outreach, dialogue, stakeholder relations, and so on (Soule 2009). However, state-remediated strategies, whether considered contentious or not, and strategies used by actors within these political games can foster both extractivism and resistance to extractivism. These strategies support the trans- 
formation of passive people into activists. By activist I mean citizens who participate in and create politics in the above-mentioned political games, forcefully drawing attention to problems. The myriad and complementary, yet also generalizable, ways in which this may or may not happen are the object of scrutiny in this study.

The different political games illustrated in figure 1 are alternative and possibly complementary ways to address an issue. The simultaneous use of all these strategies or types of political posturing might, however, also be detrimental to resistance goals. For example, if judicial politics result in the victory of the targets and not the contenders, the contenders' other political activities could lose legitimacy. In figure 1, the boxes of these political games overlap with resistance and corporate agency as political actors, suggesting that nonstate actors may become embedded in the state and with direct intention form state structures and political opportunities. As discussed, opportunities in both India and Brazil are often a product of embedded autonomy by resistance vis-à-vis the state (despite corporate agency's similar embedding attempts) and not benevolent, top-down government or state actions. ${ }^{2}$

The findings of my research suggest that where mining has been stopped or slowed down, the outcome is strongly activism dependent, relying less on proactive governmental action and more on nonstate actors. What resistance does — in other words, what strategies are used-is important. An activist, working in a professional NGO with a very long track record of successfully instigating governance processes that have led to the curbing of destructive resource extraction projects in India (interviews, December 2012), ${ }^{3}$ commented on the importance of the strategy of state embedding, for example when engaging with institutional politics by making a solid dossier to hand over to investigators:

So actually this is very important. This thing which both SPS [Karnataka, Bellary mining-critical group] and Goa people have done: collecting all the information, studying the laws, the rules, the regulations. And seeing what is [a] violation of what. This exercise unfortunately very few of our activists, very few of our movement people, are able to do or somehow do. This exercise is very important.

Governments were not proactive without prompting in any of the cases studied. Typically, states and their governments are promining actors due to their positioning as parcels of the capitalist world-system. Surveying the strategy possibilities of antimining movements, Korten $(2002,11)$ notes 
that "states are embedded in an inter-state balance of power and are often constrained in their ability to regulate." For this reason, Korten sees the regulation of corporations primarily via governmental action as "a weak and temporary solution." Studying Brazilian environmental politics, Hochstetler and Keck (2007) emphasize that contentious action is required in addition to routine strategies of mobilization. Similarly, I argue that both state-challenging and state-producing strategies are to be used, and this book demonstrates how state embedding has been central in many struggles to overcome the burden of global capitalism. Furthermore, my database of cases suggests that state-society relations, which were characterized by coproduction of the state, managed to avoid civil wars and other armed conflicts from becoming rooted in the political dynamics.

\section{The Political Game of Armed Conflicts: An Exemplary Case}

The final central box in figure 1 represents armed revolution/secessionary politics. I will discuss the theoretical framework of this political game as illustrated by an example from my research. Since its independence in 1947 , armed conflict has been a routinized political game in India (Banerjee 2013). The most widespread expression of armed resistance, territorially and demographically, has been that of Communist radical movements (Choudhary 2012). There have also been other severe armed conflicts, but these have been based on ethnic or religious reasons, often taking the form of terrorism, and do not have an ideological agenda of social justice and land reform, unlike the Maoist guerrillas of Central India (Banerjee 2013; Choudhary 2012). ${ }^{4}$ The "core issue of the Maoist insurgency" is the "exploitation of forest produce and mining of minerals" (Chenoy and Chenoy 2010, 119), which makes a study of their revolutionary agency a necessity for this book. This armed response to resource-frontier expansion also provides a fruitful comparison to the nonarmed response in Brazil by a large leftist social movement organization (in this case the Landless Workers' Movement) that easily could take up arms but has not done so.

Armed resistance cannot be explained by revolutionary agency or repression alone. As mentioned by Bosi and Giugni $(2012,93)$, "Political violence is less a strategic choice than one possible evolution of contention." In India, acts of armed protest have been triggered and strengthened when the rule of law has failed. The state has offered bullets in response to nonviolent direct action, and there is a model and ideology of pursuing change via the use of arms. Banerjee $(2013,382)$ argues that "the poor peasantry and 
landless opt for violence as the last resort in their attempt to improve their lot when all other means (such as Gandhian satyagraha [nonviolent direct action] or parliamentary reforms) have failed." This suggests that there is willingness for nonviolent direct action, and violent means are used sometimes because they have been normalized within the political arena. In other words, in many Indian contexts, when all else fails taking up arms is a viable or expected option due to the cultural normalization of armed resistance.

In India, the existence of the civil war context makes the whole spectrum of mobilization different than in Brazil, even for nonviolent resistance groups. This context keeps open an added political field of "armed revolution/secession" that is routinized as a key political game within which the outcomes of extractive investments are also partly determined. It is not only revolutionary agency that seeks to influence investment outcomes using secessionary politics. This game and its rules are mutually created by revolutionaries and an armed corporate agency backed by the state. In Chhattisgarh, India, the game has created a paramilitary organization that expands the extractive operations of public and private powerhouses (Sundar 2006).

Contentious politics and armed revolutionary politics are not just alternative ways of addressing problems but also processes that feed each other. Banerjee $(2013,388)$ gives the example of how the Naxalite armed revolutionary movement of the 1960s "set forth the demands of the poor and landless peasantry in a way that shook the atrophied Indian political scene." The 1960s armed upsurge also fostered peaceful activism in the larger society, although with a lapse:

The violent outbreak sensitized the rest of society to the problems of the hitherto downtrodden sections of the population. This was to lead to the development of a robust social activism among the Indian middle classes ... working for the empowerment of the ... dispossessed groups; intervention of the media in exposing atrocities on the depressed castes and tribal peoples by upper-caste landlords ... [and] human rights activists [taking actions] to protect citizens against police repression and illegal acts of the state. (Banerjee 2013, 388)

According to Banerjee, the second outcome of the 1960s armed revolution attempt by the Communist Party of India (Marxist-Leninist) was that

by openly asserting the right of armed resistance against the Indian state, the CPI (M-L) squarely placed violence as a persistent method of action in Indian politics. It became a precedent for armed offen- 
sives by other groups, albeit ideologically different, such as militants from religious and ethnic minority communities. ... the main achievement of this first phase of the CPI (M-L) movement was not its physical occupation and administrative control of territory, but its success in spreading its ideological message of people's power and the right of self-defense among the rural poor. (Banerjee 2013, 388)

These legacies are very visibly present in current extractive conflicts. Since Brazil lacks the experience of long-term armed revolution gaining significant land and national attention, it can be argued that the political game of armed revolution is not even available to mining-affected populations, as there is no existing organized movement or ideology that would build up such revolutionary agency.

The decisive line between peaceful resistance and armed action lies in the use of arms and an unwillingness to try to continue to embed the state, but to instead exercise revolutionary or secessionist practices, or both, by force. Secessionary action tries to create a new state, while revolutionary actions try to overthrow the existing state instead of reforming it. Both forms of resistance are used by groups that are armed in India. Importantly, these armed revolutionary and secessionary conflicts are intimately tied with the broader dynamics of extractivism, its impacts, grievances, and thus the mobilization potential among the affected populations. In this case these populations are most often the forest dwellers. Armed secessionist agency is also present in India's Northeast, where it has fewer or no real Maoist, communist, equalitarian, or environmental ideologies, does not resist mining, and coexists with an extractive boom that deepens capitalist hierarchies within the tribal communities (see Karlsson 2011 and Lahiri-Dutt 2014). Armed revolutionary agency by Indian Maoists is openly antimining, although they have also allegedly taxed mining companies and allowed promining politicians to visit their constituencies in mining areas against a levy (see Chenoy and Chenoy 2010; Sundar 2006). The Maoists use armed revolutionary politics (and de facto physical area control by expanding and seceding "liberated zones" outside the reach of the Indian state's assumed monopoly on violence) to influence other political games as well (see Chandhoke 2015). Their agency is not limited to the use of arms, and Maoist insurgents do not just consist of guerrilla squads. Sanghams, that is, unofficial Maoist bodies in the villages, are unarmed councils established to oversee village events and usually undertake nonviolent activities that are in many ways similar to an NGO (Chenoy and Chenoy 2010; Choudhary 2012). Thus, it makes sense to study sanghams as a part of resistance in the same area, to see what impact a composition 
of different and multiple agencies and strategies has in comparative terms to economic outcomes. How does a mix of armed and peaceful resistances influence the dynamics and their outcomes?

Armed revolutionary tactics often compete with peaceful strategies for peoples' attention when individuals make their choice of which action to pursue. This is particularly true in India. In Brazil the MST and other very large and well-organized movements curb the possibilities of militant armed resistance and perpetuate the practices of peaceful contention by day-today strategic choices and the formation of cadres. In Indian mining politics, the key constituents are Adivasis, whose actions are targets for change by both movements fostering nonviolent direct action and those aimed at armed revolution. For example, the All-India Adivasi Mahasabha is a movement and political party trying to unite the Adivasis in the use of embedded autonomy instead of armed resistance. In this effort, the movement criticizes both the government and the Naxalites. Mr. Moosahary, from the movement, argued that "poor administration and corruption in parts of the country had created Maoism.." In his view the Maoists should turn to parliamentary politics: "You may be fighting for a good cause but you cannot get anywhere by killing innocents. In a democracy, the solution must come from the peaceful exercise of people's power. ... The Indian Constitution is a flexible document—short of Independence, you can get virtually anything." In contrast to this view, Padel and Das (2010a, 2010b) argue that the ongoing liberalization of the Indian mining sector makes it increasingly easier for mining companies to extract resources, and more difficult for communities to resist peacefully. Studies on the injustices that lead people to take up arms abound. ${ }^{6}$ Many scholars who study these conflicts, and base their claims on field research, argue that armed resistance is the only option left for the populations who turn to this strategy. I will assess these claims in part II.

Armed revolution/secession politics and civil war conflict have been consolidated as a political opportunity and a threat for potential resistance in India; however, they will only continue to exist if there is agency in using arms. Given that this is a political opportunity, the locals assume that a possibility exists for them to use arms to resist. A local intellectual argued that if the Maoists did not resist the mines in Chhattisgarh, they would lose support, as the locals do not want the mines and barring the mines depends mostly on Maoist armed resistance. Mining politics is thus not only about mining, it is also about different types of resistance agencies. In early 2013, the same intellectual thought that there was no way to counter the mining expansion by peaceful politics in the Bastar region, for which reason he expected massive bloodshed to take place in the future-something that was 
unfolding in 2015 under the new Modi government, according local Adivasi leaders with whom I talked in May 2015. I will discuss these dynamics more in the second half of part II.

\section{Intertwining and Autonomy of Political Games in India and Brazil}

This section will explain how the above political games function and are related to each other in Brazil and India, as this is essential information for understanding how these political systems function as contexts for extractivism and its resistance. I will compare Brazil and India for their similarities and differences, which is helpful in pinpointing the reasons why different strategies of resistance function differently depending on the political system. This section also explains how the above political games are related to each other.

The political games mentioned above are intertwined, resulting in fewer possibilities for the civil society to embed the state in such settings as India, where, according to my research informants, there is no effective three-power division, that is, the separation of three powers-a legislature, an executive, and a judiciary branch-for the governance of a state. An analyst at the Centre for Science and Environment, an expert research organization that is an NGO-but also so deeply embedded as a policy-support providing institution that it can be seen as a semistate actor (for certain governments) argued that in India bureaucrats do not have much autonomy, but depend on the minister in a federal cabinet. This mixing of executive and legislative power means that in India electoral and institutional politics are quite tightly intertwined and even inseparable. This suggests that institutional embedding is less important than electoral embedding in India.

In Brazil, the outgoing president normally names the Supreme Court leader for the next president's term (historically a very conservative figure in practice, preventing major changes being introduced to extractivism via litigation at the highest level), while in India the court system elects its own members and leaders autonomously (a system that the current Modi government is trying to disrupt by giving the executive the power to name judges). For activists, courts are typically overburdened and of little use in Brazil, and it is beyond their ability to postpone projects. Additionally, the government has not historically listened to court orders, even regarding its own initiatives. For example, the construction of the Belo Monte dam in the Amazon was a notorious example of this inability to enforce orders (Kröger and Lalander 2016). In India, when the Supreme Court ordered all mines to 
be closed in Goa in 2012, the executive complied, which would not happen as easily in Brazil (as this requires major political support).

According to an analyst from the Centre for Science and the Environment, the "judiciary is more powerful than the executive," which explains why a "court order stands above ministries." Furthermore, in India, judicial politics is a field where civil society has a firm place, "local communities initiate cases," and there are "lots of progressive lawyers who take on cases for merit", pro bono, although this judicial-actor activism is a "new phenomenon" in India. In Brazil, a similar and, theoretically, largely autonomous element of the judicial system, the Ministério Público, hosts public prosecutors and an ombudsman that, as a watchdog, can also take on powerholders and companies via class-action lawsuits. This system has bred a new and substantial group of activist prosecutors (McAllister 2008), as well as prosecutors who focus on attacking social movement activists, or on coaxing them to participate in time-consuming and largely meaningless (powerless) negotiations and dialogues with companies (Zhouri and Valencio 2014). However, autonomy does not mean that the technically autonomous state actors would make independent decisions without political biases, unaffected by partisan or ideological motives. For example, according to many scholars and journalists, the greater autonomy and power afforded by President Dilma Roussef to the prosecutors and judges, following the unprecedented street protests in 2013, has led into the misuse of that new judicial power in the form of partisan and nonindependent judicial decisions. In the current situation (beyond the scope of my discussion here), the law is not applied correctly, and for some no law is applied at all. Nevertheless, in both Brazil and India, the creation of a Weberian bureaucratic autonomy (which ensures that state institutions are not captured by market actors or ideological groups) has fostered the building of some noncorrupt supporters of the rule of law seeking the best for society on the basis of more elevated ethics than their typically clientelist peers.

However, as I shall show, there are important subnational and contextspecific divergences in access to these opportunities for activists in both countries. Roughly speaking, access to the Indian judicial system typically requires such high-level professional judicial NGO or expert activist capacities and experience that its usage has been out of the reach of ethnically marginalized groups (who are also poorly educated and connected). It is pertinent to note that there are important exceptions, and the situation is starting to change. For example, the use of institutional and structural politics, via the social-cultural capital of ethnic affinities, is often off limits to Adivasis. Therefore, Adivasis have tried to push the state into new institu- 
tional avenues, and via new legislation strengthen the existing ones to which Adivasis have a privileged access. I will discuss these forest and communal rights (such as the Forest Rights Act) later in part II, when discussing how the context influences extractivist politics.

In sum, this discussion highlights how interpolitical game dynamics are place and context based, defined by those involved and the strategies used by other resistance groups and their targets in the area, thus requiring a detailed and comparative analysis at several scales of power. Figure 1 provides guidelines for including a large group of explanatory factors in the analysis in order to build a fuller picture of the situational politics.

\section{Steps of State Embedding by Resistance}

States are specific products of given societies, rather than fixed entities. Some actors in a society can better produce and embed this created entity (which is part of society) than others. I am interested in how these differences in participating in state production or in creating deep ties with powerholders might affect mobilization outcomes in varied local contexts. The discrepancy between Brazilian and Indian political opportunity configurations has meant that in Brazil activists have attained better results when embedding and using institutional and structural politics. In contrast, in India the outcomes have been more favorable to the resistance when it has focused more on judicial politics. In India, activists have also had good results with the use of institutional politics, but due to the mixing of executive and legislative powers this typically happens when the setting of electoral politics is favorable. However, I learned that this is a situation or issue that is very difficult for activists to know about. Indeed, even the most seasoned activists were surprised to receive the support of a number of the executive institutional branches of the Centre (the federal state) ${ }^{7}$ via, for example, the establishment of the Shah Commission to investigate mining illegalities. ${ }^{8}$ As a general rule, there is no easy way for activists to predict what will happen, as they are seldom cognizant of the backdrop of interpolitical game dynamics against which their actions take place.

Political opportunity structures are also often at least partially a result of accumulated actions by corporate, contentious, and government actors. Sometimes they are almost exclusively a result of prior civil society mobilizations and state production. ${ }^{9}$ The political games presented above illustrate the avenues through which different actors can try to use and change the political opportunities offered by the state. The separation of the four state- 
mediated political games, wherein nonstate actors can coproduce new rules and power relations, serves the purpose of pinpointing in detail how political opportunities are used or created. What is notable in my database is that, in the vast majority of cases, many political opportunity structures were actually created by the resistance. The bulk of prior theorizing on political opportunities has stemmed from Western experiences, and particularly from the 1960s civil rights movement (see McAdam 1999; McAdam and Boudet 2012). This was a very different situation. For example, opportunities were opened from above, which allowed the movements to prosper. However, in the history of Brazilian and Indian democratization there has been a marked bottom-up trajectory. A large social movement, led by Gandhi and Ambedkar, created the Indian state and democracy. They created the state, together with other activists against British rule, which could be considered a maximum form of embedding the state- the creation of a new state. In Brazil, a large movement for democratization spearheaded by civil society organizations and social movements, which started in the late 1970s, led to the writing of the 1988 Constitution. This document continues to offer the major political opportunities of today (Kröger 2013a). ${ }^{10}$ Showing that there is a particular civil society embedding of the state is very helpful in explaining outcomes in a dynamic and historicized way.

State embedding can occur by three avenues; (1) changing the rules of the different political games; (2) changing the power relations within the games by new interpersonal connections; and (3) aligning the mind-set of existing state actors and thus forging encompassing embeddedness around a project in a way in which progressive state actors start supporting the agenda of a civil society actor vis-à-vis a project. I will now give a few examples of what I mean by state embedding in different contexts. As mentioned, in Odisha's Keonjhar district in India, the resistance produced new informal yet applied rules for electoral politics. There, the movement invented a novel way of ensuring that elected politicians follow the movement agenda. People would only vote for candidates who signed a preelection memorandum of understanding that committed them to oppose new mines. This is not the same thing as relying on the possibility of using electoral, parliamentary politics (which might not exist in some political systems). Here, the resistance has changed the rules of the electoral game, by creating its own rules for the preelection of candidates. The strength of local movements and their close ties to the elected politicians ensured that the promises were kept. ${ }^{11}$ Only those candidates who signed the memorandum of understanding were elected. Furthermore, some of the new MPs were local movement leaders. This is another form by which resistance can embed the state. The resistance 
thus occupies state positions with people embodying two roles in key positions of the game in question. The act of joining as a common project, via encompassing embeddedness, is a third form of electoral politics embedding. For example, in Brazil's Minas Gerais, in two cases leading local politicians (mayors) were lured into joining the resistance front. Similar and other tactics within electoral politics have been found to be useful in the United States, for example for the resistance to nuclear power plants in the 1980s, where ballot-measures were used for mobilization and to pass laws that limited the industry options, as David Schmidt (1991) explains in Citizen Lawmakers: The Ballot Initiative Revolution. I will illustrate how such and other similar tactics are available also consolidating democracies such as Brazil and India; the use of such electoral embedding actually being a process that coproduces a more democratic state.

Figure 2 illustrates how the strategy of state embedding functions in general, once the resistance has secured a set of state institutions driving its agenda. This shows that civil society resistance has had an important role in investment outcomes, even where state institutions have made the final decisions. As the resistance continues to utilize and develop embedding strategies, it can advance up the steps of embedded autonomy as the figure implies. Figure 2 demonstrates how the rise through the steps of embedded autonomy brings benefits in the process of struggling for state apparatus support.

This process of embedding is not a one-way street. State actors also have a say, and their embedding by the civil society is not synonymous with capture. There is a distinct conceptual difference. State agencies as well retain autonomy, but they are in a specific kind of interaction or relation with specific civil society agendas. They coproduce the state with civil society.

In figure 2, the second step, "Deeper interpersonal ties with state actors, coproduction of the state," refers to situations where, for example, powerholders join the resistance front or start to coproduce new rules together with the resistance. The third step, "Changing rules, creating new capacities and policies," refers to the moment in time when the resistance can be considered to have been key in producing the part of the state that governs the targeted policy arena. To argue that state embedding has occurred, it is not enough that the state alone supports resistance agendas. There must be a provable causal link that the initiative (ultimate cause) has come from civil society; whereas "official resource-use decisions" (the fourth step) have come from the state (proximate cause of economic outcomes). If the three steps on the bottom are absent, while the top step is present, one cannot say that the outcome was influenced by state embedding by the resistance. In that case top-down state/government action would explain 
Steps of state co-production by resistance:

The influence of resistance embedding with the state apparatus on extractivism

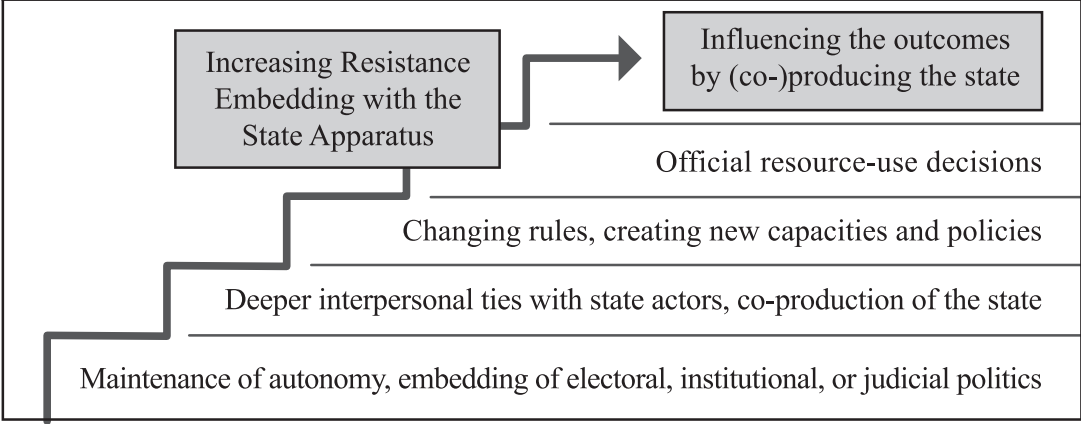

Fig. 2. There are different levels of embeddedness a resistance can achieve with governmental or institutional actors. A resistance effort can build its embeddedness in steps to achieve the ultimate goal of influencing outcomes through the production or coproduction of the state.

the outcomes. In my database, there are both types of local cases, which allows for the study of both resistance-initiated and top-down directed curbing of extractivism.

The Joda block (a block is a subdivision of a district) in Odisha, India, was a case without notable resistance to extractivism, and surely no state embedding strategies were used. In fact, the local Adivasis demanded the reopening of the legal mines, after the Odisha state government had closed down practically all iron ore mines in the state. This looks like a top-down process of curbing extractivism, as none of the three lower steps depicted in the figure 2 were active. However, the case gets more complicated when we look at the larger context. As I also study the other scales, not just the local, through incorporated comparison, I can link prior actions elsewhere to local events, for example in Joda. The closure of the mines in Joda took place within a series of nationwide extractivist politics.

I traced the causalities whereby the Odisha chief minister decided to issue an iron mining ban in the state after the devastating blows to mining mafias and chief ministers in Karnataka and Goa, knowing that the Shah Commission was heading toward Odisha. The creation of the Shah Commission was largely a result of the Goa, Karnataka, and national mining-critical civil society embedding the federal state. It offered new and very useful political opportunities for the resistance throughout the country. Such state constitutive actions carry great potential, since the federal state will spread the new 
opportunities more widely, with state resources, and without experiencing such friction on its way as civil society networking would.

In terms of research applications, figure 2 and the approach to state coproduction developed above can be fruitfully united with studies that focus on explaining development, state capacities, and industrial transformation along the lines envisaged by Evans $(1995,2010)$. Evans and Heller (2015) further enrich this literature by providing a detailed look at the political economic process from the civil society point of view. The steps of state coproduction in figure 2 can also be scaled up for the study of transnational embedding of international institutions by corporations and civil society actors. A good example is how the Food and Agriculture Organization (FAO) opened institutionalized access for the civil society to several FAO formal committees and other decision-making bodies. For example, after La Via Campesina started to try to embed the FAO to produce new rules, power relations, and structures within it, an International Planning Committee for Food Sovereignty was established. ${ }^{12}$

Having introduced a framework for analyzing the political dynamics of economic decision-making, investment projects, and extractivism across varying and complex settings, I will next provide a complementary theoretical framework to assess spatial changes. This framework is helpful in analyzing the likewise crucial material, social, and symbolic processes through which extractivism and resistance to it take place. I will use these theories right after their presentation, when I seek for explanations for how the resistance in Goa, but not in some other contexts, managed to discontinue all mining operations.

\section{Causality of Changes in Physical, Social, and Symbolic Spaces}

Figure 1 is built loosely on Bourdieu's (1991) theory of fields and more closely on the scholarship in contentious politics and institutional analysis (particularly Evans 1995; Hall and Taylor 1996; McAdam, Tarrow, and Tilly 2001; Zysman 1994). As extractivism is a deeply material and symbolic process, not just a sociopolitical change, other theoretical tools are also required, which can be used to analyze the complex spatial dimensions involved. This section presents a theory of physical, social, and symbolic spaces as interrelated and internally distinguished loci for changing power relations and differentiating and positioning social actors. I build on a relational thinking combining political ecology, world-ecology, and some classic sociological concepts. Political ecology sees environmental conflicts happening simulta- 
Causality of changes in physical, social, and symbolic spaces

Physical space

- Type, distribution and access to/control of nature (e.g., land, body, visible objects)

- Physical acts

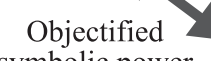
symbolic power

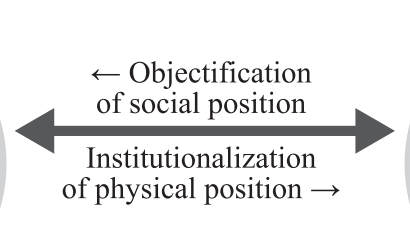

Symbolic space

- Symbolic capital differences

- Symbolic acts of merit

Fig. 3. A theory of physical, social, and symbolic spaces as interrelated and internally distinguished loci for changing power relations and differentiating and positioning of social actors. Resisting extractivism in all these spaces and through all these mechanisms is likely to lead to better outcomes for the resistance.

neously on symbolic and material fronts (see Peluso and Watts 2001). Figure 3 operationalizes and develops that understanding for analytical purposes, to provide heuristic tools for analyzing causalities in such spatial dynamics. This figure outlines the theory of spatial analysis, which I have used previously for assessing mining booms (Kröger 2015a). This theory presents the social, symbolic, and physical spaces as internally differing topologies of power relations that are simultaneously interrelated and interchangeable.

In social space, power relations and topology are defined by the distribution of economic (in most cases money), social, and cultural capital, and the social acts that change the distribution of these between actors. ${ }^{13}$

Physical space includes the body, land, and objects, as well as visible artifacts like text and pictures in existing virtual worlds such as the internet. Besides the distribution of access to and control over these forms of physical capital, the power relations of physical space are defined through physical acts.

The power relations of symbolic space are likewise defined by both differences in symbolic capital distribution and symbolic acts. Symbolic capital can legitimize differences in economic capital and ensure complicity despite inequalities. Symbolic space is the arena of legitimization battles. 
"Symbolic acts of merit" is my own concept, not one presented by Bourdieu, who did not consider morality or ethics as significant strategies of distinction. This conception differs from "symbolic capital" in that the power in these acts of merit does not come from misrecognized capital in other spaces. Rather their power arises from real competence, skills, or acts of truth where an agent displays morality, courage, strong will, or humility for the sake of the inherent value of such symbolic acts, not to gain physical or social power (for which the accrued symbolic power can nevertheless be used). Such symbolic acts of merit are available for these agents despite their low position in the other spaces, and can result in changing their positioning in symbolic space. Symbolic acts of merit work as the mechanism instigating internal change in positioning or relations in symbolic space. Honor, trustworthiness, respect, and charisma can derive their power both from symbolic capital and from "symbolic acts of merit." As I will show, symbolic acts of merit have been an extremely important avenue to continue in peaceful yet impactful resistance, especially for those who are underprivileged in multiple ways. For example, their underprivilege can manifest in relation to their ethnic, class, gender, national, and other minority positions. These are acts of key prominence given the current global crises and the thrust and power of extractivism. I will discuss cases where activists have engaged in these endeavors.

An actor can gain power in all three spaces by either internal, spacespecific acts or by using interspace mechanisms. A mechanism that can be used to link physical and symbolic space is the creation of objectified symbolic power, which links physical space changes to their symbolic dimensions, while social and symbolic spaces can be linked by creating institutionalized symbolic power. Both of these tools can be used to generate transformation in either direction, from physical to symbolic, social to symbolic, or vice versa, and also to forge links between all spaces.

When social and symbolic spaces are simultaneously changed, physical space can be transformed more rapidly and thoroughly. Mining expansion and contraction can be explained through such multispatial power changes (Kröger 2015a). The position of a social actor in social space can be made homologous with physical space by what I call the objectification of social position (see figure 3, top arrow). Examples of this are using capital to transform one's body via plastic surgery, moving to a new neighborhood, creating a website, or buying a mineral deposit and opening up a mine. Institutionalization of physical position can be used to link one's position in physical space to social space. An example of this is the formation of a company or association named after a location where one has lived, which allows the 
form of physical location that has been thus institutionalized to be legalized and made changeable (by sale). The institutionalization of physical position can be the resistance strategy of attempting to gain official recognition of ethnic-territorial rights. Indigenous and other rural populations affected by mining may also try to create and change the objectified symbolic capital on which mining relies, such as the framing of destroyed or affected beings and entities as living, instead of as mere objects that are devoid of life (e.g., "natural resources" versus animals, trees, and other entities in the web of life). They can argue that their land is holy, that a mountain is a god, and not (primarily) a mineral base, and that mining machinery are not emblems of progress and development, but of destruction-land and machinery being key objectified symbolic capital on which and through which extractivist expansion and its resistance often meet. Both these interspace mechanisms can counter mining capitalists' use of (1) the objectification of social position, whereby miners use their economic, social, and cultural capital to occupy physical space by opening mines, and (2) institutionalized symbolic power, wherein these people and companies are considered rightful developers and their projects positive to the nation-state.

The symbolic capital changes related to "nature," "natural resource"-based "development," and "indigeneity" surfaced as particularly important during my field research, and a brief discussion of these terms helps to relate the conceptual framework above to extractivism and its discontents. Culturally marginalized groups, subalterns of the subalterns, cannot easily use symbolic capital or ethnic cleavages for their own benefit in structural politics (Spivak 2004). Many Adivasis try to portray themselves as the "preservers of nature," but such linking of indigeneity and environmentalism is often fiercely resisted by the Indian state and a large part of the population in India (Nilsen and Roy 2015). Meanwhile, the efficacy of the other political games Adivasis use can also be diminished when Adivasis are linked to groups engaged in armed secession or revolutionary politics, or both, outside of the state in the form of Maoist insurgency (Chandhoke 2015; Shah 2010).

I suggest a three-space causal analysis theory to assess how these transformations take place. Of key importance are the mechanisms connecting the symbolic space to the social and physical space, and the use of symbolic acts that challenge the modern ontologies by nonmodernist framings. To travel down one of these new paths, in India, the Supreme Court's verdict against Vedanta's project to mine bauxite in the Niamgiri hills of Odisha was centrally based on the tribal peoples' framing of the mountain as an agent and a god. Studies by activist scholars cataloguing these worldviews have been central for the courts to be able to understand the dynamics more fully. The 
book by Padel and Das (2010a) was important in the Niamgiri struggle. In the foreword, Arundhati Roy, an Indian activist-writer-intellectual, discusses the framing of the bauxite hill by the tribal Kond people, a narrative that reflects resymbolizing framing in operation: ${ }^{14}$

The hills watched over the Kond. The Kond watched over the hills and worshipped them as living deities. Now these hills have been sold for the bauxite they contain. For the Kond it's as though god has been sold. They ask how much god would go for if the god were Ram or Allah or Jesus Christ? (Roy 2010, xi)

The above is a good example of the serious challenge that indigenous groups often pose to modern mining, an act that churns away entire mountains. Spatial changes take place through the politics of changing symbolic capital, revealing the violence and power inherent in framings such as "natural resource," and scaling up these changes to national levels. This change in symbolic capital can result in decision-makers, like judges, recognizing the world more in the way indigenous peoples such as the Kond see the world — or at least protecting and giving space for lived environments that challenge the values of modernity. I will provide more examples, particularly through analyzing nonmodernist framings, in action in mining conflicts. Through exposing cases with nonmodernist framings, argumentation, and lived worlds, I want to suggest that analysis should go beyond making the naïve point that "primordial, untouched nature" no longer exists in the world, and seek analytically deeper, workable (generalizable and contextually specific) human ecology relations and typologies. Figure 3 advances current theorizing by (1) distinguishing different ways through which capitalism commodifies nature (demanded by, e.g., Castree 2003); (2) developing a political ecology that draws from the conceptualization of socio-environmental movements in places of very varied human ecologies and resistances, such as Latin America (demanded by, e.g., Escobar 2008; Gudynas 2011; Hecht 2011); and (3) applying world-ecology's understanding of capitalism in the web of life (demanded by, e.g., Moore 2014, 2015).

Part I has offered several new concepts and two theoretical frameworks that can be used in complement when studying investment politics and their socio-environmental dynamics, and more generally political and spatial transformations. Part II explores the outcomes of resistance through a focus on political systems and contextual variance in Brazil and India. 


\section{Political Dynamics and Contexts}

I have divided the analysis of the cases into two major parts that have partially differing goals. Part II canvasses the contexts in which these struggles take place and how they are created. The step of canvassing the context avoids the problem of jumping directly to a merely strategy-based explanation of investment politics. Part II contextualizes the use of peaceful and armed resistance strategies, while part III isolates these strategies to explore their possibly generalizable role in affecting investment outcomes. First, part II contributes to the relational study of social movements by explaining how resistance coproduces contexts and political dynamics through the implementation of specific strategies. Simultaneously, it explores how the choice of these strategies is influenced by the present day and historically created contexts in place. Thus, I study the resistance in Goa through a focus of how it took place and its key part in the consolidation of a more democratic political system in India. I will also explore how the peaceful choices by the resistance in Brazil were essential to not escalate these conflicts into two-sided armed conflicts. I will partially return to these cases in part III, where I focus on how the specific sets of peaceful strategies used in India and Brazil impacted investment outcomes. Part III focuses on exploring how the five key strategies, or a subset of them, influenced economic outcomes and tested the hypothesis. Part III provides more details on how exactly resistance movements attain success, especially in the context of building a more democratic society, which is a process that will be opened up in chapter 3 .

In chapter 3, I dedicate specific sections to studying differing nonarmed contexts in extractive investment politics. This detailed examination sheds light on the role of consolidating democratic polities, for example, in old-mining regions (where mining is expanding into new urban contexts) and key resource peripheries, which can affect the outcomes of similar resis- 
tance strategy uses. Chapter 4 turns to how conflict outcomes vary when the resistance is accompanied by armed resistance groups, such as the guerrilla groups in Eastern India. With the separation of the cases into armed and nonarmed resistance settings, I suggest that the key cleavage in the overall configuration of political opportunities is created by whether there is nonarmed or armed conflict (from both sides).

The next two chapters focus on examining to what extent and how different political systems and contextual factors influence resistance outcomes and styles. By analyzing contexts and polities, this part tests the hypothesis- that resistance strategies explain investment politics. This contextual approach here serves to open up a series of important causalities at play in extractivist expansion and contraction in differing political dynamics, and how they might influence the outcomes. I will thus explore the role of all the explanatory factors identified in figures $1-3$ in chapter 2 . I will use an empirical analysis comparing a set of highly interesting cases from Brazil and India to provide theoretical insights to the structure-agency debate. This debate revolves around questions of how people can change the world, though typically not in the conditions of their own choosing, but sometimes in conditions they have taken part in (co)producing for themselves and other civil society actors. 


\section{Nonarmed Resistance}

During my fieldwork I traveled far off the beaten path to meet people in places in the remote regions affected by the long arm of extractivism. In Goa, with Sebastian Rodrigues as my guide, we traveled across the hinterlands. Together with Adivasis, we drove up into the Western Ghats hills several hours on roads that were in such bad shape that they required a military-grade four-wheel vehicle to cross. After hours of bumping on these roads, we set off on foot several more hours to cross the hills from Goa to the side of Karnataka. The footpaths in the jungle were muddy, so we took off our shoes. Rain was pouring down as we crossed rivers, and our feet were soon covered with a local variety of jumping leeches that I had not seen before. Soiled and bloody we arrived in a humid Adivasi village in the middle of the rainforest, surrounded by a few terraces of rice fields. The locals greeted me curiously, saying I was only the third foreigner to visit their village. This was a place where only a few people had seen the outside world. Rice and dal were offered to us on bamboo leaves spread on the ground, and we slept on the bare clay ground that had been battered hard under the huts. When returning, we saw in the foothills on the Goan side open pits from the mining boom that was quickly advancing toward the heart of the Ghats. The local villagers remained there to keep a watch on the mining trucks, occasionally setting road blockages when they knew that the ore was coming from outside lease boundaries. This reminded me of some of my earlier experiences in Pará, Brazil, where I witnessed how huge Amazon trees were eaten by the expanding open pit mines. It took a full day of driving to reach the other side of the national forest where the mine was expanding. When we returned down the backside in the blistering heat that is typical of Amazon regions stripped of their forests, we observed the worker barracks, hours and hours away from the nearest towns, yet right in the middle of what had been, before the 1980s, pristine rainforest and the homeland of indigenous peoples. While thousands 
of miles apart, the experiences in these key iron ore exporting regions of Goa and Para created a sensation about the shared experience of what the advance of global extractivism was like for the local communities during its heyday in the early 2010s.

Resistance agency is not forged in a void, rather it develops in specific contexts in actual places. In terms of nonarmed resistance contexts, three political and political economic dynamics surfaced as important variations that influenced the trajectory of the resistance. I have thus divided this chapter into three sections, to study from a contextual perspective how mobilizations take place within (1) a consolidating democracy; (2) a region with an "industrial vocation" for mining; and (3) a peripheral territory framed by government as the key national "resource frontier," where forests are proposed to be replaced by open-pit mining. Let us first examine how a context of what I call a "consolidating democracy" helps build resistance to mining, which boosts the outcomes of resistance strategies.

\section{Resisting Extractivism in and for a Consolidating Democracy: Western India}

Running along India's western edge are the high-biodiversity and forested Western Ghats mountain range. Nestled in this range are the mining areas in eastern Goa and the Kudremukh iron ore mines in Karnataka, a bit south of Goa. Goa and the Kudremukh operation were both high-profile export mines. These were not only important mining regions, but both Goa and Karnataka had already been engaged in a deep process of democratization. In both these places movement after movement managed to achieve the closure or cancellation of important extractivist and other large-scale investment projects, which would had taken land control out of the hands of the locals and irreversibly transformed the landscapes. The Kudremukh mines were shut down by a very broad civil society movement, where all kinds of actors ranging from indigenous populations, to specialist NGOs, to large-scale farmers came together in the early 2000s to demand the closure. This was the first in the series of impressive resistance efforts that spurred the closure of several mining projects. I will discuss some of these efforts in more detail later in chapter 5 . This section highlights the crucial contextual factors that need to be understood first to effectively explain why and how the resistance efforts in the Goan and the Bellary mines in Karnataka were so successful. I will build this explanation primarily by considering this movement as a type 
of Polanyian countermovement against unchecked capitalism. I contribute to the Polanyian theory by showing how an "organic society" does not build itself automatically, but through specific strategies in relation to the state and the attendant spaces in which these struggles take place. I will analyze the dynamics in these mining areas and resistance movements using the framework of investment politics, presented in figures 1 and 2 . After that, I will briefly complement this by a spatial analysis, which illustrates how figure 3 can be helpful in opening up the crucial physical and symbolic dimensions in studying extractivist politics. Let us start by setting the scene by examining the types of resistance capabilities that already existed in Goa prior to the mining scams, on which the specific mining resistance could build on.

Goa has an impressive track record of recent environmental activism, backed by different strata of society, and can build on the existing trajectory of heightened land use scrutiny. For example, in 2007-8, activists managed to block eighteen special economic zones planned for the state (Bedi 2013b; Sampat 2015). In these and other recent Goan land struggles, all five of the key strategies were utilized. Protest was used particularly fearlessly and constantly featured direct confrontations with the authorities. This mobilization built a space and the expectation of the right of civil society to share authority with the state to maintain the rule of law using (nonlethal, nonmassive) violence. The social movements were also heavily supported by a nonmodernist, spiritual conceptualization of land, whereby nature is a god and on the side of protesters (Rodrigues 2014; Sampat 2015). The same contextual setting holds in Karnataka, where several nationally important nodes of environmental activism are located, such as the Environment Support Group, which portrays itself as defending "local project affected communities and voiceless ecosystems" by helping locals to network and access the state. ${ }^{1}$

Another important organization in mining, pulp, and other environmental and social struggles in India, particularly in Karnataka, is an NGO called Samaj Parivartan Samudaya (SPS), which has a several-decade-long history. According to many newspapers and investor group analyses (e.g., EMIS 2014b), SPS was central in starting the 2011-14 mine closure wave, by filing legal cases against illegal miners in the Bellary district. This wave of closures extended beyond Western India, resulting in closures all around the country. SPS's work elucidates how "organic society" builders can operate in mining conflicts, regulating mining in their broader pursuit of democracy and justice. Their teams visited field sites to document the effects of mining, which led to questioning the sustainability and acceptability of national mining policies. SPS also conducted scientific studies, filed public interest 
litigation, trained people on how to use nonviolent direct action, and campaigned in the media. All these efforts were undertaken in order to protect "the livelihood of local people and the ecology and environment of the region" and to promote democracy. ${ }^{2}$

A Polanyian approach is helpful to open up the specificities of how these actions helped to mold the context, and vice versa. Karl Polanyi (2001) called the nineteenth-century countermovement to curb the destructive effects of the ideology of free-market liberalism the "organic society," which defends life and its reproduction and expands when capital advances too destructively. It is important to note that such an organic society consists both of progressive state actors and civil society. The regulatory moves made by SPS were some of the first attempts to consolidate democracy in the realm of extractivism, through the introduction of measures to ensure that liberalism would be checked through the inclusion of social and environmental safeguards. This Polanyian approach is useful since it opens up contexts in a dynamic constructivist way. The building of such an "organic society" in Western India was continued by the resistance to mining mafias, which in turn supported the regional and Indian democracy.

The establishment that the resistance had to face in Western India was very challenging, as decision-makers were corrupt and keen on continuing the unrule of law. A Goan activist explained (December 14, 2012) that the "industry corrupted everybody"; according to his experience, only a few actors controlled the corruption, sharing dividends among themselves. There was no monitoring, and five to six big families were responsible for the maneuvering of mining leases against the existing rules. Even the chief minister was involved, owning a part of Fomento Company, which is one of the oldest iron ore mining companies in India. The political apparatus protected companies while putting agitators in jail for short periods of time and using the legal system as a weapon. For example, 1,600 legal cases were filed against the inhabitants of just one village. In Karnataka there was a similar scheme, through which the mining mafia, including the chief minister, attained an estimated 15,000-60,000 crore (meaning ten million) rupees (about 2.7 billion USD to 10.8 billion USD in September 2012 ) from illegal extraction. ${ }^{3}$ In a conversation in December 2012 with a Supreme Court insider, he argued that

mining has become the most important issue in the country today. ... what has liberalization done? Allowed virtually uncontrolled exploitation, displacement, water pollution, rapid depletion of iron ore reserves, [an] industry where the margin of profit is 70-90 percent, this figure involving bribes and transport costs to ports. 
This neoliberal and corruption-enabling setting created a mining mafia, which is the biggest problem. There were a few studies warning of problems, such as one in 2008 by the Centre for Science and Environment. Yet in general the problem was ignored before NGOs, such as SPS, started to discuss the issue.

This setting of widespread illegality and corruption prevented the building of a sound mineral policy. For example, "nothing was done in relation to recycling minerals," as the mining mafia became "institutionalized in society." In Bellary, the illegality "maintained an atmosphere of fear, where nobody could talk," a local activist told me. An SPS member recounted that the "fear was simply unbelievable." He continued by emphasizing that "fear and democracy cannot go together." Public resistance and shows of courage via activism were necessary to change this setting. It was the broader setting of a consolidating democracy, which included key NGOs and activists with prior experience of victory in resistance, that was central in starting to mobilize larger parts of the society to tackle the problems of mining.

Within the state, no one looked at or scrutinized the obvious discrepancies. Claude Alvares from the important Goa Foundation NGO, which filed the Supreme Court petitions leading to mine closures in Goa, gave a vivid description of the situation (interviews, December 2012). By 2005 corruption had rooted the idea among central Goan powerholders that "anyone can do whatever," while simultaneously voicing "glorious phrases" and instigating a "government policy not to recruit regulators." In this setting, the resistance contacted the Indian Bureau of Mining, and using this collaboration they were able to calculate verifications of illegality-although the Goan activists remarked to me that this bureau is also involved in mining illegally. This embedding of the state's institutional politics by autonomous social movements was instrumental in changing a setting where the local states had been captured by corporate agency.

The Western Indian activists as a whole saw the iron boom episode as a demonstration of the ills of corporate agency: "over the past five to seven years we have seen what private sector involvement does" (interviews, 201213). Activists demanded state-owned mining as a first step toward remediating the situation. A seasoned activist explained that activists had garnered support for this claim, and that "in Goa even unions now say that public mining should be restored; people are fed up with [the] private sector." Elites have now been framed as "thieves and criminals" who have legal cases mounting up against them.

One Goan activist felt that the worst consequence of the mining boom was corruption: "The damage they have done to the political system is tremendous; the entire instability in Goan politics in the past decade has been 
due to mining. Now there is stability, due to our petition." The activist argued that "it's only by corrupt action that you will get something done on mines," and gave the following account of events. In the 2000s, three brothers from Bellary, Janardhana Reddy, G. Karunakara Reddy, and G. Somashekara Reddy, became influential state-level politicians. They used their political power to win illegal mining leases in the Bellary region to make themselves richer. The Reddy brothers were members of the Bharatiya Janata Party who had gained the favor of Karnataka BJP party leaders by backing BJP candidates against Sonia Gandhi in elections. All the brothers became cabinet ministers in the BJP's Karnataka state government in 2008 and remained in their posts until autumn 2011. They were removed following a mining scandal in which they, together with the BJP Karnataka chief minister at the time, B. S. Yeddyurappa, were arrested and taken into judicial custody as core members of the mining mafia. By the time they were taken down, they were in control of at least three state ministries and, through their control of the largest political bloc, were in a parliamentary position to expel other ministers. They also had substantial influence in Andhra Pradesh, the neighboring state, with patrons belonging to the same family.

In Bellary, the Reddy brothers illicitly built roads and opened mines by moving lease boundaries. The brothers also forced other miners to pay them a tax and maintained close ties with the police through their father, who was an officer. They built clientelist relations with the local municipalities, essentially converting their physical capital of iron ore into money that they used to turn a traditional Congress Party voter base into a BJP constituency. This move won them political support from high levels. However, they also had good relations with the Congress Party in Karnataka, in the early 2000s at least, and under whose rule in 2004 they were given the first iron ore license in Bellary.

What followed was an era of "selfish mining," wherein farmers sold their lands and mining decimated the agrarian base and agricultural possibilities. The definitions of constituted forest land were eased, which resulted in the destruction of water provisioning by mining. The removal of 45 percent of the green cover threatened the irrigation of two million hectares of land. In the face of this, SPS members shared with me that seven regulatory agencies failed in their duty to regulate. There were no environmental impact assessments, and the activists' demand for closure and regulation of destructive mines was not heard by local officials. There were no public hearings, and the regulators turned a blind eye to pollution. The price of iron ore that companies paid to iron collectors was set low and never increased, which effectively resulted in "looting by the rich." 
Help from the state was not forthcoming, which meant the activists had to fight on two fronts: to produce new state institutions capable of effectively regulating the industry, while simultaneously boosting resistance agency so that there would be pressure for the state to actively regulate. Activist agency was crucial for success on both fronts. I will next explain how the professional NGOs of Western India managed to remold the state and make it promote the rule of law in the areas captured by mining mafias. As this story illustrates, it is hard to distinguish "context" from activism in this and other cases. The analysis below opens up how the state embedding strategy operates in and ensures consolidating democracies.

The story of the Bellary resistance, which was the first in the series of nationwide mine closures, serves to illustrate what generated this wave and why it was so strong. A central task was the systematic collection of evidence that could be handed over in a single file to state investigators. These claims by the resistance prompted officials to initiate their own investigations, which served as the basis for later court judgments and government decrees. It is important to note that the sense of urgency fostered by protesting and campaigning was what first attracted the bureaucratic attention. In the Bellary example, the role played by SPS was central. ${ }^{4}$

In Bellary, resistance actors explained that the local "anticorruption ombudsman," the Lokayuktas, were mostly handpicked by the Reddy family. However, there remained three progressive Lokayuktas in power whom the movement could rely on in state-embedding efforts. The resistance recommended strong action to redress the problems through the official body of Lokayuktas, but the government did little. ${ }^{5}$ After this initial effort failed, SPS changed its strategy. This is when they began to build local resistance groups, visit the affected areas and local people more, and even filed a Supreme Court complaint. The illegalities of this case were blatant enough for them to rely on litigation. In other cases around India, activists told me that they avoid the courts if possible, as going to court often serves to affect the legitimacy of most of the other options. While these other options are still technically usable, their potential outcomes are more likely to be (or at least at a greater risk of being) interpreted as illegitimate in the eyes of powerholders and even the general public. Mass protests, for example, can no longer ensure that a developer will back down, and building a movement can become harder or the whole mobilization process can be interrupted when the "last word" of the courts is voiced. This does not empower people, but rather makes them consider their own efforts and local democracy as less meaningful than expert or top-down governance.

In Bellary, SPS used "powerful grassroots agitation for protection of for- 
ests," and locals themselves succeeded "very well in building people's power," according to an SPS coordinator. The first substantial protests took place on November 14 and 15, 2009, followed by the organization of a very large gathering by the participants in the SPS-led mobilization on January 25, 2010. On February 10, 2010, following national-scale civil society embedding of the state (see chapter 7), the court ordered the creation of the Shah Commission to investigate the issue, which delivered a tough report, as did the Lokayukta, which noted that 16,000 crore (2.9 billion USD) had been lost to illegal mining. ${ }^{6}$ Simultaneously, in February 2010, SPS was mobilizing approximately 600 people to protest in Bellary against the mining mafia. The Lokayukta report, which detailed the mining situation, including reserves in Bellary, was, according to one of its key organizers, "extremely helpful in court" for SPS. These efforts resulted in a complete ban on mining, as well as other unexpected outcomes, which were not so beneficial from the resistance viewpoint. ${ }^{7}$

SPS rejoiced that, in mapping the mining mafia's territorial reach, "we proved they have gone beyond lease area, blasted centenary tombs." The media called the scheme the "Republic of Bellary" in which no external control or governance mechanism had any effect, as the Reddy brothers seamlessly provided protection to unauthorized and unaccounted mining, with active connivance with government officials at all levels. ${ }^{8}$ The report argued that the mining ban left 15,000 people without jobs in Bellary, most of whom were migrants who quickly left the area. Yet many locals were also unhappy about the ban; truck drivers' incomes were cut to a third of prior earnings and they were not able to pay back their loans; and the hotel business dropped by 70 percent. One of the hardest hit populations was the exfarmers who could no longer get payments from miners, yet they also could not return to farming. Their very soils, which were considered as "overburden" by the mining industry, had been removed irreversibly, and it was only possible to ask for royalties and rents on the former agricultural lands that had been turned into open-pit mines. It comes as no surprise that a mining baron won the post-2011 local elections, as quite a few unemployed locals wanted mining jobs back.

SPS did not expect the Supreme Court decision to be in their favor, suggesting that this was not an attribution of a political opportunity. Opportunities appeared, but they were so camouflaged both from contentious and corporate agency that not even the mining mafia, with intimate knowledge of politics, could foresee the resistance efforts having any impact. Rather, these opportunities were underestimated by all parties involved. SPS had a slight hunch of how matters would proceed only with regard to the Loka- 
yuktas, knowing that a prior Lokayukta was not going to investigate, and waiting for the Lokayukta to change. This wait turned out to be "lucky," as the new Lokayukta was "good." The Lokayuktas change at times, and it depends a lot on the personality and social ties and affinities of the ombudsman on whether they might be more or less likely to investigate certain issues and be more open to attempts by civil society groups to persuade them to act in favor of the public good.

SPS saw that their "engine is the political organizing of people," which alone is not enough, and for which reason they always use a string of other strategies. For example, they use litigation, "very well-planned strategic campaigning," and embedding institutionally and structurally. This institutional embedding was described in their own words as being "fully well connected in the official part" and having friends in the bureaucracy. Together these embedding strategies ensure that they are "a well-treated group, and enjoy protection," according to an SPS outsider.

SPS members reflected that a movement success "would not have gone very far" without their engagement with judicial politics: "without Supreme Court intervention the mafia would not have been stopped." For litigation to succeed - that is, for courts to become a true political opportunity and not merely an observed one-several factors have to be taken into account. An NGO should have quite a deep history and embedded relations with the state, and it should have already been part of the judicial politics in which their formal and informal rules and power relations have been constituted (such as India's Green Tribunal, a national court established in 2010 that specializes in expedited decisions in environmental cases). That is, they should have already advanced on the steps of the state constitution (see figure 2), by creating new interpersonal relations with powerholders and by participating in the crafting of new state structures (such as the Green Tribunal), or changing the rules of existing political games. This is particularly important in the Global South where courts are typically biased. In the 1980s, one of the early struggles of SPS, which heightened their reputation, resulted in the stoppage of one of India's first large-scale pulp investments with industrial tree plantations in Karnataka. They also used the courts in this case, but "did not do very well due to partial court judges," which "taught us a lesson." They told me that in the pulp case, they quickly moved from the use of institutional politics to using electoral politics, by campaigning, mobilizing students, and attracting seventy-seven legislators from all parties who decided to close the pulp investment. This was not only an economic but also a political victory; through this electoral-politics embedding, they had gained strong allies in the legislature, which ultimately also helped to gain a 
"de facto judicial victory." The SPS was poised and ready to move to the use of electoral politics in Bellary if the judicial path had not worked.

SPS saw Bellary only as a "one-third victory." The real challenges lay in changing government strategizing, changing executive policy-making, winning elections, and removing the deep corruption the mafia caused in public life. This observation supports the views of activists in Goa on the use of the courts; as a Goa Foundation activist told me, "The first duty is to build mass awareness through agitation as otherwise we will be weak in [the] courts." In Goa organic society was not limited to state boundaries, and the large Goan expatriate population also got involved. I observed and was told many times that "the international and popular pressure was huge." An NGO activist argued that the "movement and court can and should run in parallel," with activists providing a research team to meticulously collect information that authorities could use as the basis for their investigations.

There are several features in this case that are helpful in explaining the importance and effectiveness of state embedding, including how, why, and when it can work. The network of Western Indian resistance movements has expert lawyers, legal NGOs, and professionals who are activists or are helping the activists. In addition, they have established links to important legal offices in New Delhi. Generally, in mining conflicts around the world, resistance has not had legal organizations in their networks, but when their networks include these players resistance has been more successful. ${ }^{9}$ In Goa a key activist NGO had twenty-five years of experience in court work and in certain cases knew the law better than some of the judges. According to an informant, this activist could thus "tell . . . backward judges what to do." This resistance group had a longer experience built on mining legislation than many courts, which typically lacked expertise. This creates a setting that could be considered a deliberative rule of law, where the civil society fills in for the default state. This judicial politics embedding resulted in a new set of social ties that broke the state-society boundary, as the activists helped state actors to do their jobs better, while increasing the autonomy of the state from capture by extractivist interests.

State embedding is a two-way road between the state and civil society. As this section has illustrated, embedding judicial politics means going deeper than just filing court petitions. Engaging deliberately with the court system can end up actually changing social ties and the roles between the judiciary and civil society. However, as noted above, this level of embedding relies on prior in-depth expertise on the subject matter at hand (such as environmental legislation of a given sector and context) and expertise in judicial politics.

A successful utilization of the courts by activists is more likely in a set- 
ting of consolidating democracy, where movements have built their access to the judicial system through prior judicial actions. In a federal state system this typically means that there should be at least some institutional openings both at the federal and state levels, as both need to be addressed to arrive at a policy change on an issue of such national importance as mineral policy. In India, there is federal-level support, in the form of the Supreme Court, which has, according to an activist, "honest judges-more than in the United States." The power of judicial review of policies is also "really strong-any decision of the government can be checked." In the 1980s, following a decision by a progressive judge, access to the Supreme Court was also liberalized. However, my research suggests that in order to access this court from the local level, the state where the area is located should have an "organic society," which forges and provides activists or local powerholders who know how to use this opportunity—not an easy task for the illiterate part of the Indian population.

To conclude this section on how a context of consolidating democracy enabled resistance to extractivism, I will assess the case of Western India via the three-space theory of spatial causalities presented in figure 3 in chapter 2. I discuss how power relations in the social, symbolic, and physical spaces influence the outcomes and longevity of investment politics. This analysis helps in understanding how the "double movement" is built, and under which conditions and to which extent "organic society" and democracy can function, concretizing Polanyi's theory. I will illustrate the usability of the spatial theory in explaining how physical changes such as extractivist expansions and discontinuations can take place.

A seasoned activist from Goa told me how "people were afraid to talk about mining in 2001, but I went on talking about it. Then others got the courage also." This show of courage led to a "different attitude in Goa," according to my informant. I consider this act of courage to also constitute a symbolic act of merit; the accumulation of these acts is a vital step in shifting the symbolic space. Furthermore, these local changes have led to a "general change in India in fear," a claim that I found palpable when tracking the path of resistance outcomes from Western India to Eastern India in the form of proactive government measures to curb illegalities for fear of local protests tarnishing the government's reputation. This suggests that symbolic acts of merit can be used to transform power relations. Such actions seem to be especially impactful for resisting extractivist expansion when coupled with the embedding and coproduction of the state, as discussed above. However, the outcomes of these moves can be hard to retain in the sphere of mining politics if the mining has already managed to remold the physical landscapes 
into open-pit mines. Although state embedding can result in mining discontinuations, sometimes mining elites manage to create so much economic, social, and symbolic capital during the extractivist phase that it is difficult to keep the mines closed. This is especially true if the countermovement is weak, for which reason I have hypothesized that the most efficient resistance tries to use the five key strategies simultaneously.

The absence of a mass antimining movement can easily prove to be a hurdle for the maintenance of a mining ban or regulations, while in several parts of India (and most visibly in Bellary) the mining mafia has left a legacy that is more lasting than changes in the rules of electoral or institutional politics. Through the mining activities these mafias permanently altered the physical space, which has eased maintaining a promining homology in the symbolic and social spaces. As the accumulation of social, cultural, and economic capital was tied to mining, the mining barons were able to sustain their image with their constituencies, and thus their symbolic power remained intact.

First, the mafia gained mining leases with their social and economic capital, thus objectifying their social position in physical space. This, in and of itself, was nothing new, but the depth and scale at which it was done was unprecedented in independent India. These large-scale objectifications of social positions in physical space by politicians who became entrepreneurs afterward (or land grabbers, if you prefer) have been made possible by recent procorporate and economic-growth policies (see Kohli 2012). Next, by redistributing and changing the type of access to, and control of, nature via mines extending over forests and fields, they changed power relations. Finally, after this power haul, they institutionalized their new physical position by becoming ministers and restructuring the regulatory system. This way their ability to pursue power in the symbolic space was ensured, as they attacked the space both by endowing mining with objectified symbolic power via physical space changes and by creating institutionalized symbolic power for themselves. They gathered this symbolic power by portraying themselves as benevolent political patrons who were increasing the wealth of locals with iron ore money. Such a three-pronged effort to shape power relations is hard to combat, and essentially requires the use of national or even international political support. The locally built power of mining barons will indeed be hard to reverse, as it stands steadily on three legs, one of which cannot easily be altered. The physical space, now turned into open-pit-ravaged landscapes, remains accessible to mining (and undesirable for almost any other purpose), even though lease areas can be given to other miners.

Yet it is noteworthy that even in a deeply promining setting, with a systematic failure of regulation, state capture, and nonattribution of political 
opportunities, a "handful of dedicated activists can overcome" the barriers to sound mining regulation, as an SPS member described when recounting their strategies. No mass social movement was created, although organizing and politicizing did take place. Activists went through a long training program, with twenty-day courses and "regular one-day sit-downs for continued learning" where they learn the "important factor" of considering "powerholders as equal, not superior."

This mobilizing is based on nonethnic lines, "following Ambedkar-type grassroots work" by movements. ${ }^{10}$ This included systematic training in nonviolent action for youths and protests that the police had been informed about in advance. Subsequently, activists were not attacked, which differed from Goa, where they were beaten and jailed in considerable numbers, and activists also attacked the police. SPS's typical repertoire of contention includes protests, but these have a particular quality, also followed in Bellary, of a "very deep faith in satyagraha, showing strength, willingness to go to jail, chaining oneself for five days [to other protestors to block the access to mining sites, for example]." 11

Such symbolic acts of merit, coupled with simultaneous physical space acts, such as street demonstrations, were used to counter mining capitalists in the social space. However, the absence of a mass social movement meant that the social space itself was not strongly transformed, nor, therefore, was the symbolic space, so the holders of the most capital, miner-politicians, retained their position as rightful developers of the region in the public eye. Yet the use of two-space and interspatial strategies in Bellary resulted not only in a quick and complete mining ban but also in breaking the corrupt state trajectory "at least for a while," and instigating a deep psychological transformation whereby the "whole fear has changed, gone." Such a pause created opportunities to start building a larger movement, but as we shall see, this has taken place mostly outside Bellary. Other movements were now able to identify opportunities and populations that were not as afraid of their own mining mafias as they had been previously, as it had been shown that they could be defeated. In Bellary, the physical context had become so ravaged that it made local politics less usable. The solution to combat state capture came from the broader "organic society" of Western India, and the political outcomes were even greater in places that were more open to mining criticism than Bellary.

I have used the three-space causal analysis theory to identify how power relations in the physical, social, and symbolic spaces affect movement outcomes and their perpetuation. Building an "organic society" is an effective way to resist extractivism, and as my discussion of Western India has shown, 
this is done more easily in a context of consolidating democracy. However, if a strong enough "organic society" is not created locally, but resistance relies more on professional "NGO-style" activism instead of very large-scale mass mobilizations, the weight of the power vested in the social, symbolic, and physical spaces is typically dramatically reshaped by extractivism and is likely to produce short-lived resistance outcomes. It is hard to persuade locals to turn to postextractivism when there is no going back, as mining has ravaged most agricultural lands, which happened in Bellary. In such cases extractivism has managed to reshape the physical space so that it offers perpetual power, a lock-in, for miners, as others cannot use the area easily for other purposes. Yet even in such situations the resistance can overturn the power of the physical space by recasting mining's acceptability in the symbolic space, and by cutting the possibilities for gaining capital by mining (thus severing the mechanisms linking social and physical spaces). An effective countermovement against extractivism-whose goal is to reshape what our landscapes look like, and who has access to which lived environmentsshould thus pursue not just court victories, but major equalizing of power relations in both symbolic and social spaces.

In the next section, I continue to explore the overarching political contexts, but I will focus on how promining attitudes influence extractivism and its resistance. I will provide an analysis on how mining politics, placed in urban and peripheral settings, are influenced due to this contextual difference. This helps in identifying how the presence of urban middle classes, critical mining professionals, and trade unions can help the resistance.

\section{Resistance in Old, Promining Settings: Minas Gerais in Brazil}

Mining in Minas Gerais dates back to the colonial era, and local public opinion toward mining was mostly positive in the 2000s when the new mining boom started. ${ }^{12}$ Mining is indeed one of the state's key sources of income. In fact, the people of this state, whose very name means "General Mines," call themselves mineiros, which translates directly to miners. Minas Gerais also presents the only mining project outcomes that can be considered unequivocal discontinuations in Brazil. ${ }^{13}$ This begs the question: Were the outcomes related specifically to these struggles occurring in this particular state, or were they due to the specificities of each case of investment politics with their assortment of resistance and corporate agency? The answers to these questions are-both. As I show here, there were variations within Minas Gerais depending on the case, but as a whole this was an "easier" context for 
resistance than the global resource frontiers of the Eastern Amazon in Pará. I will discuss several contextual factors that supported the resistance actions in Minas Gerais in comparison to Pará. I study here four expansion cases: the first three (Apolo, Casa de Pedra, and Mina Del Rey) are located in the Quadrilátero Ferrífero (Iron Quadrangle), which is Brazil's most important mining region (covering the central Minas Gerais southeast from Belo Horizonte), and all of them were successfully resisted, though the outcomes were different. In the end of this section, I compare these three largely "urban mining" cases with the rural Minas-Rio project located north of Belo Horizonte, which was a violent and peripheral context where resistance did not succeed nearly as well as it did in the other Minas Gerais cases.

\section{Apolo}

The first case is Vale's Apolo greenfield project close to Belo Horizonte, in the ominously named Vale do Aço (Valley of Steel). The Apolo project proposal was massive, ${ }^{14}$ but was put on hold. ${ }^{15}$ The choice of the Apolo project as one of the projects to be scrapped was based on resistance by a well-networked and embedded professional NGO, which had no massive movement behind it, but possessed technical knowledge. This resistance case offers an excellent opportunity to study whether a mass social movement needs to be created, or whether a professional NGO is enough to discontinue mining projects. ${ }^{16}$

The Apolo resistance was built using several strategies. The group started the struggle by framing it as being against a company that had no respect for the last water reservoir and forest area close to the state capital. In other words, it was framed as a Vale versus Belo Horizonte fight for resource access. Later, the resistance also included nonmodernist, utopian framing, which Coelho-De-Souza (2015) argues went beyond the use of disruptive words and phrases in typical mining struggles. The frames affected city dwellers and had a large territorial span. This excerpt from a post on the movement's website exemplifies the group's territorial framing: ${ }^{17}$

The Gandarela aquifer has been estimated as having around 1.6 trillion litres of potable water, and its recharge by rainfall is done through the "canga" (a shield of ironstone pebble conglomerates) that covers its highest peaks. Its protection is strategic to the future of the metropolitan region of Belo Horizonte ... [supplying] 60\% of Belo Horizonte's water demand. . . . the preservation of the Gandarela region is . . . a matter of survival: it is the last great untouched natural 
reserve in the Quadrilátero Aquifero and its exploitation by the mining companies would destroy the very last of the "canga" formations.

This framing worked as a scale expansion that brought the battle from the hills to the city, thereby drawing on the city's sizeable intellectual, criti$\mathrm{cal}$, and bureaucratic populations to help curb the unchecked expansion. ${ }^{18}$ Importantly, the post, titled "GANDARELA: The Avatar Is Right Here," was written by Paulo Baptista, who was both a professor at the Federal University of Minas Gerais and a member of the resistance group. This frame was produced through an interlinking of different socialized subjectivities (in this case, academic and activist), with the resulting framing drawing both on modern science and alternative knowledge that challenges the project of modernity (referring to the Avatar film that is highly critical to mining expansion destroying indigenous lived environments, and presents a resistance struggle [the director James Cameron has visited similar conflicts in Brazil to offer his solidarity to resistance], here). This demonstrates how nonmodernist framing does not signify that biocentric knowledge could not be used and produced simultaneously. Scientific facts on water impacts can be linked with a higher valuation of what exists than is explicitly present in the modern vision (which sees that places are flat and replaceable, and there is no end to resources, which can be exploited endlessly).

Vale initially filed for a mining permit in 2009. In 2010, the opponents, which consisted of the group described above together with other civil society members who were also working by embedding the Chico Mendes Institute for Biodiversity Conservation, ${ }^{19}$ officially proposed the creation of a new national park at Serra do Gandarela, posing considerable obstacles to the opening of Vale's planned Apolo, Apolo Sul, Baú, and Capanema mine projects in the Gandarela hills, which overlapped the proposed park. The new national park idea was considered an efficient tool to prevent the forestland from turning into mining pits. However, it should be noted that to propose such a park in the first place required a deep knowledge of legislative possibilities and political connections. When civil society resistance mounted and the Minas Gerais state could not find a solution that would please all stakeholders, it transferred its power to grant mining rights over to the federal government. ${ }^{20}$ Subsequently, on October 14, 2014, President Dilma Roussef, who had the power to decide whether the park would be created or Apolo would be given the license-chose both. She allocated over 31,000 hectares of Serra do Gandarela to create the national park, while retaining between 900-2,000 hectares for the Apolo project, pending proper licenses. ${ }^{21}$ While the ICMBio and Vale welcomed the decision, the 
resistance did not. The resistance argues that the national park will not save the water system or the cangas, as their recommendations for the borders of the national park were not accepted, and crucial water systems were left outside the park and inside the would-be mining areas of Vale and other mining companies, contrary to what was proposed. ${ }^{22}$

While there was not an outright victory for the resistance, the outcomes of this struggle can be considered both economically and politically significant, as the mobilization significantly changed the old, promining attitudes and possibilities in Minas Gerais, particularly in the capital. Carolina CoelhoDe-Souza (2015) wrote her doctoral dissertation on the resistance coalition against Apolo, based on insider participant observation. For Coelho-DeSouza, the resistance was not only successful in blocking mining and defending water, these being the economic outcomes to date, but also in creating what I call "important political outcomes" in the form of forging a lasting willingness and ability within civil society to actively participate in decisionmaking (which is harder to reverse than economic outcomes). The contents of this resistance agency, according to Coelho-De-Souza (2015, 6), include "deconstructing the economic discourse of the mining company," "proposing an economic alternative" (e.g., tourism), and framing "'other worlds, other human-nature relations." Thus, the anti-Apolo movement seems to be a strong case of creating and campaigning by an antimodernist framing, including references to buen vivir (good living), which fundamentally challenges capitalism. This is a major political outcome in a state called Minas Gerais. The resistance group created to challenge Apolo can offer grounds for expanding a different type of resistance in comparison to traditional leftist mass movements such as those created by Justice on the Rails, the MST, and La Via Campesina (which are discussed in the next section).

As a result of many mining-caused conflicts and disasters, the state of Minas Gerais is currently witnessing a historic surge in antimining attitudes. Minas thus offers a context to study a setting where significant segments of the existing promining citizens are beginning to look for postextractivist solutions. The cases detailed herein explain how the contextual change has taken place. Striving for a postextractivist life means that the legitimacy and, thus, the symbolic capital of mining is diminishing, which might also render mining less powerful in the physical and social space. To counter such possibilities, not only in Minas Gerais but also elsewhere, Vale has used sophisticated means to try to win over the hearts of locals around the world. They have done this, according to my informants, particularly in Minas Gerais and the Gandarela region, by corporate social responsibility and outreach campaigns such as massive arts and culture programs. 
Vale's campaigns suggest that the struggle is increasingly turning into a dialectic between Vale and an NGO that crafts nonmodernist spaces through a focus on framing, visualizing, or "glimpsing" other worlds, as described by Coelho-De-Souza (2015). To oppose these changes in symbolic space, Vale and other mining companies are trying to support contemporary culture (e.g., via patronizing the arts and theater), a culture that includes megamining, which is appropriating what is left of the forests and hills. They aim to show that the world is good and worth living in as it is, that there is no need to resist extractivist practices. Therefore, in Minas Gerais, as in Western India, it was incredibly important that the people learned not to fear, to understand that resistance is possible and can result in the stoppage of extractive operations. Before the Apolo resistance case, no one in Minas Gerais had dared to imagine that resisting mining in a state that had been promining since colonialism, let alone against Vale, would be possible, as noted by a movement informant (Coelho-de-Souza 2015, 279). ${ }^{23}$ The coordinator of Movimento dos Atingidos pelo Mineração (Movement for Popular Sovereignty in Mining, or MAM) also shared this view, regarding attitude as a key problem for mobilization. Thus, the approach of the Gandarela movement to seek a deeper change in symbolic space, by showing that it is possible to at least slow down and win a partial victory, is fruitful in starting to sow the seeds of a larger mobilization in a very old, promining context whose people cannot imagine life without the mining industry.

This subsection on the Apolo case has discussed the specific qualities of the resistance strategies that can turn a promining context into one that is actively seeking postextractivist solutions. The case shows that carefully manufactured resistance strategies, such as nonmodernist campaigning, can lead to powerful economic outcomes even in the absence of a mass social movement. This holds particularly true if urban middle classes are well connected, know how to embed the state-remediated political games support, and join the resistance. Such a resistance can win even in a very deeply promining social, symbolic, and physical space, and start to change the power of mining in these spaces. ${ }^{24}$ Three other important Minas Gerais cases, analyzed below, help to explain in more detail how resistance can succeed in challenging the objectified and institutionalized symbolic capital of mining in a promining society. In particular, the peripheral case of MinasRio will illustrate the conditions wherein this shift is a less likely outcome, including a strong discrimination against ethnic and rural minorities, who have far less capital than the urban middle classes. 


\section{Casa de Pedra}

An important case that helps to further analyze resistance in the setting of old promining attitudes and established extractivism is the case of Brazil's largest integrated steel producer, the Companhia Siderúrgica Nacional (CSN), which had an expansion project of the existing Casa de Pedra mining complex in Congonhas. This large project had an intended extraction of eighty-nine million tons per year. The resistance movement in this case was ample and consisted of diverse social actors, including Grupo Rede Congonhas (the mine trade union), environmentalist politicians, and affected locals (Ramalho, Santos, and Lima 2013). ${ }^{25}$ The outcome to this resistance effort was an almost full cancellation of the project, leading to an official nature reservation being established on 85 percent of the would-be mined area, with only 15 percent of the area left for possible exploration (these areas mostly contained already-existing mines), and the capping of mine production at thirty million tons per year (Ramalho, Santos, and Lima 2013). Thus, the resistance gained a considerable victory, especially since they did not want to close the mine. Their proposal was endorsed by the mayor who wanted to preserve tourism, and the city itself was treated as a cultural patrimony in both the resistance and official framing. Most state and municipal politicians in executive and legislative positions were allied with the company (Ramalho, Santos, and Lima 2013), though there was a small opening in the political opportunity structure, as the local political elite was divided (although the division was lopsided in favor of mining). The resistance managed to embed electoral politics by convincing the mayor to endorse their cause.

In terms of spatial analysis, there is an important causality stemming from a change (or foreseen change) in the physical space, which went beyond the established norms of what is allowed for mining, even in a promining society. In the Casa de Pedra as well as the Apolo case, we see that although mining is old and established, the recent mining boom's expansion into previously untapped areas started to provoke a deep transformation in the objectified symbolic capital of mining. Changes in the physical spaces, or attempts to change these spaces, were central for the resistance to be able to show and question the continuing and deepening power of the industry, backed by its symbolic capital of being the vanguard of local development. As in Apolo, the type of territory targeted also mattered, especially in cases where mining was threatening to move into the most important water reservoir and greenery in Congonhas, along with historic locations linked to Bra- 
zil's independence struggles. In a detailed analysis of the case, Santos (2015) emphasizes that the symbolic aspect of resistance, focusing on the immorality of grabbing water by mining expansion, was instrumental in achieving the considerable outcomes of curbing expansion and changing corporate habits. As I see it, both CSN and Apolo were not just trying to alter physical space, but physical space that was deeply objectified symbolic capital—and thus more ready to be resymbolized along antimining and ethical lines if targeted by mining.

By objectifying symbolic capital, the resistance was able to shape physical space in Congonhas, whereas CSN had its hands tied as this was its only expansion possibility, and they did not have Vale's privilege to choose between physical spaces (linked to different social and symbolic spaces). This made the project more vulnerable, according to Santos, who told me in an interview that it is easier to resist mines than, for example, industrial corporations, as the latter more often use the tactical argument that they will move their investment to a new location if their project is not approved. ${ }^{26}$

Yet the vulnerability of Congonhas arose not from its position as the company's sole source of ore, but more precisely from the fact that the resistance knew this to be the case. ${ }^{27}$ They were able to talk the company talk, which allowed the company to understand both the damage their resistance could do and that they could not be fooled into accepting company advancement disguised as false resistance victories.

The Minas Gerais resistance cases are emblematic of the broader process of busting the boom of iron ore mines. The resistance managed to slow down and curb the size of the expansion plan when the urge for this was greatest, at the global price peak of iron ore, thereby discontinuing the expansion. Here, as elsewhere, time was on the side of resistance. In April 2015, as iron ore prices continued to decline, all the major iron mining companies in Brazil, including CSN, with its Casa de Pedra project, put their projects on hold. In addition, the efforts of the resistance to curb building the infrastructure essential for new mines, such as ports and railroads, also put many projects on hold. ${ }^{28}$

\section{Mina Del Rey}

A third example that helps us to explore resistance dynamics in old promining contexts is Vale's Mina Del Rey reactivation project, also in the Quadrilátero Ferrífero, which was discontinued. The project was based in Mariana, a historic city about fifty kilometers east of Congonhas and next to the 
historic and tourist city of Ouro Preto. This was quite a specific context, an urban mining conflict like the two prior ones, which helped create an encompassive embeddedness, called for by Evans (1995, 2010), between the civil society and progressive state actors to resist mining. According to the website of a resistance group called Mariana Viva, ${ }^{29}$ this was an "urban mining" project, located just four kilometers from the historic tourist town of Mariana. The population considered themselves dependent on mining, at least according to a documentary series made on Vale-Mariana community relations called Sou Mineiro e sou de ferro (I am from Minas Gerais [or I am a miner] and made of iron), ${ }^{30}$ or on Maher's (2014) depiction of the movement as limited and most of the population being "unopposed" to the project. Maher $(2014,195)$ briefly discusses Vale's Mina Del Rey reactivation attempts and the thus far successful resistance by what he calls an "academicians' social movement." In contrast to this view, at a co-organized public hearing in June 2011, municipal authorities, civil society, Minas Gerais state's legislative assembly's Council on Mines and Energy, a wide range of civil society actors (such as the Catholic Church, trade unions, and mining resistance movements), together with the city's elected mayor and legislative assembly members, wholeheartedly rejected the reactivation of the mine. ${ }^{31}$ In this case, a resistance front with strongly encompassive embeddedness stood against rising extractivism and demonstrated that such a resistance front enjoys several strategic advantages. Importantly and interestingly, the encompassive embedding of progressive state actors and civil society resistance in institutional and electoral politics made the use of contentious politics and judicial politics unnecessary.

This was a mass movement that previously had no need to protest, although they were willing and capable of doing so. In the words of the Mariana mayor, Geraldo Sales de Souza of the Workers' Party (Partido dos Trabalhadores), "The people of Mariana do not want to accept the reactivation of Mina Del Rey. If necessary, we will go to the streets to put up barricades and protest." 32 The resistance used electoral politics, as well as institutional politics, specifically using the public hearing as a tool. There was no need to use judicial politics. The economic outcome was impressive, as were the political outcomes; Mariana Viva and the other anti-Mina Del Rey groups formed a strong link to transnational anti-Vale movements, showing how state embedding does not mean lesser radicalism or the impossibility of scaling up.

Both the Mariana and Congonhas cases suggest that the old, promining attitudes in Minas Gerais have been considerably transformed due to the emergence of a new wave of resistance that is cross-class based and includes 
a large array of members from different groups who were typically promining. Although these people were accustomed to state-company mining, they now see it as rampant and greedy expansion by increasingly multinational or irresponsible mining capital. In both cases, mining trade unions backed the resistance, either in curbing the expansion of mines (Congonhas) or keeping the mines closed (Mariana). These cases demonstrate that old, promining settings might be better equipped, and at least as willing, to curb extractivist expansion as greenfield sites, if they have technically experienced and politically capable mining workers and state officials who understand what constitutes rampant mining expansion, know what it would entail, and can thus help build resistance fronts.

Furthermore, a contextual look reveals that these projects are cases of urban mining resistance, which may have made the creation of resistance easier. It is easier to mobilize impacted city dwellers than it is to mobilize rural dwellers, since the political connections of city dwellers are typically denser. The expansion of mining to large towns is in itself an interesting topic to be studied in greater detail. The last Minas Gerais expansion case I will discuss is a greenfield project in a peripheral region of the state. This case lacks some of the contextual factors that ease resistance, including supportive middle classes, labor unions, politicians, or large towns, and it was still under the spell of a general promining zeitgeist of the state (before the Bento Rodrigues tailings pond disaster in 2015, when a dam collapsed, killing nineteen people downstream and polluting over 400 miles of waterways).

\section{Minas-Rio}

The fourth Minas Gerais case, the Minas-Rio Mineduct Project, is helpful for observing the dynamics where investment projects are not discontinued. There was a budding resistance movement in this case until the key activist was murdered in 2010, after which mobilization waned. Very sophisticated corporate counter-tactics were used to make the possibilities for affecting the licensing of the mine unusable. Only after 2015 the resistance started to protest more concertedly, via roadblock and similar acts. A part of the state prosecutors' office tried to mobilize the affected civil society and help them. During 2005-2015 the resistance was weak. This project has not been as strongly affected by resistance as those mentioned above. In fact, the person documenting the case in 2014 for the mapping project EJAtlas considered the resistance to be a failure. ${ }^{33}$ To explain this, we must turn to contextual factors and to broader investment politics. As mentioned above, this case 
had none of the above cases' contextual factors easing resistance formation or even constituting important chunks of the resistance (in the form of critical middle classes, miners' unions, or state actors), a diverging causal condition complex that helps to explain the different outcome. In fact, there were specific contextual factors that made these investment politics and conflict dynamics harder for the resistance. For one, the corporate agency was very strong, using both violent and sophisticated countermobilization tactics, and there were ethnic minorities among the locals, a contextual factor that is generally related to greater violence and worse outcomes from the point of view of resistance. Owned by the mining company Anglo American, the Minas-Rio Mineduct Project is one of the world's largest mining projects, with a feeder mine in the Conceição de Mato Dentro region and an export port in Campos in Rio de Janeiro. Minas-Rio has been studied by Pedlowski (2013), Maher (2014), and in several of the studies by Zhouri and Valencio (2014). All of these studies portray a very bleak picture of a poor rural population consisting of Afro-Brazilian quilombolas (descendants of enslaved people brought to Brazil from Africa who managed to escape and form quilombo communities, which continue to this date as specific traditional forms of rural dwelling in Brazil) and other traditional populations and peasants being displaced, their resistance facing exceedingly strong corporate violence. ${ }^{34}$ In June 2010, Delfino de Souza, known as Delzinho, who systematically denounced illegalities such as illegal logging by MMX-Anglo Ferrous, was assassinated in the community of Mumbuca. ${ }^{35}$ In a post written by another member of the resistance movement, Delzinho was remembered as "one of the most loved community members" who had spearheaded the local resistance from early on, warning others about the dire negative consequences of the mining project and how the company was causing damage. ${ }^{36}$ However, Delzinho's murder has gone largely unnoticed outside of his immediate community. This is because such assassinations of socioenvironmental activists, especially in distant rural communities, are highly common in Brazil, which is a global leader in the dire statistics of this type of murder. The rural peripheries of Brazil targeted by extractive investments are a powerfully violent context, which require extremely sophisticated resistance strategies, and the use of mass social movements, to be able to exert at least some sort of precautions, control, and denouncing capacities against the violence and its constant threat.

In many of the communities affected by the Minas-Rio project, community leaders have tried since 2008 to garner support for mobilization against forced evictions and gain support from politicians and lawyers. After 2010, the resistance in the Minas-Rio case got prosecutors to tackle this problem- 
atic project. However, corporate agency and promining state machineries soon started to erode the power and critical stance of these public prosecutors, steering their role from defenders of citizen rights to conflict managers in stakeholder discussions (Zhouri and Valencio 2014). Sophisticated corporate countermobilization tactics successfully steered prosecutors away from the institutional game and into private politics, largely turning the public prosecutor's office into a conflict manager instead of investigator and prosecutor (see Zhouri, Bolados, and Castro 2016; Zhouri and Laschefski 2017). This boosted ongoing land grabbing for the project both in Minas Gerais and in Rio de Janeiro (Pedlowski 2013). The land grab here has been very violent, and corporate agency has included the use of armed conflict as a political game (one-sidedly). This change in who is resisting illustrates that there is a weakness within the change from a primarily grassroots-based resistance agency into continuing mobilization dependent on state-actor agency. The power of state actors can be affected by steering their spheres of action away from the political games that corporate agency considers a danger to extractivism, such as contentious and institutional politics, and instead tying the state actors into mediating private politics.

In 2012, mine construction was discontinued for four months by prosecutors on the basis of the discovery of prehistoric caves in the area (Maher 2014). Although the iron-ore deposit turned out to be of lower quality than its sellers marketed, the mine opened, mainly because of the sunk cost spent in building the $525 \mathrm{~km}$ long pipeline (Pedlowski 2013). Map 3 below (based on Santos and Milanez 2015) illustrates that there are three long minerodutos (mining slurry lines) running from Minas Gerais to the coastal ports, as well as three railroad lines.

In the Minas-Rio case, the economic outcome of resistance was slowing down and changing the style of mining. Rodrigo Santos told me that the project was restructured after the mobilization. This outcome is causally related to two main violence-based dynamics. The first is a very strong, violent, and sophisticated corporate agency, boosted by the huge sunk costs Anglo American made in the 5.5 billion (USD) acquisition of the project licenses from the Brazilian MMX Mineração company, which needed to be balanced by opening the project by whatever means. Anglo American managed to embed the state more effectively than the resistance, also interfering in the working prosecutor-resistance linkage by moving this from the sphere of state-mediated institutional politics (of defending rights) to the sphere of private politics (prosecutors as conflict mediators). Second, the context was a violent rural setting with ethnic injustice and the absence of contextual factors that were present in the other Minas Gerais cases that supported building resistance. 


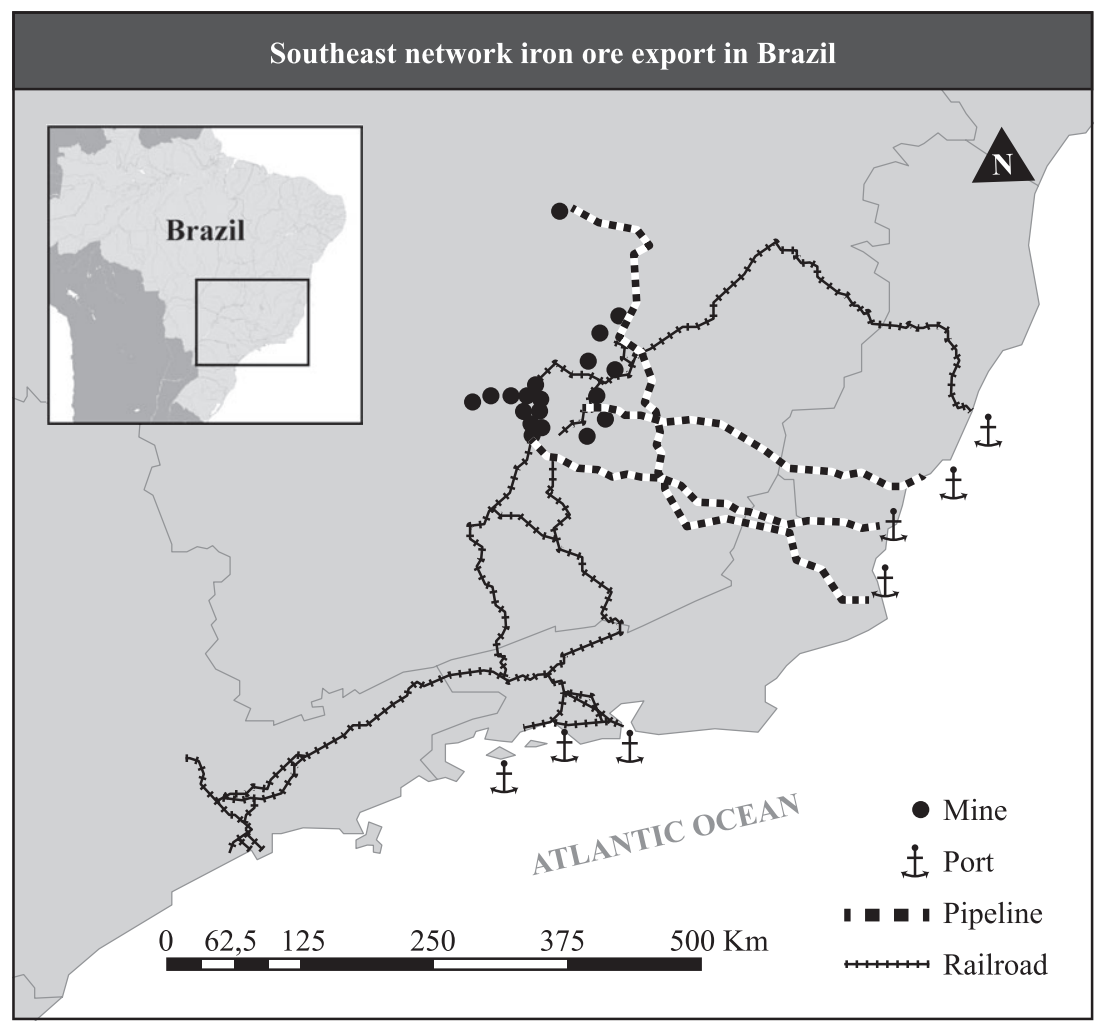

Map 3. Iron ore export logistics from Minas Gerais state to the ports in southeastern Brazil.

Although there have been increases in corporate agency and delimitations of political opportunities across Minas Gerais state in past years, there have nevertheless been cases where projects were discontinued (two Vale projects, Apolo and Mina Del Rey) or dramatically downsized (Congonhas) by resistance. This indicates that old or promining settings are not immune to the general phenomenon of resistance to extractivism. This section shows how challenging established objectified capital linked to a time-honored activity such as mining can lead to major investment discontinuations. This objectified symbolic capital acts as a tie between the physical and symbolic spaces, and the loss of symbolic capital ends up destroying old promining attitudes and social capital.

As the comparison to the discrepancy case of Minas-Rio shows, the topology of the local social space- the economic, social, and cultural capital enjoyed by the resistance vis-à-vis corporate agency-is causally related 
to changes in physical and symbolic space. A weak resistance position in the social space makes resistance more difficult and positive outcomes less likely. Conversely, having economic, social, or cultural capital, or a combination of these, does make it easier to resist insofar as one's capital is under threat by extraction expansion, not supported by it. The successful resistance both in Minas Gerais and in Western India, as discussed in the previous section, had significant capital in the Bourdieusian sense, which could be used in activism (see chapter 2 for the discussion of economic, social, cultural, and symbolic capital as theorized by Pierre Bourdieu). These movements have also included nontraditional actors resisting mining, who, most importantly, knew how to challenge the established symbolic power of mining by resymbolizing acts and framings. ${ }^{37}$ Differing compositions of social, economic, and cultural capital (forming differing class and ethnic relations locally) separated the successful resistance cases (Apolo, Mina Del Rey, and Casa de Pedra) in Minas Gerais from the not so successful (Minas-Rio). The resistance actors differed significantly: the former had an urban and largely white middle-class resistance group, while the latter had a rural, poor, and ethnic-minority composition. The resistance in the latter case had significantly less economic, social, and cultural capital on which to build a movement, and had to face national and global discrimination and violence that easily escaped the eye of the majority. Yet there are also cases where resistance from such backgrounds has managed to win considerable victories-such as the Keonjhar Adivasi resistance in Odisha in India, discussed in part III—so this is not a determining factor or an overwhelming impediment.

This section has illustrated several ways in which contextual factors are embedded in the construction of resistance and extractive dynamics, and how resistance strategies operate in conjunction with specific contextual settings to produce outcomes. Continuing the theme of drawing lessons from contextual comparisons, I will next see how the setting of a key national "resource frontier" influences extractivist and resistance dynamics.

\section{Challenging the Expansion of Resource Frontiers: Eastern Amazon, Carajás}

The third example of conflict settings marked by nonarmed resistance is the struggle in the Eastern Amazon, which illustrates the particular conflict dynamics in a national and global resource frontier, where corporategovernment agency seeks to vehemently frame and thus turn the existing lived environments, in this case the Amazon rainforests, into sources of "nat- 
ural resources" that can be appropriated for low cost. The contexts discussed above, Western India and Minas Gerais, differ from the Eastern Amazon (and the resource frontier of Eastern India, where the conflict has escalated into an armed one, discussed in the next chapter) in that these kinds of areas are strategically crucial for their governments. Whether the resistance is targeting an almost exclusively raw-material-export frontier (Eastern Amazon), or a mixed national industrialization-export frontier (Eastern India), it faces states and companies that heavily depend on these crucial commoditizing resource frontiers. This signifies that the target of resistance, and its political role, is very different than in other contexts. For example, Moore (2014) goes so far as to argue that the core of capitalism is appropriation of new natural resources via frontier expansion. The availability of these frontiers is considered to be the basis on which the whole capitalist system relies. Let us examine what the politics of investment and resistance look like in these settings, through a close look at the world's largest iron deposit and biggest iron ore mine, Carajás, in Brazil.

In the primary resource frontiers-the Eastern Amazon in Brazil and Chhattisgarh-Odisha-Jharkhand states in India-central-government-led expansion is more significant than in the Western Indian and Minas Gerais mining conflicts where the ventures were predominantly led by private corporations. Expansion of capitalism to the Eastern Amazon was the key government policy of the neodevelopmentalist Dilma Roussef presidency (2011-16) in Brazil (Kröger 2015b). Vale played the key role as one of the "National Champion" companies with its global sectoral rise and dominance in the Workers' Party government, which sought to support the crafting of industrial policies for these corporations (Kröger 2012). The construction of dams, mills, mines, biomass plantations, refineries, slaughterhouses, new urban and rural settlements, and other operations, all of which seek economic growth primarily via appropriating "natural resources," are rapidly changing the Eastern Amazon's lived environments and landscapes (Kröger 2015b, 2016). Correspondingly, and not by chance, these primary national resource frontiers are also the homes of large ethnic minority groups, affected by deep ethnic injustices. The conflicts in these areas are therefore much tenser than in the ones discussed above, and this needs to be considered when analyzing the politics of extractivism.

The state of Pará is filled with contention and grievances. Historically, Vale's Carajás mines were just one element in a far more encompassing developmental project— the Great Carajás Project—instituted during the dictatorship years from 1964 to 1984 that included the highly controversial conversion of rainforests to cattle pastures (Alvares da Silva, Costa, and 
Veiga 2011; Asselin 2009). The people affected by mining have created new movements that specifically target mineral extraction by the largely privatized and foreign-owned Vale, with the aim of creating nationwide resistance networks. One example is MAM, discussed in more detail in chapter 7. MAM, which Carajás's peasants first considered to be composed solely of urbanites and intellectuals (Gerbode 2011), is attempting, together with the MST, to inform smallholders of their legal rights regarding mining expansion before Vale manages to extend mining activities into their lands and those of agrarian reform settlements. The vision of the MST is to foster democratic decision-making with regard to the uses of nature. As one of its coordinators argued, "The people should decide, although they are very alienated. We need many things from nature, but how can we extract them without harming nature? The logic is that these resources should benefit the people, via healthcare, education."

The MST has been spearheading anti-Vale mobilization in Pará for decades. These anti-Vale actions have revolved around the Carajás mine, the export railroad, and the supporting operations such as pig iron smelters, charcoal furnaces, and eucalyptus plantations along the railroad. In this section, I focus on the conflicts in the Parauebebas municipality, where the Carajás mine is located. Their first disputes with Vale date from 1992-93, when the MST, among other protest acts, occupied a piece of woodland in the Carajás National Forest for two days. The land protestors occupied was part of a 411,000-hectare mining and forest protection complex given over to Vale's control by the state (interview with Tito, MST leader, March 5, 2011). The occupation involved 2,000 to 3,000 persons, and was regarded as "very important," leading to the first substantial and important Palmares settlement. The MST leaders argued that the action had weight "primarily due to its large size," though mass protesting was already crucial for the safety of the protesters. ${ }^{38}$ These struggles in the 1990s had significant outcomes, as a large chunk of the lands adjacent to the Carajás complex were even set aside for nonmining purposes. Alternative social and symbolic spaces were created on these physical areas by the MST, which led to the sustained forging of resistance agency during this time and for years to come.

The MST, artisanal miners, and indigenous groups continued to engage in direct conflicts with Vale with the goal of affecting mining and logistical operations. A major rupture in company-community relations came on October 7, 2007, when the MST staged a 5,000-person, twenty-sixday occupation of the export rail link in Parauebebas. According to Ulisses Manacas (Pará MST leader, interviews, 2011), the media claimed there were only 300 protesters, but "community radios and movement journals spread 
the truth." Simultaneously, a movement of artisanal miners also mobilized against Vale in Serra Pelada, the famous labor-intensive artisanal mine where over 170,000 gold miners were toiling in the 1980s. Vale's trade union joined the protest, demanding renationalization of the company (a demand for which there is continuing national support). Indigenous tribes were also present in railroad blockades. In total, Vale calculated that the occupation cost it twenty million US dollars and demanded that movement leaders be imprisoned and reimburse the company for its losses (Diário de Pará, April 19, 2008).

Since 2007, there have been several anti-Vale protests and campaigns, with direct positive outcomes from the MST viewpoint, although still far from reaching the principal goal. In 2008, Vale was pressured to finance the paving of a road in an MST settlement. On March 8, 2009, various sectors of the society networked with the movement, occupying several Vale areas. These acts have been carried out in several Brazilian states, including Pará, Maranhão, Minas Gerais, Espírito Santo, and Rio de Janeiro, where the company has its headquarters. In Imperatriz in Maranhão, a "radical act destroyed the charcoal deposits of Vale" (see Kröger 2013b for an account of this)..$^{39}$

When studying these conflicts, it became clear that there are many types of resistance movements and subgroups, which all have differing relations with Vale. In fact, such a splintering of resistance into the use of more radical and more conciliatory tactics may have contributed to a weaker overall resistance front. These complex dynamics, wherein Vale has managed to break the unity of resistance by building hegemony that infiltrates even within sectors of the MST, merits attention; the resistance in Pará is not unified in what it seeks, unlike in the Minas Gerais cases discussed above. The relationship between Vale and the MST has changed, given the MST's continuing mobilizations and its decision to not respond with violence to violent resource frontier expansion. Vale no longer wants "to have friction with movements" given their wish to expand, and they do not want the MST to occupy the railroad again (interview with Tito, March 5, 2011). The company has joint projects with the local MST, building roads in the settlements, for example, but "we know how it is with Vale: only by fighting can we achieve results." Tito said that while it was not easy to gain financing from Vale for movement projects, the company had a lot of power when exerting pressure on the government to do so. Batista from Brazil's Pastoral Land Commission in Marabá (interview, March 31, 2011) observed that when a mobilization causes direct losses and harm to a company that it cannot resolve via the mechanism of a court order coupled with police expulsion, it must negotiate the withdrawal of the pro- 
testers from the area ${ }^{40}$ if an occupation involves thousands of people, it is not easy to achieve this by force. Negotiation offers movements the opportunity to make demands of companies, though the latter are readier to respond to such demands when they involve using the leverage power of the company vis-à-vis the state rather than shouldering financial responsibility themselves. In this dynamic, the movements differentiate between powerful private companies and the state to make one a target and the other a third party used to gain leverage over that target.

Vale never negotiated directly with the MST until 2011 when it entered the settlement of Palmares in an attempt to make deals with the movement members and negotiate with settlers over iron deposits beneath the settlement, "Vale wants to eat it all," according to Ulisses Manacas from the MST. The leaders of the MST hold varying opinions of Vale. For Tito, the main problem is not Vale's magnitude, but rather the outsourcing of its business operations and its privatization. Costs have been reduced by the use of radical means at the same time as the company has been making record profits and developing into an international player. Ednalva Moreira Gomes (MST leader, interview April 23, 2013, author's translation from Portuguese) described the goal and the dilemmas of the MST in both the anti-Carajás protests and in mobilizations directed against corporate resource exploitation more generally:

As a movement, our objective is to close the [Carajás] mines. We have not worked a lot on the question of extraction, how this should be done, because we need to shut down the mine. But we have also tried to find out how to act [to this end] and have an [positive, direct] outcome for [mine]workers as well. We dream about closing [the mine], it needs to be closed, but we do not now have the political force to close it down, as the workers who now live in Eldorado dos Carajás want to maintain their jobs and do not want the mine to close. So, an objective is to work [trabalhar] on [raising] the consciousness of these workers. So, in these protests, besides having the role of informing [the public about the problems], and causing losses to financial capital, we also have the objective of gaining something for the populations. This [dilemma of needing to protect the current interests of workers in problematic resource exploitation businesses while also trying to close them down] is a great contradiction today in Brazil.

There is a possible discrepancy between local and national MST actions and attitudes toward Vale in Carajás. The local MST would like governance to 
be turned over to a multistakeholder committee; it also demands renationalization and greater protection, salaries, and rights for company workers (Alvares da Silva, Costa, and Veiga 2011). The national MST seeks the full closure of the Carajás mine due to its environmental destruction (interview with Ednalva Moreira Gomes, March 22, 2013).$^{41}$ Evidence of a splintered resistance also emerged in further interviews that I conducted at the Vale headquarters in Rio de Janeiro, in July 2014, with three key directors of corporate social responsibility, sustainability, and community relations, as well as directors of the Vale Foundation. According to the Vale directors, in 2014 people from some MST settlements used protesting to demand work from Vale, while other settlements have demanded mining curbs, not mining jobs. I asked the directors of this multinational company to reflect on how the situation in Brazil differs from conflicts elsewhere in the world (author's translation from Portuguese):

The resistance in Carajás is isolated, for example taking place through Justice on the Rails, unlike other Latin American countries where large-scale mining is generally not well regarded. This is because in Brazil we have a history of state-run mining-we had privatization, yes, but the country had been prepared for this. Mining generates revenues for the country. Vale is also typically the only mining operator, and its presence is seen [by the locals, generally] as an opportunity; there's a positive view of mining. In other countries the companies are multinationals.

The promining view, based on Vale's centrality to the local economy and still-strong state control, partly explains why there has not been cross-class resistance-including the middle classes in Carajás. Regionally situated class dynamics seem to be central in explaining investment outcomes, both economically and politically. On key resource frontiers, located in peripheries, there are seldom middle-class people who would have significant capital in the social space and would be prone to resist mining, a contextual factor explaining the weaker resistance results in economic terms in Pará. The bulk of middle-class jobs in key frontier areas are tied to managing the resource extraction, while in the Minas Gerais and Western Indian cases (which were relatively far less "peripheral" or "rural") the middle-class income sources were much more varied. However, this contextual feature has prompted the Carajás region's would-be resistance actors to self-identify as "organized working classes" (e.g., Vale trade unionists, MST members), to network horizontally, and also to seek international allies interested in steering Vale's global operations. 
There were unsatisfied mining workers, who were allied with the MST, as demonstrated in the MST-organized occupation of the railroads, where they were joined by labor movements and indigenous tribes. While conducting participant observation in the area, I witnessed very close ties between MST and the Vale workers who jointly organized my visit to the mining complex. One reason Vale workers were motivated to join the resistance was due to their profound grievances about unpaid salaries and privatization. Vale executives have not typically replied to these worker demands, but have avoided dialogue and demanded that the police and the state quell protests (Alvares da Silva, Costa, and Veiga 2011), which is why it has been natural for the workers to unite with specialists in contentious politics like the MST. The resistance surging from Carajás has been built horizontally across different working-class peoples affected globally by Vale; instead of a deep cross-class resistance on the local level, it has been a globally extensive horizontal mobilization within the working class.

Due to its class position in Brazil, the MST, in comparison to a professional NGO, does not typically have access in the judicial field as a specialist NGO would have. This is illustrated by a comparison of the resistance efforts in Carajás to Vale's Apolo project in Minas Gerais. The resistance to Apolo forged deep and positive links with the public prosecutor, while otherwise radical public prosecutors operating in Pará have started criminal processes against MST leaders for the Vale railroad occupations. Brazilian prosecutors, who privilege formal and legal means of criticism, are typically less sympathetic to radical mass protesters than to official institutions such as NGOs, churches, or trade unions. This might explain why the movements with NGOs had more success in Brazil, for example in the Apolo case, and why the MST has not managed to achieve such victories.

Thus, local resistance can do better when including NGOs that do not protest in their networks, argued Santos, who generally agreed with the hypothesis that peaceful resistance using combined and flexible strategies is most successful. Furthermore, to explore the Pará-Minas Gerais differences, the MST did not have such clear electoral embedding in Pará as the resistance had in Mariana and Congonhas. In Congonhas, two municipal council members were antimining, "and it makes a huge difference whether you have two or zero politicians on your side," as Santos put it. ${ }^{42}$ Furthermore, although the indigenous people and their allies have regularly blocked other Vale operations in Carajás and demanded, for example, direct payments from companies to let them enter their areas, ${ }^{43}$ the MST did not manage to get the indigenous people to network with them, which did not help the resistance. 
MST's Vale campaign is continuing, according to Manacas, as "there is a demand to create debate on problems, denunciate, publicize, and through this mobilization various movements, networks, and articulations are being created." This viewpoint illustrates how for the MST the most important goal was to pursue good political rather than economic outcomes. Mobilization has indeed spread. At the physical level, the protests also influenced Vale to stop charcoal production and Vale's main expansion plan was slowed down by movement litigation. In terms of economic outcomes, the Pará state government has raised the royalties Vale is obliged to pay, to be used to help suffering populations. Additionally, the courts have demanded that Vale pay massive amounts of back taxes. Rodrigo Santos told me in 2014 that MST's actions against Vale in the 2000s had managed to "substantially impact the profits and reputation of the company," although without slowing expansion much. The most important outcome, in his opinion, was that a "critical consciousness was created" along with new mining-specific resistance agency, which was also institutionalized, for example through the founding of MAM. In this sense, the MST has focused on providing political opportunities for mining resistance and particularly Vale-resisting actors around the world. The MST_a crucial movement in understanding Latin American and global peasant mobilizations of the past decades (Carter 2015) — has increasingly adopted large corporations as its primary target, wishing to fundamentally shape developmental policies by creating a counterforce to increasing transnational resource extraction.

The contextual dynamics in Pará differ radically from central Minas Gerais around the state capital, as this is a very violent, key global resource frontier - that the mining resistance in Carajás has avoided taking up arms and thus propelling the opponents toward civil war is an impressive outcome. This difference will be put into perspective in the next chapter, where I explain how a similarly crucial and violent resource frontier was turned into an armed conflict in India. In Pará, the mining conflict has been much more violent than in the rest of Brazil (or in Southern or Western India); routinized murders and other attacks on lower-class activists are endemic in all of Brazil, but particularly in this region. In this context, the ability of the MST, and other social actors opposed to Vale's activities, to steer away from the trap of reacting with violence to violent frontier expansion is particularly striking. ${ }^{44}$ Rather, they have endured state violence, and invented ways to limit its reach.

This is a political outcome that is important when compared with several parts of Eastern India, where the path chosen was armed revolutionary agency, instead of peaceful resistance. Large parts of India, particularly the 
Northeast and Eastern highlands, are mired in violent interlinked resource extraction expansion and civil war. Although the Indian Maoist insurgency has de facto placed large chunks of land outside mining and state control, this has not meant peace for the local inhabitants, nor has it allowed for the globalization of the struggle. In Brazil, in comparison, movements have also managed to set aside land from mining ventures and stopped them, without violence, although the Amazonians have had to face a similar crude drive of accumulation by dispossession as have the people in Eastern India. Yet the dynamics of contention in Brazil have not turned into a violent civil war, although the MST, for example, would have the means to turn to armed resistance and the incentive to do so after continuous massacres or murders of its members and the continued nonresolution of agrarian reform (based on the author's interviews with hundreds of MST members and other informants in Brazil since 2004). The similarity in these peaceful resistance strategies (the five key strategies) used in Brazil and parts of India partly explains the less violent context of resource extraction. However, contexts are not static or given; rather, they are constantly being created.

The anti-Vale mobilizations targeting the Carajás mines have also created large coalitions and wide networks, much more than those created by the resistance groups in Minas Gerais or India. A reason for this difference might be that the Amazon is currently one of the most crucial expansion points of the capitalist world-ecology and of Brazilian capitalism, both seeking to augment their transnational raw material flows. By contrast, Eastern Indian iron ore extraction was mostly tied to feeding local steel plants, and there were also important local steel plants in the Minas Gerais region, as mentioned. The fact that the Eastern Amazon was reserved for global tapping meant that the resistance there could use the global commodity flows as a pathway to forge resistance networks globally. Meanwhile, in Eastern India, the iron ore stayed much more tightly within local production networks, offering fewer targets for resistance. The new globalizing resistance surging from the Carajás region has followed the money and is meticulously and consciously building on the five key strategies. The MST and Justice on the Rails (which targets Vale in particular, transnationally along the export routes) movements are cases in point, illustrating how resistance against the expansion of the primary national and globally crucial capitalist commodity frontier does not have to use violence, and how mobilization can be transnational rather than local in scale. The last chapter in the book will discuss these dynamics.

This section has analyzed how key resource frontiers typically offer the would-be resistance lesser access to political games, such as institutional, 
electoral, and judicial politics, in comparison to regions that are less peripheral, where the resistance has more capital and connections to embed the state. These connections also ensure a safer resistance environment, when using contentious politics, and make it less likely for locals to be lured into private negotiations with corporations. These differences can be explained by different social spaces at resource frontiers, with the middle classes typically sparse and often involved in the management of resource extraction. In addition, social, economic, and cultural capital are not as equally distributed to would-be resistance actors across different classes and professions in these areas as in areas closer to cities. Resource frontiers are also areas where the most powerful state and corporate actors seek to dominate in the physical space, capturing it for their own extractive projects, and any resistance to this capture must face intense corporate strategies, with the goal of framing the resistance as backward, violent, nondevelopmental, barbarous, or dangerous. Sophisticated corporate tactics of corporate social responsibility and advertising often manage to divide the resistance in these poorer regions, which perpetuates an image of the key companies as the main benefactors of society, thus creating successfully symbolic capital for extractivists. This positive symbolic capital, and the negative symbolizations of resistance, functions also as symbolic violence to chastise the locals who resist. This suggests that the divisions within social space, the topology of capital distribution between those who do and do not resist extractivism, is an important starting point for analyzing investment politics, as figure 3 in chapter 2 and its application in this chapter have illustrated.

This chapter has analyzed resistance to extractivism in the nonviolent contexts of a consolidating democracy (Western India), an old promining setting (Minas Gerais), and a key global commodity frontier (Eastern Amazon). I used a Polanyian analysis to show how the resistance to extractivism has been part of a broader process of building an "organic society." Through the conceptual framework for the analysis of investment politics and spatial causalities in extractivism, I opened up how an "organic society" does not surge automatically against destructive projects, but is built by concrete resistance actions and strategies. I explained the way state coproducing actions by movements helped in the consolidation of democracy in Goa and Karnataka, and how an encompassive embeddedness by the local state and civil society actors was forged and important in central Minas Gerais. Based on these cases, I argue that the presence of a consolidating democracy, with research and legal organizations willing to join the "organic society," is a far easier context to attain movement success than other contexts. The Goa and Bellary cases illustrate particularly well how and when state coproduction by 
civil society organizations can take place through coproducing judicial politics, and how this embedding can have major consequences. Civil society can demonstrate, by its higher technical expertise and local know-how, that the state (in this case, the courts, or the state actors within judicial politics) needs not only to listen to but also share state production with civil society (while retaining autonomy) to be able to better perform its state functions. A state-constitutive civil society in the judicial game will help the resistance elsewhere in the country as well.

The comparison of the different contexts in this chapter also reveals that different contexts seem to influence the styles of resistance agencies. When extractivism has targeted areas close to cities and threatened their middle classes, more vertical, cross-class local resistance was forged, and the primary goal was to discontinue the investment or otherwise markedly influence the economic outcomes. When extractivist expansion took place in key resource frontiers in peripheries, where supportive middle classes were not to be found, class cleavages were further deepened by the resource frontier. When the primary resistance promotor was a rural landless workers' movement, horizontal yet globally extensive mobilization was forged.

To conclude, in contexts without armed conflict, or with the presence of only one-sided armed conflict (from the corporate agency side), the resistance can still make use of peaceful state-mediated political games (contentious, electoral, institutional, and judicial politics), via embedded autonomy in relation to them. However, if we are talking about a peripheral rural context, which is cast as a key resource frontier, and thus often has high violence and ethnic/class cleavages, the composition of resistance is less vertical socially, and the possibilities of using peaceful political games and embedding the state are lesser and harder than in regions that are not as peripheral. In armed conflict contexts, as will be discussed next, that specific political game seems to overtake much of the power of the other political games (see figure 1), such as peaceful, contentious, electoral, institutional, and judicial politics, which means that these state-mediated political games become less available as opportunities for the resistance. 


\section{Armed Conflicts}

Chhattisgarh was mired in an armed conflict when I arrived there. The civil war made it necessary to take extra precautions and ask for people to come to meet me in the state capital, Raipur. Many came, and I learned a lot from them about the dynamics in extremely violent contexts of resource extraction. I visited some rural areas, for example, an Adivasi village on top of a plateau, where mining operations, which had been placed on top of the indigenous people's ancestral lands, had been discontinued as the company had not paid the required state royalties. The local community and Adivasi leaders had invited a group from Finland to join them for a meeting with the community, which is how I ended up there. We observed how Adivasi leaders gave rallying speeches, and people threw their fists into the air. The mood turned tense as a convoy of black cars with men in black sunglasses arrived and demanded to see our documents and remained afterward to observe what was going on. They were apparently members of the intelligence police, and arrived at the village in the cars of the mining company, although the company did not have permission to conduct operations in the area at that moment. It was clear that the locals were not allowed to exercise free speech or actions, because the state was constantly observing them. We saw the open pits excavated right next to this local village, where people had lived and survived for generations, the red ground now exposed and growing nothing. When driving down from this plateau, we also visited a village whose Adivasi inhabitants told us that it had just been burned out by some local powerholders in an attempt to move them out of the forest. Yet even amid all the tension the Adivasis greeted us with joyful traditional dances, which the police also observed. The presence of potential violence was clearly in the air and taught me a lot about how the context of resistance does matter immensely when attempting to explain how and when people resist, and with what means and strategies. We also learned that we were not immune to the ills that 
fall upon people who must live in areas with armed conflicts. Our group of Finns was placed on the blacklist by the local powerholders, and was not allowed to reenter India, although we had the permissions needed to visit the Adivasi hill, which had been turned by the state into a mining site embroiled in a contentious episode. Even government ministers from Finland tried to get us off the list, but to no avail. We received no official explanation, but unofficially were led to understand that this had to do with mining and Adivasis, and that there were powerful local interests that did not want anyone to see what was going on in Chhattisgarh.

In India, mining expansion, particularly that of iron ore, provides the raw materials for steel plants. Iron mining is framed as the essential component in securing cheap steel and multiple downstream jobs. Steel is used in specialized metal and other industries, such as car manufacturing, making railroad tracks, and in producing all sorts of machinery and parts for industry, including equipment for constructing and building other machines. The modern economy, as we know it, simply would not and could not exist without steel. Therefore, in states such as Chhattisgarh, Odisha, and Jharkhand, it is seen as essential to keep steel mills open, avoid any stoppages, and even increase production capacity. ${ }^{1}$ Mining resistance in Western India has deep federal-level linkages due to the presence of an established "organic society," and these movements were generally able to seize more national political opportunities. This is in contrast to Eastern India where conflicts were often either local or at the state level, which left these resistance actors less able to capitalize on the same national political opportunities. Eastern India's mineral areas are also sites of armed secession, a context with important ramifications on the federal level. While the Eastern Amazon is similarly cast as a resource frontier (Kröger 2015b), it lacks such two-sided armed conflict. In Eastern India mining resistance is undertaken mostly by indigenous people, which is another factor that sets it apart from the Eastern Amazon. Therefore, these two contexts make for a useful comparison of how different dynamics of contention (armed/nonarmed resistance) across primary resource frontiers can influence outcomes.

The focus in this chapter is on exploring how resistance has influenced economic and political outcomes, broadly termed as investment politics, in armed conflict contexts. Similar to the previous chapter, I will analyze how contexts and established political systems shape both the type of actions that are taken against extractivism and how the particular resistance agencies forged end up partially creating the contexts and shaping the political economies. 


\section{Chhattisgarh}

This discussion of armed resistance mostly focuses on Eastern India's Maoist revolutionaries, particularly those in the southern part of Chhattisgarh state, which is among the key areas in India where large open-pit iron mine and steel plant expansion projects clash with a mixture of peaceful contentious and armed revolutionary agency. ${ }^{2}$ According to my informants, after the year 2000, Naxals (Naxalites) became very prominent in this Bastar Division (or region-not to be confused with the much smaller Bastar district) when the state of Chhattisgarh was formed by a separation from Madhya Pradesh. This division created the most densely populated Adivasi state in India.

The Naxals have been very active since 2005, following the very rampant expansion of so-called developmental projects during the preceding five years (Chandhoke 2015). The Maoists, who initially entered the political milieu in the 1980s, had become locally popular as they ejected the local landlords who had oppressed and terrorized the people-for example, by selling Adivasi women into brothels (Banerjee 2013). The Maoists also stripped the landlords of their exploitative control of the remunerative tendu leaf trade (used as tobacco wrapping) and were instrumental in instigating land reform. As the Maoists forced the contractors to stop exploitation, they swiftly became very popular, although according to a local lawyer there was also local resistance to their consolidating power. The Bastar region has been disrupted since 2005 when a civil war began, set into motion by the establishment of state-led paramilitaries (whose members were also mostly Adivasis). This conflict has led to the displacement of more than half a million people living in the region.

Subash Mohapatra (2007), who conducted evidence-based independent research used in court proceedings, explains how the violence is directly related to the spread of revolutionary agency in the area. It is important to note that his research indicates that violent responses to this growing agency were fueled almost exclusively by iron ore conflicts. "Naxalism" gained its name after a 1967 peasant uprising in Naxalbari village in West Bengal, after which it has spread "through the rural, marginalized and tribal populations of east and central India." Mohapatra $(2007,5-6)$ argued that the key difference between Naxalites and the over seventy other Communist parties in India is "their uncompromising desire for revolution rather than government reform and their allegiance to violence and armed struggle as the sole means to achieve their ends."

The debate about armed resistance in Eastern India is very complex and no single party can be claimed to be the sole agent. Adivasis' participation 
in and support of the Maoist insurgency are typically seen by the Indian intelligentsia as either a casualty of being caught between state and Maoist violence or as an authentic expression of Adivasi political subjectivity. However, Nilsen (2012) notes that Adivasi mobilizations are in no way exhausted by Maoism but take a much larger array of forms.

There was a major increase in violence beginning in 2005, which is directly and clearly linked to the iron supercycle and the decision by corporate agency in Chhattisgarh to embark on a massive mining expansion. However, to effectively expand the mining the corporations had to get rid of the Adivasis and revolutionaries sitting on top of the resources. Salwa Judum, ${ }^{3}$ an armed private vigilante force, began its operation the day following the signing of memorandums of understanding (MOUs) between the government and corporations, which were worth 130 billion rupees (about 3 billion USD) and focused on steel and iron ore (Mohapatra 2007). This entrance of paramilitaries changed the corporate-state agency's choice of political game into armed conflict. A May 16, 2015, editorial in the Economic \& Political Weekly, a renowned academic journal from India, reflected on the past and future dynamics and impacts of Chhattisgarh's iron-orefueled armed conflict:

In an operation backed by the security forces, the Salwa Judum evacuated hundreds of villages, hounded the inhabitants into police camps, and forced many more to just run. ... In Dantewada and Bijapur Districts, between June 2005 and 2009, 644 villages were razed to the ground, displacing some 3.5 lakh $[350,000]$ Adivasi peasants, according to one estimate; of these 47,000 to roadside camps, 40,000 fleeing across the border into the then Andhra Pradesh or Odisha, and 263,000 seeking shelter in the forests. The process in southern Chhattisgarh might very well have been one of the largest and most brutal development-induced displacements of people so far in independent India. ${ }^{4}$

In comparison to Carajás's export orientation, the iron ore from Chhattisgarh was used for the national state (e.g., the Steel Authority of India Limited [SAIL] Company) and cosmopolitan Indian private-capital run steel mills (e.g., the Mittal family). The primary battle is between a land-grabbing upper-caste elite including both the Left and Right, targeting the forestland under which a crucial ore is found, and on top of which an ethnic group considered to be an "other" (the Adivasi people) is residing.

The Indian setting of armed violence linked to extractivism is not unique 
and has many parallels around the capitalist world-ecology. Armed violence by corporate agency, according to Downey, Bonds, and Clark (2010), plays a critical role in facilitating natural resource extraction from the peripheries by those in the cores by (1) offering powerful actors the means to prevail over others in environmental conflicts, and by (2) ensuring "that natural resources critical to industrial production and state power continue to be extracted and sold in sufficient quantities to promote capital accumulation, state power, and ecological unequal exchange" (Downey, Bonds, and Clark 2010, 417). In Eastern India and the Eastern Amazon, the other political means of securing resource access have not functioned due to strong popular mobilizations, indigenous worldviews of lived environments that are critical of modernity, and at times armed resistance (in India). It could be argued that armed violence by corporate-state agency has partly surged as a method to prevail over the use of peaceful resistance strategies in other political games.

The political opportunities for peaceful mobilization between armed and nonarmed conflict contexts differs greatly. A Goan activist explained to me that in Chhattisgarh the opportunity to use the courts is not so easily available, as there is a "corrupt judiciary" and a "rogue state" that has "gone beyond the constitution, building a country of its own" with a publicly funded "vigilante army," the Salwa Judum. For Padel and Das (2007, 30), the creation of the Salwa Judum in 2005 meant that the context in Chhattisgarh shifted from an armed conflict to "a manufactured civil war" whose "aim . . . is not just to exterminate Maoists, but also to implement industrialisation plans that have faced sustained opposition from tribal society."

By 2007 the presence of armed agencies in this setting had already resulted "in the forced displacement of at least 80,000 Adivasis in Dantewada district, with human rights abuses and conditions of horror and squalor that beggar the imagination" (Padel and Das 2007, 30). In 2013, a local journalist told me that the situation in Bastar is "horrific ... like in Vietnam." Salwa Judum was headed by a Congress MLA (Member of the Legislative Assembly), Mahendra Karma, "whose support for Tata and Essar [two important companies in the mining sector in India] is well known" (Putul 2007, 62). These companies' illegal appropriation of large swathes of Adivasi land for iron ore and steel projects in the Dantewada and Bastar districts has become easier since the evictions, whether caused by mercenaries or the police; Salwa Judum and iron extraction expansion attempts appear to go hand in hand (Choudhary 2012; Putul 2007).

New Delhi-based social actors that were knowledgeable about the situation intervened to quell the civil war. Nandini Sundar, an expert scholar 
on Bastar Adivasis (e.g., see her 2006 article describing the Bastar armed conflict), wrote a petition to the Supreme Court to order the state of Chhattisgarh to abolish Salwa Judum, which the court did in 2007. Such an intervention by an academic portrays how expert power, and outside intervention by civil society, is an important component in decreasing violence and the unrule of law. Nevertheless, violence has lingered on and even intensified in the 2010s, mostly as a result of the iron ore grab. Violent extractivist agency is a hallmark of the southern Chhattisgarh region, building a specific context of resistance.

In order to understand the targets of resistance in this context, the operation of corporate agency in armed conflicts must be surveyed. Corporate agency in armed conflicts typically includes the government, which intermeshes with corporate interests. This intermingling is particularly present in the Eastern Indian civil war, as most of the mining and steel companies and other companies involved in the war are state owned, and politicians are in a central position as middlemen dealing land to corporations. A human rights advocate explained to me that "the state becomes a businessman, acquires land though eminent domain from the people and sells it at a higher price," which puts the role of the state in question. Furthermore, most of the iron ore mining is done by state-owned companies in Chhattisgarh.

A key observation that can be made through examination of the Chhattisgarh cases is that the dynamics between different political games and resistance groups work very distinctively in armed resistance contexts than they do in nonarmed resistance contexts. For these and other reasons, which I will discuss below, I have placed armed secessionary (and possibly also revolutionary) politics as a political game outside state mediation. As the state, government, and private capital are so intermeshed, the armed secessionists/ revolutionaries do not want to use state remediation. This has major consequences for the dynamics of investment politics. Peaceful contentious politics and other state-mediated political games are rendered almost obsolete, for several reasons. First, the role of the state changes in secessionist armed conflicts because the "state as an enterprise uses the military to suppress the people or those who have a difference of opinion, branding them as terrorists," as a local informant explained. This makes the choice between violent and nonviolent methods of resistance less of a difference, because one will be treated as an armed guerrilla either way. This tends to promote armed reaction when peaceful resistance is rendered obsolete. In the armed-conflict areas of Chhattisgarh, "civil society organizations are seen as ineffective, and there is no other option than to join or support armed rebel groups," argued an informant from the Dantewada district in early 2013. The locals are caught in a cross-fire: 
If Maoists come with the gun, you have to give food to them because they will ask for food with the gun. Then the police come and ask, "Why you give food to [a] Maoist? You are arrested. Let's go to the police station." (Excerpt from an Odisha-based mining activist interview)

Chhattisgarh has been producing approximately twenty-seven million tons of iron ore per year, aiming to raise this swiftly to thirty-seven million tons $s^{5}$ by opening new mines in the forests, which are now violently razed and violently contested. I met not only the powerholders, such as a former state minister, politicians, and trade union leaders, but also several victims of these actions who related to me their horrific personal tragedies of trying to face the context of Chhattisgarh with nonviolent activism. Some of them had had to go underground, particularly those who had systematically reported human rights violations and filed cases against state officials and members of the corporate elite.

In Eastern India, the elites have become accustomed to using harsh violence without fear of being brought to justice; they can easily camouflage any atrocities as part of the attacks against guerrilla groups (Verma 2004). In states with large Adivasi populations, such as Chhattisgarh, the ethnic context makes it easier to perpetrate legitimated violence and thus maintain a civil war context for expanding resource extraction. A key tool is to divide Adivasis by pitting them against each other, hiring paramilitary troops from the villages, which, according to Baviskar $(2001,368)$, "gives the state much more leeway to explain violence as a 'normal' aspect of tribal culture and to disguise its culpability in violent encounters." Such naturalization of violated populations' "primitive" peasant or indigenous moral economies as the innate cause of their miseries has been found by political ecologists to be a common mechanism for justifying and opening resource access in Africa (Carney and Watts 1990), Southeast Asia (Fox et al. 2009), and Brazil (Zhouri 2010).

When the armed route to power settles in, routine political games can lose much of their usability. Consider electoral politics. According to an activist, Maoists in West Singhbhum "forbid voting" by the locals, which results in the election only of "corrupt, pro-mining, co-opted politicians" from the old mining areas of the district. Chenoy and Chenoy $(2010,131)$ found that in some cases the Maoists have used their control over voters to tax politicians, and that "even politicians pay them, to get access to their constituencies when they come to campaign." To avoid paying such taxes, politicians have sought to displace populations using paramilitary forces. For example, in the Bastar Division in Chhattisgarh, Sundar (2006) notes how 
visits during elections "revealed deserted villages and shut polling booths. Yet 'votes' were 'cast' from them." Corrupted politicians from the BJP and the Congress, and violent land grabbers such as Karma, the founder of Salwa Judum, have gotten themselves "elected" as MPs or MLAs in this setting where there is only corporate agency and no counterparty using electoral politics to impact resource policy.

Once peaceful resistance is repressed in a political system that has armed conflict as one constituent field, the contentious thrust is more likely to turn into armed resistance, expanding the spread and strength of armed politics, rather than leading to passivity. Both corporate and revolutionary agency will want to retain armed conflict as the main means of contention, as it supports their very existence. Sundar (2006) notes how the attempt to defend their guerrilla zone by the Bastar Maoists had "overtaken people's need, including the desperate desire for peace." Some saw the Maoists' reasons for attacking mining as deriving not from antimining sentiments, but from strategic war-making. ${ }^{6}$ It is not just that the plight caused by mining and other violent dispossession leads people to join the armed resistance; often the Maoists actually force people to join them by violence.

Mohapatra $(2007,16)$ describes the terrible situation for Adivasis in Dantewada's iron ore mining areas:

In most cases an Adivasi who chooses to remain in their forest village, especially when that village is in a Naxalite stronghold area is considered by security forces to be a Naxalite. If an Adivasi chooses or is compelled to move to a displacement camp then the Naxalites consider them a part of Salwa Judum.

Practically all land with rich iron ore deposits in Chhattisgarh is Adivasi land. According to the law, they should be able to decide whether they will allow mining to enter, a right that would be further strengthened if two of the legal provisions developed to support the rights of the tribal peoples were implemented effectively in practice.

These two key political opportunities, which the ethnic forest-based minorities in India have helped to establish, are the 2006 Forest Rights Act (FRA) and the Panchayats (Extension to Scheduled Areas) Act of 1996 (PESA). The FRA created a legal framework that was pro-Adivasi and pro other forest dwellers (designated as Scheduled Tribes by the government) (Kumar and Kerr 2012). It has been effectively used in mining conflicts, although it "has not yet stopped mining," according to one national activist, as it has not been implemented evenly. If the Adivasis' many-generational 
habitation is not recognized, that is, if the FRA is not implemented, the Adivasis "will not get any recompensation package" for displacement, a coordinator from the Bhubaneswar-based National Center for Advocacy argued. ${ }^{7}$

The PESA enables a larger number of tribal populations to self-govern their areas directly via their village-level self-government organizations (Gram Panchayats), elected by all adult members of the village (Gram Sabha). ${ }^{8}$ PESA extended the rights of municipalities to the tribal areas of nine states, demanding that state legislation on Panchayats take care of tribal customs, religious practices, and traditional management practices of community resources. This legislation is part of a growing tendency to increase and deepen local and autonomous decision-making, which has been taking place since the 1990s (Tiwari 2016). Based on the analysis in Tiwari (2016), PESA can be argued to have created radical governance powers for tribal communities (de jure rights), but, similarly to FRA, it has not yet led to radical outcomes in terms of implementation (de facto rights), largely because implementation was left to the states.

During my interviews, National Adivasi Alliance leaders argued that Gram Sabhas are strong tools, as "under government rules, land can be acquired only after the Gram Sabha's consent is obtained." However, to give an example of how this "political opportunity" has become a reality in practice, during the conflict over the steel plant installation by the state-owned National Mineral Development Corporation (NMDC) in Dantewada in Chhattisgarh in 2000, this interpretation of the rule of law was obeyed only after the Adivasis organized themselves and protested. This action step was required to ensure that "the complaints finally reached Delhi." These acts led to NMDC's relocating its steel plant project to nearby Nagarnar (in Jagdalpur at the border of Odisha) (Putul 2007, 54). This showed that Gram Sabhas can be a potential "political opportunity." In other words, they are an institutional political game that can be embedded, for some and in some instances-but at the cost of others if the investment is merely moved somewhere else.

The Gram Sabhas' power, as that of almost all institutions, is under constant redefinition, mostly due to differing interpretations of the contradictory set of ethnic-territorial rights in the Indian constitution. In 2006, the Adivasis displaced by the Tata steel plant in Bastar in Chhattisgarh petitioned the Chhattisgarh High Court to stop the project, referring to intimidation (despite this action, consensus for the project was not acquired). The court ruled that the Gram Sabha or Panchayat must be consulted, but that obtaining consent is not necessary (Hinmon 2007, 135). Frustrated at this limited interpretation of PESA, which provides democratic legitimacy to 
government strong-arm tactics in land acquisition, many locals have turned into Naxalite guerrillas as they have seen no other option to resist displacement (Choudhary 2012). A local journalist told me that Panchayats do matter, but they exist "only on paper." This shows how the closure of routine political opportunities can lead to a rise in armed revolutionary agency at the cost of promoting peaceful activism. The future of such a transformation is that movements will face settings with an open political game (opportunity/ threat) of armed conflict. ${ }^{9}$

The utilization of institutional politics is hard in this context of potential and existing violence. Despite this, the peaceful resistance is trying to use institutional politics and the political opportunities afforded by the FRA. The Adivasi-led Samta Manch movement is trying to foster understanding of nonarmed resistance opportunities at the village level and how to resist extractivism peacefully by focusing on the FRA. In addition, there are at least nine other organizations doing the same type of work in the larger Chhattisgarh civil society network. Currently, all potential Bastar region mining areas are "under scheduled area" (the rights afforded by PESA). However, this is another example where institutional opportunity is only latently present, "just on paper." These legal provisions will not be helpful without resistance that activates and ensures them. In areas of armed conflicts and ethnic minorities, there are many people who are "not aware of their rights," which is a reason why there is displacement, according to two Adivasi coordinating activists and members of the national network Mines, Minerals and People (MMP). Furthermore, they add, there has been a "complete disregard of FRA when distributing mining leases." Their work in 2013, which I closely observed, centered on building evidence of these infringements to hand over to state investigators, including the Shah Commission that had recently arrived in the state, so that it would not look just at illegal mining (narrowly defined), but at the whole leasing system as illegal in the context of the FRA.

On the contextual level, the expansion of institutional opportunities from more democratic regions of the country to the more violent ones can be seen as an attempt to homogenize the political opportunity structures across the country. These attempts have had better success in some places than others. Odisha is a positive example, discussed in part III, while in Chhattisgarh the government intervened. As part of this intervention the government dismantled the Shah Commission while it was in Chhattisgarh, stopping the process of homogenization of democratic norms.

The activists encountered severe barriers to this embedding work, as the area in which they should have been collecting evidence-requiring exten- 
sive field visits and effective organizing and politicizing of the Adivasishas so many Naxalites. The Naxalites claimed that the activists were police informers, while the local police said they were Naxalites-both stances served to prevent state embedding. The presence of the armed conflict has made the crucial work of extending de jure rights into a de facto situation in Chhattisgarh very difficult, indeed almost impossible. In parts of Odisha the activists have managed to steer away from this dilemma by using a series of linked strategies (the five key strategies) to endure violence and convince the authorities that they are not Naxalites.

The armed revolutionary agency by Naxals in relation to mining includes more than just the use of arms. They have "issued warnings in local media" to villagers not to give land to miners. Such armed-resistance agency works more as a threat, placing full responsibility on the villagers; if the villagers do not obey, the Maoists may punish them. Such operational logics are typical in many armed revolutionary movements, but absent in peaceful resistance, where movements do not have such threatening physical power, and where the aim is increasing proactiveness and debate, not subservience.

Using threats, the Naxals are trying to increase the locals' cost for allowing mining; this way they do not necessarily even need direct armed conflictsthey can use their clout to instill fear. Resisting mines becomes a more attractive option for locals, as refraining from resisting would incur greater costs than in a nonarmed revolution context. Such contexts, with their threats, may thus also partially increase the willingness to resist by locals, but it is clear that the overall negative effects for activism override these partial boosts. Furthermore, resisting out of fear is not really a basis for forging a lasting activism; resistance agency is unlikely to last, and those who have experienced threats by armed groups might turn into pro-mining attitudes after the armed groups leave. Problematically, the mining issue becomes politicized as a government versus Naxalite political issue, rather than focusing on the actual impacts of the investment on lived environments.

Adivasi activists claimed in interviews that in early 2013 about 60 percent of Kanker and 80 percent of Bastar and Dantewada districts were Naxal-affected. This makes "day-to-day community work very difficult" in these areas. Furthermore, it brings an influx of outside migrants, such as people of the trader caste, middlemen, and authorities, to the towns, who are very promining and frame Adivasis as antidevelopment and Naxalite. This dynamic has made it difficult to build antimining movements even in the relatively safe urban centers of these otherwise rural areas. Demographically, the numbers of outsiders increase with the civil war, while Adivasis are displaced and killed. It is in the interest of the influx population to advance 
the resource frontier, since their class and capital formation is principally tied to extractivist appropriation. This is not an isolated situation, as these dynamics can be found in other areas of the world that are also experiencing outsider-based resource frontier expansion (see Tsing 2005 for an example in the Indonesian context).

Many civil society organizations are trying to work in the Bastar Division/region that comprises southern Chhattisgarh, ${ }^{10}$ and have managed some small achievements. Yet the central Adivasi activists of the state proclaimed to me that no such organizations have their base there, and that "Naxals have raised the issue" of mining. Kanker district had the least peaceful peoples' movement against mining of all the three southern iron ore mining districts in Chhattisgarh, according to the Adivasi leaders. The Naxal movement was "very hard-core" in Rowghat, the new greenfield mining area of Kanker.

I will next do a comparative analysis of mining politics across the key cases in Chhattisgarh, drawing lessons from their contextual differences, strategy sets, and outcomes. ${ }^{11}$ The analysis includes both old mining sites and greenfield expansion projects. I will first briefly describe the cases of Dalli Rajhara and the Manpur mines in western Chhattisgarh, after which I will dedicate specific subsections to the more crucial cases of Rowghat, an attempted greenfield project, and Dantewada, where an already established mining project is trying to expand. The dynamics that unfold when targeting a virgin forest area, which is devoid of major mining operations, may differ greatly from expanding an existing mine-although strong Maoist insurgencies resist both expansions. These virgin areas, both with several mining projects close to each other, require their own subsections. In the section on Rowghat, I will also briefly discuss the case of Kawardha greenfield project in northwestern Chhattisgarh (both of which are expansion projects of the Bhilai Steel Plant—Dalli Rajhara being a depleting mine of the same plant), where there is no Naxal (or other type of) resistance, as the project existed only on paper and the locals were not aware of the project.

\section{Dalli Rajhara and Manpur Mines}

In old mining areas such as the Durg district's Dalli Rajhara mining complex, there was allegedly "no Naxal presence" and "mining goes on." However, "Naxal presence" is a very rapidly changing concept, and if they wanted to, the Maoists could be in Dalli Rajhara. By this I mean that Maoists from other regions could come to Dalli Rajhara, as it is unlikely that the residents 
living there now would suddenly turn into Maoists. The nearby Sarda mines in Manpur Panchayat, over the district line from Durg to Rajnandgaon district's southern part, are controlled by Godawari Power \& Ispat and Sarda Energy \& Minerals Limited. Both private companies—the latter is primarily a sponge iron producer in the Raipur area-were closed down or blocked by the Maoists in 2008, according to a lawyer I spoke with. ${ }^{12}$ The lawyer argued that the company did not take the Maoists seriously. ${ }^{13}$ The Maoists, who consider their acts in Manpur (wherein the Pallamad mining area named below is located) a key success, ${ }^{14}$ argued that

this Manpur area situated on the southern part of Rajanandgaon adjacent to Kanker and Durg districts on one side and Gadchiroli district of Maharashtra on other side is an important strategical area. This region has rich mineral wealth and for this many big Indian and foreign companies are eyeing. Particularly in Pallamad area, many big capitalist houses are playing with the livelihood of people opening mines in that area. They have all set to enact the destruction of water, forest and land of this region. But the people organized under our party leadership has become a major obstacle for this path for exploitation. ${ }^{15}$

The Maoists explained that the closure of Sarda's mine (called Raipur Alloys in the extract below, though it was bought by Sarda) took place due to a mixture of a mass social movement and armed resistance (not explicitly mentioned):

People launched militant struggle against Raipur Alloys that started the Pallamad mines in this area. More than a thousand people and workers rallied in 2008 January and closed this mine. But after some period, the management started work again. Once again people rallied on a huge scale in December and not only closed the mine but had also sent back the machines and vehicles from there. People are building movements opposing this mine that is proving to be a disaster to the agricultural fields, forests and people's lives as a whole and other proposed mining projects. ${ }^{16}$

The Maoists attacked the Sarda mines and even effected the closure of most of them, but they have not messed with Dalli Rajhara, which is mostly explainable by the absence of a strong trade union movement in the private Sarda mine and the existence of a strong and alternative trade union in 
Dalli Rajhara. The union, Chhattisgarh Mukti Morcha (Chhattisgarh Liberation Front, or CMM), is so strong that even the truck owners are linked to it. Typically, truck owners do not join the trade unions of miners or the workers in other larger operations, but rather see themselves as entrepreneurs employing drivers and being closely and uncritically aligned with the interests of large capital. The CMM is interesting from a global perspective because it is a radical trade union that incorporates environmentalism and criticism of mechanization, yet it also seems to have significant de facto control over local land use policy. I will discuss how this specific form of peaceful agency shapes extractivism below.

The heavily mining-critical and arms-using stance of Naxals against mining was visible also in the crucial Rowghat expansion project. In 2011, according to the newspaper The Hindu,

Maoist spokesperson Gudsa Usendi said the guerrillas were categorically opposed to mining operations in Rowghat. ... "They [the establishment] are trying to squeeze us. The Rowghat mountains are very important to the ecology of the area and the Maria tribes who live there," said Mr. Usendi. "The adivasis did not benefit from the mines in Dalli and they will not benefit from mines in Rowghat." On Saturday, the Raipur and Bilaspur editions of the Dainik Bhaskar reported that BSP [Bhilai Steel Plant] had offered to pay for the cost of raising, training and deploying an armed battalion (800 to 1,000 men) of policemen to secure the Rowghat mines. ${ }^{17}$

\section{Rowghat and Kawardha Greenfield Project}

The Bhilai Steel Plant is one of India's first five initial steel plants, and was constructed in 1955 with the help of the Soviet Union. ${ }^{18}$ The plant owners and trade union leaders want to expand the production from 4.7 to 7.5 million tons per annum, but this expansion cannot be done without building a railroad from the depleting Dalli Rajhara area to the Rowghat area, ${ }^{19}$ and using extreme violence to kill the Adivasis living in the area, who are largely armed and resist the appropriation. The corporate agency in Chhattisgarh includes the strong Communist trade union of the Bhilai Steel Plant, which backs the opening of the railroad to Rowghat and starting to mine these forested hills of the Adivasis, which would benefit the steel plant, which employs 30,000-40,000 workers. The conflicts of the "Communist" 
state steel plant workers with Maoist guerrillas are interesting expressions of the actual forms that the capitalist world-ecology takes at the points of production.

The BSP argues that it must open up the Rowghat mine to avoid closure and the loss of jobs at the plant. However, the BSP is not the only proponent of the project; there are important private companies that could benefit even more from the state's efforts to open this iron ore frontier. The initial stage of the project includes building a railroad north to the state-owned BSP of the SAIL Company, with the state assuming the risk of this very unsure operation. According to an interview with a tax lawyer affiliated with the Congress Party, there is a major intercapitalist struggle ongoing around the Rowghat reservation, with the procorporate BJP-led state government backing the private corporations (such as Tata) more than the public companies, SAIL and NMDC. Prior studies have found that such schisms between elites create political opportunities for movements (McAdam 1999) and foster an environment that supports the efforts of nonelite actors in equalizing the use of endowments (Nugent and Robinson 2010).

There are also internal schisms inside the BSP, and not only between the would-be miners of the Rowghat hills. These schisms can be seen as further political opportunities for resistance, though in a somewhat equivocal way as they offer possibilities that a significant part of the resistance might not see as worth pursuing. The BSP and its mines differ from other steeliron complexes, as the legendary Dalli Rajhara mine trade union movement (which differs radically from the Communist Party of India [CPI] -led BSP Steel Plant union) extended by forming its own political party, both the movement and the party being called CMM. ${ }^{20}$ The CMM resists the violent resource grab. The role of CMM and the Communist parties and trade unions is complicated in current mining politics, considering the political opportunities in resisting extractivism. On the one hand, they might be seen as allying with corporate agency pushing for new mines (as long as these are not too mechanized or privatized), and partly directing a large proportion of potential resistance into seeking alternative models of mining, rather than resisting mining per se. On the other hand, without such presence, the situation could have been much worse than it is now, and certainly this would have been the case for (official) workers and mining town community development. ${ }^{21}$ The CMM has demanded that the Centre (the Indian government, which is also sometimes referred to as "New Delhi" to distinguish this central government power from the state powers) continue the operation of the Shah Commission in Chhattisgarh to investigate illegal mining. ${ }^{22}$ In this 
sense, it has been a boon for the general tendency of trying to expand the context of a consolidating democracy from Western India to Eastern India, and thus help to dismantle the context of armed conflict.

Although the CMM is critical of mining expansion, and is particularly against the violent expansion of mechanized mines, the larger and more powerful trade unions are in line with the BSP and the government in supporting corporate agency in this matter. A worker at the BSP and also the president of the Chhattisgarh's iron ore miners' union shared with me in 2013 that the Rowghat mine must be opened, as there are only 5-10 years of ore left for the plant. ${ }^{23}$ In his opinion, importing ore from Jharkhand or Odisha would "cost more than the ore," as the price of transport is based on the market value of the ore (which is high due to the iron ore boom and the local scarcity of ore). The opening of the mine would thus allow the mine to escape the market and continue producing "cheap iron ore." Importing from elsewhere would also be possible, as (according to the company website) the Bhilai Steel Plant is by far SAIL's most cost-efficient and profitable plant; turning to imports would just mean lower profit margins and abandoning steel-production expansion plans.

In fact, Rowghat is not the only nearby option, as in 2012 SAIL signed an MOU with the government to build an iron ore mine in the Eklama area of Kawardha district in the northwestern part of the state. ${ }^{24}$ This greenfield project would require far less railroad building than Rowghat, and the area does not have Naxalites. When I visited the area's Adivasi villages, however, the villagers and even their leaders were unaware of the whole project. By 2015, I had not heard of the project being advanced. According to initial estimates, there were at least 200 million tons of high-grade iron ore in Eklama, ${ }^{25}$ which is far less than in Rowghat. The region has also had a very strong and successful local resistance trajectory against mining, and a bauxite miner has been driven out of one of the Adivasi hillocks; resistance is strong in Kawardha, and the peaceful Adivasi network is dense. The corporatestate nexus could not use the pretext of fighting Naxalites in combatting resistance - which would undoubtedly surge - if they opened the mine in Kawardha. This might be one reason why Rowghat is targeted instead. ${ }^{26}$ According to a lawyer, the Kawardha area is densely forested and there is strict enforcement of forest protection. Rowghat is likewise richly forested. Yet, for the state, in the de facto application of law, a Naxal-affected forest apparently has less value than a nonaffected one-particularly as officially its forest rights have not been protected or respected strongly. ${ }^{27}$

It should be noted that resistance in Rowghat was not limited to Maoists; there were fervent attempts by activists to support peaceful mobilization 
aiming to retain the existing lived environments. In my interviews, local Adivasi social movement leaders from the Rowghat area argued that all the locals living in Rowghat are against the project, which has erected police stations every five kilometers around the village to prevent any outsider activists coming to help the villagers. In essence, the villagers are trapped between the expanding miners, their military and paramilitary allies, and the Naxalites. The local Adivasis do not want the mine, according to the movement leaders:

Part of their livelihood is based on [forest product] collection. . . . That particular mountain [in Rowghat] and foothills around it [are very rich in forest products].... they get things like jar, which is kind of a dry fruit and very, very expensive. And then mahua, which is also used for producing liquor and so many things. And tentupata, from which smokes are made. ... the opinion of the community [is] that it [the mining project] should not be there.

Chhattisgarh Bachao Andolan (press release, February 18, 2014), a social movement consisting of Adivasis, farmers, environmentalists, and human rights activists, proclaimed:

Anyone opposing Bhilai Steel Plant (BSP)/SAIL is being arrested, beaten, tortured or attacked by the police. . . . None of the $35+$ tribal villages surrounding the mine have given their consent, nor have had their rights settled under The Forest Rights Act—in direct violation of the law and the Supreme Court's April 2013 judgment [prohibiting the company from expanding in the area]. . . no legal process of land acquisition has taken place, and no plan for rehabilitation, resettlement, or compensation of these Scheduled villages exists in the project documents. In April 2013 members of Chhattisgarh PUCL [People's Union for Civil Liberties] found that the local police are threatening the people at gunpoint to "leave the village and settle in Narayanpur town"; the people are not even aware of the [Rowghat] project. ... Chattisgarh Bachao Andolan activists trying to hold meetings on tribal rights have been prevented and their mobile phones and ID cards seized.

What can be said about the role the armed and nonarmed resistance played in the stalling of the Rowghat project, given that they both operated at the same time? State-level Adivasi leaders, among several others who 
do not resist mining, such as trade union leaders and CPI leaders, shared the argument with me in 2013 that the reason why mining work has not been started in Rowghat was the resistance by Naxals. The Naxal strategy in Rowghat has been based, according to outside Adivasi activists, on "generating fear" by using landmines, publishing media reports, and forcing workers to strike and locals to block roads and not ask for road construction into their areas. In line with the trade unionists' understanding of the case, Chattisgarh Adivasi leaders did not mention their own peaceful movementbuilding work as having played a role in stalling the Rowghat project. These leaders also emphasized that corporate agency weakness is unlikely to have been a cause for stalling, which seems accurate given, for example, the ample support of the state in the form of military support. Yet it cannot be ruled out that peaceful mobilizations have had some impact in the overall causal condition complex. A national activist explained how on February 10, 2013, there was a "huge rally against the Rowghat mine" by the local communities. There have also been "small-scale rallies" of about 2,000 people against the Rowghat project. The peaceful movement that sprung up among the locals has been a "spontaneous, new, and loose movement."

In sum, the simultaneous presence of peaceful resistance strategies (the five key strategies), together with the "big Naxal presence," could explain why expansion has not taken place in Rowghat. In fact, in all the cases involving armed conflict, two to five of the five peaceful resistance strategies were used. Based on this, the exact role that peaceful or armed resistance had in producing the outcomes cannot be ascertained — a finding that broadly parallels prior findings on the somewhat unclear role of violence in influencing movement outcomes (see Giugni 2004).

\section{Dantewada}

I will next analyze the important Dantewada iron ore mining region (which has high-quality ore in substantial quantities), as this case adds new detail about the relation of armed conflict and revolutionary armed resistance with mining investment outcomes. Dantewada is an old brownfield mining area, where the Maoists and the state-owned mine, with its Communist trade union, have built a complex coexistence. The Maoists strongly steer the extraction policy of the region by using arms to block private corporate investments. Peaceful resistance building has been very difficult in this region as it has been cordoned off from the rest of India by state, paramilitary, and Maoist armed forces. Despite this overwhelming presence of 
armed resistance, it is interesting to study how the peaceful strategies of movement-building, campaigning, protesting (but not networking), and judicial embedding were used in this context. As an outcome, several private steel and iron ore projects were discontinued, apparently mostly due to the Maoist actions, while the existing Dantewada mine continued its operations. The analysis of Dantewada further illustrates how armed resistance can influence and even block the type of extractivist expansion it considers harmful.

Dantewada contains a mix of established mines and greenfield mining projects, but had no steel plants as of 2015, thus making the context possibly easier to resist. The main functioning mines in Bailadila (in the hills west from Dantewada town) have been run by the public iron ore mining company NMDC since they opened in 1966. In 2011 Dantewada was the district most severely affected by the Naxals and was also by far the highestvalue iron ore extraction site and reserve in Chhattisgarh. ${ }^{28}$ The district has a 65 percent forest cover and an 80 percent proportion of Adivasis (which only captures those who are officially part of Scheduled Tribes) in the population (CSE 2011). ${ }^{29} \mathrm{I}$ will discuss how and why the resistance has been so strong in Dantewada, including armed revolutionary agency.

The relations between mining expansion and resistance in Dantewada are long and tumultuous. The resistance has lingered on since the 1960s, a period that, according to one lawyer, saw a massive indigenous peoples' uprising against displacement (see Sundar 2008 for an account). However, the 1960s movement did not manage to stop the investment, which was heavily backed by Japan. ${ }^{30}$ The mining expansion has led to an accumulation of grievances around the impacts, such as considerable iron dust and waste pollution.

The 1980s saw the arrival of Naxalite armed organizations in the area (Choudhary 2012). Since then, the NMDC Dantewada mines' "staff and property have been targeted in frequent Naxal offensives" (Hinmon 2007, 125). However, a journalist argued that although the Naxalites "attack at times NMDC, their relations are okay." The Maoists often derail trains to disrupt mine operations, which, according to the journalist, the companies and the state "cannot stop." However, the expansion of mines has been markedly stalled by the resistance. The journalist thought that "no peaceful movement has managed to slow down" mining expansion in Dantewada. There is a constant attempt to cordon off the region from peaceful resistance strategies (such as state embedding) by both the state and the Naxalites, a strategy that would support such an analysis. "Maoists are the only [resistance] the Adivasis have seen," said the journalist. However, I found that 
local resistance formation is more complex, as Adivasis have also spontaneously and peacefully resisted new expansion by private mining companies in Dantewada, much like in Rowghat. Both spontaneous and armed resistance are strongly linked to the fact that the government uses armed forces to take over Adivasi lands, and that the locals often do not have official land titles or are not recognized as locals, and thus cannot, for example, use state embedding via FRA demands. Choudhary (2012, 160-61), who did seven years of participant observation among Dantewada Maoists, writes about the 2005-initiated government and paramilitary attacks in Bailadila:

I wondered why the state attacks were concentrated on this area. The answer lay in its location. These villages are only a few kilometres from the Bailadila mines numbered 1 and 3, leased to Tata and Essar [private Indian companies] by the NMDC. A team of revenue officials had visited these villages with Mahendra Karma [founder of the Salwa Judum] to ask for land to make roads, ponds, an airport and railway lines which would facilitate mining, but the villagers had driven them away. Many of these villages are not even mentioned in the government revenue records and so, they are unlikely to be compensated for any land they give up.

Such a setting makes it understandable that the resistance uses all means to resist, particularly when they are attacked by the powerful corporategovernment nexus, which uses severe violence against the locals on top of the iron ore.

There is a constant push to expand mining to the whole hill range in Dantewada. In 2013, there were attempts to cut down forests, which the local Adivasis resisted, according to a lawyer, who added that the Adivasis in the Bailadila area no longer resisted mining per se, but its expansion. A Tehelka journalist informed me that there were twenty-one MOUs with private miners in early 2013 in Dantewada, of which the villagers were very angry. The lawyer also observed that Adivasis must take sides as either Naxalites or promining locals, as the whole area is isolated from the work of environmental NGOs or peaceful social movements.

I received varying accounts from my informants on the role of resistance in affecting Dantewada outcomes and on the motives of local resistance. In 2013 Adivasi leaders said to me that the Naxals in Dantewada frame the new mining thrust as a "complete government resource grab," which they are trying to resist. They have not succeeded in closing the existing mines, although "at times [they] disrupt railroad traffic" by exploding dynamite on the tracks 
or sabotaging the power supply. In reality, however, activists argue they "do not want to close the Bailadila mine," as they have never destroyed the mine or said categorically that the mine should be closed.

In this light, the claim above that the mine could not be closed by the Naxals must be understood as referring not only to the strength of corporate agency but also to the unwillingness of resistance agency to close the mine. Chenoy and Chenoy $(2010,132)$ found that Maoists extorted about a fifth (400-500 million rupees) of the total of massive illegal mining proceeds in the neighboring Jharkhand state, in the form of protection fees from miners. Similar dynamics are likely to be found or practiced in other places, such as Dantewada, which makes the supposed antimining stance of Maoists less clear. Of course, one could tax an industry while simultaneously resisting it, but the existence of these two tendencies might explain why some mines were closed in Chhattisgarh by the Maoists while others were left operational, and why they will not close all mines.

The Naxal presence has had an impact; "you can say that expansion has slowed down in Dantewada due to this resistance," but in comparative terms the resistance in Rowghat against greenfield mines "seems stronger" to the Adivasi movement members I talked to in 2013. Other informants and data, however, suggest that Naxal-NMDC relations have been much starker than the above informants claimed, and that they have worsened since 2013, which led to major stalling of Bailadila mine expansion. In March 2014, Naxals burned "the downhill conveyor of $11 \mathrm{~B}$ deposit over a length of 500 meters"; such attacks have, according to the NMDC, "seriously hindered" its six-billion-rupee expansion project in Bailadila. ${ }^{31}$

That Dantewada mines remained state owned and had a strong CPI trade union helped in the interactions between the mine and the Naxals. I talked to several leading trade unionists, and they seemed to be on speaking terms with the Naxals, even while the sabotage described above was happening. While the CPI and CPI (Maoist) do not share the viewpoint that armed revolution should be the way forward, they share similar views on workers' rights. ${ }^{32}$ For instance, CPI presence in NMDC Dantewada mines has, according to a tax lawyer, provided very good employment and health services to those employed, much better than the private companies that do not have similar trade unions. ${ }^{33}$ The CPI leader argued that the Naxals attacked the NMDC mine "to pressure the state government" and to demand a "no-export" mineral policy.

The NMDC mine seemed to have comparatively better relations with the Adivasis and Naxals than SAIL's Bhilai Steel Plant and the Rowghat project-although none of these relations can be called peaceful or good in 
the conventional sense. Several of my informants claimed that the iron projects benefit and employ mostly non-Adivasis, and when they are hired, they are typically offered positions as the lowest-ranking workers in the industry. ${ }^{34}$ In any case, working in a factory is deeply at odds with the traditional way of life in the forests for the Adivasis, who thus become alienated from dwelling in their traditional lived environment.

In 2013, a long-term worker in the Bhilai Steel Plant and president of the iron miners' union in Chhattisgarh told me that the unions oppose the central and state government's willingness to privatize the mining industry. $\mathrm{He}$ argued that "Tata and Essar want the Dantewada mines," but these mines "should be of people, tribal people," whose land right is "ancestral." He then continued to raise a question that was revealing of the underlying worldview of these mining trade unionists: "They [the Adivasis] have saved the mineral, the forest, why should [the lands] go into private hands?" This kind of discourse illustrates the general trend of opinion held by trade unionists, steel and iron mine workers, and CPI members in India, which frames public mining as no problem to Adivasis, and private mining as the key problem. This view both unites and differentiates many (but not all) trade unionists and mining workers from the Adivasis and the Naxals.

The rising push of extractivism by private capital seems to have made the conflict worse and bloodier, given that the Naxals resist private capital in particular, which is then protected by new paramilitary forces. This entrance of new players (Tata, Essar, and the paramilitaries) shatters the existing dynamics of contention. A mining activist claimed that at least since 2005 Tata has "taken over land without environmental clearance" and "organized [a] massacre of Adivasis in July 2005 in a steel plant area" that would be fed by the Rowghat mine. According to this person, "thousands have been killed for the steel and other projects" in the Bastar Division.

Steel plants are the first required step for prospective miners before opening mines under the Indian government's iron mining policy. This means that along with banning illegal mining, resisting steel plants is also essential for resistance targeting the iron industry. The Maoists have attacked many private steel project plans, and almost all of these have been scrapped. ${ }^{35}$

The entrance of private capital has deepened the civil war and triggered armed revolutionary agency. The post-2005 increase in signing MOUs with private companies, such as Essar and Tata, had many impacts on the mining industry. These MOUs outline deals that include taking over at least a part of the state mines; establishing private mines; and installing steel plants and building infrastructure in Dantewada. These agreements, according to a non-Adivasi forest rights activist, have led to stronger attacks by the Nax- 
als against the prospective privatized projects. One target of these stronger attacks was the Essar slurry pipeline running to the Andhra Pradesh coast, for the purpose of exporting iron ore. ${ }^{36}$ The escalation of violence has been two-sided, and this has led to a situation where the adoption and use of peaceful politics has been rendered almost impossible.

According to Hinmon $(2007,132)$, in Dhurli in Dantewada in 2006 the government was grabbing land for Essar, and communication with the village was cordoned off days before the Gram Sabha meeting, that is, the official decision-making meeting of the villagers. Thousands of police officers arrested protestors, canvassed households, threatened inhabitants to make them "behave," and forced people who did not sign documents giving up their land to leave. In addition, they allowed fifty outsiders, including the Salwa Judum leader Karma, to be present at the meeting. Under these conditions, only four of the villagers did not sign the documents—-for which they had to pay dearly. "After the Gram Sabha, in a series of midnight arrests, four Dhurli villagers who refused to sign over their land were arrested under Indian Penal Code 151-107 (knowingly joining or continuing in an assembly of five or more persons after it has been commanded to disperse)."

When such breaches of the rule of law are systematically allowed, and activists are unable to use state embedding or other peaceful strategies despite repeated attempts, more people turn to armed struggle. The Dhurli and many other similar cases suggests that the extractivists choose the type of politics they prefer, to which the locals must respond by participating in those politics. The existence of budding armed revolutionary and paramilitary agencies furthers this spiral of violence. This is particularly the case when the option of becoming a guerrilla or paramilitary is omnipresent. This has major impacts on how economic and political outcomes are defined, what types of corporate and resistance agencies are formed, and which political games are usable for them and how. Essentially, electoral politics is rendered unusable for the would-be peaceful resistance in the iron mining civil war areas, as, according to a local journalist, "Naxals demand nonvoting from communities." Institutional politics is rendered mostly unusable due to the simultaneous existence of active armed conflict as a political game, and as a key strategy. Even the Gram Sabhas lose their otherwise substantial power (these are institutional politics, which they could enjoy in a democratic, non-civil-war context) as the state-corporate nexus can use armed violence to enforce compliance. However, "nothing can be done without Gram Sabha in Adivasi areas," as I was told by an Odishan political party leader, geologist, and retired high-level bureaucrat from the Indian Administrative Service of Andhra Pradesh. The Gram Sabhas also influence the arrangement of 
political games in civil war contexts. The highly successful embedding of institutional politics by the creation and control of Gram Sabhas in many tribal areas of India has meant that in those places where the governmentcorporate nexus truly wants to expand, it more or less has to resort to armed conflict as the means to the desired end. This applies especially in the primary resource frontier of Eastern India, which has very crucial resource endowments. In many instances, corporate-government agency first "shuts down" the possibility of using peaceful political games where the resistance is powerful, before continuing by pushing with the full force of violence.

In comparison to other Indian iron mining struggles, Chhattisgarh offers the worst context for peaceful resistance. In comparison to Goa and the rest of Southern and Western India, which are more urbanized and connected to India as a whole, Chhattisgarh is a backwater. According to a lawyer I interviewed, in Chhattisgarh the establishment of the rule of law and democratic civil society has been tried and failed. In 2009, 150,000 people marched 130 kilometers in Chhattisgarh to protest against all of the projects described above, but according to the lawyer, no one reported on this peaceful march, ${ }^{37}$ which demonstrated for him that the democratic voice is not heard in the state. ${ }^{38}$ However, I would not affirm these claims on the futility of nonviolent activism even in civil war contexts, as it is obvious from the above analysis that peaceful resistance has also been present and played a role in Chhattisgarh in many ways. So much so that it is impossible to say whether it could have or could not have affected the outcomes. Even in a civil war, the story of resistance is not exhausted by a recital of the acts of armed revolutionaries. The resistance has found ways to curb and even discontinue extractivism, even in the midst of the dire armed conflict contexts of Eastern India. In fact, the resistance has succeeded exceedingly well in all civil war-context iron ore expansion conflicts. This outcome has been related to a causal condition complex that involves an amalgam of both armed and peaceful resistance strategies.

The rest of this chapter will briefly compare the Chhattisgarh cases with other armed resource conflicts. First, I study the neighboring Jharkhand state's important West Singhbhum area, where there is a similarly strong push to turn the forests inhabited by Adivasis into iron mines. I will end the chapter by making some comparisons to international examples. These comparisons will be helpful in exploring the role of civil war contexts in defining extractivist politics. The Jharkhand case shows how government policies, which supersede the possibilities of peaceful resistance and democracy in order to pursue resource extraction, have ended up paving the road to armed conflict and deepening armed revolutionary agency. 


\section{Jharkhand}

Jharkhand illustrates how a context comes into being where armed resource conflict clearly surpasses other political games in importance. At first in Jharkhand there was a strong attempt at peaceful resistance against extractivism, but government and corporate agency were either unresponsive or violent in their response, which turned the whole political dynamics violent. Until the 2000s iron ore boom, most attention was on peaceful resistance by the forest dwellers. However, as their attempts to embed and coproduce the state along nonextractivist lines were not heard, the resistance had to turn to the use of arms to protect the forests where they were living. This situation provides answers to the complex relationships between peaceful and armed resistance in the same locality.

Beginning in 2006, there was massive local and regional resistance in the form of peaceful rallies against mining MOUs, which blocked expansion. As an example of the networking taking place, a Traditional Leaders Forum was established, which united the Gram Panchayats, Adivasi groups, and NGOs. Networking across the state linked the struggles between captive mining areas and their projected steel plant areas. ${ }^{39}$ In West Singhbhum, the key mining expansion site in Jharkhand, the activists' politicizing and movement organizing work consisted of going around to the villages and trying to convince people to live in accordance with FRA stipulations regarding how traditional forest dwellers should live in a forest. The activists also encouraged villagers to demand official recognition of their area as a self-governable unit. However, none of the state-mediated political games were successfully embedded by the resistance in West Singhbhum. In the late 1990s they formed a political party, Jharkhand Mukti Morcha, which united Adivasis affected by mining in West Singhbhum. They also created a network uniting parties and movements whose aim was to save the forests. However, they did not win political power as the neighboring mining areas' people voted for promining politicians, which led to people becoming disillusioned with electoral politics.

In parallel with this peaceful mobilization, since 2000 there has been a rising Maoist revolutionary agency built in the West Singhbhum area, which also has been resisting extractivism. Since 2010, the political dynamics have been increasingly turning away from peaceful and routine political games, which were found inaccessible, and toward armed resistance, in a dialectic where the state has used militarization to try to push for mining expansion.

The creation of civil war contexts has happened from both directions. As in Chhattisgarh, the informants in Jharkhand also mentioned a series of dif- 
ferent factors explaining why armed resistance became a key political game. Saranda forest dwellers have been turning to Maoism in greater numbers in recent years, according to an NGO informant. According to this informant, the local Adivasis, called the Hos, in comparison to many other rural populations, have never been fully dominated by the state or subjugated to capitalism - this suggests that they have had alternative and autonomous physical, social, and symbolic spaces. Locals in West Singhbhum saw nature as including approximately 200 Adivasi forest villages (and a similar number of nonforest villages), as well as their ancestors and the spirits of the forest. This area also included a large area of huge, ancient sal trees, which comprised a sacred Saranda grove. The local Ho people wanted to protect this sacred grove by any means necessary. Instead of embracing extractivism, the Hos have retained and strengthened their "strong, traditional self-rule system" and their willingness to defend their territory by any means. Thus, according to a local informant, it is not surprising that they welcomed the Maoists around 2000, because the Maoists "provided arms that the Hos were looking for." After this, West Singhbhum "became a Maoist stronghold and since then the Maoists have become more and more powerful in that area." A forest movement leader told me in early 2013:

No mining companies or industries can function there smoothly. That's why the minister says I'll fight the Maoists with development. So now they are constructing huge roads. Infrastructure is going on. Construction of infrastructure is going on. You won't believe the kinds of roads they're building deep inside the forest. Six lane, four lane ... Yeah, nine feet thick concrete roads.... So you can imagine the reason. Obviously not for the Adivasis who usually ride bicycles or have bullock carts.

In 2010 the government and mining capital started placing armed forces in the region. A Jharkhand-based activist told me that by 2013 approximately 16,000 paramilitary forces and a mass of Central Reserve Police (an army-equivalent force that only handles internal security) were already stationed around the West Singhbhum brownfield and greenfield mining project areas. This military apparatus had been operating actively since 2012 as the Anaconda Operation in the Saranda Forest and as the Green Hunt Operation (aimed at the Maoists). This militarization suggests that the area was being transformed into another Bastar-like context (as discussed in chapter 2).

While peaceful resistance had managed to stop expansion in the past, by 
August 2012 it was no longer possible to conduct rallies or demonstrations. "Those days are gone," an activist explained. Now, "people have no alternative than to surrender or oppose mining by joining the Maoists." This activist further explained how mining politics in 2013 took place "between the Maoists on the one side and paramilitary forces on the other." He saw that "the future is very bleak. Lots of bloodshed is going on and it will increase over the years, I think ... Ho societies are passing through a tragic time ... in the near future we will have very little scope to turn the tide in the other direction." In contrast, some activists who were also knowledgeable, for example, about the Shah Commission (unlike the above activist), saw that there were still possibilities for peaceful resistance, and provided a less grim or uniform picture of the situation and the potential future. According to a local forest movement coordinator (interview, March 2013):

Proposals, new mines, and new industrial proposals in Saranda are for the time being stopped. And the most interesting thing is that the minister of rural development of the central government of India, Mr. Jairam Ramesh, who has been frequenting this West Singhbhum region of Saranda forest, has requested the government of India to stop all mining leases for the time being in that area. So he is a powerful minister and we hope that his request will be heard by the highlevel decision-making body in the government and for some time at least in future there'll not be much mining activities in the area.

The activist said that Jharkhand had its "democratic moment," with a democratic grassroots movement in 1975-2000, a period he saw as "very important to sort out issues. That is a period when the crisis should have been addressed by the state. The moment the state fails to do that and takes a strong position to ignore it then that phase is lost. And another phase of struggle begins. A more militant movement." This activist said that they had observed how since the 1970s the context had changed through three phases, "peaceful agitation, militancy, and then armed struggle." For him, it was the government that had made the errors:

If you fail to address the issue in the first phase, when people are peacefully agitating, [then you should] still try to look at the issue more closely in the second phase because you're on the road to a more bloody conflict. So before you enter into the bloody conflict you should address the issue and resolve the issue. In both phases the government did nothing. So now it will have to face the trouble. ... 
[the government in 2013 has] the least interest in the future, peace, and good governance in Jharkhand.

Consequently, this activist, whose movement had for years tried to intervene at critical moments, by visiting ministers and urging them, to no avail, to take the issues seriously, framed the post-2000 mining politics in West Singhbhum as follows:

When a democratic movement fails then there are two options left for the people. One is to accept the misery of defeat; one is to take up arms. I think the Hos taking up arms is very tragic but it was unavoidable and inevitable. Because armed [mining interests are taking over] the entire habitat of the Ho people. They're sitting on iron ore.

I asked this activist whether the people could have chosen to use just peaceful resistance, to which he replied that mining politics is not a one-sided game and is not explicable by resistance strength alone:

When there is a democratic movement, peaceful agitation, and people raising genuine concerns, then the government will have also to respond to it positively. ... Unfortunately, when the region was raising its issues democratically, the government did not pay any attention to it.

The case of Jharkhand illustrates how agencies-resistance, corporate, and government-are in a dialectical relationship, creating a specific arrangement of political games through which both extractive expansion and its resistance are pursued. These dynamics are interscalar, local, and substate events that influence national-level events. These dynamics can even influence those at the national and international level—such as resistance efforts elsewhere-which in turn influences the local contexts. Later, the Shah Commission shut down most of the existing iron ore mines in Jharkhand due to their irregularities (not paying royalties, mining without licenses and outside lease areas, and so on), but the move mostly did not affect the politics of the greenfield mining projects discussed above. ${ }^{40}$

I will conclude this chapter and part II with a short comparison of the different armed conflicts. This discussion will help to assess how different armed conflict contexts influence the possibilities of resisting extractivism. 


\section{Comparison of the East Indian Experience with Other Armed Conflicts}

Not all armed conflicts are similar. Rather, they are dictated by the types of revolutionary/secessionary and government-corporate agencies and strategies creating the political dynamics, as figure 1 in chapter 3 suggests. I compared six Eastern Indian iron ore investment cases in this chapter: West Singhbhum, Dantewada, Rowghat, Manpur, Dalli Rajhara, and Kawardha. This affords a broader and systematic comparison that draws conclusions on the key causalities. The first four of these cases all showed a trajectory where a violent expansion of extractivism, by state-corporate agency, led to a spiraling of civil war. This created a context that Maoist guerrillas found easy to take advantage of after peaceful means of contention were rendered largely obsolete, or dangerous to use. ${ }^{41}$ However, even in these armed conflicts, there were peaceful resistance strategies employed alongside armed strategies. Movement building and protesting were used in all the five cases (the Kawardha project still existed only on paper, so no resistance was forming against it, with locals not even being aware of it). None of these cases used private politics (by this I mean that they did not participate in private dialogues with corporations in which an agreement was reached), which can be explained by the presence of Maoist revolutionaries, who particularly resist private capital, as well as public corporations, that seek to destroy the forests and hill areas on which the revolutionaries depend on geographically to continue their guerrilla warfare. Campaigning by nonmodernist framing and networking were also used in three of the cases. Therefore, peaceful resistance agency was also surely formed and operational in all these contexts and cases, for which reason the investment outcomes cannot be attributed solely to armed resistance, but the efforts are pooled.

However, electoral politics were rendered unusable in all these armed conflicts, and institutional and judicial politics were hardly used. If they were used, as in the case of Dantewada, the judicial decisions coming from the federal level were not followed by the Chhattisgarh and regional authorities. This suggests that even localized armed conflicts can render nationallevel state embedding by peaceful resistance ineffective, as the outcomes of this federal embedding are applied weakly or not at all in the armed conflict areas. Nevertheless, in most cases when this happened, Maoists stepped in and stopped the projects by force. In all, the barring of extractivist expansion by this conjunction of armed and peaceful resistance was impressive in Chhattisgarh and Jharkhand. The greenfield projects could not be opened despite huge army and paramilitary operations. Even some existing mines were closed, and their extraction styles, logistical operations, and expansion 
plans were modified by this resistance. Yet, when comparing these economic outcomes with Western and Southern India, where all iron ore mines were closed and plans were scrapped, it becomes clear that resistance in peaceful, democratizing contexts, or merely peaceful resistance, if using the right set of strategies (which I will study in the next part), can attain even more impressive results. The political outcome of deepening democracy instead of a civil war is even more impressive in this comparison.

Besides armed revolutionary agency, which tries to capture the state (rather than embed it), there is also armed secessionary agency, and there are instances where both of these agencies have become intermeshed, in different ways, with mining conflicts. Armed revolutionary/secessionary resistance does not typically resist mining per se, but rather uses the possibility of resistance instrumentally. Sometimes these goals become intermeshed, as in the case of Eastern India. Perhaps the best-known case of armed mining resistance globally is that of Bougainville in Papua New Guinea (Evans, Goodman, and Lansbury 2002). This conflict dragged on for decades, and the resistance used all means possible, finally taking up arms against the neocolonial mine as resistance intermeshed with Bougainville's secessionary agency, which sought self-determination from Australia and Papua New Guinea via a war of independence. In response, the government of Papua New Guinea sent in the army to try to keep the mine open, which created a context of lengthy civil war (Benson and Kirsch 2010). Ultimately, the resistance won, as the mine was not reopened (Kirsch 2013).

Not all armed resource conflicts mean that the locals resist extractivism, not even always those closely tied to land and resource control in the form of independence struggles. The Papua New Guinea case differs from Northeast India, where the armed struggle for self-determination has used most mining operations as a tax levy base for arming guerrilla forces, rather than tying mining resistance and the independence struggle together (uranium mining project resistance being a slight exception to this) (Karlsson 2011). When comparing the armed secessionary groups of "mainland India's" mining regions to those in the Northeast, several differences are apparent. In his discussion of the Northeast context of resource extraction (including mining), Karlsson (2011) notes that the indigenous hill societies are becoming unequal class societies. The armed resistance in the Northeast is not Maoist or Adivasi-ideology based; rather, it is the result of a prolonged quest for autonomy or independence from India in nationalist terms. In Eastern India, based on the accounts of Sundar $(2006,2008)$ and many others (e.g., many writers in Paul 2013), a leftist ideology of struggle against class injustices (including attempts to root out traditional tribal power hierarchies) has 
merged with the traditional Adivasi notions of ecology, and resulted in a type of "green war" over the essential basis of life, such as water, cultivable land, and forests (Karlsson 2011). Yet news media, such as the New York Times, have reported that the Northeast indigenous populations, armed or not, are making (use of) the resource rush to finance their struggle for autonomy, whether regional or family-based. ${ }^{42}$ This portrays a mining setting that is in extremely stark contrast to the politics of metal mining in "mainland India," whose expansion is fiercely resisted in almost all cases.

Can armed resistance, revolutionary or secessionary, provide for a postextractivist setting based on democratic decision-making on what constitutes lived environments? This is highly doubtful, given the violence inherent in armed resistance, which often also levies taxes on miners to buy arms; the key goals are also different. Currently the mining conflict in the Northeast is subsumed under the broad struggle for self-determination. From the viewpoint of political games, almost all attention is paid to the field of armed secession, which subsumes all others, meaning that other strategies are scarcely used. Indeed, true sovereignty in these predominantly indigenous lands cannot be attained by this path. Karlsson (2011, 276) notes, "Women's rights and respect for nature are thus central facets in the process of achieving indigenous sovereignty. This is not something that can be adopted at a later stage." Once agency of a specific kind is created, it becomes hard to turn away from the path set into motion. As social beings, the agency and socialized subjectivity of humans is created in and tied to particular social fields (Bourdieu 1991). When the field of choice is armed conflict, this will also be the political outcome in terms of the political agency that is created. For this reason, it is important to compare not only the economic outcomes but also the political outcomes of investment politics.

In this part of the book, I have discussed the major cleavages in the political dynamics, contextual conditions, and types of resistance agencies available to prospective mining activists in differing regions. I have sought to convey how political dynamics do and do not influence the forged agency, available strategies, conflicts, and investment outcomes. In the absence of civil war, the resistance could make a very efficient use of, for example, judicial and institutional politics in the context of consolidating democracy, and to consolidate democracy (as in Western India). The reliance on mass protesting in contentious politics can be used to directly influence the flow of iron ore and to forge transnational working class coalitions (as in the global commodity frontier of Carajás). This resistance could also challenge extractivism, even in very old and promining contexts, through an encompassing embedding that includes the state, government, NGOs, trade unions, envi- 
ronmentalists, urban middle classes, mining professionals, and other resistance groups - as in the (peri-)urban mining cases in Minas Gerais.

The analysis showed how figures 1 and 2 from chapter 2 can be utilized as helpful analytical tools to study the key arenas of investment politics. I also showed how an analysis of causalities between and within social, symbolic, and physical spaces, as theorized in figure 3 (also from chapter 2), can be used to explain how extractivism and its resistance transform power relations through different spaces. Finally, I analyzed the relation of several important contingency factors on the outcomes, such as the role of middle classes and the proximity of the urban centers to the proposed mines.

The comparison of armed and nonarmed investment contexts offers troubling insights into why extractivism became linked with armed conflicts and violence as the commodity boom of 2005-14 advanced. In several places, "resource-war-type" mineral extraction has proven at least instrumental, and possibly essential, to maintaining the flow of cheap minerals in spite of local land rights. ${ }^{43}$ In Chhattisgarh, according to a local activist-scholar, "It suits the government to militarize the area; a peaceful solution would signify giving all the lands to scheduled tribes, as these belong to them by law. Now it is also possible to mine there using the argument of war against terrorism."

There are extractivist ideologies and policies that appear to perpetuate rather than extinguish the fires of civil war in Eastern India. ${ }^{44}$ The foreseen changes in the physical space are important partial explanations of the continued armed conflict. After a mining boom closes the forest frontier there will be far fewer geographical possibilities for waging guerrilla war, even if the push toward armed revolutionary agency would be much stronger and the absence of other political opportunities would force people to pursue it. The current extractivist thrust of large open-pit mining — meaning the expansion of infrastructure, felling of forests, and depletion of water and arable landdiffers radically from the geography of past conflict contexts, causing a more desperate, back against the wall situation for the guerrillas.

This suggests that if the main goal were to end a civil war, one component would be to put a hold on rampant and violent mining expansion, which both generates and boosts armed conflict. First, the areas of armed conflicts should be pacified and the rule of law guaranteed, so that routine politics and peaceful contention do not lose efficacy due to the presence of armed forces. Yet the reality is that extractivism is waged in and by armed conflicts in many parts of the globe. I hope that this chapter has opened up these often-forgotten or unknown dynamics behind global extractivism. I also hope that the reader has seen how, despite very violent resource crunches, there are always some possibilities and strategies to resist, and that 
these can lead, more than just sometimes, to the desired outcome of retaining the lived environments that are home to many.

Having surveyed a large array of contextual factors, including armed conflicts and other situations, and their role in investment politics within the resistance to extractivism, I will next move to a detailed study of how exactly the five peaceful resistance strategies have resulted in notable political and economic outcomes. 


\section{Peaceful Resistance Strategies}

We have now come to understand how the broad differences in contextual factors can influence the type of resistance that is formed against global extractivism, and how the type of resistance strategies implemented can create contextual changes. I will now further examine the hypothesis by studying the role of differing strategy sets. This will highlight the strategies that are the building blocks used in boosting activism and those that are not. This last section of the book looks at mining politics from the bottom up, the grassroots point of view, but with an understanding of the interplay between strategies and political dynamics.

When resistance groups or fronts choose or embark on a strategy path, the new recruits and activists tend to conduct their actions within the lines specified by those strategies. The group's actions are strongly shaped by the avenues of activism that the chosen strategies recommend, and these actions are adopted by the larger social group. Thus, strategies are a key object of study to be able to understand the causal outcomes of resistance efforts over time, including how the resistance influences the political dynamics and opportunities of future activists and of other resistance efforts. For example, when a resistance group is experienced in embedding the state via judicial politics, then the newcomers to the group will gain expertise in this strategy and are more likely to continue working within this strategic avenue. When the only viable option for would-be resistance is armed revolutionary action - whether or not this choice is a result of coercion - then this strategy and style of resistance agency is boosted. I believe that this dynamic view of strategies can open up, in great detail, the causalities at play in politics in general, as this view is formed through the interaction of different political agencies that meet in differing political games.

The sections below detail the specificities of each case to illuminate in 
greater detail how different strategies can influence the economic outcomes of conflicts. Thus, this part of the book discusses the multiple pathways for the resistance to make an impact in mining politics, with the separate sections illustrating how specific combinations of strategies can be used to forge contention and thus influence investment pace and style.

The material is divided into chapters, partially to keep the cases separated, but each chapter also has a central unifying lesson, based on the cases discussed, for understanding how resistance can impact extractivism. First, chapter 5 analyzes the impacts of protesting by mass social movements through two important variations in the selection of key strategies by two large and important resistance movements (one in Kudremukh and two in Tamil Nadu). Next, chapter 6 focuses on the states of Odisha and Goa, which both saw the use of a broad set of strategies of resistance and can thus be used to compare the impacts of this broad quality of resistance in the different contexts of Western and Eastern India. Finally, chapter 7 analyzes the role of global and national resistance coalitions in the politics of extractivism in Brazil and India. After discussing all the cases, the conclusion will serve as a reflection on all the themes raised in this book. 


\section{Protesting by Mass Social Movements}

We left the coastal city of Udub at 5 a.m. to drive through the lush hills of the Western Ghats rainforests, up to the former mining town of Kudremukh, for a scheduled early morning meeting. It was a beautiful dawn, and the air was fresh with mist and gentle rays of sun. There was ample time for me and my partner Jenni, who joined me on several field visits, to wander around the town, getting to know the unique feeling of a town whose main purpose for being built has disappeared. I was curious to learn about the events that had led to this current situation. The place had a very special, even magical feeling to it with all the infrastructure and none of the hustle. After spending the day talking to former mining workers and activists, I mused about what the postextractivism future would look like. Would the rural areas of formerly extractivist states be dotted with these partial ghost towns as movements had success shutting down polluting facilities? With this thought in my mind, we left for a long drive along the tiny winding and bumpy roads of Karnataka's countryside, across the coffee growing regions to the southern and eastern parts of the state, and, finally, to Bangalore. On the way, we talked to the state's most seasoned activists, visiting their homes. Although the trips were tiresome, they were truly worth it, and the welcome at new places by the locals was overwhelmingly friendly. People gave their time to talk to me very late into the night, and even cooked breakfast early in the morning, consisting of so many different types of and flavors of rotis, chapatis, and naan breads that we had not even known existed. From Bangalore we continued to Tamil Nadu, where we traveled around the proposed mining areas. While visiting peoples' houses, we heard the constant chirping of textile machines and saw the steeply rising hill of Salem next to the houses where we talked with the locals, who had stopped the plans to mine away the hill next door. Several times the local villagers spontaneously expressed words of joy and how happy they were now that they had been able to stop 
the projects that would have ended their current ways of life and livelihoods, and would have changed the place to one without a hill, fresh air, and home industries such as textile-making and agriculture. This was still a thriving place and not a partial ghost town because they had managed to stop the mining before it had started. Thus, to preserve the physical, social, and symbolic aspects of place is not just about shutting mines but about stopping projects before these changes are made-as the towns are not the same after mining takes root.

This chapter discusses three cases where resistance strength came primarily from forging a new mass social movement and organizing large-scale protests. These cases clearly illustrate the importance that organizing a mass social movement and protesting had for resisting extractivism in this context. I will first look at Kudremukh in Karnataka, India, which was the first iron ore conflict in my database and shows how networking across traditionally hostile movements can yield remarkable outcomes. I will then analyze the Tamil Nadu cases of Salem and Tiruvannamalai, also in India, showing how resistance by a mass social movement can succeed even by using a very limited set of peaceful strategies, by focusing on mass protesting.

\section{Organizing and Unifying Rural and Environmental Movements: Kudremukh}

I will start the discussion of resistance cases with the first struggle that took place that resulted in the closure of an existing mine. Kudremukh Iron Ore Company Limited, the state-company owned mine in Kudremukh, Western Ghats, was the first mine to be shut down by resistance efforts in India or Brazil. The mine shut down in 2005, but even when I visited in early 2013 , the remnants of a public company town were still highly visible. Rows of neat company houses were provided for worker families, and indeed in 2013 these looked like accommodation way above the standard for workers in India. However, the mine had been closed for twelve years and there was none of the noise or dust that would have dominated the senses when the mine was still open. What was left was only a lush, pristine-looking rainforest, which surrounded the former mine in all directions and formed a national park-it was now a spectacular place. The forests that now surrounded the slopes downhill from the mine had many animals, tree species, and a "very good ecology" (referring to the very rich biodiversity, which was of major importance in offering many bases of livelihood and life to a vast 
array of peoples and life forms). This evaluation of the state of the area was given to me by the mine-displaced Adivasis with whom I talked. Some of these informants had also worked for two decades in the mine as engineers and were able to relate both sides of the story of the place.

When the mine and the accompanying factory were installed, according to my informants, a lot of pollution followed. Three rivers were poisoned by pollution from the factory wastewater, fish started dying, and harvest yields dropped from two annual crops to not even one. Similar damage to agricultural fields was also present in Goa. In Kudremukh, factory pollution aggravated all these problems downriver. Mobilization started in 1994 to prevent the renewal of a lease expiring in 1999. The affected public in the lowlands made a complaint first to a the Karnataka High Court, and then in 2002 to the Supreme Court, which decided to order a shutdown of the complex in 2005 (Sridhar 2010). Thus, using judicial politics was a key proximate cause for the outcome, while electoral or institutional politics were not used. The deeper causes lay in building a massive social movement that bridged old barriers by development of exemplary networking across movements. Currently, it is legally impossible to reopen the mine, although in practice this could be done as all the facilities are there. Even many of the workers still remain in the area after about a decade of closure, and many of them would like to see the mine reopened because it provided a monetary livelihood. The specificity of this struggle was that almost all the major social movements of Karnataka joined the fight from 1996 onward. This has not happened in the state on any other occasion; rather, rivalry and hostility between movements has been common.

An Adivasi who worked as a mechanical engineer in the mine said he felt good when he heard about the Supreme Court decision, although it meant losing his job. He wanted to see the pollution stop, and although he was employed by the mine, it had not been providing work to local Adivasis or people from Karnataka in general. He estimated that about 90 percent of the workers were outsiders. Thus, he, along with the 10 percent of the workforce who were locals, backed the activists even though they were working for the company. This is a telling example of how there can be resistance to extractivism even from those who are physically doing the extraction. The people involved directly in the extraction quite often also include indigenous people who are forced into this work by the powers of development.

Another Adivasi leader, who was also the president of one of the districts impacted by the mine, wanted us to move away from the company town center to discuss the ten-year struggle. He shared that this discretion is needed, as unemployed ex-workers continued to live there, and it was 
not the right place to speak critically about the company. This suggested that the whole town continued to be company controlled even though the mine itself was long closed. This control extended beyond the simple physical space and even into the symbolic space as critical discussions about the mining company were not be held within the boundaries of the town. We relocated to an area that was further afield, but still looked down over the shuttered mine. My informant related how the mine had eaten into the main living source of a large and impacted population for decades, constantly expanding and in need of more land. However, it was the contamination of the local water sources that was the tipping point that caused the Adivasis to start agitating against the mine. Their Adivasi group had been ordered to move away from the Western Ghats in the early 1990s when the hills were turned into a national park. They fought back, however, staying in the forests and developing deep hostilities with environmentalists over the creation of the national park.

The Kudremukh struggle united several groups—at least into a loose front and for a while. A senior NGO networker from Kushalnagar in Karnataka related how, for example, the Karnataka Rajya Raitha Sangha was already in a land fight with the Adivasis in 1987 (this organization is now a large farmers' movement and member of the transnational peasant movement La Via Campesina, which had in the early years been largely composed of successful Karnataka farmers). He argued that the substantial and united protests since 1997 were crucial in influencing the court decision on Kudremukh, as "when protest takes place, it is easier for the court to make a decision," and for the government to obey that decision. As the mine was state-owned, the lease was long and the price was low, which meant that the owner was not willing to relinquish this asset lightly. The mine was also the sole target of action, meaning that the state could not be used as a partner or third party helping the activists; electoral or institutional embedding was out of the question. Considerable mobilization was therefore essential.

One of the key organizations in this struggle was the Environment Support Group from Bangalore. Their NGO activists had long-term experience in taking problematic projects to court and shutting down polluting plants. In 1996 they had been the intermediator in filing a suit against a steel mill in Mangalore, which was using Kudremukh ore. The suit was successful, and the Supreme Court ordered the mill to be shut down in 1997. The Environment Support Group had also fought against paper mills and dams on the west coast of India. Leo Saldanha related to me how Kudremukh was 
a special case, to which they devoted more attention: "we brought different people together-[we saw that] if the resistance split, this will become a people versus wildlife struggle." The Environment Support Group knew that the thirty-year mine lease was ending soon, and that Japanese interests wanted to buy the public company. If there was ever an appropriate time to act, this was the moment. ${ }^{1}$ Although officially the mine was closed by a court order, and the victory came by having the capacity to target judicial politics, Saldanha asserted that "we came very close to stopping the mine politically by local mobilization."

The outcome of the court case was preferential to the wildlife groups. This is because these groups had drafted the litigation slanted in their favor, which created a problem with the broader antimine front. They wished to close the mine and simultaneously create a national park in the Western Ghats. However, the Adivasis wanted to continue to live in the forest and were not in favor of creating a park-they continue to live there even now. Although the conflict is not active, it has not waned. The Adivasis I interviewed hinted that one key reason for the resolution of the conflict could have been the calculation by powerholders that if the mine were not stopped, the locals could quite easily become Naxalites. In fact, in secret negotiations, they apparently had also hinted at this possibility to the powerholders. Saldanha similarly argued that the area around the mine would have become a "hotbed of Naxalites, worker oppression and homelessness" had the operations continued.

The Kudremukh case shows how building a large resistance front that includes different types of organizations (NGOs, environmentalists of different sorts, Adivasis, farmers, mining workers, engineers, and others), uses all of the five key strategies to mobilize, and even hints that the resistance could turn to the use of arms if their voice is not heeded can lead to the complete shutdown of extraction. However, the political outcomes were not as impressive as in some of the other cases, as only locally enduring resistance capacities were created. This was possibly because the conflict came to an end via judicial politics, instead of waiting for the other strategies to produce results. This suggests that the selection of resistance strategies influences both economic and political outcomes in particular causal ways. The Tamil Nadu cases, discussed next, help to study in more detail the impact of social movement creation and protesting as a deliberate and isolated strategy pair. Thus, these next cases will focus on the tandem use of those two strategies. This is an example of a situation where resistance can be successful even if all five strategies are not used simultaneously. 


\section{Mass Protesting without Negotiation or State Embedding: Tamil Nadu}

After the 2005 Kudremukh closure, the next interruptions to iron mining projects in India were experienced in Tamil Nadu in the late 2000s. There are not many iron ore or manganese deposits in Tamil Nadu, but in the boom years of the late 2000s the national and state elite, consisting of leading politicians, their families, and businessmen, tried to grab two of the most promising iron ore deposits. These project areas were situated in Salem, which was the site of the first attempted mine, and Tiruvannamalai in the northern part of the state, where the second project attempt occurred. Both projects were interrupted by direct resistance action before mining was even started. Nonetheless, there was still a push in August 2015 to begin these projects by the Jindal Steel \& Power company and its associates in government. However, the prospects of realizing these projects are quite limited as illustrated by the following analysis of resistance strengths and strategies.

Across all the investments cases studied in this book, these were the clearest examples of the importance of quick organizing and politicizing a mass social movement, in addition to protesting against a sudden extractivist push. Mass protests early on, before the commencement of construction, were enough to warrant project closures even before there was a need to start embedding electoral, institutional, or judicial politics. Instead, the protesters could rely on a strategy of politicizing and organizing the potentially impacted populations around the hills that were to be mined. These efforts were then followed by either arranging a large targeted protest in the local government offices (Salem) or campaigning on nonmodernist lines (by expressing that the mountain in question was among the holiest places in India and lay beyond any monetary valuations) and protesting (in the case of Tiruvannamalai). Some national networking took place in Tiruvannamalai, where mining targeted an important holy mountain that had many temples. Salem also has an important hill with ayurvedic herbal medicinal plants and a temple dedicated to their use. Mining this hill would affect many people and industries, as well as the spiritual heritage of the area.

The Tamil Nadu cases are comparatively important as they show that there are multiple pathways to resistance success, which do not necessarily have to rely on the simultaneous use of all the five key strategies; rather, the resistance can be selective about which ones to deploy. Protesting and avoiding private negotiations with companies were the necessary, but not always solely sufficient, strategies to create conditions that supported success for movements across all major iron mining cases in Brazil and India. The Tamil Nadu examples can illustrate how these two strategic choices of 
action/inaction around protesting and private negotiation in some contexts can take the protagonists a long way in the battle, and the ways in which they are necessary.

Tamil Nadu has a long history of mobilization, with perhaps the largest current environmental conflict in India. The construction of a nuclear plant at the southern tip of the state was resisted by approximately 100,000 coastal people living in fishing villages. Although the nuclear plant protests were not directly linked to northeastern Tamil Nadu's iron mining conflicts, which were small in comparison, the latter are symptomatic of the general dynamics of mobilization that situate Tamil Nadu more closely with Western India's building of an "organic society," rather than Eastern India's civil war. There was a smaller proportion of Adivasis present in the Western and Southern Indian resistance groups (almost none in Tamil Nadu), as were the number of Naxalite threats. Tamil Nadu had also made some of the most impressive moves in the direction of abolishing caste-discrimination-based politics by introducing considerable allocations for non-upper-caste communities, as a result of which numerous upper-caste people had left the state (Banerjee 2013). Thus, there were better possibilities to gain power despite one's caste, as the opportunities presented were based more on competence than ethnic ties. As a consequence, Kohli (2012) argued that state institutions are more progressive and superior in administrative quality in comparison to the Hindi heartland, which is still more dominated by Brahmins. This also meant there are better overall educational standards. In this context, bringing to light misuses of state institutions and the rule of law mattered more than in the armed-conflict context of Chhattisgarh, where state-level institutional politics do not carry much weight. These contextual considerations help to explain why fewer strategies were needed in this context.

The project-specific contingency in these cases was that the proposed mines were, according to many participants that I spoke with, including Piyush Manush, "absolutely illegal," which made mobilizing against them "easy." Briefly explained, Manush and his companions formed a large movement of thousands of local people under the banner of "Speak out, Salem," joined by other movements, which marched into government offices and demanded to see the mining project documents based on the Right to Information Act. This 2006 act, according to a national activist, is a "very powerful tool in India to stop illegalities." By 2008 the resistance in Tamil Nadu had already used this tool in other cases, for example, closing down an aluminum plant and several non-iron-mine projects or mines whose operation would have been illegal. That said, the act may not be as useful in cases where legal mines are targeted to be stopped. 
Manush recounted his view of the mobilization as follows:

In 2009, we got to know of iron ore mining applications in two places, in Tiruvannamalai (about 300 hectares) and another larger area close to Salem, in the Ganjamale hill. It was too late when I knew about the projects. [I got to know about the cases as] CEC [Central Empowered Committee, a Supreme Court-appointed body to handle environment-related issues especially in the mining sector] arrived in Salem, and a local reporter called me. Then, in early 2009, we had four months of action. We started mobilizing people, as the threat to people's life was very clear. We had three actions. We rallied the Forest Department by a protest of $550-1,000$ people and filed there our Right to Information Act demands. Then we raided the mine office with 150 people, the Direction of Mines [a state office]. Last, we also raided the collectorate [administration] of the Salem district with 2,000 people [with similar demands for information]. These were the most important offices processing the files. We said we would not leave the offices without the documents.

After these raids, the activists got the data they demanded, and discovered several important facts, which, when made public, meant that the project in Salem could not proceed. For example, they found out that the state's chief minister was a part owner of the proposed mine, through his VKG Steel and Energy company. The clearance for the mine was given on June 13, 2008, which was the same date the project was proposed. It was clear that it was illegal as it is not possible to propose and give clearance to a mine in less than twenty-four hours. I asked Manush to explain to me why the people's knowledge of these illegalities was so important:

Nothing works like people's power . . humor scares the state, but shame scares them most. Corporations are not scared of shaming, but violence. We never use violence against the state, but against corporations [we use] limited [violence], scaring them [about possible economic losses].... All that you need to do [to organize a social movement] is to provide information to people: they will mobilize themselves. The community is empowering itself, [this is] not politicization. If people are limited in knowledge, mobilization is easy when information is spread [through] sharing by locals and village meetings. 
However, my field visits and further conversation with Manush also suggested that mobilization might not be an automatic response to information, as he detailed how some villages had taken more responsibility for "convening blocks, whose members had the role to organize people, manage funds, and call for meetings."

The movement did not have media support. Manush pointed out that the mere possibility of the data going public was enough for the project to be scrapped by the chief minister and other top powerholders who would have lost their reputation. The movement was cross-class and cross-caste, and included farmers, textile mill owners, and their laborers. Many of the movement leaders consisted of middle-class entrepreneurs, whose highquality garment industry next to the hill would be destroyed by the "red haze," which was the name for the dust coming from the open-pit iron ore mines. This dust would also destroy the extremely productive and intensive agricultural and dairy industries of the area. I visited these areas - they were a very rich mosaic of rural-urban, high-value, small-scale, agriculture-based industries, which were highly valuable economically, but located right next to the hillside. The resistance front had the support of the middle class and even had middle-class professionals participating in the movement, and there was a strong third party that opposed mines, which took the form of powerful nonmining textile and agriculture industries. Only the rich did not get involved, for "money rules the rich, not the public good," explained Manush. In general, "people shed [their] differences and came together in this kind of movement." Now, as the mine has been closed, Manush told me how "not allowing them to take the hill gives me great satisfaction ... we saved the area around a $40 \mathrm{~km}$ perimeter around the hill. . . . I feel the hill talks to me: 'thank you, thank you.' I am so happy, [I] have understood the value of what I have, this clean air."

The mine project was pushed by a strong corporate agency, as the companies involved were large, and as closely tied to the state apparatus as the mining mafia in Karnataka. I spoke to another activist in Salem, who was also an important state-level political party member, and he told me that "the state government forest minister had come to Salem six times to push the project." Although political parties supported the project, the members of these parties living in Salem said that they would lose votes in the area if they pushed the protesters who comprised a genuine mass social movement.

The activist-politician quoted above was also from the hillside and a leading member of a party that openly supported the project. Still, he joined the social movement, and carried out activism on its behalf, explaining that it 
was a "tough task going around villages and convincing people." He organized different blocks (a subdivision of a district) that held meetings at multiple levels. The response of his political party was "first to resist and protest his political organizing at the local level," as it went against the party policy, but later the party "gave independence to organize locally, although we were in government." He was the elected counselor of the area, which consisted of fifteen wards and about 1,000 people. I have observed that the involvement of activists who also have secondary positions in political parties or as state bureaucrats is in general a positive factor in the movements' achieving their goals both in Brazil and India. However, this is not a necessary factor, as the Salem case demonstrates. The politician-activist I interviewed was the sole member of his party not in favor of the project, which meant that in this case the Gram Sabha could not be used to discontinue the project. The politician felt that, as the others had their "hands tied," "people power was the only, best way" because after the struggle, now, people locally "feel much more confident about themselves."

This type of organizing resembles the style of the MST in Brazil. The Salem politician-activist remarked that "this organization can be revived anytime. Now if there is any trouble against livelihood, people will surely stand about it." It is a notion that is possibly even more important when applied in the context of Indian culture, where long-term personal and communal relations are extremely important and durable and can be used for mobilization. This means that alliances that have already been created can easily be relied upon in the future, as these successfully draw from longestablished cultural frames and the replication of prior models of resistance.

The cultural context of compounding mobilization resources in the long term is an asset in India, but it can also mean that forging new movements may be a tougher job than elsewhere. Forging new movements in areas that have not previously had the experience of failed or destructive mining projects, or both, is not easy. The Tamil Nadu politician explained how convincing people in Salem was "a little tough . . . as people do not know about mining. The notion of someone coming and uprooting forests is not there." In Salem, it was very helpful that there were activists with experience in other parts of India who could display photos of exactly what the impacts would be, in visual and scientific terms, if a large open-pit mine were to be constructed in the region. These were visceral and relatable illustrations of what it would mean for the people. The pictures of industrial towns with heavy pollution and destroyed environments were convincing and thus countered the efforts of the project marketers to sell the project as "development." The key messages to counter the development claim were that this 
would be a bad project for securing (1) livelihood; (2) health; and (3) water security. The overarching message was that the project would have a negative impact on prosperity. At first, "a few people were in favor of the project, out of ignorance: they were cheated." However, after movement-building, no locals were in favor of the project, and "people threatened the government that they would return their ration cards and nationality if the project runs. Another threat was to go to the company gates. A person doing wrong feels he may be exposed [in such situations]," explained an activist.

After the attempt to mine the Salem sacred hill was swiftly rejected because of mass social movement protesting in 2009, the activists from Salem turned to Tiruvannamalai to support the mobilizations, partly generated by Dalit and feminist organizations, against a similar iron ore project there. Directed participation in public hearings was important there, alongside the use of similar tactics as in Salem. In both cases organizing and politicizing a local (and in Tiruvannamalai, also national) social movement, small-scale campaigning, and protesting were enough to lead to project closures. No use of state embedding or networking with other movements was needed in Salem, and in Tiruvannamalai the use of networking was also quite limited. Yet the latter was different as they had the support of the recently successful activists from Salem to help in the activism activities and did not have to rely on solely local mobilization. Furthermore, the hill in Tiruvannamalai was easier to mobilize people over than the Salem hill, as it was among the top ten holy hills of Hinduism and other religions of India, a sacred site of pilgrimage with many visitors annually. As of 2015, there were still discussions about Jindal opening both these Tamil Nadu mines, backed by the authorities, but the willingness and capability to reactivate powerful resistance makes it very unlikely that the mines will ever be opened. In the words of one activist from Tiruvannamalai, S. Sankaran, a resident of the temple town, "lakhs [hundreds of thousands] of people are prepared to die."

That the mining capitalists targeted even these relatively iron-poor hills illustrates the race for minerals and quick wealth that was rampant in the late 2000s. This fervor was partially caused by the disparity of a radical increase in global iron prices coupled with the extremely low production costs for iron ore and the possibilities for corruption and land grabs in India. It was no coincidence that the Jindal company was the prime actor here. Many of my informants in Jharkhand and Odisha explained that this private company had been behind the bulk of the illegal mining schemes there, yet it had managed to escape most of the public scrutiny by buying the ore for under the normal price from small miners, who bore the brunt of the blame. Meanwhile, the Tamil Nadu and other cases portray how global price 
increases or corporate embedding/capturing of state-remediated political games - which favor mining by skewing access to state and business power toward promining elites-do not explain investment outcomes. Ironically, by liberalizing capital these moves have helped to consolidate, create, and make visible a similar "organic society," as discussed in the cases of Goa and Karnataka in chapter 3, that defends livelihoods and sustainable lived environments.

The Tamil Nadu cases offer two crucial insights: first, even implementation of very few resistance strategies can yield major outcomes; and second, this causal chain was operational in a context and contingency setting that was in many ways more favorable for mobilization in comparison to similar (iron ore) conflicts elsewhere. Both the strategies and the political dynamics matter, and when investment outcomes are primarily defined by the resistance strategies of protesting by a mass social movement, the political dynamics molded and created during the mobilization and the conflict are prone to provide more longer lasting benefits for resisting extractivism. Next, a detailed study of the resistance strategies implemented in Odisha allows us to contrast the Kudremukh and Tamil Nadu cases-which were both in the more democratic and peaceful Western and Southern regions of India - with a context where the threat of violence and an armed conflict is omnipresent. 


\title{
Using a Broad Set of Strategies
}

\begin{abstract}
Having explored India's West and South, I left to study the rest of India's iron ore mining regions. Thus, I traveled to Odisha, while my partner visited Amma's ashram in Kerala. Besides its hundreds of ancient gray, stone temples, full of noises from rituals, devotees, and priests without shirts, the holy city of Bhubaneshwar, the capital of Odisha, had a very lively intellectual and activist crowd. I spent much time in their meetings and events where I learned about the long history and strong current presence of struggles. People were trying to protect their lived environments across the state, and were largely succeeding in this, despite the very strong and coercive attempts to impose steel mills and mines on top of their villages, forests, waterfalls, and farmlands. It was intellectually and emotionally rewarding to hear about all the successful stories of resistance directly from these people. I spent time talking with the activists in steel towns and on the roads while traveling toward now-saved waterfalls, on top of viewing platforms in the middle of saved forests, and at ancient princely palaces, like the palace ruins of Keonjhar where it felt like I had been transported back hundreds of years to the India of ancient stories. This feeling was augmented by the moonlight that shone brightly on the top of the old walls surrounding the palace garden, which was lush and full of trees. This time left a strong impression and feeling about the necessity to put oneself in the line of fire to save what good is still left. I was humbled as I learned the stories of how people had sacrificed themselves bodily and mentally for the sake of so many others. There was a lot to learn about these heroic acts and also the everyday resistance actions being practiced by people fighting for the survival of their communities and future generations.
\end{abstract}

This chapter discusses several cases in Odisha and Goa, where the resistance used all the five key strategies simultaneously. I will contrast the successful outcomes in these cases to cases where the resistance did not use all five 
key strategies in concert. In this chapter, I will also explain how the use of all five strategies in Odisha and Goa was key in helping to ensure that the resistance was successful and did not succumb to a cycle of violence. The Goan resistance is also studied in more detail here, which opens up the role of particular key resistance actors. This Goan example provides the backdrop for a discussion that provides concrete viewpoints on how an impactful resistance can be created in practice. This section thus tests the hypothesis on the importance of using all the five key strategies simultaneously.

I will start with a detailed study of the resistance movements in Odisha, India. In this study, I compare different districts and subdistrict areas, which portray both local resistance and mining support cases. Odisha hosts many important cases that help to generate an in-depth understanding of contemporary extractivism and the way it is or is not successfully resisted. The uniting theme of the many successful Odishan conflict cases is activists managing to avoid the path of taking up arms, instead using a linked set of peaceful strategies (the five key strategies), to counter extractivism. It is interesting to note that this resistance is enacted in a quite similar political economic context as that of the neighboring Jharkhand and Chhattisgarh, which did succumb to at least partial violence by a significant part of the resistance efforts. After the study of Odisha, I will examine how the use of the five key strategies worked in the crucial case of Goa. I will highlight the interesting dynamics, specifically, how innovative campaigning based on nonmodernist framing, organizing, and politicizing several separate resistance movements based on ethnic (caste) cleavages can perhaps unexpectedly be a boon to the overall resistance effort. The case of Goa is also important in showing how consistent and forceful use of all possible peaceful resistance strategies can yield globally momentous outcomes.

\section{Enduring Violence through a Series of Linked Strategies: Odisha}

This chapter surveys in detail iron ore mining and related steel plant expansions and the types of possible resistance to them in all major areas of the state of Odisha. These projects include POSCO and its prospective mine area in Khandadhar in the Sundargarh district; the rest of Sundargarh, such as the heavily mined Koida block; Keonjhar district's heavily mined Joda block; and the rest of Keonjhar (Banspal and other blocks in the south and west, where Adivasis have stopped expansions). These cases reveal differences in the sets of strategies and specific tactics used for state embedding. There are also cases in this selection with little or 
no conflict and limited resistance (such as Joda and Koida), which show how the absence of specific resistance methods reduced the capacity of the resistance to stall mine expansions.

Odisha is India's most important mining state and produces the most mining revenue. Thus, it is not a surprise that this state has seen a multitude of mining conflicts in the past decades (CSE 2008). Odisha was the playing field for the most globally known Indian mining conflict. This conflict, not specifically an iron-ore related conflict, is Vedanta's Niamgiri bauxite project (Padel and Das 2010a). According to a member of the MMP network, the overarching protest in the state of Odisha has been "very strong" and there has been more opposition due to bad rehabilitation, which has left approximately 5-6 million people without homes. Mishra (2010) reviewed the situation and the crucial impact that the protest waves of the 2000s, directed at "industrialization" and mining booms, have had in curbing large projects. His arguments also support my conclusions and help in opening up the long trajectory of projects and their resistance in the state.

Odisha is a key steel producing state and has massive new steel and iron mine complexes in the planning and implementation phase. However, the resistance in the state has managed to block most of these projects. Indian law demands that to start a new iron ore mine, a company must first have a steel plant. Thus, a key feature of mining politics has been conflicts that revolve around the construction and opening of steel mills. The key struggle that concerned POSCO from South Korea has dragged on for over a decade. This struggle is over POSCO's steel mill project called Paradeep in coastal Odisha (the largest ever foreign direct investment project in India). The MOU that the government has given to POSCO has been criticized by a plethora of people because of its terms. For example, it promises thirty-year mining leases to supply a total of 600 million tons of iron ore at a cost of only Rs 400 per ton (Das 2005). The project has been blocked for years by a strong resistance opposing the "establishment of industry on multi-crop land" (see Mishra 2010, 50).

Why has the resistance in Odisha been successful? Mishra (2010) argued that the cornerstone of success is that the movement is more horizontal than elsewhere in India. By horizontal he meant that the movement had a broader base of militancy and less hierarchy between leaders from political parties or NGOs and the rest of the participants in the movement. These qualities have indeed been a great help to this resistance effort, which stands out as distinctly successful among my cases, even though the context contains a very strong government attempt to frame all activists as Maoists and thus render the game as an armed conflict. Yet in the broader context there 
remains a strong mass movement organizing and politicizing — but not all focusing on Odishan iron ore mining sites, as I will discuss.

A nationally working activist, who was not sympathetic to protesting as a tool, but preferred to use litigation, argued that human barricades have been "necessary" in the case of POSCO, "as there have been no other alternatives." The Supreme Court has not listened to the activists, and they have not been able to get the financial resources or contacts to start sound litigation. The cost for one day of a Supreme Court lawyer's salary is equivalent to approximately five years of earnings for the activists in the lowest socioeconomic status. Not that court orders would matter-the company has not obeyed any of the orders handed down by judicial or other state powerholders to close the project. In 2013, a human rights activist from Bhubaneshwar told me that "the Green Tribunal gave a POSCO closure order and did not give an environmental clearance. And there is not even a valid MOU anymore for the investment. People are losing their faith in the legal system." In this context, the activist, who also had his own litigation against many multinationals in an attempt to stop their "exploitation of Indian national wealth," argued that "whatever mechanism is usable, the activists do that." He insisted that "even an excess of protest can be defended as far more exploitation is done by the powerful."

As a consequence of losing faith in many routine (i.e., noncontentious) state-remediated politics (including the use of nonviolent contentious politics), the human rights activist was certain that in the future there will be resistance that will be "more violent, more felt." However, practically all resistance against iron and steel projects in Odisha, and other similar initiatives, has remarkably steered away from the use of violence or armed revolutionary agency. This tact is in stark contrast to the Maoist resistance that is spearheading activism in parts of neighboring Jharkhand and Chhattisgarh, as discussed in chapter 4. While armed resistance seemed to be a reality in parts of West Singhbhum and Sundargarh, all my numerous informants argued that there are either no or very few armed Maoists in Keonjhar district. In the words of one informant, their alleged presence was "invented" to "create fear by the mining mafias and administrators." Facing the violence that powerholders legitimize by framing communities as "Maoist," the struggle to endure this stance becomes a "battle of the community's integrity."

The resistance of local communities to POSCO has dragged on for years and used all possible means; it is one of the most important reasons for the impediment of mining expansion in the inlands of Odisha, primarily in the virgin lands of Khandadhar that were promised to POSCO for min- 
ing. The movement that has developed in the POSCO area, called POSCO Pratirodh Sangram Samiti (the Anti-POSCO People's Movement, or PPSS), was set up right after the locals heard of the steel investment plan in 2005. Since then, members of the resistance have endured strong violence directed against them, but they have remained nonviolent, using the slogan to frame their united struggle, "Whatever be the nature of attack on us, we will not raise our hand." According to a report by the National Center for Advocacy Studies $(2011,94)$, "this slogan announced the non-violence strategy of the struggle and it attracted many villagers to join the struggle. To date the people have not taken to violence."

According to the National Center for Advocacy Studies (2011), the movement had gotten its members elected to the Panchayats, which was helpful, as were the political party connections. The anti-POSCO movement leader is a local activist and a politician of the Communist Party of India (Marxist). He could also use electoral politics effectively due to being intimately involved with politics through his presence in a major political party. According to several informants, this allowed the movement important support from a political perspective. However, some informants said that the leader's party affiliation also meant that the movement would not be able to stand against a state-owned steel project, and that POSCO is a foreign company explains a part of the successful resistance, but I could not directly validate this claim. ${ }^{1}$

Beginning in 2013, the POSCO resistance also started to influence other mining struggles in Odisha. For example, PPSS has started networking with the new resistance movements that have grown in the proposed mining areas, as a post by its spokesperson Prashant Paikray on April 13, 2015, suggests:

We have also expressed our total solidarity with our brothers and sisters from the Particularly Vulnerable Tribal Groups like Paudi Bhunya community and other forest dwellers of Keonjhar and Sundhargarh district of Odisha who have come under the banner of "Khandadhar Surakhya Sangram Samiti." They have been continuing their struggle to protect the waterfalls and rich biodiversity as well as their livelihood. The perennial spring of Khandadhar waterfall provides water to river Brahmani as well as irrigates agriculture down the hill. People have demanded to declare the hill as national natural heritage. At least 5,000 [members of] Particularly Vulnerable Tribal Groups (PVTG) and 16,000 other forest dwellers will be deprived of their right to live and livelihood if POSCO will be allowed to mine iron ore from Khanadadhar $[s i c]$ Hill. 
My informants called for continued state- and federal-level networking by mining activists. Currently the Odishan use of networking to connect all the concerned movements is "still in its infant-stage," according to a coordinator from a human rights NGO. My visits across the major areas of existing or projected iron ore mines support this claim, as quite a few of the local activists I talked to did not know prominent activists even in nearby areas, for example, between the neighboring Sundargarh and Keonjhar districts (Khandadhar is located partly on both of these districts' lands.) Currently the movement organizations differ substantially on the local level, as they are autonomous local entities.

In comparison to the Kudremukh, Tiruvannamalai, or Goan cases, which relied on significant state-spanning networking to create links, unite movements, and pool protests, conscious network creation among mining activists in Odisha was just starting in 2013. Yet another type of networking, which I call replicative networking (Kröger 2010, 2013a), had already taken place in several parts of the state, for several decades. This replicative networking means that a group starts to replicate the resistance model of a progenitor movement in its own activism strategies, replacing its own prior strategies and ideological stances with the progenitor's strategy set. ${ }^{2}$ There has been a compounding replication of resistance strategies in historic Odishan struggles against extractive and other large-scale investment projects that would have had negative socio-environmental impacts. The temporal trajectory through which the Odishan resistance has been able to face violence peacefully is quite old. These political dynamics continue to be strengthened by a spreading replication of peaceful resistance strategies.

Many of my informants participated in early struggles against largescale projects and carried and replicated the lessons learned through their central role in these mining conflicts. The years 1981-86 saw a strong and peaceful resistance movement against a missile test base in a coastal area of Odisha. This conflict developed the understanding that it was essential to be constantly ready for mass protesting. The leaders of this struggle used a horn alarm that allowed them to summon a large mass within one hour to the base's gate to forbid access. This was a successful movement that "could not be displaced." Several different movements "have adopted its methods," according to an informant. Using a similar strategy of mass protesting, an aluminum plant project on the northern coast was resisted and stopped in 1990-95. Activists from that case told me that this struggle was successful for many reasons. In particular, the role of corporate agency was weaker in this case. The aluminum plant was a government project, which meant that the "company could not bribe parties"; thus, "the movement was stronger" 
than the target. This strength emanated from the people forming a united front, bolstered by their strong spiritual commitment to preserve the area and its many temples.

In 1995-2002, a Tata steel plant was stopped by using similar tactics and a strong movement, but in this case, activists were killed. Deaths have been common in these direct-action struggles in Odisha, but these deaths have served to increase the willingness to resist peacefully. This result suggests that the terrorizing attempts of corporate-state agency do not have an effect of demoralization or pacification in a context of sympathetic public opinion for contentious resistance to investment. Following the conceptual framework introduced in figure 3 in chapter 2, I would argue that the reason for this turn is that the deaths of peaceful activists ultimately create symbolic power for the resistance front in general; these deaths function as symbolic acts of merit that can counter the effects of symbolic violence.

The battle in Odisha is fought especially in the symbolic space. A key reason for this contextual specificity is that the most affected groups in Odisha are the indigenous people and Dalits (an ethnic group in India who have been kept depressed or oppressed; they, or a part of them, are also referred sometimes as the Scheduled Castes, the "untouchable castes," or the "backward castes"). According to a state-level human rights organization activist I interviewed, 70-80 percent of those whose rights are being violated are Adivasis, and the peasants impacted by the POSCO and other steel projects are typically Dalits. While both minority groups have some support from professional NGOs, they often must use whatever means are available to defend their case, without much support from the broader Indian society, and in an atmosphere where the powerholders respond to their protests with violence. There are very few possibilities for these lower-caste and racism-facing groups to gain economic, social, or cultural capital, which would allow them to accrue clout in the regional social space. A rise in social-space positioning would allow for the use of the mechanism of objectification of social position to assure a better physical-space position, or at least the possibility to use mass protesting without fear of violent repression.

In the absence of possibilities for social ascendancy, and to distance activism from guerrilla militancy, particularly useful tools in Eastern India are what I call "symbolic acts of merit." These are always available, even in the most oppressive situations. Examples of these in Eastern India, recounted to me by a local activist, have included Adivasi women in a remote mining area of the Balco aluminum company "putting their babies in front of trucks, saying 'drive over, as they will have no future." The POSCO movement leaders went to jail for a long time in defense of their fellow villagers. Several of 
my informants exclaimed that such "[a] giving of leadership," which shows "[a] high personal commitment," is the most crucial of the many strategies needed for successful resistance. Symbolic acts of merit are not available to unethical persons, as they require the building of morality by moral deeds that can counter the power of symbolic capital/violence. Often, they require sacrifice and selflessness, and a will to endure violence and injustice. The POSCO resistance also developed mechanisms to ensure that rapid surges in anger, in response to counterattacks against their mobilization, do not turn into destructive violence. For example, "PPSS managed to channel people's discontent in a positive manner by engaging them in shramdan (physical labor donated by people for building village assets)" and by using simulation exercises (National Center for Advocacy Studies 2011, 97).

A senior researcher from Odisha, a key figure in many struggles that have terminated large investment projects in past decades, said to me that "absolute nonviolence" has been the strongest tactic leading to movement success. He argued that in Odisha the "opposition has always been by local people, not guerrillas," and that the "Maoists have used" the locals, possibly sometimes offering "implicit support," which has nevertheless "not influenced the outcome." The nonviolent resistance in POSCO and some other cases has included human chains that were maintained even during the night, with people sleeping in rows and lines to prevent entrance to an installation. This resistance strategy has postponed projects around the clock, which meant rising costs to the company. The fact that the company has not managed to start the project and destroy the village suggests that the resistance is winning, and that this is a successful strategy. In fact, in general, it can be considered that in extractivist conflicts, so far as there is no landscape change or difficult and costly-to-reverse physical space change, or both, the resistance is winning.

While the price paid by the resistance is high, it is a burden that is easier to carry when their community is so united. The anti-POSCO villages have been cordoned off from the nation, and random arrests and court cases await anyone leaving the area. The people are on permanent sit-in in their own homes. A June 30, 2015, email update by the PPSS stated:

More than 2,000 villagers and activists are facing over 350 false and fabricated charges. . . Many villagers cannot go out even when there is a medical emergency for fear of getting arrested. . . . The state administration has cut down thousands of old trees for POSCO and destroyed the greenery of our locality and has made us vulnerable to cyclones. 
Yet the resistance was holding and had spread its agency to other parts of Odisha and India. The strategies employed by the POSCO resistance have been remarkably solid and well deployed, including all the five key strategies. The POSCO case illustrates how the interstrategy relations, that is, the conjuncture of the strategies used, their multiplicity and synergy, is important in explaining outcomes, particularly in difficult resistance contexts. It also shows how symbolic acts of merit can be a key tool leading to success.

Besides the POSCO case, there are many other iron ore-related struggles in Odisha, which I will now discuss. ${ }^{3}$ First, I will examine the cases in the Sundargarh district, after which I will turn to Keonjhar, next making comparisons between the two cases. This helps to explain how and why people (in this case, Adivasis) do resist extractivism, and how and why they do not resist.

In the early 2010s, forty-one of Odisha's iron ore mines were in the northernmost Keonjhar district, twenty-one of them in Sundargarh and ten in Mayurbhanj, according to Development Initiative, an Odishan NGO that focuses on mining, trying to diminish its impacts (interview February 2013). The Mayurbhanj district had not seen important mine expansion since 2000 during the iron ore boom, but this is an old mining area with mines that are quickly depleting. It did not, therefore, present important conflicts or resistance movements for observation. The Sundargarh district is home to the large Rourkela Steel Plant, which opened in 1959, amid waves of dispossession of Adivasis who were forced to become "migrants" (as the displaced are officially called in India). Sundargarh differed from Keonjhar in that there was generally a much less organized resistance against mining expansion in Sundargarh (interviews with several activists and experts from Rourkela, the rural areas in Sundargarh, and all around Keonjhar, February 2013). ${ }^{4}$

An activist lamented how a process of forced mass migration has increasingly escalated in the past years in Sundargarh and some adjacent mining areas: "Many young girls started to work in the mines, as the tribes are matrilineal. Mafias took their lands and at the same time [as they were at the mines, they took their] food security. Now [the locals, including the girls, are] not raising a voice. Somebody should go there." However, this activist, who had long-term experience resisting in Sundargarh, also observed that there had been some mobilization in the struggles over iron ore between 1996 and 2002. In this struggle there were approximately ten leaders and 800 people in the district's sole movement in Koida (also written Koira). He explained how in that struggle the "farmers resisted waste dumping on their fields by tycoons from the mines" and "supported the Adivasis." Together, 
they managed to close mines including some of the mines of Essel Mining, the leading Indian iron ore firm. According to him, "Whenever people raised [their] voice, people closed mines—small groups played big roles in closing the mines."

The pre-2005 struggles in Sundargarh used mass movement protesting and networking, which resulted in some closed mines, but no veritable political outcomes were created, such as lasting resistance capacities. Thus, the post-2005 situation has been less positive in terms of movement building or outcomes in Sundargarh (apart from Khandadhar). A displaced Adivasi activist from the Sundargarh rural areas told me that the areas' lack of organized resistance was due to the absence of a good leader, a movement organizer. The attempts to build a movement were being "suppressed" as the "atmosphere" was "very hot" in the area, which meant that people were "not raising [their] voice against industrialists," although the Adivasis are "in a boiling state that can explode at any moment," particularly in the miningaffected areas of northern Sundargarh. In the eastern parts, such as Koida, several other informants told me that part of the population had accepted mining as the state of affairs or business as usual in the area. An NGO working in these already greatly ravaged areas was occupied with requesting compensation, jobs, and better social policy for the affected, rather than with safeguarding the environment or blocking and hindering mining expansion. Private politics with corporations were also used in this arena.

Moreover, in Sundargarh, networking efforts were seen as promulgated only if someone from the outside came to the affected areas. The prospect of state embedding was a far cry: as two activists and a journalist put it, no politician would be inclined to take the trouble of reaching out or listening to distant Adivasi from the forests. The main purpose of the 2006 protest, the largest protest that had been organized in the area to date, was demanding work for all the displaced. In this protest 20,000 people held up a train for fifty-five hours, which did result in some of them getting jobs. Besides this incident there were no major protests organized that could have influenced the mine closure ordeals in the 2010s. In sum, post-2005 Sundargarh (with the exception of Khandadhar) was lacking on several fronts in terms of peaceful strategies of contention. For example, until 2011 there was no organizing and politicizing leadership, and thus no social movement organization or resistance campaign, and no networking or state embedding while retaining autonomy. Nevertheless, even this timid resistance in Sundargarh post-2005 came to enjoy the fruits of mobilizations elsewhere, which led the Odisha state government to proactively shut down many of the illegal mines all around the state. Most of the mines in Sundargarh were also closed. 
Another Adivasi activist displaced by the Rourkela Steel Plant who had been living in Sundargarh's Khandadhar forests for a decade (after retiring from a career as a mechanical engineer and government employee) said that by 2013 identity-building had become the key tool and goal of mobilization. He argued that after a strong Adivasi identity was created, it would be possible to have 100 percent autonomy, and to network effectively. The basis for this would be that an Adivasi identity would facilitate the fight for the recognition of the FRA, which would render " 70 percent of forest and 80 percent of minerals" outside the bounds of exploitation (without Adivasi permission). FRA recognition would make the exploiters "lose [the] right to those areas." Thus, ethnic-territorial rights are a key goal for these movements with a current focus on identity-building, given that in places like Koida it has been splintered and lost due to mining. ${ }^{5}$

It can be said that networking to boost Adivasi identity, by making FRA claims in institutional politics and thus trying to change the institutional status of the lands, and private politics have been actively used in the case of post-2005 Sundargarh (exluding Khandadhar). This has led to no political outcomes worthy of explicit mention (notably not even to building armed revolutionary agency), but has yielded some mining project discontinuations. I will next analyze the highly illustrative and analytically rich examples of the Keonjhar district cases. There are globally important lessons to be learned by telling the Keonjhar stories about effective mobilization and resistance to extractivism. These stories are so rich and necessary to tell because the results of this resistance were realized in an extremely tough context where the extractivist corporate-state agency was strongly pushing for a militarization of these struggles.

\section{Keonjhar}

Keonjhar had several iron ore mines that were closed by activist efforts, mostly in the Keonjhar Sadar, Banspal (also known as Bansapal and Bansapani), Harichandanpur, and Telkoi blocks. ${ }^{6}$ Peaceful mass protesting has been a key element in Keonjhar for the local movements and has successfully discontinued mining expansions. This was not a process of trickling down of resistance efforts elsewhere, through a mediation of top-down executive orders. This was a very real, long-term, and concerted effort of building strength for peaceful grassroots movements across Keonjhar, by several advocacy groups and villagers' mobilizations. Very few activists in Sundargarh or Bhubaneshwar, the state capital, were aware of these efforts 
and dynamics on the ground in Keonjhar, due to very weak networking across the places of discontent in the state. I was able to gain insight and understanding into the story of the Keonjhar resistance through the coordinator of an NGO and advocacy group in Keonjhar, which operates across the district. I traveled with him and some of his assistants for many days around the state, and in this time, they shared a lot of information with me. I cross-checked the stories they told as best I could with other people and scholars also knowledgeable about the case. I carved out this explanatory story from these many meetings and recordings, which were transcribed. I use this material as the basis for the narrative in this section, where the coordinator is the strongest voice.

The coordinator explained to me that most of the locals are now resisting mining expansion, since they have seen the negative impacts. They are "not allowing even mining surveying vehicles" to enter their spaces. Women are central in blocking these attempts, threatening to damage vehicles if they do not stop. When the miners did enter without permission, "people got angry, went to the hot mood, went with sticks, and said [you] have to leave," after which the miners left.

In addition to such direct actions, the locals have pooled their resources to allow community members to travel to cities for training in activism, and to organize massive protests in the state capital against the many projects in the district. These have included "thousands and thousands" of people in "many many marches" in front of company headquarters and government offices. Targets have included Mittal, Vedanta, and Rio Tinto in particular, none of which has been able to acquire agricultural land since about the mid-2000s, when the protests against their steel/iron ore complexes started. In the 2000s, the Keonjhar NGO organized the people resisting the steel plants and those resisting the mines into one movement, something that had only recently started with the POSCO-Khandadhar movements.

I will next explore the causal condition complex of resistance strategies in Keonjhar by examining key strategic features. I start by explaining how three tactics have been particularly important features for organizing and politicizing a robust and autonomous mass social movement, while avoiding the dangers of private politics and armed conflicts. These three tactics are first, organizing financially autonomous village resistance (this contributes to the building of movements with embedded autonomy); second, abstaining from private politics; and third, using nonviolent resistance and limited violent action to avoid losing land control.

After exploring these tactics of organizing and politicizing, I explain certain tactical features in each of the other four key strategies (campaigning, 
protesting, networking, and state embedding). The points raised about these tactics specify how the rest of the five key strategies can be developed and used, even in peripheral contexts with limited help from outside.

Perhaps the first move that supported the success of the resistance in Keonhjar was building a strong autonomy, via financial independence and control of physical space. A standout feature of the Keonjhar actions has been this autonomy, which extends so far that not even the local NGOs distribute financial resources to the villages to assist them to travel and mobilize. Instead, if people can themselves manage to get the resources to come to training centers and places of power to protest, they come. The Keonjhar NGO coordinator, who is the dominant voice in this section describing the Keonjhar movement, explained their mobilization "strategy" to me, claiming that it has worked well, as it is attuned to local realities. The NGO advises people on various issues including

how to address people and how to address the government. So they [the villagers] come, they stay here, learn, they go back. Also they visit other groups [who cannot come]. They come, stay, learn and then go back. So that is [our] strategy: listen, learn, get stronger and listen ... leadership multiplies in this process. We are actually having this process. Learning and doing. Reflecting a lot.

Such a tactic of indirect help, where the NGO does not directly lead the campaigns or fund them, is necessary in the context of violence against activists in Odisha. The members of this NGO had already been jailed, tortured, had their offices destroyed, and some of them even killed, through wanton acts by the police who accused them of being Maoists. In Sundargarh, the activists noted that it is forbidden to receive any money from abroad for political organization, or even from national entities. Besides the goal of averting violent attacks, the above strategy better fosters the ability and readiness for peaceful contention, as the people must create their own resources and become the messengers that the NGO activists cannot be.

Second, the resistance in Keonjhar has been very avidly against all kinds of attempts by companies to lure villagers into private politics, such as stakeholder compensation(s) or being friendly and open toward the corporate social responsibility policies of the mine owners. Vedanta tried to send a sponsored vehicle of doctors to an Adivasi village that it wanted displaced, but the villagers attacked the vehicle and detained the Vedanta officials, demanding, prior to releasing the doctors, a promise from the company not to enter their lands again. In another case, 
Vedanta had distributed school bags for school children. So what they [the villagers] did, they collected all the bags from the children and burned them in front of the collectorate [the administration in charge of a district]. Around 1,000 bags [were] distributed to the area's school children. So they were all collected and burned.

Third, the resistance has been peaceful, or at least tried to limit violent response. When the alternative of private politics was rendered unusable by the resistance, the companies tried to enter with the help of state violence: "The government has tried many times with the military to enter. Many times [with] many many police and military [personnel]. But they are still not able to [enter]. . . . So this fight between military and Adivasi is going on." As a result of resistance, which was both nonviolent and occasionally violent, "the government became tolerant" and started to "avoid the resistance, avoid the violence ... . in spite of violent resistance from the Adivasis, the government, the police and the military became tolerant." I asked why the government became "tolerant" toward the (nonlethal or physically damaging) violent resistance, to which the coordinator answered:

Because otherwise many people will die. If they fired, many Adivasi will die. If Adivasi die, there will be a lot of questions. The government won't get votes. After all, they're Adivasis. And this news will circulate everywhere-although Adivasi may not support the government. And internationally and at the national level also the government and companies will be immediately punished.

In comparison to Sundargarh, Keonjhar, which had received the visits of nationally renowned environmentalists "to boost the morale of people not to give land to companies," had a much more robust resistance front built among the villagers. The NGO coordinator noted that in Sundargarh the resistance was "a bit weak." As a result, the villages had accepted the gifts of the companies and their promises of wealth. In the absence of peoples' movements,

the corporate made people understand that it will benefit them a great [deal]. They [the corporate] will bring electricity, they will give new medical, they will give new house, they will give water, food, everything. Very nicely. Who? The corporation. They [the villagers] say, corporate says we'll give house, we'll give light, we'll give water, 
we'll give food, we'll give cloth. You don't owe for it anything. We'll double your earning. Don't worry. Let us do mining. That is the way they [convince people].

The coordinator argued that many leaders in Sundargarh had been coopted and received monetary compensation and became middlemen for the mining companies, instead of becoming "critical educators" exposing the ground-level devastation for the villagers:

They [the villagers] can't imagine that their own people will cheat them. Their own people will fool them. So they blindly believe, they trust on the corporate agent because corporate himself is not coming. It is the villagers' own man convincing them. Own agent. Because corporate keep their own agent in the village. [Your] brother, sister ... they're coming and convincing [you]. In the village. On behalf of corporates.

However, "when there is an exposer, then naturally people say 'no: we will fight,' [but] in many places in India there is no critical educator, movement never takes place. People become tolerant. And finally, they leave their place and go somewhere else." This combination of avoiding private politics and firmly keeping up the autonomy of physical space, through strict control over land access, seems to have been an important strategy, given the real danger of co-optation that has taken place in other nearby areas. This illustrates that it may be crucially important to organize and politicize a mass social movement in peripheral areas inhabited by ethnic minorities without outside support. Moreover, this also suggests that financial autonomy and de facto control over a particular place are intertwined with the successful building of such a movement in areas cast as resource peripheries. It is important to note that all the other of the five key strategies were central in this case, as the last four points below open up.

Fourth, there has been a major effort of campaigning along nonmodernist lines, ${ }^{7}$ which was firmly rooted in the strong grievances that the locals could see when visiting mined areas near their own villages. At the beginning of extractivism, people did not resist mining as they did not know what it would do to their lived environments. Now they know, and the resulting massive displacement has caused deep grievances of all types, which are by themselves, according to the NGO coordinator, the biggest explanation of why people resist: 
[If you] go to Joda [the heavily mined block of Keonjhar], you won't be able to see Adivasis. In many, many villages they have already left and gone to somewhere else. In the Tata area [in Joda] there are 22,000 Adivasis still missing, nobody knows where they are. Population of the Joda, even government doesn't know where they are. They have been displaced and gone somewhere else.

The locals know what it means to lose land, having observed others undergoing the change. When the Adivasis are displaced,

they lose their emotional attachment to the motherland. They lose their deity, their village deity, they lose the right to worship. They lose everything. They lose water. They lose [their] environment. They lose their cultivable land. They lose habitats. They lose house. Everything. In the name of development.

With the expansion of extractivism, in Keonjhar this process is increasingly also caused indirectly, particularly by destroying peoples' water sources and not offering "even a glass of water," let alone access to a river or stream, which thereby instigates a process of self-eviction. This self-eviction occurs even despite the new mining jobs, which are poorly remunerated:

Government makes the environment such a dusty and such an unhealthy place there that self-eviction started. Government did not evict people. People evict themselves. Automatically because government makes the area very poisonous, very unhealthy. People cannot live. So self-eviction started. The Adivasi cannot live in an environment like that.

When I questioned how people managed to resist, the coordinator answered that the most important reason for this was that they saw the impacts described above. This spurred resistance in nearby areas, not only directly next to their own villages. Now that the people in Keonjhar have seen these effects, they began to resist. To further this resistance, they have formed a campaign where they display slogans such as "Stop! Stop mining! Stop iron ore! Stop anything which destroys our forest! The forest is our life-we cannot live without forest. We are like fish in the water-we cannot be separated from the forest." Protests also display Adivasi culture: "they're having the placard, they're having banner, they're having traditional drums, they're having blowing instrument in the rally." This display of Adi- 
vasi objects and their use in these place-based rallies creates objectified symbolic power for the Adivasis' way of life to continue in that place. This kind of objectification of symbolic power helps in marking both the symbolic and the physical space as belonging to the Adivasis.

Fifth, the resistance movement in Keonjhar was tightly rooted to their physical space, and not just campaigning and protesting. The NGO coordinator argued that a rally alone does not make sense. For a rally to work, he saw that there was a need for "ground measures," meaning that villagers "are able to protect their forest from mining, are able to stop mining survey in the village." This means blocking the exploration or mining by any means, including using their physical bodies. One of my main takeaways from the strategies of resistance in Keonjhar was the crucial importance of having land control at the village level, not just protests. In this sense, it is essential to have power and good positioning in the physical space to be able to make the other strategies work. "If you have significant control of all the resources, or significant changes, significant achievements in a village, people will get convinced," the NGO coordinator argued. "People have their own conversation. . . . Okay, that village they are able to protect [themselves]. We can also protect." He emphasized the importance of "real village action," which is resistance action that physically bans the entrance of companies to their space as the basis of all rallies, otherwise they are useless, as there will be "nothing to learn, nothing to share" with other protesters. ${ }^{8}$ In an illustrative example, in 2006, the mining surveyors entered an area of people the NGO had been working with since 1996:

So the people were well organized, and when forest survey came, people resisted. People said, "No. You cannot survey our forest. We are living here." And there is iron ore of course. . . But in spite of their resistance, the company came again for survey. The locals blocked the road. They did not allow the vehicle to go inside. So the survey company filed a police case against eighty tribal leaders.

After the coordinator heard this, he suggested that the leaders file similar cases against the company. However, the police would not accept this, saying, "You know police and the government and the company and the survey, they are one, no? ... So then we filed a complaint against the police by the district post," which the police had to accept.

After some days, the police came again, to arrest these eighty people. Yet the people continued to resist and said, "If you want to take us, take all the people from all the villages. We are people from six villages. So you take all 
the people of six villages. Why eighty people only? We'll go together. We'll stay there happily. Because you know we can have our life there. Like a family." The police left. With this example, the coordinator wanted to make the point that if only eighty people protest, they can be easily jailed, but if the protests are rooted in whole communities, they cannot be so easily ignored and cast away. Grounding the resistance not only to the land but also to the bodies of the community members is an effective way of controlling the physical space-which will, of course, provide immense benefits in the social and symbolic spaces as well, as demonstrated by the theory of spatial causalities outlined in figure 3 in chapter 2 .

Sixth, there was a successful, although painful, experience of using networking to overcome the massive violence that tried to break this powerful movement. The coordinator explained how in 2008, the police entered the area again

in the name of Maoists. ... Then around 10 o'clock they [the police] arrested three of my colleagues and two community leaders. Altogether they [the police] arrested fifteen people. And immediately they [the locals arrested] are sent to unknown places.... [the] Police said that they arrested some Maoists.

The coordinator then went to file a complaint against the collector (an Indian Administrative Service officer in charge of revenue collection and administration of a district) with his colleagues, but the collector was not present. ${ }^{9}$ After that the coordinator fled to the state capital, as his and his colleagues' names were also posted on the list of Maoists. He explained to me the different ways the media tried to publicly smear his reputation: "[The media said that] 'I'm the leader of the Maoists; I have an AK47; I do this and that in the forest.' All the dirty things they wrote." His friends suggested he should not attack or criticize the press, as "otherwise how can we win?" A fact-finding mission was quickly assembled and dispatched immediately to Keonjhar. The fact-finding team included a High Court member, several activists, NGO employees, and senior press people. When this team tried to interview the superintendent of police, however, "[he] said, 'I won't be available. I cannot give my comment." Nor was the collector available. The coordinator continued to tell me of his harrowing experiences:

Then, in the meantime, all of my colleagues were sent to jail. . . . They [my colleagues] were beaten very heavily ... They [the police] had beaten and asked them [my colleagues] to say that they are Mao- 
ist. So that is the reason they have beaten. One of them said no: "I cannot, I cannot, we are not Maoist." So he was beaten very heavily. ... after all they [the fact-finding mission] took the interview of many, many senior people like the subcollector [who gave a statement on the NGO people that] "They are good people. They have fought for the protection of the Adivasi rights. They have filed 120 cases in courts [on mining issues], this organization. I don't think that they're Maoist. I don't know how police knew that they are Maoist." And also they [the fact-finding mission] took the interview of [the] assistant police commissioner. He's a tribal. He also said that until now we don't have any evidence of that they are Maoist.

The NGO went to the High Court for a "one-year fight," but did not get bail granted for those incarcerated, and then appealed to Amnesty International and many other international human rights organizations. The NGO also "wrote to the government of India, Supreme Court, High Court, prime minister ... We remain[ed] underground for six months." Had they stayed in Keonjhar, the coordinator asserted, "We would have also been beaten up, picked up and sent to jail. So fortunately, we went to Bhubaneshwar." Amnesty International's letters after taking the case and the pleading of a local Adivasi directly to the chief minister were, in the coordinator's estimation, central in releasing all his colleagues from police custody in 2012.

After this incident people recommended that the coordinator no longer stay in the area for safety reasons, but he declined to leave:

I said, "If I go to Bhubaneshwar, then how will this problem be resolved?" People, government will attack me. I will go to Bhubaneshwar, government will attack other activist, he [the potentially attacked activist] will also go to Bhubaneshwar. So everybody will go to Bhubaneshwar. Then who will address the situation, the problem? So we go to Bhubaneshwar and let the government to do whatever? It's life. [This] we cannot [do], we will be with the people. And we are still with the people.

Out of fear, some locals paused their resistance for a year or two during this incident, but after the coordinator's resolution to return and continue the struggle, combined with "some justice from the High Court" and "consolation and encouragement" from people all over India, the local activists continued and escalated their mobilization. This case was an exception in Eastern India, as in most cases when "you have been presented as Maoist, 
anti-state and anti-government, you get a life sentence, you are not able to come out. You are not able to get a bail to come out. This is actually a very serious issue." A turning point in this struggle was when the local NGO and the Adivasi activists (collectively the Keonjhar resistance organizations) gained the support of the local and national media after a press conference conducted by the fact-finding mission, which had collected convincing evidence to prove the reality of what had happened in this situation. From that moment onward the activist's position began to improve, and the "police also kept a low [profile] because all the national newspapers also wrote that what the police had done is not right."

There were some Maoists in the area in the mid-2000s, but by 2013 they had moved on, which allowed the NGO activists to "get democratic rights" for their operations. Since this series of incidents, the movement understood the importance of networking and creating as many links with as many different entities in different places as possible. For example, this incident started the practice of networking with Adivasis from Jharkhand and Chhattisgarh. The activists felt that the most important element for positive activism outcomes in the future was to "widen the network and voice." One important facet of this process was to demand and allow the processes of human rights law to be exercised in India.

Lastly, besides movement organizing, campaigning, protesting, and networking, state embedding was also a strategy used in this resistance effort. The way electoral politics were embedded, redesigned, and produced by the resistance in Keonjhar is the seventh highly interesting strategic feature to be drawn from this case. The resistance decided to abstain from judicial politics and institutional embedding, while focusing on electoral embedding in a very innovative way. Favoring electoral embedding over the other types of embedding was not a random circumstance: the Keonjhar resistance had good reasons for these embedding choices. I will briefly outline the reasons they had for not pursuing all potential forms of embedding. The Keonjhar resistance organizations were very skeptical about the use of courts, which they had not previously used in their resistance efforts. They saw considerable danger in this course of action because of the Indian constitution and laws, such as the Land Acquisition Act, which grants the government the legal right to displace people for "developmental" projects. While the government should pay compensation for this displacement, the monetary compensation stands as just another way to destroy the place-based and place-reliant Adivasi way of life and their spaces. If this is the law, the activists choose not to use the courts as a tool of resistance.

The movement also did not try to use or embed the state institutions 
such as the pollution control board, the collectorate (the district level politics under the authority of a collector), and so on, as "they are always in the pocket of the corporates. . . . they close their eyes." The movement had, however, made use of the Right to Information Act, by "fighting for information continuously and strongly," and getting data on mining leases. The movement was required to complete several rounds of applications, for each different institution involved in licensing mining, before they got what these institutions were obliged by law to provide outright. For example, this included the information on who had reserved which areas, and for what purposes. This kind of information was very helpful for the movement because they learned things like in some villages 100 percent of the land had been reserved. Knowing this helped them to determine key areas to target with the resistance efforts. The movement used the information to inform the people about their rights so that when "the company comes and says that, 'This [is] my mining lease area, you go!,' the people can say, 'No, get out of our area. And since our Gram Sabha has power, unless we give the right to you to come, you cannot come."”

The coordinator observed that the institutions in their area are completely corrupted by mining mafia money and are therefore useless. The state bureaucracies were also very militarized. For example, when state officials went to villages to ask whether people wanted mines, they went with a heavy military presence. Bringing arms to an introductory discussion naturally inhibits an honest response in most cases as people are afraid of this show of power. This indicates that there was a notable difference between Eastern and Western India in terms of political opportunities that allowed the use of institutional and even judicial politics. However, these limitations did not apply to electoral politics, which the movement started to engage with, and even started to change the rules as a result of their action and intervention.

The Keonjhar movement differed from the other iron mining conflicts in India and Brazil because of its strong embedding of electoral politics. The most innovative example of this was the process introduced by the movement of demanding that electoral candidates sign an MOU before they were even allowed to enter an area. This MOU stated explicitly that the candidate would not support mining operations in an electoral area. Many candidates and even local party leaders signed these MOUs against mining investment, "and got elected accordingly." This type of vote pooling, or shaping the political arena, represented a new political power in the electoral field. This power proved quite useful, as the movement could make use of the promises (and the candidates' fear of not being reelected). The coordinator told me that even with all this positive momentum, after the elections, 
in spite of all this [effort], mining tests started. So the people went to meet the chairperson. They [the people] said, "You have signed our agreement telling that you do not allow mining operation. But how come this testing is going on? You have to go. You have to go and stop it. There's no other way." Then this poor chairperson came, of course, along with the people, and stopped the mining operations.

After these initial efforts, this strategy was fine-tuned to spread it more effectively by replication. The movement called for large meetings of people, including candidates, in traditional vote-buying areas, saying that, "We have experience that [the] one who gives you feast, liquor, rice, potato, everything, the dal, you vote them [the traditional clientelist politicians, who typically support the expansion of mining]. Why do this again this year?" After this, someone asked, "Can we use our power to stop this?," to which another person suggested, "Can we have one common election meeting where we can put our demand that the one who says no to mining, we'll vote for him." The mining-project-affected communities in Keonjhar agreed to such an arrangement, as it meant that the candidates also did not have to travel from village to village. Official invitations were sent to people by the electoral system to attend this meeting, and a "huge number of people" attended. Votes were pooled for the candidates who promised to protect the Adivasi villages, hills, and forests. Now many people in Keonjhar's rural areas would not vote for anyone who had not signed the MOU. The coordinator argued that this was essential, and had been a very positive experience, as unless the powerful political participants of large public meetings are "linked with [the] vote," the affected communities cannot "make them bend." So, "[the] vote is the main power, main weapon."

Targeted voting is a form of state coproduction, meaning that it goes beyond simply influencing who gets elected to decision-making power. This type of state constitutive action yields an extended executive arm for the resistance against mining. As political and policy-making outcomes, the clientelist system begins to break and be replaced by one where the people can control their representatives. Moreover, public meetings are steered according to the wishes of the mining resistance, and not by politicians who are not necessarily interested in these issues. This state coproduction has managed to turn elected politicians, at different levels of power, against mining in the richest iron ore reserve areas of Odisha and has thus helped in blocking greenfield mining projects. In comparison, I did not find similar tactics used in brownfield mining areas or non-iron-ore areas. This reshaping of the state has also grounded the understanding of the influence of voting, by 
increasing the salience of democracy and the importance of electoral politics as the second-most important political game (after contentious politics) in Keonjhar, thus avoiding the dangers of armed conflict and private politics. Furthermore, almost all the elected MLAs are now Adivasis and not outsiders, which has meant a structural change in the social space toward a more equal distribution of social, cultural, and economic capital. In addition, this has also led to a change in the larger symbolic space as it is a shift in the perceived role of local Adivasis in the political process through the power they now yield.

\section{Outcomes in Odisha}

Having discussed many cases and tactics of resistance in Odisha, I will link them more explicitly to the outcomes of extractivist investment projects. As a result of the multiple strategies discussed in the previous section, the coordinator was confident enough to claim that "without our intervention or any mobilization in Khandadhar [the Keonjhar parcel, located in the Bansapal block], there would have been a mining operation. There would have been eviction." Thus, the outcomes of the efforts in Keonjhar were significant. The coordinator also pointed out that the Shah Commission was interested only in illegal mining, not in the legal mining that also devastates the lives of Adivasis. For this and other reasons, he did not believe the Shah Commission was chiefly responsible for closing the mining operations. In fact, the kind of grassroots process described in this section on what happened in Odisha works very differently in comparison to the curbing of illegal mining by the powerholders and shapes a whole spectrum of political games wherein mining politics takes place.

When looking at the broader picture of the Odisha state, and not just Keonjhar, the outcomes of the Odisha iron ore mining resistance are perhaps most easily visible in preventing the opening of the Khandadhar mining area in Sundargarh. This landscape is still rich with natural features including the huge waterfalls that are still gushing water. ${ }^{10}$ Yet it cannot be said that the outcome in Khandadhar, which blocked the mine, was produced solely by local resistance. The outcome in this case was also a result of resistance by the POSCO steel-plant activists and other factors. The Supreme Court was also involved in the dynamics of contention in this case-a shared feature with many other cases in India where projects were suspended. An intercorporate agency struggle for the mining resources also partly explains why the mine's opening had been postponed. ${ }^{11}$ These outcomes are the product of invest- 
ment politics where resistance strategies operate and interact with corporate and government strategies.

There were a myriad of different forms of resistance groups and types of strategies in use in Odisha, whose joint impact helped in banning the greenfield mining projects. Their role in the large-scale closing down of the existing mines was less direct. Odisha hosts about 200 mines, all of which are small, including seventy-seven iron ore mines. According to the coordinators of the Development Initiative, an NGO and MMP member from Bhubaneshwar offering advocacy for locals (including workers) in mining areas, about sixty of Odisha's mines were closed between June 2012 and January 2013. The Development Initiative argued that these outcomes were due to the Shah Commission report, which was the basis for the central government's request that the Odisha government address illegal mining. ${ }^{12}$

When the chief minister of Odisha obeyed the initial orders of the Shah Commission, he secured his continuity in power. The chief ministers of Karnataka and Goa were forced out of office when the mining mafias in power during their terms of office were revealed by the efforts of the "organic society" that formed in Western India. In fact, the Odisha chief minister not only shielded himself while watching the politics of mining-caused term interruption unfold elsewhere in India, he also dramatically increased the vote count of his party in subsequent elections.

Generally, blockage of iron ore and steel megaprojects in India and Brazil has been a grassroots-led process. Besides POSCO, there are Mittal's and Tata's large captive steel plant projects (called captive because these plants have earmarked mines, whose ore can be used only by that company), which are being blocked in Odisha. Additionally, there are projects by several other companies, such as Sterlite (a part of Vedanta) and Essar, and state-owned companies' expansions or greenfield plants, such as those of KIOCL (Kudremukh Iron Ore Company Limited) and SAIL. For example, according to journalist for Tehelka, an investigative news magazine, in Odisha the "Mittal project was not able to take off because of local opposition." My field research in Keonjhar and Sundargarh also revealed that there are many more local and highly sophisticated and proficient resistance groups that have had a direct impact, before and independently of the Shah Commission, which has blocked iron extraction expansions.

However, Odisha was not a story of full-blown resistance to mining. In fact, many locals are in favor of mining, and these locals are typically Adivasis. Nevertheless, these promining local constituencies are almost exclusively present only in the old mining areas with few possibilities for all those now employed in mining to return to livelihoods based in either the forest or agri- 
culture. Following the central government's orders to close most iron mines in Odisha in 2014, as these mines were illegal, thousands of people, mostly Adivasis, lost their mining and mining-affiliated jobs in heavily mined areas. Koida in Sundargarh and Joda in neighboring Keonjhar were hit particularly hard by this ruling, with approximately 10,000 people losing their jobs. The unemployed organized huge protests in December 2014, demanding a swift reopening of a group of mines that they considered to be legal. ${ }^{13}$

Demands for reopening the mines resonated with the Modi government's hyperextractivist agenda. However, this government's agenda was met by the enhanced capacities of activists and progressive state officials who sought to uphold the rule of law, after the Shah Commission and other investigations had unveiled the illegal mining schemes. For example, at the end of 2014, Subash Mohapatra, a human rights activist, asked the Odisha government to collect unpaid Net Present Value, which the Times of India newspaper explained as "the amount mining lease agencies need to deposit, according to a Supreme Court order in 2002, for diversion of forest land for non-forest use". The unpaid fees amounted to Rs 715 crore (about 0.96 billion euros) from 111 mining agencies. ${ }^{14}$ When the government did not obey, Mohapatra instigated a public-interest litigation to the Odisha High Court, which gave notice in May to the Centre and state governments that they have to collect the Net Present Value. Such residual outcomes are typical in mobilizations, and it is likely that many more collections of unpaid payments, to counter the looting of valuable minerals beyond lease areas by the mining mafias, companies, and politicians, will be made in the future.

Broadening the analytical scope, the situation does not look quite so bright just across the border in Jharkhand. The local resistance has failed in electoral politics and other state embedding, which caused a partial turn to using arms, as this felt like the only viable option left to defend their sacred forests. As discussed at length in chapter 4 , these forests are intimately tied to their way of life, ethnic identity, and livelihoods. State lines, and even the lines of municipalities in many cases, seem to differentiate and even separate activist groups quite effectively in India, which is not the case in Brazil. The affected people, or even the local activists, were not well connected between Jharkhand, Odisha, and Chhattisgarh. There was no consistent communication and cooperation between the nearby mining areas on the JharkhandOdisha border. Therefore, the institution of broader and deeper networking in India seems to hold great promise for effective broader efforts.

I will next discuss the strategies and tactics through which the Goan resistance was forged. This detailed discussion complements the broader approach in part II, which started with an observation of the larger struc- 
tural and contextual changes in overall political dynamics. For example, the consolidation of democracy in Goa and Karnataka during the 2010-15 period was no miraculous structural change, but was created by specific and concrete social actions. Mining conflicts were central in these states' development and exercise of more democratic decision-making over the use of natural resources and the environment. The discussion of resistance strategies to extractivism offers important insights into how democracy has been consolidated in Goa. The Goan case, like the one in Keonjhar, illustrates how the simultaneous use of all five key strategies can have massive impacts. It is important to study several cases and contexts where all these strategies were active to be able to more accurately generalize their causal consequences.

\section{Cross-Caste and Cross-Class Resistance in Goa}

This section explains how the strategies of resistance in Goa were formed. This more detailed scoping of the tactics and tasks involved is important in highlighting what the activists actually did. Another takeaway from this section are the notes on how the overall resistance can actually benefit from the presence of several resistance factions. This finding directly challenges some prior studies on movement outcomes.

The Goan cases allows for exploration of the role that the existence of several cross-caste/class resistance movements can have. It should be noted that in this case, all these movements were fighting for the same goal of resisting extractivism, yet they were based on ethnically or economically differing constituencies, or both. Does this kind of splintering impede resistance success? My results indicate that it does not, but this is premised on the condition that these groups are using similar strategy sets. In the case that they are employing similar strategy sets, the presence of several groups ensures better internal cohesion, and aids in avoiding fights within the resistance based on ethnic/class cleavages. In India these cleavages do exist and are gaining importance as bases of mobilization. I also found that in this situation the multiple fronts of pressure are also a harder target for corporations to stand against. When the Chinese boom started around 2005, Goa felt the effects very strongly. Goa has a mining lease system dating back to the colonial era, which placed large parcels of land under iron ore leases. For example, I found one village that was dotted with twenty-three separate leases. Mining had been accumulating pollution for decades, but this was not taken seriously before the Chinese export boom "made the [many] cumulative impacts visible [at] one time," as an activist explained. Suddenly 
there were many more struggles aimed at preventing mining over the water, agrarian land, and forest use. Yet the powerholders were mine owners and thus very much in favor of mining. These owners had so much accumulated power that their desires to continue mining sidelined the voices of the "organic society." For example, in 2005 at a public hearing in Bicholim that concerned Sesa Goa's project (Sesa Goa Iron Ore is a subsidiary company of Vedanta, operating in Goa and Karnataka), the whole hall, more than 800 people, was against the project, but still the project was given a lease.

In Goa, what followed was the creation of a cross-class movement. All my informants saw this as an inevitable consequence within this situational context. While movement building did not start with the more educated and higher-income people from the coast, it soon included these middle classes. A key channel of this networking was Goa-net, an email list of over 60,000 subscribers, which was used as a platform along with blogging, speeches, and protests (interviews in Goa, 2010-13). ${ }^{15}$ Goa-net attracted a middleclass urban professional audience; it linked the plight of impoverished rural dwellers - whose livelihoods were being destroyed by mining expansion- to the interests of progressive middle-class people seeking to build a new Goa. For example, when the Adivasi village of Velip "refused to compromise" and blocked roads in 2007, blogging about this protest on Goa-net "gave international attention" to mining problems. Activist and blogger Sebastian Rodrigues saw that Goa-net was "really central," as "without it, it would not have been possible to achieve this so fast-otherwise one village cannot achieve results." In 2008, Kolham village revolted, and then others, as they came to know about the issue through this virtual networking.

Besides uniting the lower-class villagers into one movement, the uppercaste people (Brahmins) formed another movement, after "part of them got our messages and aligned with us - we shared information, but they had their own movement, not dictating our agenda," explained Rodrigues. The villagers also got ideas from the coastal activists. For example, the idea to attack mines directly and close their traffic seems to have come from the coastal people because, in general, the "popular movement" was not "experienced in protest organizing." After some initial protests where many activists were arrested and beaten, many coastal people got demoralized and left the movement. The "fearful people were not invited anymore to actions," while the core of the more direct-action group was formed of about one hundred people who were "not afraid of any harassment or arrest."

Different parts of the larger movement specialized in specific tasks related to the overarching goal. Each of these task force teams were led by a particular individual. For example, Ramesh Gauns focused on using all 
possible institutional channels in Goa to question the authority of mining licenses. Additionally, he was a key local movement organizer in his village. Claude Alvares, with his colleagues at the Goa Foundation NGO, focused on instigating litigation in the Supreme Court and other courts (an important dynamic I discussed in chapter 3). Sebastian Rodrigues was concerned with winning over the established media by making the story of mining illegalities in Goa attractive to them and creating new alternative media, like the aforementioned blog. Local villagers organized the protests, which were frequent, almost daily after 2007, although often involving very few people. Yet even these small-scale protests were enough to make big news in Goa. Others, like Samarendra Das, helped with international contacts and networking. Hartman de Sousa took tourists from across India into the mining belt on buses, to spread knowledge of the problems, and wrote assiduously. The looting of mineral wealth belonging to the citizens and its resistance were captured in the local documentary film Goa, Goa, Gone, whose distribution was one way to expand the movement to different audiences. There were also many others who were actively involved in leading important teams. In total, this myriad of actions led to a full use of the five key strategies, which form the core of my hypothesis of what actions are very impactful when used in concert in extractivist conflict. Major positive outcomes in resistance can sometimes even be explained solely through the implementation of the five key strategies.

The mobilization made effective use of campaigning on nonmodernist lines. This kind of campaigning emphasizes that a particular place that would be destroyed by mining cannot be compensated monetarily, as so many lives and existences are wiped away in the process. This nonmodernist campaigning is typically also working more on the level of emotions than the intellect. Strongly emotionally charged discourses about the devastation caused by mines (particularly in rural areas) were crafted and effectively distributed. The main frames were "Attack on Goa" and "Mining Terrorism," while writing open blog posts and giving public speeches were the key communication strategies. Rodrigues thought it was essential to focus on changing attitudes through massive campaigning and what I call symbolic acts of merit, as "Goa is a small state, a fearful state." Movements can be invigorated by symbolic acts that put an issue on the agenda. A particularly useful and impactful facet of this strategy were poetic forms that were charged with emotion. A poem written by Rodrigues called "I Love Pissurlem" was posted on the blog on April 1, 2002, and was subsequently circulated widely in Goa. ${ }^{16}$ Below are a few lines from the beginning of this poem, which calls the people to action against mining, to express their feelings and love for what is being destroyed: 
Mining has played havoc

With the lives of people

With the agriculture

With the forest cover and its

microbe wealth

With workers

With the wells and water

With the tiger, fox and squirrel

With the nests of Mainah, Sparrow

and Parrot

With the habitat of snakes and

Calothes

With the fish, fishing ponds and

Frog

With the natural springs and its

Coolness

With the trees-big and small.

Mining has pumped dust

Into the lungs of neighbourhood

Residents.

Mining has corrupted

Politicians and bureaurocrats

Mining makes joke

Of the democracy of my land.

The efficacy of such poems dispersed via blogs was a surprise. It was regarded as a key mobilizing tool that built bridges, expressed emotions, and united the sentiments of people- - both those previously unaware of the problem and those who shared the views expressed therein. The resistance in Goa was further assisted and supported by the campaigning in two or three local newspapers, which became critical of mining as mobilization advanced. This was further bolstered by some important national newspapers that elevated mining problems to a national scale.

The organizing and politicizing of resistance also took place vertically in many social fields. Around 2007-8 the resistance started to come together, perhaps most visibly in the formation of the Goa Federation of Mine Affected People, a nexus of "20-25 working people" meeting in Panjim to discuss strategies. This group worked meticulously and tirelessly for the subsequent three years. At this juncture, the movement was heterogeneous, had important connections, and knew how to exert political pressure. The Cath- 
olic Church was, for example, used as a space of mobilization—something also true of the resistance in the Carajás region (in Brazil's Pará and Maranhão states), where liberation-theology missionaries had an ingrained habit of pursuing nondiscriminatory movement-building. In general, the movement was a "ragtag alliance, not a strong organization," where "talking strongly made the organizing." In fact, there were several separate resistance groups, of which the Goa Federation of Mine Affected People was just one, though perhaps the most centrally located node. All the groups "had the full freedom to attach [to the larger movement in] any way possible," claimed an activist. As an example of a major resistance group, the Adivasis in Goa, who were concentrated in the south and marginalized, "got up very late" in their struggle but "made a lot of noise," and were instrumental in using the FRA clearance requirement as a tool against mine expansion. Together, the effect of these different groups' attacks against mining amounted to a "struggle against Goliath from different places," according to a western Goan activist.

However, the context for mobilization was not completely in favor of resistance, since many still supported extractivism. For example, corporate agency was very strong, and the state government was deeply involved in mining extraction. Thus, as the resistance movement started gaining traction, for example through a mining moratorium in 2010, its most visible networking activists and ideologues, such as Sebastian Rodrigues, were charged by companies, alleged to be Naxalists, and briefly jailed. Yet this did nothing to quell the disquiet. The agitation got almost all villages protesting, although very few were unanimous in their resistance; about half in eastern Goa was in favor of mining, and the activists I accompanied on field visits to the area were aware that some people were not in favor of their presence in the area.

Village-level mobilization was challenging, and a state-level approach was more suitable for concerted mass direct actions. This was also because village-level protests, such as blocking the road to ore trucks, led to mass action suits by companies against anywhere from fifty to one hundred villagers, and were accompanied by injunctions against the village itself. The battle was fierce, and the stakes were high; under these conditions it was quite easy for companies to break village-level organization. Furthermore, the villagers were mostly "interested only in daily local mine problems," "had no time for activism," and "must be able to come back by the evening." At the same time, by 2012 many people in nonmining areas had turned fiercely against mining, "but do not want to mention their names," as after the mining ban life was hard for workers in the mining area. Yet these shortcomings on the local scale of activism were more than compensated for by the global scale 
of activism, as national and international pressure was considerable through the active networking done by the resistance. The National Human Rights Commission was brought in by activists to investigate the beatings of protesters, and ordered compensation payments, which was "one more shock to companies." By calling in the federal state institution for human rights, and getting its support, the resistance had thus managed to make the federal government "decide it is better to be more sensitive." Gaining this kind of support for the right to protest was a difference in comparison to Eastern India and supports the suggestion of the importance of the context of a nonperipheral consolidating democracy.

The miners tried to use sophisticated corporate countertactics to curb mobilization. One visible activist said to me that the companies' attempts at building a "constituency in mining towns," and using their backing in their several counterstrategies that attacked the activists, was the "most disagreeable aspect of it." He mentioned that if the ban had occurred in Chhattisgarh, the counterstrategies would certainly have included severe violence against activists. In Goa the countermovement included, for example, a statewide road blockade by 600 promining truck drivers on November 27, 2012. Neither they, nor anyone else, expected the "heavy consequence of going to [the] Supreme Court," which led to a complete ban on mining and trucking. This meant that a large numbers of truckers, between 15,000 and 20,000, had their activity curtailed and actions monitored by the Shah Commission and other authorities.

Goa had one of the most visible state coproductions of the Indian cases. I will illustrate this by describing the work of Ramesh Gauns who was the most active producer of new rules and power relations in institutional politics. He was also a key figure in forging resistance agency through the simultaneous use of all the five strategies, which he considered to be the most essential factor for success. He has had a long history as an activist, succeeding in 1997 in protecting a lake near his hometown, Bicholim, the mining hotbed introduced at the beginning of this book. In 2003, he managed to change the way the Goan cabinet of the collector conducted its environmental impact assessments, moving these from remote offices to the actual places of investment. He saw this as the first victory in the battle against mines, and he was later able to build on this success. He got "fully into the business of mining" in 2007, when mine expansion more severely and directly affected his town and the school where he was working. After this it was "an everyday job to find out the area where mines were expanding," and take all the village elders to visit the area, call the media, tell locals to speak on the site, and help locals with media interaction. 
This type of local politicizing was crucial for the success of the movement. Gauns considered that the first phase of such politicizing is to "boost the morale of common men and demoralize miners." After such politicizing, the locals knew what to say, were empowered to speak, and started writing articles themselves. They managed to win over important public hearings by demonstrating that they were all against the mines. However, this did not prevent the authorities from granting mining licenses. This propelled the resistance into trying all other possible strategies of potential influence, including studying laws, organizing protest marches, and using the courts.

It is unlikely for state institutions to uphold the rule of law, especially in the Global South, without activation from a resistance movement. State institutions typically require this kind of external, continued coproduction of their right to operate in contexts of strong corporate-government pushed extractivism. Gauns kept the Pollution Control Board busy by filing several complaints. This is an important juncture in the mining process as the board must give its consent to mines before mining can start. Following Gauns's plea, the board refused consent, which led many companies to file a complaint against the board in the administrative court. Gauns stepped in at this point as well, to make an intervention in the same court to oppose the move by the companies and support the board. However, other professional NGO activists in Western India considered that the Pollution Control Boards are "by and large corrupt," and not autonomous, even though they should be autonomous. Yet a Bangalore-based professional activist commented that though the boards are "weakly set up," they "can be used tactically," and "work sometimes," but in general "take too much energy, so people become frustrated or even cynical." Gauns seemingly was not one of those people with a lack of energy, and he tackled these boards many times.

In line with many activists with whom I have discussed the five key resistance strategies, Gauns considered that the simultaneous use of strategies is indeed crucial. He affirmed that, in his experience, "it is all to be done simultaneously; otherwise you face losing the battle in court and so on." He continually intervened in the Goa High Court, which led to an environmental clearance order given for a mine near his school to be set aside. Local people like him were central in documenting illegal mining operations before the authorities knew of the infractions, producing records that became key evidence in courts when tracing back the events. Gauns won the respect of local authorities and others nationally for his work, and was empowered via awards to concentrate on this work for seven years, denouncing problems and seeking solutions. ${ }^{17} \mathrm{He}$ considered that the most essential part in activism is gaining knowledge, and with the creation of alternative 
knowledge, "you can win over the Goliath if you have the knowledge." This claim suggests that when symbolic space is transformed via concerted efforts, changes in social and physical space will follow.

Besides showing the importance of using the five key strategies simultaneously, Goa is also a unique case in demonstrating that resistance can be dispersed and even have internal conflict, yet still be effective in the outcome. Goa is an interesting case consisting of different resistance movements divided by caste cleavages, and I will end this chapter by discussing the relation of these dynamics to outcomes. Cleavages among the resistance could be hypothesized as weakening its impact (based on, e.g., Watts 2004), but the Goan case suggests that the opposite can also happen. In essence, when a resistance movement is divided into many actors it can be harder to attack, and division and struggles between resistance groups can take place without harm done to the outcomes (this contrasts with Hadden 2015).

After 2010 there was an important rupture in the Goan antimining movement, as some important activists deliberately created an openly antiupper caste movement. One might suggest that claims based on ethnic/caste discord could easily become combustible, but Wilkinson (2013) argues that the growth of caste politics has been generally helpful for communal peace in India, alleviating more volatile divisions, such as those between religious groups. ${ }^{18}$ The Goan case supports this argument, and suggests that castebased campaigning might not automatically be negative for retaining peace.

In Goa, Adivasis were included both in lower-caste and upper-caste-led mining resistance movements. This splintering into different movements probably helped the resistance, as demands and pressure came from two autonomous directions simultaneously. This was not, therefore, a case of networking between all castes in a unified manner-many informants reported to me serious hostilities between upper- and lower-caste activists-but a case of vertical politicizing and campaigning, whereby both upper and lower social power strata are included in a loose resistance front. This feature in Goa is also in tune with my prior analysis of Western India as a "consolidating democracy," as a polity where a splintered society, composed of roughly equally voiced but separate groups, seeks to express the views of their constituents, which can be considered a step toward a deeper democracy.

Upper castes are a minority, while the lower castes or noncaste people are increasingly aware of their power as the majority. For example, after 2010 a portion of mining activists in Goa "deliberately" relinquished euphemisms such as "mining terrorism," a framing that did not mention caste, but was known to refer to upper-caste actions. The term "mining terrorism" allowed for the initial mobilization of a very large group of people, includ- 
ing those from the upper caste. When a significant part of the resistance started to instead emphasize that this terror by mining was done by particular castes and classes, the resistance started splitting into factions. The resistance continued to take place through the non-upper-caste movement, and the movement that consisted of both upper caste and other people. The non-upper-caste movement tried to unite Other Backward Classes (i.e., lower castes), Scheduled Castes (i.e., Dalits, untouchables), Muslims, and Adivasis. According to Rodrigues, these classes and castes comprised approximately 85 percent of the Indian and Goan population (a majority group called Mulnivasis), which were against upper-caste-controlled mining, and thus created a new front of mobilization. Such use of communalism is a key political tool in Indian society's cleavage making and can be very effectively used to mobilize an electorate. Hindu pogroms against muslims have for example been used to unite Hindus in urban areas to combat the tendency of anti-upper-caste politics to diminish the importance of religion as a communal distinction maker (Wilkinson 2013). Anti-upper-caste framings are an especially powerful tool for creating a larger communal movement, and many mining activists were aware of this. "Mulvinasi-movement people are all over Goa and able to connect across barriers within the 85 percent and unite against the attackers," Rodrigues suggested.

This turn to using the mechanism of communalism, working on the lines of vertical politicizing, may have been quite influential. According to Rodrigues, "The top level got scared of Mulnivasi strength. It became a central issue for Brahmins to close down mining to stop the [Mulnivasi] movement [from growing, based on mining/local upper-caste grievances]." Whether or not this caste dimension of the conflict was the key reason for success, I do not know. However, the appearance of an antimining movement that excluded upper castes, working parallel to a more general inclusive movement, increased the stakes and issues in play, mitigated the risk of a perceived "upper-caste takeover" of the movement and made it hard for mine owners to attack just one movement (or treat mining resistance as forming only along ethnic lines). Mining scams were a particularly volatile issue, and upper-caste politicians and businessmen were considered key culprits. As long as these issues were not resolved, Mulnivasi and non-ethnicitybased mobilization grew.

Though splintered into two factions, both general processes of mobilization in Goa shared the same metaprocess of using all the five key strategies simultaneously. There was no clear strategy cleavage between two groups of activists, unlike the global climate negotiation mobilizations in the case discussed by Hadden (2015). Comparing Hadden's anatomy of the rupture 
between professional environmental NGOs using conventional tactics and movements using more radical forms of protest to the case of Goan mining politics suggests that the splintering of a single-issue movement into contentious and conventional strategies is not beneficial in terms of the larger movement's goal. Rather, such a rupture opens possibilities to attack the movement, create confusion, and hinder the use of the five key strategies. Conversely, if the different movements addressing the same issue share similar peaceful strategies (including protests), splintering into two or more factions seems to increase the likelihood of achieving the overarching goals. My finding that several separate resistance groups sharing similar peaceful strategy-sets (as in Goa) have had more success than resistance, which has splintered into factions using both violent and peaceful strategy-sets in the same region (as in Chhattisgarh) supports the analysis by Erica Chenoweth and Maria J. Stephan (2011) on the advantages of peaceful resistance vis-àvis violence. They found that it is easier to attain more people from different backgrounds to join resistance when it does not include violent insurgency. I would add to their findings in Why Civil Resistance Works that within this peaceful resistance it seems to best to (1) have distinct groups for distinct social strata and (2) utilize the five key strategies in all of them.

The distinct groups can operate in different social strata and this verticality can help bring different kinds of people into contact with an issue. Particularly in a deeply communalist society, with cleavages along caste and religious lines that impede normal interaction between certain groups, such a division can lead more quickly and peacefully to the desired outcome. The history of India is replete with failed or too-costly attempts to pursue change through a united front, such as Gandhi's demand for a united greater India that includes Pakistan. Although networking over divisive lines might be possible for a short time, in the long run an artificial top-down unification of movement fronts, whose members have considerable animosity toward each other, is likely to lead to internal conflict that will ultimately weaken the outcome (such as the resistance capacity and willingness, or democracy in India, or the maintenance of good mining regulation), even if there are initial victories.

Thus far, this part of the book has discussed in detail resistance mobilizations in different parts of India, through a multisited political ethnography that looked at the strategies used and their outcomes. In the next chapter, I will discuss several Brazilian cases to show how resistance can forge global activism against extractivism, illustrating the relation between resistance strategies and political outcomes on the global scale. While the Indian cases discussed thus far in this part were clear cases of resistance with major eco- 
nomic outcomes discontinuing extractivist operations, the following Brazilian cases typically had comparatively less impressive economic outcomes, but more impressive global political outcomes. After examining how global resistance agency has been forged in Brazil, the final chapter of part III studies the role of national networks in Brazil and India in curbing extractivism. This last chapter complements the state-level or local-level based political ethnographies of the resistance strategies discussed, looking at the role of national and global efforts and outcomes in resisting extractivism, which allows for a more nuanced exploration of interscale causalities. 


\section{Global and National Coalitions}

To get a more holistic view of the impacts of mining, I tracked the flow of iron ore downstream from the world's largest mine in Carajas in the Eastern Amazon. I followed the railroad tracks by car and motorcycle from the mining site through the land reform settlements, reaching the pig iron plants in the state of Maranhão, where the ore was processed before being shipped from the ports. These regions were among the poorest and most violent of all the destitute regions of Brazil. I slept on floors and in hammocks in the back rooms of social movement offices, and visited the communities living next door to polluting facilities, listening to and experiencing their lived environments. The air was hot and full of smoke from the iron processing plants, and the workers' neighborhoods nearby were full of dust. However, in the same visit, I also sat in the clean and cool air-conditioned offices of the companies and state officials. The locals had for a long time been looking at the iron ore wealth being carried away every day by trains with upward of 300 wagons. There were two worlds existing side by side, and those who suffered the consequences of the mining pollution did not reap the benefits. The locals started to organize themselves to remedy this unjust situation. These uprisings were organized and executed in places that were little known to the wider world. Not many outsiders had been to these places before. I could find scant prior public data on these places or what was going on there in the early 2010s. It was impressive to note how globally impactful movements were first crafted within these peripheral places, the upstream areas of the flow of iron ore. It was interesting to note the parallels between the resistance and the policy agenda setters, when I visited the offices of corporations and mining advocacy NGOs, and movements in Rio de Janeiro and New Delhi. There, chatting over a strong chai or coffee, the key policymakers shared with me the dynamics of national and global iron ore politics. There were many important nodal activists and other people whose scope 
of action was not only local, but even broader. It was interesting to note how their work paralleled the place-based struggles I had witnessed in the field. Much of their work also goes unnoticed, taking place behind closed doors in the cabinets of power. My takeaway from these experiences is that actions targeting the local, national, and global-scale decision-makers are all essential.

This chapter demonstrates the importance of understanding how resistance to extractivism has differing goals, some aimed toward primarily economic outcomes, such as shutting down mining expansion or changing the style of operations, while others focus on political outcomes, such as forging more widespread and deeper activist agencies. The first section of this chapter looks at how local upstream struggles against the international flow of iron ore from Brazil's Carajás region in the Eastern Amazon have been able to forge an important new global transnational coalition that transcends traditional social movement boundaries, for example, through the inclusion of mining trade unions and groups from both the Global North and Global South. This first section will focus primarily on place-based local struggles and their unique strategy combinations. In the second section of this chapter, I will discuss the strategies of the nationwide network movements of mining activists and their role in the politics of extractivism in both India and Brazil.

\section{Forging Upstream Struggles: Justice on the Rails}

Brazil offers several examples of how transnational resistance against extractivism has been created, and I turn now to one of these cases. A national MST director explained the reason for seeking widespread mobilization, which is nevertheless still place based:

[In May 2012 in Parauepebas in] a meeting with many Brazilian organizations working against mining companies and large-scale projects, we met to discuss the possibility of creating a new social movement, because in Pará they already even have the name and symbols for such a [antimining] movement. The objective of this movement would be that families who live in the mining regions, who are impacted by them, would organize, so this would be a movement with an organizational structure and objectives which would fortify this articulation internationally and across territories, because many of the people in the mining-company-controlled territories do not 
have an association, are not organized. For example, the people in Serra Pelada, including the syndicate, were very enthusiastic, saying they would join the movement, as alone they could not manage to win their rights. But in other states the organizations do not need such a movement.... We do not have the position to force action; we have to construct [this new movement]. There is political articulation already, but we have noticed that large mining extraction operations require a strong movement as a counterplayer, not isolated groups that often just study the impacts. There's already a lot of resistance in various states, but more is needed. Now, after the May 2012 meeting, there are heated ongoing debates across states concerning the creation of this movement. (Interview with Ednalva Moreira Gomes, MST leader, March 22, 2013, author's translation from Portuguese)

The movement was created soon after, taking the name Movimento dos Atingidos pelo Mineraçáo (MAM, however, the name changed in 2014 to Movimento Nacional pela Soberania Popular frente à Mineraçáo; more on this change later in this chapter). MAM had an office in Belo Horizonte in 2013 and opened a new one in Marabá in October 2014, which provided a venue for encounters between disparate mining-focused groups. As Ednalva Moreira Gomes noted in our 2013 interview, the movement has been tenacious, as the initial successes by "isolated groups" in Minas Gerais were followed by other outcomes in favor of needy groups in 2014. Meanwhile, boosted by the development of a strong place-based resistance in Carajás, agitation had been stirring on the international anti-Vale front since the 2000s. Resistance was globalizing from an epicenter in the Eastern Amazon's upstream as struggles arose over the control of iron extraction at key points of production and transportation.

The first conscious attempt to create a transnational movement by those impacted by Vale, and targeting Vale, was at the World Social Forum in Belém in 2001 (the following narrative is from an interview with Father Antonio, founding member of Justice on the Rails (JoR) and a member of Combonian Missionaries, March 17, 2011, author's translation). Justice on the Rails was born in Pequiá, but it is part of the larger International Articulation of People Affected by Vale, which includes many different social actors critical of Vale, both in Brazil and abroad. It is notable that JoR, or the International Articulation, was not created as a "not in my backyard" movement. In other words, it was not interested merely in avoiding destruction of the local setting (which was already destroyed). Rather, these resistance groups were created with the intention of warning others of similar dangers 
and seeking to transform the broader setting based on a liberation theology ideology rooted in the lived experience of asymmetric and physically violent power relations. ${ }^{1}$ Father Antonio noted that the JoR movement "was created out of the reality of the very strong injustice [of] mining, the railroad, steel mills, eucalyptus, charcoal furnaces, of environmental injustice, and degradation." The building of the transnational movement was based on the local and global use of all five of the strategies for resistance.

JoR has three lines of action: (1) to build the organization of the movement, politicize the people, and campaign; (2) to engage in judicial politics by generating a series of class action suits in the courts; and (3) to deploy political means in electoral politics, aiming at steering Vale via the influence of politicians. While I was conducting field research in the heavily polluted pig-iron-producing town of Pequiá where Father Antonio lived, he commented on these lines of action:

First, raising the consciousness of communities, about the effects of the doubling of the railroad [Vale tried to double the railroad capacity, which had created new grievances]. We want the company to pay remuneration to communities, not individuals. We have already won remuneration from Vale based on a decision by the judge of Açailândia in favor of the relatives of someone whose death was caused by Vale. Now the people are more aware. Those who have direct experience have a negative view of Vale.

The image of Vale is very real for the people residing in Maranhão, which is the Vale railroad junction and a center of Pequiá pig-iron and charcoal production. A 330-wagon train passes twenty-four times a day, carrying twenty million dollars' worth of iron ore every day. "The money that passes and the ore that we see allows us to see, this is an open vein of Latin America," said Father Antonio, who has been living for years within the impacted population and developing opportunities for mobilization via strategies such as the creation of alternative frames to aid in understanding reality in a critical way, thus politicizing a movement and offering a base for campaign framing. He counters the framing of the company as a "national champion," and provides a critical frame:

Vale is taking abroad the blood, presenting itself as a Brazilian company, a champion of sustainability that protects the Amazon, etc. [In fact, it is] a champion of labor abuse fines, killing people and animals on the rails, expelling families, transporting people [on the railroads] only because it is forced to, so as not to lose the railroad concession. 
JoR has already gained powerful allies through networking during its brief existence. An ex-manager of Vale and a lawyer of the Organization of Brazilian Lawyers - a powerful bar association-has joined the trade union movement that is part of JoR. Father Antonio explained:

He knows all the mechanisms of Vale. We started to work with him with the population in key locations of the railroad. Judges and prosecutors helped us to make the work real. The greatest articulation started on a $100 \mathrm{~km}$ patch stretching from Bom Jesus da Silva to Buriticupu, and since 2009 we have also had meetings in São Luis.

A specialist national movement of judges, called "Judges for Democracy," has also started to help the JoR movement, and there are many prosecutors assisting the movement behind the scenes. This suggests that the movement has successfully embedded the state, while still retaining autonomy. The JoR movement has also achieved extensive cross-national and transnational networking, which is the strongest asset of this small movement in comparison to the movements in the other cases. In Brazil, JoR headquarters are situated in the state of Minas Gerais. They network actively with Observatorio de Conflictos Mineros de América Latina-an observer of mining conflicts based in Peru - and are aligned with the United Steel Workers of Canada.

Contentious politics (via protesting) had not been used to a great extent by JoR until March 2011. One protest had occurred, but it involved only about 200 people. This was a march to the headquarters of Vale in Rio de Janeiro and was not acknowledged by the company. However, during our early 2011 interview, Father Antonio anticipated that in Pequiá they would block the railroad or perform some other more radical protest with greater numbers, "when the time is ripe and right. Protest is a powerful weapon, one that has to be used carefully, pacifically. We have recognized three focal points we can cut, which will influence the whole iron production system." In consequence, on December 7, 2011, 2,000 inhabitants of Pequiá, including workers producing pig iron and charcoal, protested Vale, via marches and blockages of Federal Highway BR222. The complaint that this protest hinged on was the damage caused by Vale's pig-iron complexes, which dominated the industrial hub. ${ }^{2}$ Vale was targeted because it was seen as the principal agent in installing the complexes, and because it "continues to be the real decision-maker," transporting ore and seeking to double iron extraction. A few days later, the state governor visited the area and promised, as a matter of urgency, to commence the construction of new housing for people living literally next to the highly polluting pig-iron furnaces and the unsafe railroad and highway. 
JoR did not engage in private politics such as non-state-mediated direct negotiation and corporate social responsibility schemes. Instead, JoR has bought company shares, entitling its representatives to speak at annual meetings, "just to be able to voice views" as owners; such creation of critical shareholders can be considered a form of embedding companies by the resistance. In comparison, some local MST organizations have received help from Vale and other companies, for example, by receiving the proposed funds for road construction in agrarian reform settlements. JoR has the most radical anti-Vale attitude, according to the Vale directors I interviewed, and does not have any shared projects with Vale's development fund. According to Father Antonio, the goal of the movement has been to start long-term, general public discussion about what a development fund should do in the contemporary world, and thus "to force Vale to work continuously in the municipalities." JoR has not taken the bait to engage in private politics but has worked to improve the rules of the game, and the distribution of games in the overall political arena, by boosting resistance willingness and capacities using particular strategies. ${ }^{3}$

These remarks on the initial steps of the JoR and MST's efforts to create a national and global coalition targeting Vale have been radically realized since 2011. In August 2015, JoR and other new members of the anti-Vale movement toured mining-affected areas all over Brazil, and organized meetings and networking with movements all around the world, with the intent of creating a global coalition. These actions brought very significant political outcomes whose true economic outcomes have yet to materialize. This movement is particularly important as the bulk of it is formed by critical workers' movements that bridge the cleavage of environment versus jobs, including miners and ore transporters at vital commodity-flow points. Globally, Carajás has tremendous significance as the key node of iron ore extraction. Whatever happens with the export-oriented point of production in Carajás and with Vale will have direct consequences for mining workers and towns from Mozambique to Canada and New Caledonia. This allows activists to take their resistance directly to the transnational level, and to unite working classes across the globe into the same network that is trying to steer capital. Ultimately, this means that upstream struggles against iron ore extraction can create transnational coalitions against extractivism.

It is not by coincidence that the global Vale resistance has been built from the base of the struggles at the point of key extraction in Carajás, and that this global activism has been based and made possible-as a political outcome-through the use and building of the five key strategies (and abstaining from private politics and armed resistance). This signifies that the 
same set of strategies (the five key strategies used simultaneously) seem to be generally related to major economic outcomes as well as major political outcomes. However, the creation of new and significant global activist agency has not been the result in all cases that utilize these five strategies. I suggest that one explanation for this is found in the nature of the capital targeted. The case of global resistance against Vale suggests that the transnationality of capital and its extractive impacts across the globe serve as a mobilizing platform uniting dispersed local people and entities into global resistance networks-something that might not occur against different local companies. India, whose iron ore mining projects present a much larger variety of different companies than Brazil (where Vale is by far the key player), has not produced global political outcomes for the resistance to extractivism. This discussion of political outcomes is important to understand the cleavage lines between global, national, and local environmental governance, especially as this relates to when they emerge, and to what extent they do or do not define politics.

\section{National Mining Advocacy and Networking}

This last section briefly compares the use of strategies by the national organizations, networks, and movements that work on mining politics in India and Brazil. National networks and organizations can operate as opportunities for local activists, particularly as they have taken over several of the defaulted functions of the state institutions that are supposed to monitor or steer mining policy and stakeholder relations. However, these are primarily civil society organizations in the formal sense, and they have their own strategies for embedding the state or forging resistance networks on a nationwide scale, or both. Thus, it is productive to assess their role here. I assess the strategies of these national coalitions, and their impact in resistance to extractivism, and the building of different resistance strategies by local groups.

The Brazilian national movement, MAM, experienced a name change in 2014. In a June 2014 interview, the coordinator of the movement explained to me that the new name, Movimento Nacional pela Soberania Popular frente à Mineração, adopted in 2014, emphasizes the national character of the network, and reflects the turn from a movement for those who have been impacted by mining and require compensation to a proactive movement that creates "popular sovereignty" in order to stop mining before it even begins. The national network in India, called Mines, Minerals and People (MMP), has a much longer history and a larger presence in mining politics. 
According to my interviews with its coordinators, the network-involving about 150 communities and twelve support groups-aimed to "keep minerals in the ground as long as possible," but also to follow local views (if they for example preferred to have mining in some form, against a compensation, whose terms the network helped to negotiate). Besides offering contacts, its activities include training people around the technicalities of environmental impact assessments and taking cases to court. In December 2012, the MMP had a "portfolio of 80-90 cases" against companies. In brief, MAM is less focused on litigation than MMP, and more focused on building a radical mass social movement.

The MMP network has three basic strategies that are used successively. In other words, if the first does not work they continue to the second and then on to the third. The first strategy is to create awareness in project areas, educate people about false company information, and teach how to demand compensation and to register grievances. If this does not work, MMP helps organize protests. If protests do not work, they offer help to affected peoples to work with the courts. This suggests that MMP focuses on activities that support the locals to be able to use the five key strategies themselves if they want to, and MMP may become directly involved particularly in protesting and judicial embedding efforts if it is needed. They also support community meetings and exchanges to a degree, but this activity is limited due to its high costs. Since 2010, the MMP has held national meetings, which indicates that several local movements dealing with mining problems are starting to converge under the MMP banner.

Given the many different and often conflicting forms of mobilization by mining activists in India, the MMP network is much looser than its counterpart MAM in Brazil. However, it should be noted that practically all resistance efforts in India are involved in some way with the MMP, whether it is in the form of support or receiving direct assistance. The MMP is composed of a mix of alliances between social movements and specialist NGOs, differing from other Indian mass social movements, like the land rights movement Ekta Parishad, in that it is more closely linked to state governance structures. It has several committees addressing policy, and it also offers legal aid to activists. The coordinating staff is quite small and consists of a handful of traveling national secretariat members that help move cases to the capital in conjunction with the local organizers. Indeed, they find it "necessary" to maintain a presence in New Delhi. According to the MMP, in 2010-12 it was involved in the following five key cases: (1) Vedanta bauxite mines in Odisha; (2) Jindal's Chhattisgarh coal and steel projects; (3) Goa's iron projects, where they were performing "systematic work"; (4) Tata's Kalinga 
Nagar steel project in Odisha, where the Tata company-state apparatus killed twelve Adivasis on January 2, 2006; and (5) ArcelorMittal's steel project in Ranchi, Jharkhand. All these cases have experienced the suspension or closure of projects or mining/steelmaking activities.

The MMP steers away from private politics. A coordinator told me, "Our dialogue with companies is only in court. ... Many companies have come to us, but we have had bad experiences. Companies say, 'what is the problem, we will resolve it."' Yet companies do nothing, and the MMP has been actively working to change this dynamic, and I was told, "now we are framing the companies differently." However, the coordinator emphasized that they are not targeting the companies, but rather the implementation of the law. Initially only the state is involved in legal cases, but later in the process companies get drawn in. This was the case in Vedanta's Niamgiri litigation, which was initially against the Ministry of the Environment, but later the company joined. I asked other important national and local organizations about their views of each other, and their views of the MMP. A member of the Centre for Science and Environment (CSE), a national research organization, argued that the MMP is a "very powerful organization" that has helped to "bring change so that only tribals can own land in tribal areas," which was a "big blow to the industry."

The CSE has possibly been the second-most impactful national network or organization in mining activism, producing the most in-depth independent analyses of mining impacts and problems and trying to change policies in India. A human rights activist in Odisha said to me that the massive CSE (2008) report has made it easier for the government to understand the issue of mining, and that the CSE has had a "role as a bridge in our state, helping in information collection." The CSE, however, is "not contentious," according to one of its coordinators. It does not do protesting: "It is not Greenpeace. ... O Our biggest strength is data-based research to show government is doing something wrong."

Brazil has a similar organization, the Brazilian Institute for Social and Economic Analysis (IBASE), which has published extensive alternative proposals on mining policy, and is collecting data and doing deep analysis of mining and other important extractive sectors. However, in comparison to CSE, IBASE is much more rooted in mass social movement organizations, in addition to its role as a top-notch think tank. Yet the CSE has more resources and is more embedded in the state. The CSE has also been influential through the publication of a renowned national magazine and the delivery of extensive reports to the public. Both IBASE and CSE have taken over functions that the state has defaulted on. A state bureaucrat told me 
that "even ministries do not have the information [on mining] coded and consolidated" to the same extent and depth as the CSE. My review of existing publications on the mining sector revealed that this was the case. The CSE sees that improving transparency is the key to solving these problems: "The CSE sheets [on mining] are the only data in the public domain. Transparency is the most important thing." This has changed since 2013 with the Shah Commission and Supreme Court producing detailed data, but they are not as easily accessible or readable as the CSE sheets.

In many ways, therefore, these civil society organizations form a part of the de facto state by performing functions that should be done by the state. Such an occupation of state capacities by critical NGOs can be seen as a boon to mobilization and activism in the sense that it is much easier to embed these semistate apparatuses than the official state institutions. This is particularly true in political systems where institutional politics are almost completely steered by the results of electoral politics, as in India. In Brazil this was not such a big issue (in the period before 2016), when the autonomy of proper state institutions such as the Ministry for Agrarian Development allowed the landless movements to embed the ministry thoroughly and use it in the same way as the Rural Caucus of large landholders has almost completely embedded the much larger and more powerful Ministry of Agriculture.

Both agribusiness and the MST have largely retained their autonomy despite their coproduction of these Brazilian ministries and other state institutions. A CSE member argued that "we work with the government, but [also] against them. I need to have the dialogue with the government to get something done." The CSE was the crucial bridge maker with local communities in the Manmohan Singh central government's attempt to draft a new mining bill. According to the CSE member, "we went to places and organized dialogues, educated people about the bill, giving everyone a space to dialogue." Unfortunately (from the point of view of crafting a solid mining law), the government changed, and these efforts were rendered almost fruitless. This sudden shift caused by governmental change demonstrates the danger in single-party-focused electoral embedding; from this point of view the production of new institutions or institutional rules would be safer. The CSE has also participated in institutional embedding activities. They were a key organization pressuring the central government to set up the Shah Commission in 2009, through their work collecting research data on how much money the government was losing due to mining mafia thievery. Indeed, the establishment of this commission was seen by one member of the CSE as its first significant impact. She was possibly too modest about what the CSE 
achieves - several independent observers agreed that the organization plays a salient role in government embedding, talking their language, and having the right connections at the top. In fact, institutional coproduction at the federal level can be far more powerful than electoral embedding, as it can change the dynamics of how candidates get elected. After the Shah Commission gave recommendations concerning moratoriums on mining, the state governments "had to follow these to get reelected." ${ }^{4}$

In addition to the MMP and CSE, there is a third, more grassrootpoliticization-based national movement network working closely on mining activism in India, the Campaign for Survival and Dignity (CSD). These three networks overlapped and included organizations and movements that were interconnected, but also separate groups. According to one of CSD's coordinators, whom I interviewed several times in 2012 and 2013, CSD is a national platform of Adivasi and forest dwellers' organizations operating in ten states, mostly in the civil war contexts of Eastern India. They are a key platform for pursuing the Forest Rights Act, and a considerable actor in India, much like La Via Campesina's Brazilian organization. ${ }^{5}$ According to one of its national coordinators, the CSD (which consists of 150-200 mass organizations that have their own state-level federations and a very large number of members) takes a more general view of mining, treating its problems as part of general land-rights issues. The CSD coordinator noted how "it does not make sense to look just at mining," as, in general, he saw that it is "the same principle_capitalism — that is applied in all these struggles" where nature is seen as "resources."

The CSD is radical in comparison to MMP and CSE and steers the furthest away from dialogue with corporations or the state: "we don't want to fall into the trap of the state; mining is not our [issue], but the state's issue." By this the coordinator of CSD meant that they do not even want to start talk about "mining" per se, as they are rather advocating for the talk to be held around the "forest rights of people," as their goal is "a collective control of land and resources, also against mining of course." The movement aims to support the vision and development of alternative spaces controlled by the peoples' alternative culture, in the same vein as the MST in Brazil. CSD has gained more traction since 2002 with the explosive rise in mobilization in India, moving toward agitation increasingly based on mass movements (not NGOs). The framing of its goal very closely resembles the latest form and goal of Brazil's new national antimining movement, MAM, which is nevertheless a very small actor in comparison to CSD. While the CSE, along with many other NGOs, held Minister of Rural Development Jairam Ramesh's actions in very high esteem, a CSD member called Ramesh's land reform 
promises "mostly meaningless," demonstrating the different stances among the Indian national networks.

In comparative terms, the three large national networks in India (MMP, CSE, and CSD) have had more activists, greater resources, and have been more successful in closing mines than the national organizations in Brazil. However, most of the attention of national-level networking in Brazil has been much more international from the beginning, aiming to create a globally new movement for targeting large mining corporations. This has taken form in the movement called International Articulation of Those Affected by Vale, in which JoR and the MST are key members. Their main goal has been to build a radical mass social movement that is global and has many constituents. The results of this difference in scope-national versus international—are still to be seen.

The Brazilians sought primarily political outcomes, and with this political focus they created more coherent and encompassing national activist networks around mining than in India. Carlos Bittencourt from IBASE emphasized the importance of this national political networking; after a few years of such efforts, a "national public debate on mining" has started in Brazil. There have been important synergies in uniting the struggles of local communities, which have learned the logic of litigation. Companies are now recognizing that resistance can slow down and cancel projects. They have also realized the importance of mayoral support for movements: "it is possible to win small victories now." Major victories have even been won, such as discontinuing Apolo in Belo Horizonte, but the clearest victory, according to Bittencourt, was the bauxite mine project blocked by the villagers of Jurutí in Pará, next to the Amazon River. ${ }^{6}$ Future research should consider these early major resistance initiatives in the context of the historical iron ore boom, and see how the differences in created political agencies influenced future economic outcomes.

Part III has described and analyzed many important and as--yet unheard of and undocumented struggles from places cast as global peripheries, where local people have stood up to resist the turning of their homelands into resource frontiers and points of extraction, appropriation, and dispossession. The rich, empirical depictions offer many insights into how people can resist the expansion of destructive projects even in very difficult situations, and without resorting to violence.

Part II examined the major cleavage lines that explain how resistance does not take place in a void, but in social settings that offer different opportunities and threats to activism. The takeaway message from this comparison is that we need more analyses that do not compare blindly across all dif- 
ferent types of polities and settings of broad political dynamics, under the assumption that social mechanisms and causalities can be generalized across the board, but also make contextual and contingency analyses. Having done this before moving into a concentrated analysis of strategies and their relation to outcomes in part III, it is possible to say that a surprisingly large portion of different strategy combinations' causal relation to outcomes can be generalized.

In sum, the hypothesis has proved robust in explaining the Indian cases; the use of the five key strategies was sufficient to bust the boom of iron mines across all the cases. This was not, however, the case in all the Brazilian cases, suggesting that the contextual and contingency differences between Brazil and India, and among the Brazilian cases, are important to understand the limits of generalization. The five strategies were always important in one way or another, creating either crucial political or economic outcomes, but sometimes the local resistance faced an extractivist push and violence that were too much to handle, even by a potent peaceful resistance.

Parts II and III brought forth competing and complementary explanations that placed maximum pressure on the initial hypothesis, so that the concerted examination of the strategies' impact would not be based on a naïve romanticizing of activist possibilities, or on a shallow understanding of causal complexities. Most studies on social movements against extractivism have focused on the roots of mobilizations, trying to explain why people resist (Conde 2017; Haslam and Tanimoune 2016); it is an even more complicated task to study how they produce or do not produce the outcomes that they do, and to explain the role of resistance in the overall investment politics, as has been done here. ${ }^{7}$ I have tested and refined these five resistance strategies via the study of contexts, contingencies, and multiple cases. The hypothesis alone is sufficient to explain when extractivist booms can be busted. This book has analyzed the resistance to the global iron ore boom in Brazil and India. Next, it is time to draw conclusions. 


\title{
Conclusion
}

\author{
Resisting the Global Political Economy \\ of Extractivism
}

After finishing the field research trips for this book in Brazil and India, I was invited on a trip to Canada as an observer of their mining sector governance mechanisms. I represented civil society; I was accompanied by representatives of industry and of the state. We visited the mining region of Sudbury, whose tall forests had been cut and burned in their totality to fuel the nickel smelters, whose sulfur emissions had turned this onceverdant region into a moonscape. Now some trees were growing like in the Arctic, as miniatures, after enormous efforts of restoration - an artificially made Lapland fell with dwarf birch and tundra-like landscapes. We observed the corporate-community meetings in Canada, which offered glimpses into how the most critical voices were silenced and not welcome in the so-called stakeholder dialogues. In a meeting in Ottawa, mining executives pondered how their industry association should reward the best performing corporation. Many options were weighed, including a fist-size model of the Earth, made of metals, or something like a glass placard. The globe made of different metals won. These experiences were helpful when developing a conceptual framework on the political games that are used in investment politics, which include not only state-mediated politics but also private and other kinds of politics. In one visit I was invited to a mining company headquarters in Toronto, the mining capital of the world, where half of the global mining equity financing is done. Disconnected from the earth on the thirtieth floor, one corporation's directors were proudly explaining how each floor of the building was responsible for managing a different mineral, and that they led all the global operations of making money with that mineral. While this Toronto tower gleamed, the sky was dark and stormy as rain poured down the glass and steel walls 
of the tall building. Being an up-close participant observer to the sheer magnitude and clout of the corporate side of mining expansion, from Canada to Finland, Sweden, Brazil, India, Peru, and elsewhere, was important to understanding the true globality of extractivism, and what the resistance movements were actually up against.

I started this book by explaining how I went to Goa in 2010 and 2019 to understand how the resistance to mining extractivism in India resulted in a globally unprecedented wave of discontinuation of over half the iron ore mines and scrapping most greenfield projects. As I am writing this conclusion, in September 2019, the mines in Goa remain closed. Activists keep on advancing their cause, even reaching further cancellations of mining leases. It seems that these activists have managed to forge a robust will to resist. This book has explained how this resistance can be forged in the myriad situations faced by those whose homelands have been cast as extractable regions. A broad lesson that came out of this exploration into the lived experience of mining resistance in India and Brazil is that the best results came when five key strategies were used in combination, and conciliatory strategies were actively avoided. I will readdress these strategies throughout the conclusion as I tie up some of the loose ends around this multifaceted research topic. By way of review, the five strategies are: (a) organizing and politicizing a mass social movement; (b) campaigning by nonmodernist framing; (c) protesting peacefully and physically so that this is noted, for example by blocking important resource export routes; (d) networking; and (e) state embedding actions that redefine the rules or power relations of electoral, institutional, and structural or judicial politics, or both, while retaining autonomy. The long-term observation of the practical and theoretical lessons learned by the resistance movements around how to start and make change was the basis for the development of the concise articulation of these strategies. These strategies should be heeded and utilized by future resistance movements as the problems caused by global extractivism and solutions to the climate and socio-environmental crises described herein are likely to become ever-more central and pressing around the world.

This book compared several different locations in Brazil and India that have shown signs of a marked increase in resource extraction, but differ in contextual, geographical, and sociocultural settings. This is the first book to systematically map, document, and compare the politics of such a large number of iron ore mining areas and projects in the world. In addition, this project also took into account most of the related steel plants, as these sites provided an important set of unique, but related, political dynamics in 
both Brazil and India. Maps 1 and 2 served to spatially situate the projects during the 2005-15 study period. These maps were qualitatively produced based on my experiences in the field, as the information regarding the true extent of these projects is not easily gleaned from the available geographic data, which comes mostly from the companies or the government. The process of producing these maps served as a grave reminder that the true extent of a project area is made up of many different types of space, including the sociocultural-these maps honored this more complex geography. In the process of surveying and ground truthing the extent of the project areas, I encountered widespread and deep conflicts, which had innumerable human rights and other violations in these extractivist regions. There is even a major civil war being consistently waged around the question of whether iron ore extraction should or should not expand into forests inhabited by indigenous populations. It is surprising how little knowledge has previously existed (outside the immediate battlefields) on these conflicts and projects, especially given their global centrality. Thus, an important mission of this book is to document and bring to light these cases.

Beyond the documentation of an important slice of global extractivism and the resistance efforts, my theoretical starting point was to seek commonalities in how movements have influenced investment pace and style despite contingencies from the grassroots perspective. In this conclusion I will first summarize the key points and then situate these findings in the appropriate broader literatures, illustrating how these conceptual frameworks influence broader and specific theorizations. I will pay specific attention to the contribution of these analyses to the study of contentious politics, investment politics, world-ecology, and global environmental governance. Finally, I will discuss the general implications for global extractivism as suggested by these cases, and I will point toward new directions for research.

\section{Contentious Politics and Investment Outcomes}

The findings provide new insights, which focus on the outcomes of civil society strategies, mobilization trajectories, and the differing dynamics of contention in the recent global commodity boom. Although these insights are not limited solely to the study of contentious politics, this analysis serves to extend the agenda of that field, by demonstrating that there are multiple possible pathways to reach the desired outcomes, particularly via the use of differing sets of strategies. I have tried to answer the call of McAdam, Tarrow, and Tilly $(2001,2008)$ for a more dynamic and relational approach 
to studying social movements. McAdam, Tarrow, and Tilly (2001) theorize on several generalizable mechanisms of contention, through a focus on the characteristics and the role played by these mechanisms in mobilizations. However, these authors do not make any claims about the causalities these mechanisms might have in relation to mobilization outcomes, which is an important facet of the larger discussion.

Iron Will contributes to the social movement literature by outlining in detail the complex causal interrelationships that exist between strategies, dynamics, and outcomes. My working hypothesis was that the simultaneous use of five specific resistance strategies could explain investment outcomes. In order to test this hypothesis, this book examined the relationship of these strategies to outcomes, through political ethnographies of place-based struggles. Partly as a way of introducing the cases and the overall settings and polities where these take place, part II looked at how discrepancies between political dynamics and contextual factors might offer better or complementary explanations. By way of example, I found that the cleavage between an armed conflict and one without two-sided use of arms carries major explanatory force. Nevertheless, certain strategies do seem to carry general importance in resisting extractivism. The working hypothesis was that five key strategies could generally explain when extractivist booms are busted by resistance movements. This hypothesis received robust support and proved sufficient to explain all the cases across India, but not the cases in Brazil. The reasons for this discrepancy were explored by incorporating a comparative study of political dynamics, contexts, opportunities, and contingencies. This analysis shows how resistance strategies produce outcomes, but also that the causalities are intermediated by polities and contextual contingencies.

In order to identify these strategies of resistance, as well as many other important factors, I have developed a conceptual framework based on multiple, contextually varying empirical cases that do not easily fall into traditional Marxist labor emancipation, modern social movement, or environmentalpolitics analyses. The two resulting conceptual frameworks of the political games of policy-making (figures 1 and 2, chapter 2) and the spatial causalities of power relations (figure 3, chapter 2) are powerful and complementary explanatory tools, as they are based on detailed, yet large-scale, analysis of empirical realities. These figures when taken together offer a tool set to study the quality of state-society relations, as well as offer a comprehensive explanation of causalities in investment politics. The framework is helpful in explaining the locally specific governance settings in their multiplicity and complex interrelations, instead of imposing a rigid framework on top of complex realities. At the same time, the framework allows a comparison 
across very different cases, as the political games and spaces identified are loose enough as heuristic tools. This analytical framework offers the possibility of understanding the global political economy and world-ecology through incorporating comparisons across differing sets of extractivist and investment politics.

My Indian and Brazilian field research between 2010 and 2014 disclosed that all iron ore mining projects in Western and Southern India (i.e., Kudremukh and Bellary in Karnataka state, Salem and Tiruvannamalai in Tamil Nadu and Goa) had been discontinued, and quite a few in Eastern India as well-this was the work of ongoing, globally unprecedented, antimining mobilization. In Brazil, the Eastern Amazon (Pará, Maranhão) has witnessed some changes in investment style as a result of the mobilization of the poorer working classes into social movements, while the clearest project discontinuations have occurred in the state of Minas Gerais. The third principal iron ore producing region in Brazil, around Corumbá in Mato Grosso do Sul, had not experienced major mining curtailment based on a resistance effort. However, this region produces a relatively low-production volume.

This book responds to calls by Bosi, Giugni, and Uba (2016), Amenta et al. (2010), and others for rigorous research on movement outcomes. By analyzing these important yet previously unstudied cases, I have demonstrated empirically that movement action coproducing new electoral politics can be influential. This influence is shown through actions, for example, by signing antimining MOUs with prospective political candidates in local regions, and then pooling votes for these candidates, as in the Keonjhar case. Likewise, analysis of the Iron Quadrangle of Minas Gerais, around Belo Horizonte, emphasized the importance of city politics in supporting resistance efforts. Successful state embedding, including electoral politics, is a central component by which mayors and other politicians were incorporated into resistance movements, and is a powerful strategy that has both political and economic outcomes. State embedding also creates a changed reality for future movements, providing them opportunities to more reliably secure favorable outcomes. I also found that court litigation can be a very effective tool, but it should be used with caution. Simple litigation, without prior judicial embedding with resistance autonomy, typically requires building skills and capacities via organizing, campaigning, protesting, and networking. Direct litigation without the use of these other resistance strategies before or simultaneously can be perilous and have an unintended backlash.

I study which causal condition complexes of strategies of resistance were related to what outcomes. The findings suggest that the simultaneous use of many strategies more securely leads to better outcomes from the movement view- 
point, which is in line with the findings of prior movement outcome studies (Luders 2010; Kröger 2011, 2013a). By contrast, engaging in private politics initiated by companies (e.g., stakeholder dialogues) seemed to not have a positive impact on boosting resistance or influencing investment outcomes. This resonates with previous studies on the negative impact of dialogue with stakeholders for activists and civil society that is adversely affected by investments (Maher 2014; Zhouri and Valencio 2014). The cases with the strongest engagement in private politics also had the least vigorous creation of resistance and the least impressive economic outcomes.

These findings are globally important. The Pará and Maranhão mobilizations had major global political outcomes, with the result of boosting resistance elsewhere, and therefore are the most interesting for a study of how transnational coalitions against extractivism are forged. Both the MST (Pará) and JoR (Maranhão) mobilizations against Vale managed to influence the company's investment pace and style, and not only in their local operating areas as the movement's networking has been transnational and helped to politicize those impacted by Vale's operations from Canada to Mozambique. Both mobilizations shared the simultaneous use of the five key strategies, which suggests that while the use of these strategies might not lead to discontinuing all mining operations in all places, their use is likely (and possibly even more importantly) to lead to the creation of new political agency that can shape global environmental and investment governance.

I also found that not all the five key strategies have been necessary to bust mining booms - in some cases the use of a subset of these has sufficed. Yet, even more importantly, some of these strategies were more crucial than others for blocking or discontinuing projects. In India, the necessary (but insufficient) strategies for peaceful resistance to either halt or stall the expansion of mining have been peaceful protesting and avoidance of private politics. In terms of movement scholarship, these findings support Walsh, Warland, and Smith (1997), who found that resistance was more successful when using political instead of legal tactics— both protesting and avoiding private politics are largely political strategies. However, I found that the legal path, specifically through the embedding of judicial politics, could bring great success for resistance in the right political opportunity context, such as in the case of India's Supreme Court design. In India, as discussed in chapter 3, specialist legal NGOs focusing on environmental issues, and having the right connections inside the Supreme Court, can make petitions directly to the Supreme Court's Green Tribunal, skipping the lower level courts and getting specialized and good attention to their petitions relatively quickly. Such an opportunity is not present for similarly equipped NGOs in Brazil. 
This supports Evans's claims (1995) that the mobilization in Kerala that he studied would not have been successful without the already-existing, bureaucratic coherency, which assured at the federal level that the movement could embed the state. However, in order to use judicial politics toward the desired ends, movements had to have already been using political tools to create the willingness and capacity to contend among the civil society. It is essential that they had to be able to not only embed but also to coproduce new rules and working practices, and thus power relations, for the state-remediated political games - this reinforces the primacy of politics.

Forging unforeseen willingness to resist extractivism, this "iron will" activism, within a large group of people has lasting and important developmental and democratic ramifications. In Brazil, a horizontal expansion of contention was created, leading to a new movement network with the specific agenda of targeting a multinational company (Vale), and expanding both nationally and transnationally among those directly affected. In India, populations in Goa became more involved and critical of the politics of mining across ethnic and class lines. The comparison revealed that any attempts to steer mining policies in a better direction were either grassroots-led or professional-NGO based, or both, and not proactive top-down government processes. ${ }^{1}$

\section{Can These Findings Be Generalized?}

In comparison to another natural resource sector, industrial forestry, which has been the main focus of my academic work, the causalities in iron ore politics have greater differences than similarities between the cases. In largescale pulp investments, a set of resistance strategies similar to the five key strategies was necessary and sufficient to lead to either discontinuing or slowing down the pace of tree plantation expansion (Kröger 2013a). In India the (economic) outcomes of using the five key strategies were generally more impressive than in Brazil, in both forestry and mining, halting to a greater extent both the expansion of industrial tree plantations and many mining projects. Since success seems to breed success, there looks to have been a marked difference in the variety of resistance possibilities (using the same strategies) available in Brazil and India. Although both Brazil and India were consolidating democracies during the study period, which ran until 2015, it has generally been easier for the resistance to reach major outcomes in India than in Brazil. ${ }^{2}$ On one hand, this suggests that variations, particularly 
in political systems and the social contexts of activism, but also in the issue examined, render it difficult to universalize causalities between strategies and outcomes. Overtly universalizing claims purporting to explain how movements are most influential should be avoided. On the other hand, these findings do exemplify that the more deeply, broadly, and simultaneously the five key strategies are used, the more likely it is that resistance will reach its goals. Context and issue function as amplifiers or mitigators of the impact, but so does the depth or superficiality of resistance. For example, the readiness of the elite to deploy violence and limit the use of democratic channels to report grievances can be countered by using all the five strategies. The actions in Odisha, for example, demonstrated that a very effective form of peaceful resistance was to fill the physical space targeted by companies with locals.

These findings are likely to hold in other contexts, based on the existing mining literature that I consulted for this study. Most of the research on extractivism and its attendant conflicts has focused on the general mining projects of Spanish-speaking regions of Latin America, many of which have been shelved by resistance efforts. This book has expanded the study of mining-based extractivism through the deep ethnographic examination of rarely studied contexts. Based on my investigation and evaluation of the existing research on extractivism in Latin America, the simultaneous use of the five key strategies has led to a massive wave of high-profile mine blockings and closures throughout the region. It should be noted that the key strategies that are most often used in these situations are organizing and politicizing strong local mass social movements with a focus on concerns about the impact of mining on water, agriculture, and forests. Arce (2014), Bebbington and Bury (2013), Broad and Cavanagh (2015), Haslam and Tanimoune (2016), and the EJOLT project Environmental Justice Atlas ${ }^{3}$ provide accounts of the large number of successful mining resistance cases, particularly in the Andean countries and Central America. ${ }^{4}$ In the Andean countries and Central America, mass social movements have been particularly visible, and, not surprisingly, quite impactful. This is also clearly seen with a recent large iron ore project in Uruguay, which was successfully blocked by a resistance movement. In Peru, mobilizations against resource extraction have led to a number of other important changes, including the political outcome in 2011 of electing President Ollanta Humala, who listened to the demand of movements to have prior consultation, requiring consensus on extraction from locals, as a law, while particular resistance cases, such as against the Yanacocha project in Cajamarca, led to important national-scale changes (Arce 2014). 


\section{Why Was Physical Protesting a Key Factor in Resisting Extractivism?}

Disruptive and innovative protests have been found in general to work well for movements (Tarrow 2011). They do not have to target elected state officials; disruptive mass protests aimed directly at corporations can be a direct and effective way to reduce their power to influence the government. In addition, mass protests serve as a mechanism to urge corporations to think twice about proceeding with their investment (Young and Schwartz 2014). Based mostly on U.S. cases, Young and Schwartz (2014) argue that targeting economic actors to change government policy is more effective than targeting politicians. In the natural resource sectors, mass movements can block the flow of commodities more easily than in service sectors such as banking or retailing.

The resistance efforts I observed have led to major changes in the actual possibilities to expand or continue the economic activities of mining, but to fewer changes in official mining laws. The choice of resistance movements to primarily target the operations of companies at the point of production has led to some government policy changes. In quite a few cases there have been greater royalties, greater respect for prior consultation, and a tendency for powerholders to clamp down on heavily destructive mines. However, the major policy outcomes, on the actual use of environments, have come from the de facto political blockage of projects, not from the de jure rights of the citizenry. This finding supports the aforementioned claim by Young and Schwartz (2014) that targeting economic actors to change policy is more effective than targeting politicians. In my data this concept applied locally, but was not so clear nationally.

Disruptive, pioneering, nonviolent, and massive protesting surfaced as a necessary condition for movements' ability to significantly influence investment trajectories. While protesting is a necessary causal condition in slowing extraction projects, the use of this mechanism alone was not typically a sufficient condition for change. Earlier studies of environmental activism in Brazil support this finding, confirming that combining the use of both contentious and conventional means of resistance is far more likely to guarantee an impact (Hochstetler and Keck 2007). Both Brazil and India from 2000 to 2015 had many regions that were undergoing a consolidation into democracy. This offered several innovative federal-level possibilities, which had not yet been tapped into, and were unlikely to be developed without their active coproduction by civil society. Thus, using the contentious strategies of state coproduction, movement autonomy, and capacity building simultaneously was a fruitful avenue for civil society to become a key partner in building 
democracy. This can result in encompassing embeddedness, which Evans (2010) sees as a cornerstone solution for building twenty-first- century developmental states that also solves many of the problems related to the deep and seemingly unsolvable developmental dilemmas of today.

\section{Iron Ore Cases as Challengers of Existing Knowledge on Land and Resource Politics?}

These new mining data allow us to challenge several previous claims made in scholarship, for example, regarding resistance to land grabbing and environmental conflicts in India. Levien (2011) argues that India's agrarian countermovements have been successful in politicizing land acquisition more broadly, which puts states on the defensive and disrupts their abilities to broker land for special economic zones and other ventures. Undoubtedly, iron mine closures build on land politics, but nevertheless the success of mining resistance is arguably greater than that seen in other sectors. This may be related to the resistance strategies in use. Those studying land grabbing, dispossession, and the general resistance to these activities in India, such as Levien (2011, 2012, 2013b, 2018), have argued that cross-class alliances are a typical feature of local resistance in these fields and that movement organizations are typically ad-hoc, autonomous, single-issue, and not affiliated with political parties (Levien 2013a). Apart from the autonomy claim, for which I did find support (autonomy failing in only two of the sixteen cases of Indian iron mine dynamics), the features above did not apply. Cross-class alliances were present in only four cases. Most movements were party affiliated. ${ }^{5}$ Most mining movements were not just mining focused, but had already mobilized to resist the unchecked expansion of forestry and GMOs, and around other issues. These were not just ad-hoc movements formed specifically for mining resistance, but rather were building on deep roots of activism over a long period of time. These findings illustrate a deep need to reassess the existing understanding(s) of India's rural and environmental social movements.

The findings also help to change the focus in the debate on endowmentbased "resource curses" (see Watts 2004), tying geographical and political explanations more fully together instead of pitting one against the other. I found that ecological endowments are not fate, but the geographical particularity of mines is an important political component that movements can use strategically. Mines are easier targets for resistance to achieve their goals than more movable investment projects if (a) the resistance has knowledge of 
potential immobility and manages to use this as a bargaining tool, and (b) the targets are not desperate enough to use any and all means to push the project through.

Upstream struggles to choke the flow of resources at the source (Bridge 2010) were of great importance in busting the boom of iron mines. This stands as a key finding and answers Gavin Bridge's call for more studies on these upstream strategies, instead of looking just at downstream strategies. The discrepancies between the politics (particularly resistance strategies) of coltan (Nest 2011), bauxite (Padel and Das 2010a), nickel (Kirsch 2013), and iron ore show that resistance has gathered downstream around some minerals, such as coltan (through actions like boycotts), and upstream in the case of other minerals, such as iron and other bulky minerals. Bauxite and nickel are somewhere in between the upstream and downstream approaches, with successful resistance efforts having relied on both strategic positions. Point-of-production politics, like those the population in Papua New Guinea relied on, were the basis for the social movement's ultimately managing to convince buyers not to buy nickel from the mine (Kirsch 2013). To achieve their goals, it was necessary to organize and politicize a resistance group that could make an in-depth study of the spatial distribution of nickel capital. These studies traced the global production network and commodity chain in an effort that Kirsch (2013) called a "politics of space." In contrast to the three aforementioned minerals, due to the globality and generality of iron ore, the options of both consumer boycotting and tracking and pressuring commodity chains are less usable, and most politics revolves quite limitedly around resistance at the points of production and the logistical network in a more Mitchellian way of obstructing extraction (see Mitchell 2011).

\section{What Was the Role of Corporate-State Agency?}

I also studied the role of corporate agency, third parties, and the state. My database included both small and large companies, and government and nongovernment prioritized project areas. The mining literature suggests that the odds against blocking state-backed mining investment are overwhelming in many political systems, though the existence of countermovements can slow this type of investment (Gerbode 2011). In the Carajás region of Brazil's Eastern Amazon, the most important national "resource frontier" in the country's growth strategy (as the region is officially called), expansion is principally driven by the federal government (Kröger 2015b). Goa's mining expansion, on the other hand, was largely a 
private-interest, substate initiative led by upper castes or classes, or both, rather than the federal state apparatus, which regards Eastern India, and not Goa, as the nation's principal region to be turned into a "resource frontier." Not coincidentally, these regions are also mostly densely forested homelands of indigenous populations, which are framed as in need of "development." A related key factor is the presence of large steel plants in Eastern India, which are thought to require the opening of new iron ore deposits nearby. This has provided a markedly easier playing field for Goa's antiexpansion activists compared to that in Carajás or Eastern India. It should be noted, however, that the feat of fully halting all mining activities in Goa and rendering them difficult to fully reinitiate was not a predictable outcome. Meanwhile, although the resistance did not bring mining to a halt as in Goa, the activists in Carajás have managed to significantly influence the expansion pace and style of the extractivist practices. These findings suggest that in the politics of extractivism, the presence of a key national or global resource frontier means a much harder context for resistance, in terms of state-corporate agency and the target. Facing a situation wherein your homeland is labeled by the government or would-be "developers" as a "resource frontier" or a "periphery" does not necessarily seal one's fate. This was seen in the many cases where resistance was nevertheless able to block turning their lands into extraction zones whose people are treated like they do not matter and that they must surrender their way of life for a "greater good" to provide minerals for outsiders, these indigenous peoples barely using or needing them themselves (such as Keonjhar and Rowghat). In these contexts, however, the process of resistance is likely to be more difficult, and the extractivist violence tougher.

The underestimation of resistance potential by the targets of these efforts was a factor that augmented success outcomes. This suggests that an elite attitude can support the ability of resistance to steer investment. These findings are relevant not only for the movement and corporate social responsibility literatures but also for the study of site-based politics, which explores the implementation of large-scale projects and the presence of conflicts. This existing literature has found that not taking resistance potential into account, or adopting a solely technocratic and expert-based approach to determine where an investment site will be, has led to serious trouble for corporatestate agency to implement projects (Lesbirel and Shaw 2005). My analyses corroborate these findings, and in particular the case of the POSCO resistance in Odisha offers a classic example of this underestimation. Investors' underestimation of resistance potential is not, however, a necessary factor in influencing investments. Even in cases that did not have this corporate- 
agency weakness, resistance was able to attain investment changes and boost mobilization not only locally but also in other places.

It is important to note that neither India or Brazil had mining-critical national business elites or governments - two nonmovement conditions that Broad and Cavanagh (2015) found crucial for explaining when mining bans have occurred. In fact, the elite and all the governments in the period studied (2000-2015) were markedly extractivist in both countries. Considering this, the outcomes are impressive, and illustrate how "easy" contexts are not as essential for resistance to emerge or to have powerful impacts, contrary to what is assumed in the bulk of social movement theorizing. Yet, when looking at the dynamics locally, in places with a significant industry sector that would be negatively impacted by mining, or that for some other reason was silent instead of defending mining, the results were more impressive for resistance than in the cases that lacked such economic third parties. This was the case with beach tourism in Goa, historic tourism in the cities of Mariana and Congonhas in Minas Gerais, and religious tourism in Tiruvannamalai in Tamil Nadu. This condition was also present in areas with nontourist sectors, for example, in Kudremukh with agriculture, and in Salem with the textile industry. These factors eased but did not cause mobilization efforts.

\section{Does Armed Resistance Pay Off?}

Often armed resource conflicts are left out of comparisons, as they have been suspected to have such radically differing dynamics that they require their own, separate studies (e.g., Haslam and Tanimoune 2016). This book has presented a large-scale, detailed study that includes both armed and nonarmed mining politics. Studies of the consequences of armed groups have been on the rise in security and social movement literature but are still limited. There is a particular need for studies on the economic outcomes of all kinds of protest activities (including violent and armed) that offer process- and mechanism-based explanations, rather than studies that just compare conditions (Bosi and Giugni 2012). This has been one of the main goals of this book. The findings suggest that violent actions by leftist groups in India are not simply or mostly negative for the economy, as many existing terrorism and security studies purport. This is because these projects are deeply destructive from the socio-environmental perspective, causing a lot of dispossession and serious trouble also economically, when existing jobs and livelihoods, and possibilities for sustainable ways of life, are destroyed alongside the expansion of mines over forested villages. Such dispossession 
does mean the accumulation and economic growth in terms of GDP for the investors-and when following this neoclassical view on development, the existing literature has found the economic effects of protest acts are mostly negative.

However, my findings also illustrate that nonviolent direct action can lead to even more profound economic impacts than armed resistance, which challenges conventional thinking about the power of arms. Armed revolutionary agency typically forges a very strong willingness to resist, especially in situation where the resistance has exhausted other means of impacting the local situation and seeks new expressions of contention. Yet the turn to armed resistance has mixed political outcomes; it partly supports other forms of contention and allows and relies on activism, but it also starts to eat away at the basis of critical and contentious stances when the war or the armed organization forces a stronger hierarchy of command. Armed revolutionary resistance is a perilous and unpredictable path, with potentially high rewards if it is based on the threat of using arms (as in the case of the Zapatistas) instead of waging a bloody civil war. Tragically, in some mining expansion dynamics, it is the only lasting option for people who do not want to choose passivity, fleeing, facing ethnocide, or permanent landlessness. This is because in many cases, such as in parts of India, extractivist corporate agency has been deliberately militarizing the targeted "resource frontiers," even manufacturing civil wars to ensure enclosures and resource access despite local resistance.

I also found that armed resistance both supported and blocked peaceful contention, though further studies of the specificities of armed resistance agencies are still needed. However, what is indisputable is that armed revolutionary agency, when coupled with peaceful strategies, was effective in stalling mining expansion, changing mining style, and building antimining resistance (peaceful resistance coincided with these cases, suggesting that alone the use of arms might not be enough). In addition to looking at armed resistance strategies, I also studied armed conflicts as a contextual issue. My comparison suggests that there are many reasons for the emergence of armed resource conflict, such as differing political systems. India and Brazil, for example, differ in their organization of security and the right to use police force. In India, the states are responsible for security, which means that there are wildly differing stances on handling security issues (Mohapatra 2007), varying from extreme violence and the use of paramilitary forces to peaceful deployment. In Brazil, by contrast, the federal state has the most power in security matters, while the state executive, the governor, controls only the military police, not the several federal police forces, the armed forces stationed in the state, 
or the civil police. Federal institutional politics has thus helped to avoid a long-term civil war context in Brazil, as rogue governors have been stripped of their overly violent responses to conflicts, deterring a spiral of deepening violence. Violence escalates interactively, and if the other party does not participate, it cannot continue. Brazil, India, and Colombia are currently the world's most dangerous places for environmental and land rights activists, who are murdered and harassed routinely and in high numbers. While Brazil has the world's highest number of murders of such groups as environmental, rural activists, and urban, nonwhite youth, targeted by the elite and their hired gunmen, the major leftist groups in Brazil have not taken up arms or followed the type of ideology that the Maoists in India promote.

In Chhattisgarh and Jharkhand, the affected populations (Adivasis) often lacked the means and knowledge to use the court system, electoral politics, or to lobby institutions and bureaucrats. They were prohibited from their use, failed in their use, or the achieved results were not respected (e.g., Supreme Court orders). Partly for this reason, but also because of the secessionist tendencies of the guerrilla movements, a large proportion of the process of demanding rights took place in non-statemediated politics. This played out as an armed revolutionary struggle that often aimed at Adivasi survival—survival of the cultures, populations, and livelihoods of forest dwellers. Activism based on revolutionary ideas is typically tricky and more prone to escalate into a cycle of violence than a strategy based on embedding and trying to coproduce state-remediated political games while retaining autonomy. In India, it is very hard for low or noncaste people to be accepted as partners in routine politics or in coproducing new rules for them (Banerjee 2013). Thus, these deep ethnic cleavages have partially caused the armed conflicts.

My comparison of strategies together with contexts provides further information on how resistance actors select their strategies for resisting. Dalton, Recchia, and Rohrschneider (2003) found that both conventional and nonconventional strategies are used in dramatically different contexts, arguing that the choice of strategies relies more on activist agency than on contextual differences. Challenging this finding, I found that context was an important reason that a part of the resistance in India's Bastar region and West Singhbhum had to use armed resistance. However, as I discussed, context is not destiny. In the Odisha case, with a very similar context, the resistance did not take the path of armed revolutionary agency, but rather forged peaceful resistance. Context and agency are not competing factors, but instead complementary ones. 


\section{What Are the Long-Term and Short-Term Impacts of Resistance, and What Are the Causes?}

I have focused on the more or less immediate outcomes of movements, those visible after a few years or at most about fifteen years of very active protesting. However, movements also have long-term impacts. I have demonstrated how mobilizations against mining built on prior outcomes achieved by other resistance groups, often in other places. These cases illustrate how important it is to track the spatial-temporal movement of capital and resistance in order to understand how investment outcomes vary. In cases that lack a local resistance, the crucial differentiator of outcomes can be, for example, the presence or absence of "outside help," whether temporally or spatially, or both, in the form of activists who travel to help organizing resistance elsewhere or the collateral impact of resistance outcomes elsewhere within the same jurisdiction.

Imposing a greater rule of law in mining across India has been an extension of democracy from the context of a consolidating Polanyian "organic society" in the West and South to the armed conflict that plagued Eastern India. Antimining activism has been a main driving force to unifying the political system of India across space, demonstrated by the creation and work of the Shah Commission, a new state institution whose establishment was an important component in the process that led to the discontinuation of about half of existing iron ore mines in India.

It is likely that the significant outcomes achieved in Latin American and Indian mining protests since 2005 will produce long-term and large-scale policy changes. In the latter part of the 2010s, extreme-right-wing parties and populist authoritarian politicians have risen to power in many parts of the world, their rise being related to the increased financial proceeds and other new political dynamics ushered in by the 2005-15 resource extraction boom. The interest of the current Brazilian and Indian governments seems poised to continue and seriously deepen the extractivism that was started before they rose to power. These governments are trying to turn this existing extractivist thrust to hyperextractivism, as they see this as a way to take away the lands that are controlled by the indigenous populations, which will enrich their own constituencies quickly through massive expansion of resource extraction in these previously protected areas. However, these policies by Brazil's Jair Bolsonaro and India's Narendra Modi are not in line with the current and rapidly worsening climate and other planetary crises, which will affect Brazil and India especially strongly and negatively. Clamping 
down on movements or implementing policies contrary to resistance wishes, such as what the Modi government is doing in India, and Bolsonaro in Brazil, or what is happening under Latin American neoextractivism, reflects an antiquated economic model that does not consider world-ecological limits. The results of the willingness and capacities forged by the resistance will be even more visible in the future, as the world-ecological limits start to be experienced even more acutely than at present. After the slump of 2016, states and corporations that invested in extraction during the 2005 to 2014 boom should be thankful to the resistance that busted their efforts. Of course, there is lasting and almost irreversible ecological damage done to many areas that experienced the mining boom's open-pit expansions, which renders these areas usable only for mining and makes it difficult for displaced locals to return them to their prior uses.

Goa is now a largely postextractivist context, as the resistance has created a largely nonmining future. A key activist felt that the resumption of mining activities would be "highly unlikely," while another thought in 2012 that the "moratorium will stand at least two years, and then mining will resume perhaps with 5-10 mt [million tons] per year, on a small scale, or not at all." The latter estimate proved to be more accurate, as one mine reopened in August 2015. This is a major outcome against the backdrop of Goa's sixtyyear history of iron ore mining for export, which peaked in the 2000s, and against Goa having been the most important iron exporting state of India (despite its minuscule size and low-grade ore).

Greediness and overexploitation, met by fierce social mobilization, led to a complete closure of mining operations in Goa, which is a lesson to be considered. However, the surge of a regulatory movement is not an automatic process of capitalism, as it does not happen everywhere, but rather a process that is very much dependent on resistance. As Marx (1887) famously noted, history repeats itself. However, the history of resistance is based on a defined set of strategies that causes specific outcomes to repeat themselves more strongly than the history of capitalist expansion—although they are supposedly susceptible to being curbed "automatically" (as in many theories) and by any kind of resistance.

\section{Mining as an Outcome of Physical, Symbolic, and Social Conflicts?}

The findings confirm that it is best to resist mines before they are opened. However, they also provide evidence that effective resistance can close very large mining areas, making the shutting down of operations a reality, in spite 
of strong corporate agency or (nonattributed) political opportunities. This is not a typical finding. Normally, it is assumed that investment projects with lower sunk costs are easier targets, but this is not necessarily true in every situation. In fact, cases such as Kudremukh, Goa, Congonhas, and Mariana highlight that built infrastructures and social capital (including jobs) for mines are not an impediment to forming a mining resistance movement. Movements can also include the mine's trade unions, which might also be against mining expansion and ecologically concerned about the place. This is perhaps due to these mining areas having the dual role as work space and homelands, with the workers having an embedded history in place. Thus, they resisted the unchecked style of extraction and its expansion.

This study indicates that the examination of social movements, NGOs, and other forms of civil society organization must be integrated more fully into a range of social scientific and environmental disciplines when studying the politics of natural resources and climate change mitigation, among many other contentious issues. These civil society actors not only shape concrete places and land uses, they also shape symbolic and social spaces, and when they create and exercise resistance, their members benefit by exploring their own strengths in the face of contestation. The new mining mobilizations are globally significant examples of how activists can earn themselves considerable say in politics, and thus in the longer-term developmental and environmental trajectories, even when working under very negative and difficult circumstances.

As mentioned in the introduction, besides being a book on investment politics, this is also a work of world-ecology scholarship, building on the recent attempts to go beyond Cartesian dualism in studies of the environment. In addition to intensely studying different political games and strategies across many contexts (via figures 1 and 2 in chapter 2), I also present a theory of spatial power relations and causalities (via figure 3 also in chapter 2). This theory of spatial power relations takes into consideration the changes present within social, symbolic, and physical spaces, and outlines the interspace mechanisms. This new spatial view can explain how resource frontiers expand or retract, which is important to consider when examining the implications of this research for world-ecology. When the symbolic and social space of the state has not been embedded by mining resistance, the state's proextractivist attitude will, sooner or later, manifest itself in the physical space-such is the nature of spatial causalities. Capitalism unfolds in close or sequential parallel across all of these spaces, as it is a world-ecology. In other words, in order to exist it requires the changing of physical space through framing this space as consisting of "resources," which are further- 
more framed as being the most valuable thing in that space, so valuable that to leave them in the ground would be madness, and that the collateral damages must be accepted; after these symbolic moves the resources can then be more easily appropriated. Put conversely, anticapitalist movements must be able to win over at least two spaces on a large enough scale so that they can ensure that the game does not revert to "capitalism-as-usual." In the case of Jharkhand, by 2013 the iron-mining resistance had won control over the physical, social, and symbolic space in West Singhbhum, but it had not changed the social or symbolic space in the rest of the state, for which reason this was in a way a secessionary trajectory.

The particularities of Indian armed secession in the mining areas I surveyed included armed control over physical space and an alternative social and symbolic space. There were many indigenous groups with nonmodernist cosmologies resisting extractivism. They saw their lived environment as consisting of indigenous forest villages, as well as their ancestors, forest spirits, trees, tree groves, and other entities and beings that cannot be made commensurable through quantification or modern mapping. Most importantly, these resources cannot be ecologically compensated for if destroyed. Capitalists cannot win the struggle over symbolic space when physical space is still controlled by such a cosmology, such objectified symbolic power. An activist explained to me that Lakshmi Mittal, the owner of ArcelorMittal, had argued in Ranchi, Jharkhand's capital, that "money is no issue. Whatever amount of money people require, want as compensation, I am willing to pay." Mittal also used "hundreds of millions of rupees for awarenessbuilding" in mining areas and made landowners shareholders in his company. These moves were an attempt to widen the capitalist mining base in social space and build symbolic capital for mining, which could lead to a setting where large sections of the society would encourage the locals to accept money for allowing mining across the state. However, some locals resisted, and the reply below, by a leader of the Adivasi movement in Jharkhand to the steel industry, captures the alternative, noncapitalist symbolic-physicalsocial space on the other side of the frontier:

What will money do for us? You tell us. Where will our boys spend all the money within a few years? We lose our forest. We lose our land that we cultivate. We are happy with that. We don't need money. We want to live peacefully in our own environment. What will happen to our ancestors? Their spirits are there in our village. Their last remains are buried in the village. How can we leave them alone? 
As the creation of social or symbolic capital by miners in the West Singhbhum forest areas had not been successful, the prominers started to use physical acts such as violence and armed occupation of the area. In the view of the activist and movement leader from Jharkhand, they did this to instill fear in locals so that they would not dare to take part any further in the mass rallies, whose participants were framed as terrorists. The current thrust of turning the last remaining areas outside the bounds of Western modernity and its extractivist appetite into resource areas is very violent.

\section{What Are the Lessons for Global Environmental Governance?}

The Indian and Brazilian cases offer an opportunity to make significant contributions to both the political opportunity discussion in movement literature and the debate on the role of states in development and environmental politics literatures. There are five major findings that both challenge and corroborate existing studies on global (environmental) governance.

First, despite the prevalence and focus on globalization, I found that national politics, that is, the pressure exerted by the resistance on the state, is a crucial axis around which natural resource disputes still revolve. According to Khagram $(2004,3)$, who studied large dam resistance outcomes in the Global South, "outcomes are most likely to be altered when domestic communities and social movements capable of sustaining mass mobilization and linked to transnational advocacy efforts contest these projects." My findings, when taken in comparison to Khagram (2004), show that the dynamics within the domestic state and society have been more important for blocking the mines than transnational action. This is perhaps owing to the differences in conflicts over large dam projects and iron ore mines. One illustration of this difference are the essential and significant cases of local resistance success in India and Brazil, which are not very well known on the international level and have not received the attention that their empirical existence merits, in terms of informing our understanding of the global setting of environmental governance.

Second, sectoral specificities have had a prominent role in explaining both global investment and environmental politics. There are many important sector specificities related to iron mining including the geographical particularities of iron ore deposit locations, the bulkiness of this resource, the comparatively slow pace at which its extraction shows signs of environmental degradation and side effects (in comparison to, for example, gold 
or bauxite), and the fact that it is not a closely consumer-society-related commodity. Resistance is not formed in a void, but in real places that are being threatened in particular ways. A comparison with resistance to global industrial forestry expansion (Kröger 2013a) illustrates that different sectors can have notable differences in terms of what kinds of resistance may influence investments, and when.

Third, these resistance cases were not driven by transnational advocacy networks, but by locally born resistance groups of varied kinds, a few of which engaged in transnational advocacy (and became the cornerstones of those coalitions). Like Rodrigues (2003), who compared transnational environmental activism in Brazil, India, and Ecuador, I found that local resistance groups are the key actors in forming transnational resistance coalitions to extractivism. The reason for this is that in extractivism, the actors who hold the most direct control over the flow of resources, that is, those in direct touch with "upstream struggles" (see Bridge 2010), hold a key position. They can, for example, use territorial, geographic strategies in the physical space, such as sit-ins and occupations, to block the flow of resources or new investment projects. Local groups can also avoid the danger that participation in transnational networking can harm the movement (as identified by Rodrigues 2003); if the resistance group was formed through the five key strategies, it avoided this danger. By showing how local action can be supplemented by transnational coalition building, and how action can affect the global operation of iron production, I illustrate how local behavior is embedded in, and therefore affects, global governance.

Fourth, I found support for the findings of Fuentes-George (2016), who compared the conditions under which transnational civil society actors and local communities in Jamaica, Mexico, and Egypt managed to promote biodiversity and resist harmful investments. In some of my cases (such as Kudremukh), there were clashing local resistance groups dynamics, which were successfully united by an outsider arbitrator. Similar to the findings of Fuentes-George (2016), I found that the new resistance coalitions were successful under the following circumstances: (1) when scientific consensus was framed in social justice terms (for example, the mining wastewaters were severely harming agriculture); (2) When social relationships were created with local actors (which aided in uniting quarrelling factions) and (3) when biodiversity and biocentric worldviews were advocated for in a way that promoted local environmental justice (for example, including the indigenous forest dwellers and not just environmental NGOs).

Fifth, I found support for the claims that there is a strong ethnic, social, and class injustice incorporated in global relations that unequally distributes the most damaging environmental activities (Martinez-Alier et al. 2016). 
The most severe extractivist pressures were taking place in the key global and national resource frontiers, particularly where those on the other side of the frontier were poorer or from despised ethnic minorities, or both. I further explored the roles that ethnicity and class play in resistance, which are key parameters that were identified by Pellow (2007) in global toxic dumping and its resistance. Like Sawyer (2004), who illustrates how the resistance to oil extraction in Ecuador was as much a struggle against environmental destruction as for the recognition of ethnic injustices and for building new national belonging for excluded groups, I explained how minority groups reached important political outcomes through their struggles. For example, in Odisha indigenous populations and impoverished rural communities remolded the rules of political games, while retaining their autonomy; in Keonjhar new informal yet forceful rules for electoral politics where indigenous and mining-critical politicians got elected were produced, thus creating real and stronger political power for the minorities in their resistance to extractivism. I also identified cases where this did not happen and explained the different reasons in cases where this occurred, such as in Joda and West Singhbhum where ethnic injustices deepened. Providing more detail to Pellow's (2007) call for paying attention to ethnicity and class as key parameters of inquiry, I discussed both the potentials and pitfalls of single-ethnicity/ class and cross-class/ethnicity resistance groups, and the compounded effects of multiple distinct ethnic resistance groups working against the same extractivist process. There is indeed a global environmental justice movement-if the compound effects of different local struggles against extractivism are considered as forming a "global movement" (this is one level of movement conceptualization) (Martinez-Alier et al. 2016). However, a closer look at this global movement illustrates that it is not unified or nonstratified. I provide several specific ways to disaggregate such "global resistance." This overarching theme requires further study, as it will help in avoiding far too broad analyses that are still common and forecast, for example, that capitalism is coming to its end, or that there will or will not be a global counterhegemonic movement. The situation is much more complex than this, there being tendencies and forces at play that both support and undermine such prognoses, and these need to be analyzed in much more detail.

\section{Toward a Hyperextractivist or Postextractivist World?}

This final section will reflect on the lessons in this book directly through the lens of extractivism; the prior parts of the conclusion have reflected more on how the book has contributed to other, more established fields of scholar- 
ship. I will also present the broader picture where the world seems to be heading and point to directions for future research. I will discuss the unconventional, not so commonly voiced ways forward for starting to solve the pressing global crises.

This book examines the political economy of resource extractive industries under current rising global powers. While most theorizing on the global political economy is still largely at the macro level, this book presents a detailed multisited political ethnography of how macro- and micropolitics operate in economies that are growing rapidly and whose extractive nature is currently presenting serious challenges of environmental sustainability with significant implications for humanity and all life on this planet. This study of two giants, Brazil and India, shows how extractivism is at the heart of their political strategies, and how local people have revolted against such policies, with differing outcomes. By doing so, this book deviates from the all-toocommon "resource conflicts" strand in the literature on political economy and deepens these discussions by adding the social movements' perspective.

Many scholars have criticized extractivism, and from many viewpoints. The writers in Petras and Veltmeyer (2014), for example, discuss how progressive governments can be seen as having imperialist dimensions under the new extractivism-or neoextractivism, the developmental paradigm adopted by many Latin American governments during the 2000s, where they siphoned off a larger part of extractive proceeds to the populace than the old extractivism. Latin American thinker Raúl Zibechi has argued that extractivism was a big mistake for Latin American progressive governments, and led to the collapse of progressivism, which makes it hard and even impossible to make systemic changes. Zibechi also argues that extractivism, as an activity that displaces people from the rural areas by its highly mechanized extractive technologies and models, has made it much harder for social movements to mobilize (as extractivism "creates a society without subjects" that could mobilize). ${ }^{6}$ Gudynas (2016) argues that extractivism has made it much harder for alternative political economic and human ecological models to be created, sustained, and developed, while other studies (see Kröger and Lalander 2016) show how extractivism has led governments to violate the progressive constitutions that they themselves created in the 2000s. There is also a large literature criticizing the "old extractivism," which refers to the typical situation where the population of the country of origin gets almost nothing in return for extraction, showing how it causes underdevelopment, with Bunker and Ciccantell (2005) providing a good list of examples and references. Iron Will demonstrates that "old" and "new" extractivism still coexist in the world, and that both can be successfully resisted. 
Extractivism is based on a specific world-ecology and the idea that boundless extraction of nature's bounty would be possible. Jason Moore (2015) argues that capitalism was not created by the steam engine and the industrial revolution of the late eighteenth century, but as a result of a changed understanding of nature and increased human appropriation of nature beginning in the late fifteenth century (when the discovery/conquest of the Americas and the rest of the non-West allowed for a major extractivist opportunity). Similarly, Naomi Klein (2014), in her book on climate change and the importance of tackling capitalism if climate disruption is to be quelled, argues that an ideology that is unfit for its material setting is at the core of our problem. Through the case of Nauru island, she describes how its remote geographical location largely impacted its overextraction, with most of its topsoil cast off to mine the phosphate needed for making fertilizer to support the agro-industrial sector, which is located at the core of the world economy. The people of Nauru allowed themselves to be deceived, spending frivolously while mining their own future away. As possibilities for self-sustaining were irreversibly lost, the nation resorted to desperate measures, for example trying to become a global money-laundering haven and a refugee camp for Australia (wherein gruesome conditions prevailed, according to witnesses). That peripheral nations will seemingly destroy their own possibilities for self-sustaining life speaks more generally of the options remote regions have in the current world-ecology. This world-ecology is based on a double idea/practice: powerholders locate extraction, with its attendant pollution, in remote areas out of sight and mind, and then profess to be surprised by the negative impacts of these extractive operations, although they knew from experience this would occur.

Active resistance stemming from upstream struggles against extractivism can bring to light the firsthand, lived experiences of people facing the destruction of their sustainable livelihood. The sum of the local struggles in all these different small remote areas changes the overall picture of global environmental governance. The world is growing smaller through the ease of transportation and communication across space. At the same time, new extraction peripheries are being created even in the old core areas, as the recent mining booms in the Nordic welfare countries demonstrate (Kröger 2015a). This means that new sets of people will be forced to experience the push of extractivist projects firsthand. Capitalism seeks territories to appropriate, but as this process meets with ever-more diverse and larger numbers of people, their responses will vary. At one extreme, we have the Nauruans described by Klein (2014) who embrace the model without a thought of tomorrow; at the other extreme we have the people who are taking up arms 
as their last attempt to protect their livelihoods and environment. There is also a vast middle, where we have all sorts of peaceful civil society actors who try to use a varied assortment of strategies to shift their region's political choices away from extractivism.

If extractivism is the core habit of thought behind the surge of capitalism, as Moore and Klein, among others, suggest, then the resistance to this process could mean the end of the capitalist world-system/world-ecology, or at least represent its most serious challenge. Klein (2014) describes extractivism as a nonreciprocal relation of taking by domination, where the key move is to reduce life to objects. For Moore (2015), the overappropriation of what is separated from humanity as "nature" and the overexploitation of paid labor is a particular historic nature-relation within the larger web of life. In this web, stewardship or sustaining of life can be forgotten as life's basic elements (such as water, soil, and forests) are rendered into abstract objects with no intrinsic value outside their role in accumulation. What the recent cases of resistance to extractivism have increasingly illustrated, however, is that people can retain and defend their nonextractivist lived environments, start to change their habits of thought, and make others change theirs as well. They turn their emotions into poetry about their beautiful forested hills being ground to dust, as happened in Goa. They raise their voices loudly, so the world knows that a mountain is their god, as happened in Odisha. They wake up to the fact that their last remaining stretches of forest and sources of water are being destroyed, which will make it impossible for them to continue living sustainably, as happened in Chhattisgarh and Minas Gerais. Granting a greater political agency to all forms of life, much more than what was possible during the heyday of extractivist thought, may well be the greatest unaccounted challenge to the development projects of modern civilization.

Social ecologist Eduardo Gudynas (personal communication, 2016) suggests that, as the modern world was built by the extractivist mind-set, it is hard for us inside modernity to challenge extractivism. Many resistance struggles in the so-called developed world might actually be what could be called "Not in My Backyard" or "NIMBY" struggles. In other words, this type of struggle does not really question extractivism as a practice of the capitalist world-ecology. In fact, in a NIMBY situation, extraction is okay if it does not take place in "my" backyard. Thus, if people can continue to enjoy of the freedom of movement and freedom from work that overextraction affords without suffering the negative impacts, then extractivism is fine by them. In one sense, Western liberal democracies might actually be just carbon-based democracies (see Mitchell 2011), basing their ways of life and 
political economic stability to a large degree on massive imports of resources extracted elsewhere, by under- or maldeveloping those polities. However, the struggles I have discussed herein are not NIMBY struggles; the people affected have little access to the benefits of modern society, and many of them do not share the modern mind-set. The people in Brazil and India who resist extractivism are not those who benefit from the extractivism of their governments.

The global political economy, particularly since the 2008 financial crisis, is predominantly based on the extractivist mind-set and the presumption that resource extraction could and should be the basis for development. However, as the current political economic turmoil in Brazil and other resource-dependent economies illustrates, the growth-through-resourceextraction model is a myth in most cases. The possibilities to "develop" - in the modern sense of the word-depend on a large assortment of factors that ensure that the capital accumulated by extractive sectors could be made to serve larger social, economic, and state-power-building ends (Walker 2001). The cases in which resource extraction has led to so-called development have been anomalies (Bunker and Ciccantell 2005), including Norway and nineteenth-century California, both of which had very particular resource and wealth governance settings, and were progenitor cases with favored world-system embedding (factors that both Brazil and India lack). ${ }^{7}$ What is worse, studies on resource-based development rarely ever discuss the negative impacts that this process will have once the new corporations, built to master the extraction of resources in one setting, are eventually globalized. Globalization typically leads to unequal power relations where the resource extraction model of the new target investment areas is deliberately built on a different model, not the one that led to the development of global power players in the host country (Kröger 2013c). For this reason, the hype about building, for example, a leading Arctic resource extraction industry in one Arctic country where there are welfare-state-like functions (such as Finland or Norway) is blind to the future consequences of deepening extractivist expertise and investing capital and technological know-how in this process (Kröger 2015a). The extraction process is bound to create particularly extrahuman suffering and devastation when the machineries and investment models are expanded to more peripheral regions, to ever-more hard-to-get mineral sources, as old areas are depleted, or when projects in core areas are subject to greater resistance by locals.

Most of the resistance to mining in Brazil and India does not believe that those rare conditions in which resource extraction could lead to "development" could be achieved in their countries and regions. They have seen 
such arguments before and rebuffed them through their own experiences. In many senses, these populations are much closer to the solution to our modern crises than those who believe in resource-based growth models. This is particularly the case with those populations who have environmental ontologies that challenge ontologies of modernity. To counter these tendencies, extractivist governments have rolled out social welfare increases to ease the tensions. In the areas with fierce resistance, extractivists need to increasingly resort either to distributing a larger chunk of the accumulated wealth to the larger citizenry (as in parts of Latin American neoextractivism by so-called progressive governments; see Gudynas 2016) or to militarizing and paramilitarizing areas that are to be turned into the sacrificial zones of extraction (Valdivia 2015) (such as in many parts of India and Brazil). Both the governments of Brazil and India have, during the years of the global commodity boom, used a mixture of both countermeasures against the resistance to extractivism. However, as I have shown, the learning curve of impacted populations is getting shorter, as activists are networking across larger spaces and in faster time. Transnational coalitions might make the whole setting for global extractivisms much harder, in an ever-larger number of cases, and in different contexts. In addition to this expansion in the scale of resistance, the scope of resistance seems also to be shifting radically, and a qualitative change may be even more important in the deep-level challenge to extractivism.

The rise of authoritarian regimes across the globe since 2015 may be detrimental to the advance of the new global resistance against extractivism examined in this book; at least in the short term the setting has gotten more violent. Global resistance coalitions, formed by locally rooted struggles, greatly rely on peaceful and democratic settings for success. As this book has illustrated, the extractivist boom created windfall gains and power for authoritarian politicians to rise to power. Busting this boom has started to cut into the basis of this authoritarian power. The rise of this authoritarianism seems to be a reaction to an already-deepened resistance agency, a desperate attempt by a vanishing way of life and thinking to cling to power to use nature for their dark ends. Thus, it is understandable that these regimes, such as that of Bolsonaro's Brazil backed by the landowning elite, seem to have as their key agenda to attack and quell the will to resist, condemning the building of contentious agency and particularly environmental activism. In the future, these two processes promise a more difficult context and a stronger corporate-state push for extractivism and against resistance. It should be acknowledged that the resistance movements detailed here have 
also changed the broader setting, by making it difficult, if not impossible, to restart once-discontinued mining operations in many areas. The locals are politicized and organized, and in many cases capital has moved elsewhere. Nevertheless, the rise of authoritarianism seems to have already intensified the spread of armed resource conflicts, especially one-sided conflicts, where the assassinations of environmental activists have spiked both in Brazil and India since 2015, at least in comparison to the 2000-2015 era. This suggests that the armed resistance struggles will not be disappearing from India, where the existence of this political game as a rooted possibility will be strengthened by the rise in authoritarian response by the government. However, in the contexts that are less markedly armed conflicts, with at least some openings to use electoral, institutional, or judicial politics, the possibility of using all the five key strategies simultaneously will remain as a way for people to live through the difficult period and ensure their land is not churned up by extractivist operations.

In some conflicts, those resisting have challenged modern ontological notions of what constitutes "nature." For example, Mario Blaser (2013) argues that conflicts based on ontological cleavages are on the rise. Members of local indigenous groups in Andean mining conflicts, for example, have claimed that a targeted mountain is angry about the project. Anthropologist Marisol de la Cadena (2014) explains how in Cusco, a mountain (perhaps replete with gold) was also an earth-being and participated in a political contest where "the mountain won, the mining company lost." For de la Cadena (2014), this type of environmental conflict with "ontological openings" may challenge the hegemony of modern politics by exposing it "to what it cannot deal with, to what may constitute its excess." I noted how such ontological openings have already yielded significant outcomes. In India's Odisha state, the local Kond and other indigenous people worship the Niamgiri Hills as their god. These hills are also targeted for bauxite production, which conflicts directly with their contention that they are holy (Padel and Das 2010a); for this reason, and because researchers had documented this state of affairs, the Supreme Court of India ruled that the mine cannot be established. Such an imbuing of sacredness and also agency to what the modern worldview considers merely a natural resource or environment (or in some cases deserving of special rights to exist, e.g., in connection with endangered species) should be studied in more detail.

In future research on extractivism and its resistance, more theoretical attention should be paid to these metapolitics, a field that goes beyond conventional and also a large part of contentious politics. As Gudynas (2016) 
has pointed out, when a monetary value is given to a "natural resource," then such a framing of nature is still an act within politics as usual. There is no attempt to transform the underlying ontological assumptions of what are, what can be, and what should be the scales and scope of valuation and politics. In politics as usual, radically different conceptualizations, worldviews, understandings, and cosmologies are not pursued; rather, the rules of the games and the set of games go unchallenged.

The difference between engaging in politics or metapolitics may have profound impacts. For example, Joan Martinez-Alier (2016) argues that when the resistance places monetary values on nature-exemplified in the recent rise of environmental economics and "environmental services" calculations by some proponents of a "green economy" (see Kröger 2016)—it has already lost the battle, as it has joined the project of positing alternative ontologies as mere curiosities or oddities. This claim merits further investigation.

New ontological conflicts have received attention from scholars interested in "political ontology," particularly in Latin America. Mario Blaser (2013) argues that the whole project of modernity is globally in crisis and alternative notions gaining public awareness are cracks that are getting larger as the modern project fails to deliver the solutions it has promised. Indeed, the modernity project is seen by many as a cause of the problems, and alternatives are sought that could provide more sustainable, more sound "lived environments." This book has applied this useful post-Cartesian concept by Marcus Taylor (2015), which offers a fruitful avenue for future research. So far, study of these new metapolitics has been sporadic rather than systematic, and more research is needed to examine how metapolitics works (as a political mechanism), and what impacts it might have. The political analysis in this book provides a step in this direction, as through application of the factors presented herein to the study of metapolitics, the impacts of these processes can be analyzed. In particular, the strategy of campaigning by nonmodernist framing against extractive operations could be divided into more detailed subcategories and tactics, and the impacts of this framing process on extractivist processes should be studied for possible causalities.

In many cities of the old promining state of Minas Gerais, people are no longer willing to let mining expand, and are indeed trying to return the mining industry's "overburden" back into living entities such as rivers, forests, fields, and the humans who inhabit them. In Odisha, several groups have endorsed peasant, communal, and indigenous lived environments, and brought natural wonders, such as large waterfalls located in forested mountains, with their spirits, into public consciousness. In Goa and Tamil Nadu, 
resistance capacities and willingness have been built through the metapolitics of poetry, and the framing of rampant mining as a threat to life, beauty, and feeling has left a lasting imprint on the popular mind-set that will ensure a continued resistance to extractivism and support for regeneration. These and other similar practices deserve further study, for they lie at the heart of building postextractivist worlds. 


\section{Epilogue}

In September 2019, as I finished this book, the leaves were turning from green into red, yellow, and bright orange- all colors of the fall in the North. During this time, I often looked at the Finnish forests, and thought about all the existences being jeopardized by the extractivist thrust. The children of today, like my son, can no longer see the forests in which I was able to play as a child, as these forests are being decimated all around by expanding extractivist mind-sets. What kind of nature will the children of tomorrow face? The weakening of life in its current expressions in the forthcoming environments is evident in the burning of the Amazon rainforest and the attempts to reopen mines in India. Yet there is hope: people are marching around the world in climate strikes, the birth of a new global social movement. Even though many political leaders call the strikers delirious, and continue to make speeches that result in very few concrete actions, global consciousness is rising. Though sometimes it can be hard to see amid all the chaos and noise and distraction of modernity, there are multiplying and myriad voices of people who are involved in onthe-ground tangible action around the world. Those who struggle daily to maintain their lived environments continue to gain strength, even if the world has not put a spotlight on them. The concrete actions of these peoples, who are working to resolve the global crises day by day by safeguarding the sustenance of their homes-now and for the future-using their courage, endurance, ingenuity, and connectedness, merit much more credit. I have tried to use these pages to bring attention to their actions and to their iron will to resist. 


\section{Methodological Appendix}

\section{Participant Observation and Qualitative Comparative Analysis}

I began the field research for this project in 2010, after finishing my $\mathrm{PhD}$ in world politics. My dissertation addressed the impact of resistance on industrial forestry expansion in Latin America (Kröger 2010). My broad initial hypothesis at the beginning of this project was directly informed by my field experiences during my dissertation project. During the dissertation I identified a set of resistance strategies in the forestry context, and I wanted to test whether these strategies could be applied more generally to other types of resistance, across sectors-despite changes in contingencies and contexts. To test whether this was the case, I made a detailed study of twenty-three mining areas, with functioning or proposed mines, or both.

I did not know the cases, outcomes, or causal conditions when starting this study, but gathered this knowledge over the course of the field research. The methodology in the field research was primarily to provide an open space in which informants could describe their views on mining politics in the cases they personally knew. The new categories that cropped up in these discussions were codified and then I looked at whether these potential causalities or dynamics were also present in other cases. I also conducted semistructured interviews to ask more specifically whether the strategies that have been considered central in movement scholarship were used in the lived experience of the interviewees.

The research first mapped all major iron mining projects in Brazil and India, using the snowball method for conducting field research. This was complemented by an extensive literature and secondary-document review. I systematically compared the cases where the impacted locals or other concerned peoples had either affected mining trajectories, mobilized new 
mining-focused movements, resisted in some other capacity, or did nothing at all. I also studied cases where the resistance did not manage to make an impact on expansion or made only a small difference; such comparison across variation in the dependent variable allowed me to establish sufficient causal conditions.

The material for this book was collected using multisited ethnography (Marcus 1995) with a focus on political ethnography, through which rich empirical materials can be compared and used in analyses of process and power (Schatz 2009). This method, which incorporates participant observation and semistructured interviews, creates knowledge through engaged, microscopic, and long-term exposure to the lives and experiences of the research subjects (Auyero and Swistun 2009), and it has been used to study routine politics (established political practices such as clientelism), the socioenvironmental dilemmas of investment projects, civil war, and other violent settings (Auyero 2007; Auyero and Swistun 2009; Schatz 2009). This work combines multisited ethnography (which is not limited to one place or culture but uses ethnographic approaches to study global processes-in this case, the resistance to extractivism) and political ethnography (which aims to make ethnography useful for political scientists in broadening their tools of inquiry and explanation, via a focus on power relations). My ethnographic approach is a world-political ethnography, close to the approach discussed by MacKay and Levin (2015).

I created a very large and detailed database from the observations and data collected, including hundreds of recorded interviews and extensive field notes. This material was then analyzed systematically. For each case, I studied the presence of several explanatory factors and outcomes. To assess this dataset, I used crisp-set Qualitative Comparative Analysis (csQCA), a set theoretic, configurational comparative method developed initially by Charles Ragin and later by others (Rihoux 2008). I compared the use of the strategies and outcomes described in the hypothesis section of the introduction.

I identified the factors in this study after reading existing theories, gathering the field research material, and analyzing the dynamics between the cases via QCA, looking for anomalies, generalities, and the need for more precise explanatory tools. The methodological reasons for including these specific factors, some of which might seem quite similar, comes from a scale of analysis that is primarily detailed and local, looking at each investment project area via multisited political ethnography. There were important differences in the presence of each of the causal conditions between the cases. If the unit of analysis were larger, I would be analyzing Brazilian and Indian resistance as two large movements. Or perhaps these could even be thought 
of as local expressions of a single global movement against extractivism, albeit with different expressions. However, it would not be pertinent or even possible to distinguish the existence of specific factors to the same extent when they are considered at such a macro scale. One resistance or corporate actor might be involved in several cases, each of which can have their own dynamics. Resistance is therefore formed by a set of different strategies in different cases (if all cases were compounded as a totality, the movement would be using all strategies), and I assess the causal relation of these strategies with different outcomes.

I used QCA throughout the research to ascertain the presence or absence of causal conditions (strategies, processes, and dynamics) and outcomes (creation of new resistance agencies and actors, effects on investment pace and style). The QCA technique facilitates analysis of multiple causation and interaction effects, where a given outcome may follow from different causal "paths" (Rihoux 2008, 726); furthermore, it assists in summarizing data, detecting logical contradictions, and producing new hypotheses-all pressing demands in the new land rush or land grabbing literature (Edelman, Oya, and Borras 2013). I placed the rich ethnographic accounts into a relative perspective in relation to the overall database, demonstrating to what extent each case is either an anomaly or supportive of the overall general findings. This type of analysis is rare in studies based on rich empirical material collection and large qualitative databases, since, first of all, ethnographers seldom go beyond particular areas, and if they do, they do not use QCA or similar systematic methods of comparison. On the other hand, political scientists or comparative politics or international relations scholars seldom include field research visits and participant observation in their research to the extent done here.

If I found that the dynamics differed within one case, such as in the district of Keonjhar in Odisha, where the administrative block of Joda showed less widespread resistance to mining in comparison to several other blocks with fiercer resistance, I divided the initial "case" into several cases, to facilitate analysis of the differing dynamics. If I saw that there was a need to add a new central strategy or other causal condition to explain the particularity of case dynamics, I added that condition, and then also looked for the values related to that causality in the other cases as well. If a large area had similar dynamics, I did not disaggregate it into smaller parcels, but discussed the largest possible, contextually united area as a single case. Thus, I did not separate Goa into the south (where most mining was taking place) and north, as the resistance was statewide with very small interstate variation in comparison to the differences relativized by the larger comparative apparatus. 


\section{Ethics of Data Presentation and Information Integrity}

The personal, social, and political situation of many of my informants continues to be increasingly difficult, both in India and Brazil. Revealing their names could lead to serious problems for them, and hence I have not mentioned by name many of the organizations and most of the individuals who were interviewed. Some of them also spoke on the condition of anonymity and confidentiality.

The key ethical issue I must consider in producing a book delving deep into resistance strategies is the avoidance of divulging insider information or data that could be used by the movements' opponents against the activists. The informants were aware that the results of my data collection would be published, for which reason information that was not meant for public eyes has almost certainly not been disclosed to me. I also asked many of my key informants to read through parts of this book and make comments to ensure that no confidential or harmful information is contained in these pages.

\section{Data Limitations and Triangulation}

Multisited ethnography requires making numerous compromises on what is observed and who is interviewed. These choices were guided by my political ethnographic focus on the process of resistance to extractivism. Thus, my informants were mostly well-known activists, such as coordinators, movement leaders, NGO directors, scholars, politicians, bureaucrats, lawyers, experts, and journalists. In other words, they tended to be key policymakers. I did not conduct many interviews, or do much participant observation, with "lower-ranking" movement members, as my focus was not on movement ontology, organizing specifics, internal problems, or hierarchies. Rather, my focus remained on confrontations with companies and the key strategies used therein, which could be best opened up by the key policymakers. This focus allowed me to make a contribution to political ecology, which has historically lacked studies on social movements, or looked mostly at movement hierarchies (Wolford and Keene 2015).

I visited most of the areas detailed in map 1 and 2, but I did not go to Bellary (3) or Tiruvannamalai (5), as I managed to interview a large number of the leading resistance organizers and other actors elsewhere. Entrance to West Singhbhum (8), Dantewada (11), Rowghat (12), Dalli Rajah (13) and Manpur (14) was forbidden or not recommended by the authorities as they were civil war areas, so I approached as closely as I could and invited locals to 
join me for discussions that lasted from several hours to days, and included over 200 people in total.

I have been studying rural Brazil since 2003, including the mining areas that have been the principal focus of my research since 2010 (via participant observation in Carajás). I focused especially on mining dynamics in 2011, during a period of participant observation in the Palmares settlements of the MST in Parauebebas, and inside and around the Carajás mine next to Palmares. I also followed the commodity chain and studied the broader context of mining politics, including charcoal and pig iron production and transportation politics connected with the export railroad, particularly in Marabá and western Maranhão. I did not study the cases of Minas Gerais, Bahia, or Mato Grosso do Sul in such detail (via my own field research). Minas Gerais has a huge number of iron ore mines and conflicts related to these mines, and they should be systematically explained in a separate studyresearch to this end is already under way by other scholars. One effort has been made by Grupo de Estudos em Temáticas Ambientais (Study Group on Environmental Themes) from the Federal University of Minas Gerais to update a Map of Environmental Conflicts in Minas Gerais, including iron ore mines. ${ }^{1}$ The Oswaldo Cruz Foundation (Fiocruz), an academic specialist research institute that is publicly funded by the Brazilian state, had a similar mapping project with quite a bit of data on some iron ore mine conflicts. Both of these efforts could be used to triangulate my findings. Similarly, some of the notes on mining projects written in the EJOLT Atlas (ejatlas.org) were used to triangulate and supplement my findings. Brazil had the world's four largest iron ore mines during the studied period. These were Carajás (7.27 billion tons of reserves and a production of $106.7 \mathrm{mt}$ [million tons] in 2012, Vale); Samarco Alegria (2.97 bt [billion tons] of reserves, $21.8 \mathrm{mt}$ of production, owned $50 / 50$ by Vale and $\mathrm{BHB}) ;{ }^{2}$ Minas Itabiritos (2.78 bt, $31.8 \mathrm{mt}$, Vale); and Vargem Grande (2.53 bt, $22.6 \mathrm{mt}$, Vale). ${ }^{3}$ The last three mines are located in Minas Gerais. They are old operations, with expansion happening mostly inside the existing mines during the studied period. I have not studied the conflicts around them in detail, ${ }^{4}$ as I focused on greenfield expansions in Minas Gerais. These greenfield projects had more problems and much more resistance as they encroached on land that has not previously been mined. It is worth mentioning that Vale was founded in Itabira (where Minas Itabiritos has been in operation since the 1940s), and that there were no mass social movements against mining there by 2015 (although a new reopening plan of an old mine by Vale may stir problems), despite claims by the anti-Vale network that Vale has committed people to slave-labor-like conditions in Itabira. ${ }^{5}$ I have studied these three 
massive Minas Gerais mines, and others in Minas that were not explicitly discussed in this book, from a broader contextual perspective, not in detail. These mines indirectly formed which I characterized as an old, promining context, and I used this context to see how this "pro" could influence resistance outcomes. This analysis is offered in part II.

Different languages were used to conduct this research. I am comfortable communicating in Portuguese, Spanish, and English, but not in Hindi or other local Indian languages. In Brazil I could interview anyone without the need for an interpreter. In India there were some problems with translation, particularly when meeting some of the Adivasis. While I used the help of translators to converse with non-English speakers in India, the quality of the data was problematic, as my methodological apparatus sometimes required a quite lengthy explanation of what I wanted the informants to reflect on in their cases (after having had open discussions about the mining situation and their views on its politics in the localities that each person knew). Translators were hard to find for localized Adivasi languages, and the translators typically had their own ideas, intermeshed into the translations, often to a degree that I could not decipher. Consequently, I mostly avoid quoting the translated interview data from India.

Some of the recorded interviews were transcribed, resulting in a 50,000word document, which could be used for verifying quotations and for analyzing anything that was missed when handwriting the key points in field memos (which covered most points).

Lastly, in some cases, I could not find more than a few people who knew the local mining politics well enough to be considered potential informants, which could be a risk for data integrity. For example, in the discussions I had while staying in Keonjhar in Odisha, visiting mining regions and stalledproject areas, I had to rely on a small number of informants. These informants shared with me the dynamics and very specific issues in remote rural areas that people in the state capital did not know about, for which there was no media or other public coverage, or prior research, but which were very important.

I used multiple forms of verification of the material, including data triangulation (e.g., reading existing academic publications, media accounts, and other secondary documents, and talking to other scholars and experts at conferences and elsewhere); method triangulation (e.g., looking at satellite images to spot whether a mine had expanded or existed in a place that was mentioned by an informant, to verify whether their accounts were precise or trustworthy, and physically visiting the areas besides talking to people about local politics); researcher-analysis triangulation (e.g., asking what other 
scholars who had been in the area had found, using field research assistants in some cases, using assistants to read through the transcriptions and draw their own analytical findings, and then juxtaposing these findings with my own analysis); and theoretical triangulation (e.g., having three complementary parts in this book that approach the data from different theoretical viewpoints-political context, contingency, and movement strategies-to explain the dynamics).

\section{List of Cases Studied}

Table 1 lists the cases studied, location, case type, main companies, and main resistance groups. Column 1 lists the case name with district, block, or other region-specifying attributes in parentheses; column 2, the state; column 3, case type. I used numbers as a shorthand for the type: 1 refers to the existence of mine(s) in the case area, and 0 indicates that there are mining projects, but no ready mine as of July 2015 . Column 4 lists the main companies with mines, including those in the process of attempting to open up a mine in parentheses. Finally, column 5 lists examples of the resistance groups involved in the case. 
Table I. Indian Cases

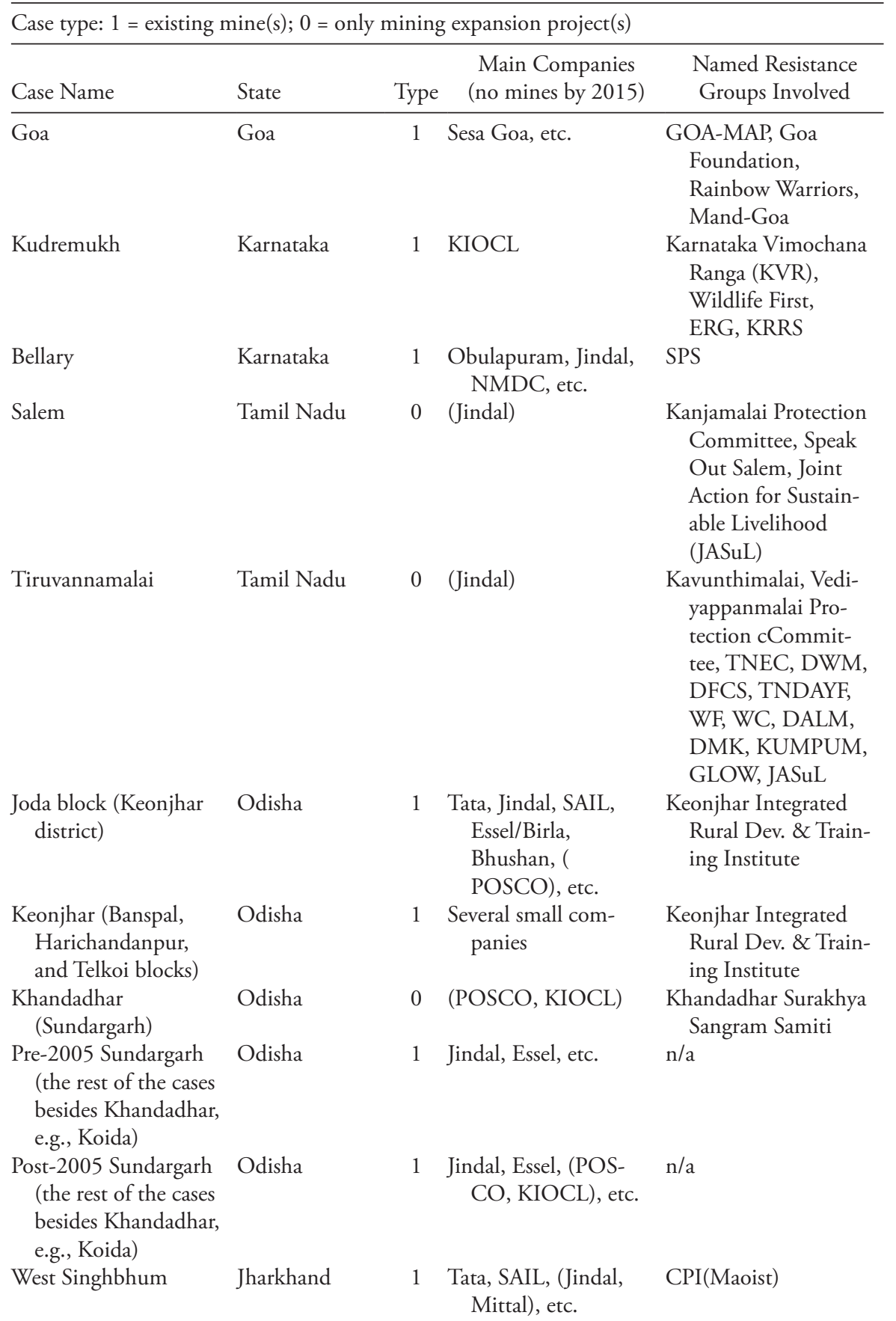




\section{Table I.-Continued}

\begin{tabular}{llccc}
\hline Case type: 1 = existing mine(s); 0 = only mining expansion project(s) \\
\hline Case Name & State & Type & $\begin{array}{c}\text { Main Companies } \\
\text { (no mines by 2015) }\end{array}$ & $\begin{array}{c}\text { Named Resistance } \\
\text { Groups Involved }\end{array}$ \\
\hline Rowghat & Chhattisgarh & 0 & $\begin{array}{c}\text { (Bhilai Steel Plant- } \\
\text { BSP) }\end{array}$ & CPI(Maoist) \\
Manpur & Chhattisgarh & 1 & $\begin{array}{c}\text { Sarda/SEML, Goda- } \\
\text { vari }\end{array}$ & CPI(Maoist) \\
Dalli Rajhara & Chhattisgarh & 1 & BSP & $\begin{array}{c}\text { Chattisgarh Mukti } \\
\text { Morcha }\end{array}$ \\
Kawardha & Chhattisgarh & 0 & (BSP) & n/a
\end{tabular}




\section{Table 2. Brazilian Cases}

\begin{tabular}{|c|c|c|c|c|}
\hline \multicolumn{5}{|c|}{ Case type: $1=$ existing mine $(s) ; 0=$ only mining expansion project $(s)$} \\
\hline Case Name & State & Type & $\begin{array}{l}\text { Main Companies (no } \\
\text { mines by 2015) }\end{array}$ & $\begin{array}{l}\text { Named Resistance } \\
\text { Groups Involved }\end{array}$ \\
\hline $\begin{array}{l}\text { Carajás (old mine) } \\
\text { (Parauebebas) }\end{array}$ & Pará & 1 & Vale, etc. & $\begin{array}{l}\text { MST, La Via Campe- } \\
\text { sina, MAM, indig- } \\
\text { enous movements, } \\
\text { Comissao Pastoral da } \\
\text { Terra (CPT), trade } \\
\text { unions, Justice on } \\
\text { the Rails }\end{array}$ \\
\hline $\begin{array}{l}\text { Carajás (new S11D } \\
\text { mining project) }\end{array}$ & Pará & 1 & Vale, etc. & $\begin{array}{c}\text { MST, La Via Campe- } \\
\text { sina, MAM, indig- } \\
\text { enous movements, } \\
\text { CPT, trade unions, } \\
\text { Justice on the Rails }\end{array}$ \\
\hline $\begin{array}{l}\text { Minas-Rio (Conceição } \\
\text { de Mato Dentro) }\end{array}$ & Minas Gerais & 0 & Anglo American & $\begin{array}{l}\text { CPT, Movimento } \\
\text { pelas Serras e Águas } \\
\text { de Minas, Fórum } \\
\text { do Desenvolvim- } \\
\text { ento Sustentável de } \\
\text { Conceição do Mato } \\
\text { Dentro }\end{array}$ \\
\hline $\begin{array}{l}\text { Apolo (Serra do } \\
\text { Gandarela) }\end{array}$ & Minas Gerais & 0 & Vale & $\begin{array}{l}\text { Movimento pela Preser- } \\
\text { vação da Serra do } \\
\text { Gandarela, etc }\end{array}$ \\
\hline Casa de Pedra & Minas Gerais & 1 & CSN & $\begin{array}{l}\text { Grupo Rede Con- } \\
\text { gonhas, trade union } \\
\text { of the mine, } \\
\text { politicians }\end{array}$ \\
\hline Mina Del Rey & Minas Gerais & 1 & Vale & $\begin{array}{l}\text { Mariana Viva, churches, } \\
\text { trade unions, mayor, } \\
\text { politicians, etc. }\end{array}$ \\
\hline Corumbá & $\begin{array}{l}\text { Mato Grosso } \\
\text { do Sul }\end{array}$ & 1 & Vale, MMX, etc. & $\begin{array}{l}\text { Kadiwéu indigenous } \\
\text { people, Associacao } \\
\text { Civil Ecologia e } \\
\text { Acao (ECOA), Rede } \\
\text { Brasileira de Justica } \\
\text { Ambiental (RBJA) }\end{array}$ \\
\hline
\end{tabular}




\title{
Notes
}

\author{
Introduction
}

1. See a collection of photos from the field sites visited in this book here: https:// blogs.helsinki.fi/mkroger/photo-gallery-field-sites/

2. There is an expansive literature in political ecology, political ontology, worldecology, and related approaches that explains how "natural resources" do not just inherently exist. They are created in the sense that such things need to be first framed as existing in a certain place, and second, they need to be considered as having a higher value than the other things existing there. For example, are the underground minerals, the aboveground forests, the agricultural soils, or water reserves considered to be the key "natural resource" in a given area? Is a part of the nature or the web of life even being cast as such things, to serve primarily for human extraction or exploitation? Through this kind of questioning, the carving out of "natural resources" from nature can also be seen as a form of violence, which turns a part of the web of life with living beings turned into objects that can be calculated, managed, and extracted. The creation of natural resources is at the core of expanding resource frontiers, an ideological work that precedes extractive operations and extractivism, including mining projects.

3. See the figures in this link for an analysis of Grantham's "Great Paradigm Shift," whose claim that we have entered a new paradigm seems to be holding even in 2020: http://claritycoalition.net/en_GB/knowledge-base/resources-commodities-2014/ (accessed 9 January 2020). The prices of most commodities are currently higher, or much higher, than in the pre-2005 period, even after the partial decline in prices at around 2014-16 (see: https://www.indexmundi.com/).

4. These include, for example, Khagram's (2004) classic comparison of resistance to big dams and Rodrigues's (2003) analysis on the role played by Brazilian, Indian, and Ecuadorian local movements in transnational environmentalist coalitions.

5. Examples of the prior books that compare the role of resistance in global environmental governance/politics, which I will be supplementing with my contribution, include Duit (2014), Fuentes-George (2016), Hochstetler and Keck (2007), Klein (2014), Kröger (2013a), Pellow (2007), Sawyer (2004), and Sowers (2013).

6. The processes leading to conflict outcomes receive little examination in the 
literature on mining and grassroots resistance. More attention is paid to explaining where, when, why, or how resistance occurs (e.g., Arsel, Hogenboom, and Pellegrini 2016; Bebbington and Bury 2013; Dougherty and Olsen 2014; Haslam and Tanimoune 2016), or on resistance networking and state and corporate responses (e.g., Conde 2017), but investment outcomes are dealt with only cursorily.

7. Iron ore was by far the most valuable metallic mineral produced in India in financial year 2013, comprising 81.04 percent of total value; second was chromite with 6.03 percent. In Brazil iron ore is even more central, accounting for about 90 percent of mineral exports, and alone it is the most important factor behind the positive trade balance of the Brazilian economy (EMIS 2014b).

8. By "consolidating democracies," I refer to such polities that are formally democratic, but where there are serious power imbalances that are usually related to colonial legacies and deeply entrenched social cleavages based on ethnic, caste, racial, gender, or class lines, but which are nevertheless being challenged by subaltern groups. These struggles seek to promote democracy in the sense of expanding the power of those who have not previously had a real voice in making important political and economic decisions, that is, expanding the scope and scale of democracy in that polity, and seeing that the formal rules of democracy are applied, followed, and expanded. Democracy has not yet been consolidated in these polities, and it is under constant threat by authoritarian and nondemocratic politics. As I will discuss, the resistance to extractivism has been a key force in ensuring that the wider populations are asked how they would or would not like to see their home regions being changed through extractive operations. As these political processes have been recently, not only locally but also nationally, crucial in both Brazil and India, these politics of resisting rampant extractivism have also been politics of ensuring that democratic rules are respected and even advanced. The forging of active citizenship through participation in the resistance has also been a boon to consolidating democracy, as the state has been unlikely to uphold the constitutions and laws of these democracies without civil society inputs.

9. The categories of similar rankings include Rule of Law (Brazil: 95; India: 97); Government Effectiveness (Brazil: 91; India: 95); and Voice and Accountability (Brazil: 78; India: 87). In the following categories India and Brazil displayed slight differences: Control of Corruption (Brazil: 93; India: 113); Regulatory Quality (Brazil: 93; India: 128); and Political Stability (Brazil: 111; India: 190).

10. Brazil was the third and India the fourth largest iron ore producer in the world in 2010, behind China and Australia (USGS 2011); in the dollar value of iron exports, Brazil was the world leader and India third (UNCTAD/WTO 2012). These statistics highlight the centrality of these countries in the global political economy of iron. In 2014 , these four countries represented around 80 percent of global iron ore production. China consumes almost three-quarters of the global seaborne iron ore trade (EMIS 2014a; 2014b; Parallaxis Economic Research, Commodity Trend: Iron Ore). Since 2010, Brazil and India have embarked on dramatically different pathways. Brazil has been caught up in a cycle of gigantic expansion in mineral extraction: iron ore production was $351 \mathrm{mt}$ (million tons) in 2008 and was targeted by the state's Plano Nacional de Mineração 2030 (MME 2010) to be $585 \mathrm{mt}$ in 2015, and a whopping $1,098 \mathrm{mt}$ in 2030. The share of mineral extraction of Brazil's GDP was 4.1 percent in 2013, and the main export markets for Brazil's iron ore were China (51 percent) and 
Japan (10 percent) (EMIS 2014b). In 2011, Minas Gerais produced most of the iron ore (71 percent), followed by Pará (26 percent).

11. See Bedi 2013a; Meher 2009, 2011; Mishra 2010; Moody 2007; Padel and Das 2010b; Sridhar 2010; and Kalshian 2007. Some books deal with mining in general in India (Karlsson 2011; Lahiri-Dutt 2011, 2014; Padel and Das 2010a). There are also a few policy studies on mining sector impacts in India, such as Centre for Science and the Environment $(2008,2011)$ and Human Rights Watch (2012) as well as more advocacy-focused studies such as Rodrigues (2014).

12. For example, Vale mining company had its operating revenues from iron grow more than 300 percent between 2009 and 2011, while iron extraction grew by only 35.5 percent, but realized average prices jumped from USD \$56 per metric ton to USD \$136 (Vale 2012). Vale, with headquarters in Rio de Janeiro, and deep roots as an important state-owned mining company, which was largely privatized in the 1990s, is one of the world's largest mining companies, and hugely important in global iron ore production. Brazilian iron ore exports comprised the single most important export commodity of Brazil. In 2011, iron still accounted for 71.5 percent of Vale's operating revenues, thereby retaining iron extraction as the bone of contention in revenue and power distribution and resulting in ongoing targeting by activists. For example, Vale was awarded the Public Eye award in 2012 as the corporation causing the most harm globally to the environment and human rights. Since the 2014 fall in prices, many iron ore operations are being shut down.

13. In this book, by Eastern India I refer to the states of Jharkhand, Odisha, Chhattisgarh, and Telangana; by Western India to Goa and Karnataka; by Southern India to Tamil Nadu and Kerala; and by the Eastern Amazon to Pará, Maranhão, Amapá, and Tocantins.

14. "Iron Ore Mining to Partly Resume in Karnataka," Reuters, September 3, 2012 (accessed August 10, 2015).

15. "Goa Government Mum on Recovery of Losses from Illegal Mine Owners," Economic Times, September 13, 2012 (accessed August 10, 2015).

16. Besides the BJP, the Congress Party and other parties have had mining barons engaged in illegal mining as electoral candidates, which has caused consternation among the critics of mining scams (defrauding the government and others of revenue while producing ore, for example by mining without permits, over the limits, outside lease boundaries, and without paying royalties) around India, especially in states such as Karnataka and Chhattisgarh. See https:/www.thehindubusinessline.com/news/ national/reddy-troika-no-longer-kings-but-mining-lords-still-rule/article23115625. ece (accessed June 26, 2019). Several experts and scholars on these matters in India confirmed to me the veracity of the link between illegal iron ore proceeds and their crucial role in election funding.

17. Political power was used to allow illegal and damaging mining to continue and deepen during the boom, according to an NGO coordinator who said that "systemic corruption was rampant." Another activist lamented that the Centre (India's federal government) "has been useless, an advocate for mining companies. The elite increased this loot." Leading politicians were directly connected to the Reddy Brothers mining mafia in Bellary. It was claimed that "if not for the resistance, India would have looked like Indonesia." 
18. http://www.mining.com/india-picks-worst-time-to-resume-iron-ore-mininganalysts/ (accessed August 17, 2015).

19. https://uk.reuters.com/article/us-india-mining/indias-top-court-cancels-ironore-mining-permits-in-goa-petitioners-idUKKBN1FR0FZ (accessed November 28, 2018).

20. As Reuters noted, "Restrictions aimed at curbing illegal mining in Goa and Karnataka states have choked the iron ore industry, with India's production falling to 136 million tons in 2013/14 from a peak of 218 million in 2009/10, according to industry lobby group ASSOCHAM. India was once the world's third largest exporter of iron ore, sending out more than 117 million tons in the fiscal year through March 2010. It slipped to No. 10 last fiscal year, with exports estimated at less than 20 million tons." Reuters, June 2, 2014, http://in.reuters.com/article/2014/06/02/india-ironoreodisha-idINKBN0ED0BI20140602 (accessed August 10, 2015).

21. Source: Cargo Traffic: ytd: Iron Ore, CEIC, Indian Ports Association.

22. Private politics are a dangerous path for mobilization that is not based on a strong and large mass movement, but on isolated local resistance. The example of Corumbá, on the border of Mato Grosso do Sul with Bolivia, exemplifies the dangers of private politics. Based on my analysis of Diogo Rocho's notes on the Corumbá case, taken in April 2014 for the EJOLT Environmental Justice Atlas (http://ejatlas.org/ conflict/corumba-indigenous-communities-and-mining-brazil (accessed August 13, 2015), the reason the local indigenous peoples' and NGOs' joint resistance against Corumbá iron ore mine expansion failed (though they did use the five key strategies) was that they mostly relied on private negotiations with companies. Significantly, the movement did not manage to even slow down the expansion or create a lasting mobilization, as it was satisfied by a promise of a new study on impacts, funded by the companies.

\section{Chapter I}

1. Adivasis are a large and heterogenous group of indigenous peoples in India. It has been argued that there are about 100 million people given this designation, including those who have been able to take advantage of the protection and benefits guaranteed to them under the Constitution, and those who have been oppressed (Sisodia and Dalapati 2015); both these groups are represented in the cases I study.

2. While a concise literature review on this topic is beyond the aims of this book, it is worth mentioning some of the prior key works on social movements in India in general, and their theoretical contributions. Basu (1992), Omvedt (1993), and Ray (1999) have looked at how the new social movements were born in the 1970s and have mobilized around concerns about the environment, class, caste, and gender. Shah (2004) has tried to position social movements more centrally in political analysis, offering an analytically more precise and dynamic way to look at resistance than that of subaltern studies, which is a mostly historical study of colonial India with people as central political actors (Ludden 2001; Spivak 2004). The writers in Ray and Katzenstein (2005) provide an overview of movement organizations and resistance struggles since the 1947 independence in many fields, including trade unions and par- 
ties, emphasizing right-wing Hindu movements as the most central civil society actors. Basu (2015) confirms this finding in a detailed study of the Hindutva social movement organization's relation to party politics, while my own analysis integrates the role of political parties and electoral politics in defining mining resistance outcomes.

3. World-ecology has mostly focused on explaining the expansion and workings of capitalism, and not on the resistance to capitalist expansion. I follow the call of world-ecology "to put our post-Cartesian worldview to work on the crucible of world-historical transformation-understood not as history from above but as the fundamental co-production of earth-moving, idea-making, and power-creating across the geographical layers of human experience" (Moore 2015, 3). This yields analysis of the historic natures (or "lived environments," as they are termed by Taylor 2015) of extractivism and its resistance, and particularly of the ways in which such futures are currently being created (and, in some cases, expanded to global scales). World-ecology is usually based on a methodology akin to world-systems analysis, where field research, let alone multisited ethnography, is used less than longer-term historical analysis. This book, however, is primarily based on participant observation, and can therefore ground the theory-building of world-ecology.

4. Adivasi is a Hindi term meaning the descendants of a given place and refers to India's original inhabitants. The term was first used as a political category by which indigenous people referred to themselves in the 1930s and 1940s, but the older categories of "indigenous," "tribal," and "aboriginal" are also still in use in India (Rycroft and Dasgupta 2011). The official Indian state ideology, on a par with the far-right Hindutva movement that pursues a unitary Hindu nation, does not recognize that there are indigenous people in India. It finds the notion of Adivasis a threat to its project of gaining political power through a national myth of Hindus as the original dwellers of India (Karlsson 2011). Lately this strategy has worked, as evidenced by the rise of Bharatiya Janata Party (BJP) currently in government and led by Narendra Modi (Basu 2015). This political party is one of the two major parties in India and directly translates to the People's Party. Hindutva supporters see that notions of indigeneity are harmful for the "forest-dwellers" (a term by which they refer to the Adivasis). "Development"-meaning more mines, steel plants, dams, resource extraction, factories, and capitalist expansion of markets-is what this government wants to provide, as benefactors, to these populations. Some Adivasis agree and are in political alliance with the BJP (and some other parties), which has led to significant disillusionment between elected Adivasi MPs and constituents in the would-be mining regions who are highly critical of the projects they experience daily as "undevelopmental" and unjust. The (de-)framing of indigeneity is a major way to legitimize nature uses and is a key ingredient of symbolic politics.

5. For example, Coelho (2012) detailed the potential damages of Vale's projected Apolo mining project in Minas Gerais, just a short distance from Belo Horizonte to the east, arguing that the absence of a popular class or local movements is the result of mineral dependency and a discourse of progress and development that demobilizes critical movements; Maher (2014) has made a similar argument, emphasizing community dependency on mining jobs as the key condition of "un-opposition" (that is, the absence of visible resistance). It is interesting to note, however, that since 2012 the Apolo project has been discontinued; Coelho's (2012) prognosis did not foresee 
the impacts of an NGO-based resistance against a large company, which Coelho-DeSouza (2015) studies in detail. Coelho-De-Souza (2015) is a deep case study on the importance of the quality of resistance in the Apolo project discontinuation. Maher (2014) and Coelho (2012) provide warning examples of how overreliance on contextual analysis can result in unexplained cases and unforeseen events, particularly given that resistance, in one form or another, still manages to check mining, a result that runs against the theoretical foundations of structural arguments.

6. Personal communication, June 2015. By "modernics" Gudynas refers to the dominant language of today, which is so deeply ingrained in most of the world's current politics that it is difficult to even consider issues outside "modernics" as existing or having agency.

7. Vivir Bien refers to many Latin American indigenous communities' conceptions of good life as being created through different ways of "living well together." Vivir Bien refers to this practice, the analyses of overall policies, and contexts of practices that discuss Buen Vivir, translated as "good living." This Buen Vivir challenges Western and modernistic notions of development through its emphasis on nonanthropocentric value-giving, which gives equal rights to nonhuman beings and entities to exist and live. Reciprocity and giving back to Mother Earth are key ideas and practices. There are many expressions of this Buen Vivir among different indigenous and other groups. These depict a whole set of values, practices, cosmologies, ontologies, epistemologies, and ways of life that create communities that are seen as being more sustainable and nonmodernist in comparison to Western ideas and practices. Further exploration of Buen Vivir is provided, for example, by Alberto Acosta: https://www. degrowth.info/en/dim/degrowth-in-movements/buen-vivir/ (accessed September 10, 2019).

8. Keynote in the panel on "Social/Climate/Agrarian/Environmental Justice, Social Movements \& Alternatives," February 5, 2016, The Hague http://www.iss.nl/ fileadmin/ASSETS/iss/Research_and_projects/Research_networks/ICAS/2016_col loquium_draft_Programme_10_Dec_2015.pdf

9. This phenomenon of a single individual working on both on the regulatory and business side of mining, in what could be thought of as a revolving door, is also present in the Global North, including Finland, where mining regulators have worked as company directors and received stock options. Thus, the expansion of global extractivism seems to influence nations very strongly and quite independently, despite different political systems (see Kröger 2015a). The autonomy and technical expertise of the regulators seems to be a key factor in determining where new reckless resource booms are given leeway to expand, which would support Max Weber's (1968) classic argument about the crucial importance of the bureaucracy's autonomy and technical expertise in development. Mauno Vilminko (personal communication, November 2016), a senior mining manager experienced in opening and running several mines and knowledgeable about both the recent Finnish and Swedish mining booms (200515 ), argued that similar kinds of reckless mining projects, with no solid basis in profitmaking or environmental impact terms, were proposed during the boom in both Sweden and Finland. In Sweden, these were mostly blocked by regulators, as there were still mining experts available to judge the projects independently. In Finland, however, cuts in the training of mining experts to work as regulators in the $1990 \mathrm{~s}$ left a regula- 
tory setting where no one was technically capable of judging whether there was ore or not in a proposed project. Talvivaara mine is one of the most notorious examples of this oversight. In recent years, revolving doors and policies dismantling the autonomy and insulation of state bureaucracies seriously diminished regulatory capacities in Finland, in contrast to Sweden (Kröger 2015a). Regulatory capacities thus matter, and in the absence of the state, civil society has started to provide this oversight, as I will explain later in this book.

10. Evans $(1995,12)$ likens the "internal organization of developmental states" (whose effectiveness in industrial transformation was the goal of his study) to being "embedded in a concrete set of social ties that binds the state to society and provides institutionalized channels for the continual negotiation and re-negotiation of goals and policies." This institutionalization of continual channels for negotiating policies can be equated with the creation of "consistency," which also is interestingly a required element in the conceptualization of a "political opportunity" by Tarrow (2005). When such consistency has been created or some state actors have changed their views by a series of events where the civil society has been the primary motor, then state embedding by civil society has occurred. Following Tarrow's (2005) theory, this would then suggest better political opportunities for resistance, and following Evans's (1995) theory, also a more developmental transformation.

11. As my focus is more on the resistance side and particularly on explaining its impact on outcomes, I build on Evans's (1995, 236) brief notes on "encompassive embeddedness," wherein the state and social groups, and possibly also progressive parts of the industry, all have embedded relations. This is in contrast to a situation where only state-industry embeddedness would exist. Evans $(1995,236)$ argues that development in the state of Kerala in Southern India, with globally notable advancements in social welfare (for which reason Kerala has been studied as a key explanatory case in comparative developmental analyses), has been a result of the mobilized resistance groups (to capital) embedding the state, which has nevertheless retained autonomy. Evans's interpretation thus contrasts with the view that Kerala's changed social structures and the new welfare institutions were simply an outcome of leftist mobilization. He argues that "regardless of the level of protest," the mobilization would not have reached these outcomes without adequate state capacity — an administrative apparatus that already existed for usage, to be embedded, for example, by making "full use of the competence built into the Indian civil service."

12. Brazil's Land Reform Institute, embedded by MST (in a way that retained both the Land Reform Institute and MST autonomy), has acted as a powerful state institution (in a way that would not have been possible for a nonstate actor) in upholding the rule of law. In Rio Grande do Sul, the Land Reform Institute blocked corporate intrusions that were expanding industrial tree plantations onto land under agrarian reform settlements of the MST (Kröger 2010, 2011).

13. States would have reason to increase their role in steering extractive policies. Building on Evans $(1995,2010)$, this would result in more value-adding growth and could be done by increasing embeddedness in civil society and among corporations by (1) regulating excessive extractivism and (2) increasing state autonomy by shedding the ties that have allowed states or parts of them to be captured by extractivist interests. Some state actors in India have pursued this goal, but it is important to note that 
governments (federal and some state-level regional governments) did this only after resistance pinpointed the problems of extractivism and the massive losses it causes, for example, to state exchequers.

14. A discussion of the post-2015 slide toward different forms of authoritarianism is beyond the scope of this book, although the discussion here is essential to understand how many authoritarian leaders gained power and clout. The windfall gains from the iron mining boom financed many important fanatical, nonconventional, and totalitarian politicians' political campaigns in Brazil and India. Their rise to power was premised on extractivist gains, which explains why they want to clamp down on the mobilization that is starting to cut the flow of ore and thus barring the road to power via extractivism.

15. I follow the Gramscian separation of dominance as open violence and hegemony as a subtler use of force based on at least partial agreement by the subjects to be governed; see Arrighi (1994).

16. Scott $(1998,2009)$ emphasizes the duality of state and nonstate space in his conceptualization of the state as a modernizing project, but for the purposes of a more fine-grained analysis of both antistate and state-embedding strategies, I have disaggregated the "state" and "nonstate" into different political processes and games. Similarly, Max Weber's (1968) monopoly of violence is only one part of the explanation of staterelated processes, to which I have added more detailed heuristic tools.

\section{Chapter 2}

1. The extension of the boxes of varied political games across the state and into different types of agencies shows how they can be embedded or coproduced; nonstate actors can form a part of the actual state-making practices and politics. Nature is everywhere in the figure, and the global setting is also embedded in the agencies and games mentioned.

2. For example, in India, the "protection of the land rights of the poor is one of the most important provisions made by the Constitution. Since the land is subject to state control, many Indian states have state-specific Acts that protect the land rights of the tribals and Dalits [Dalits are the noncaste people in India, often in even worse conditions than Adivasis]. In many cases these Acts are a result of the tribal and agrarian resistance and movements by tribal and other deprived people to protect their rights over land and natural resources" (Ahmad 2014, 260).

3. For informant safety I have decided to leave out detailed referencing of most informant-obtained data used in the text. I have also omitted dates and places of discussions in many cases, to minimize the connection of the data presented to specific informants.

4. A large number of India's many different leftist revolutionary groups came together in 2004 and formed the Communist Party of India (Maoists), a loose alliance, which the state termed a terrorist organization in 2009. This designation generated an operation in 2012 called the "Green Hunt," which involved approximately 100,000 federal paramilitary officers, to exterminate these "Naxalites," which the government sees as its greatest internal security threat (Kohli 2012, 75). 
5. http://www.thehindu.com/news/national/allindia-adivasi-mahasabha-callsfor-unity-among-tribals/article1579773.ece (accessed July 2, 2015).

6. For example, in Jharkhand, "Activists are prosecuted in law to discourage them from organizing resistance against forced evictions or forced sale of land" for mining, and "the police prevent activists from campaigning near land acquisition sites" (LahiriDutt, Krishnan, and Ahmad 2014, 172).

7. In India, the federal state is called the Centre, as India is not a collection of federal states with their own political will in the same way as, for example, the United States of America. Control is much more centralized. A coordinator from Mines, Minerals and People (MMP, a national alliance of those concerned by mining) told me in December 2012 that if differences arise at the state-federal level of political dynamics in India, then the Centre government will act, meaning that the Centre ministers will also override their counterparts in the states. According to the MMP coordinator, the "Indian Centre government is more despotic than the old monarchs." However, this does not mean that the federal state apparatus does not offer opportunities for activists. The court system in particular shows the robustness of Indian democracy: "we can go to court against the government without fear," he explained to me.

8. The Justice MB Shah Commission was appointed in November 2010 to probe the illegal mining of iron and manganese ore in contravention of provisions of the Mines and Minerals (Development and Regulation) Act, 1957, the Forest (Conservation) Act, 1980, and the Environment (Protection) Act, 1986. By the time the government ended the commission's tenure in October 2013, its investigations had "led to the closure of hundreds of illegal mines" (http://www.tehelka.com/who-is-the-minesministry-trying-to-save/, accessed June 30, 2015). These outcomes were not a result of the commission per se, as civil society activism played a crucial role.

9. For example, much recent mining resistance in India has based its protesting and campaigning strategies on the premise of a mid-2000s progressive law that gave the right to information, a law that would not exist without the actions of a particular social movement and its agency. This has swiftly become "structure" that has been relied upon when activists occupied government offices demanding that government officials disclose mining project documents. In this relational approach, opportunities are disaggregated to their constituent causal paths.

10. The MST was central in promoting the inclusion of clauses in the Constitution that made it legal to appropriate and redistribute land that was socially unproductive or even idle. The MST continues to be a pivotal movement resisting extractivism and uses those very clauses, which it was in a central position to push through in the 1988 Constitution (Carter 2015). The movement is not just attributing or using a political opportunity structure in this case (which would imply a top-down process of a larger "openness" by decision-makers), but has in fact created earlier that very structure while coproducing several key institutional positions to ensure that the law is implemented.

11. Targeted voting has also been used as a political tool in mining conflicts elsewhere. In Peru's Arequipa region, the local farmers used a concerted voting for proagriculture politicians in the 2015 municipal elections, which brought a major change in the power distribution (Romero 2017). According to José Romero (interview, May 5, 2017), this was a key reason why the Tia Maria mining project, which threatened 
the agricultural lands, was not advanced, alongside other factors, such as a sixty-day clash between the locals and the police and military apparatuses that left several activists dead. However, as Romero argued, in 2017 many of the politicians elected via targeted antimining voting were turning promining, and bribery tapes appeared, in a sign of the strength of Latin American clientelism as an overriding and deep-rooted political mechanism through which corporate interests can wipe out the gains made in reshaping electoral politics by movements. Still, the 2015 episode might have been enough to close the project, and at least it discontinued the project, so targeted voting can have major impacts even in polities where state coproduction by the resistance to extractivism is not easy or does not easily have a lasting effort.

12. While the new Food and Agriculture Organization (FAO) director had a role creating possibilities to tap into the knowledge of civil societies and build deeper democracy, this cannot be conceived solely as a case of a top-down creation of political opportunities. The embedding work and actual constitution of the Committee for Food Sovereignty by La Via Campesina members had been intense in the previous years, and the outcome would not have been reached without their actions and changing of the institutional game around food governance at the international level. FAO director José Graziano da Silva mentioned at the signing of the official pact with the Committee on Food Sovereignty that "we do not want to take the responsibility away from states, but we also want to give the opportunity to other actors to participate in the processes." This statement can be seen as an indication of a successful civil society embedding of the state/interstate spaces. See http:/www.fao.org/about/who-we-are/ director-gen/faodg-news-archive/detail/en/c/232697/ (accessed May 30, 2019).

13. The identification of the heuristic devices of cultural, economic, social, and symbolic capital as analytical and empirical categories derives from Bourdieu (1986, 1991, 1998). Social space includes social positions, particularly class relations and other positions of power that economic, cultural, and social capital offer, but also social acts that change these. Physical space change signifies, for example, landscape or bodily changes; in other words, material changes in landscapes and territories. Redistribution of power in symbolic space occurs through a different logic. When differences in capital are misperceived as differences in honor, they function as what Bourdieu calls "symbolic capital," which also functions as symbolic violence $(1991,238)$. Symbolic power is "the power to constitute the given by enunciating it, to make people see and believe, to confirm or transform the vision of the world, and thereby action upon the world, and thus the world itself" (Bourdieu 1991, 170). In other words, it consists of ideas. An example of symbolic power at work is the framing of a region in the Amazon as a "natural resource frontier" by a government policy, which then leads companies, state officials, and even the locals to relate to that lived environment more as an area to be extracted of "riches" than as a valued home of many beings. A resistance strategy of nonmodernist framing would try to counterbalance such framings, challenging symbolic power. If the symbolic power of those in favor of mining is weakened-that is, their honor and their position as agents of rightful, merit-based, or natural development becomes perceived as a product of the control of disproportionate amounts of social, economic, or cultural capital - then their power to expand extraction also diminishes.

14. The aim of this book is not to explore ontological questions of whether a 
thing actually exists or can exist, but rather the political nature and impact of acts and processes. I do not judge, for example, framings as either right or wrong, primordial, essentialist, or by some other category. Rather, following the line of political ontology (see Blaser 2009; Escobar 2011), I seek to understand the world as it is made and constructed through framings and other acts.

\section{Chapter 3}

1. http://www.esgindia.org/about-us/index.html, accessed April 21, 2015.

2. http://www.spscommunitycontrol.org/fight-against-illegal-mining.html, accessed April 21, 2015.

3. See, e.g., http://www.downtoearth.org.in/coverage/chaos-in-the-iron-age41038 and http://bellary0.hpage.co.in/india-illegal-mining_83098762.html, accessed February 15, 2016. The amounts vary depending on who and how the lost value of the loot is calculated.

4. http://www.spscommunitycontrol.org/fight-against-illegal-mining.html (accessed April 21, 2015).

5. According to several different informants from around India, Karnataka is the only state where the Lokayukta system has worked even to some extent; in Bellary, an effective Lokayukta even facilitated an investigation by "organic society." Lokayuktas were established approximately thirty years ago following activist coproduction of the state and could be turned into working and effective bodies of governance, based on the Karnataka example.

6. See: http://www.deccanherald.com/images/editor_images1/2011/07/28/MIN ES\%20PART-II.pdf; http://www.indiaenvironmentportal.org.in/content/345125/ interim-report-of-justice-mb-shah-commission-of-inquiry-for-illegal-mining-of-ironore-and-manganese/ and http://www.downtoearth.org.in/coverage/how-bellary-waslaid-waste-33862 and http://adrindia.org/sites/default/files/EPW_Mining_Article. pdf, accessed February 15, 2016.

7. The mapping of minerals by the new "organic society" also had unforeseen consequences. The mining barons "used the report to find out the highest 69 percent ore deposits!" Such an outcome would not have been surprising to the scholars of historical capitalism such as Moore (2014), who proclaim that mapping is essential for creating capitalism. This troubling dynamic between "organic society" promoting both democracy and capitalism is an issue to be revisited, and it speaks of the need to build movement agendas and frames on nonmonetary terms (not based, for example, on mineral quantities or wealth), but on nonmodernist values, as suggested by the examples of Buen Vivir (good living) (see Gudynas 2015), Gandhi's Swaraj (self-rule or independence), and the Nguni Bantu term Ubuntu (humanity, or I am because we are).

8. "In the 'Republic of Bellary,' a Minister's 'Muscle Power'," Indian Express, August 1, 2011.

9. Only 1.56 percent of the mining conflicts observed by Özkaynak et al. 2015, or thirty-six in total, had links between activists and legal organizations, which is striking, as in 43 percent of those cases the communities tried to use legal tools. This 
suggests that an increase in access to law, via the inclusion of legal organizations in resistance networks, might be one of the fastest ways for movements to increase the likelihood of securing their objectives. My data support this suggestion, particularly given that the resistance uses this potential to embed and coproduce the judicial politics.

10. B. R. Ambedkar, as noted above, is the creator of India's Constitution and the key figure in the historical Dalit movement against casteism in India (see Omvedt 1993).

11. Satyagraha translates as truth force. Chaining oneself in front of mining machines or in key locations, to call for attention or to block the access to the areas that locals want to protect, has been a key and successful tactic in Indian mass protests. I will talk more about the use of these tactics in part III.

12. The promining stance of Minas Gerais withered away after the November 5, 2015, Samarco tailings dam collapse in Bento Rodrigues, which caused the biggest socio-environmental catastrophe mining has produced in Brazil; see Zonta and Trocate (2016). I study the events preceding that catastrophe, in the heyday of the extractivist "commodity paradigm," particularly between 2007 and 2014. The breaking of the dam created a "tsulama," a tsunami of mud, silt, mining waste, and hazardous toxins, which wiped out entire towns from the riversides, killing nineteen people and leaving large numbers homeless and jobless. A fierce debate continues in Brazil about the consequences and who to blame, and it will be interesting to study in the future whether this occurrence has played a role in possibly checking the problems of rampant and unregulated mining. Samarco is an iron ore joint venture of Vale and BHB Billiton.

13. Also, according to Rodrigo Santos (interview, June 25, 2014), an experienced steel-politics researcher, and Maria Júlia Gomes Andrade, the coordinator of Movimento Nacional pela Soberania Popular frente à Mineração (interview, June 27, 2014). MAM is a new mining-focused social movement and a member of La Via Campesina, created principally by the MST.

14. Located in the Rio Acima and Caeté districts, the Apolo project would have had access to 1.1 billion metric tons of iron ore reserves; Vale bought the deposit exploitation rights from another company (http://www.vale.com/EN/investors/homepress-releases/Press-Releases/Pages/vale-adquire-direitos-minerarios-da-mineracaoapolo.aspx accessed July 30, 2015).

15. Vale started to sell some noncore assets around 2014 and decided to concentrate its iron ore production in Carajás, according to Santos (personal communication, August 16, 2015). The blocking of Apolo's project might have been facilitated by these corporate decisions.

16. The Apolo Project was Vale's second most important investment project after the Carajás expansion (via the $\mathrm{S} 11 \mathrm{D}$ project in Pará). While the anti-Apolo group was short on mass participation, and indeed was more like an NGO in structure, according to Andrade from MAM, it included members of the middle classes, forest protectors, poor workers, and semirural peoples. Later, it turned into a small movement. On July 30, 2015, the resistance group, called Movimento pela Preservação da Serra do Gandarela, had over 1,000 publicly named members with individual profiles on their website. However, the major economic outcomes were mostly a result of the early 
actions of the more NGO-like group. See a long list of actors who became involved later and a detailed discussion of the case at http://conflitosambientaismg.lcc.ufmg.br/ conflito/?id=498 (accessed August 13, 2015).

17. http://www.aguasdogandarela.org/page/english-language-1 (accessed July 30, 2015).

18. Gaining urban middle-class support was a move that concurrently prevented the dismantling of local resistance by the typical means of rural conflict-resolution in Brazil—a mix of dialogue, clientelism, brute force, and neglect (see Maher 2014; Zhouri and Valencio 2014).

19. The Apolo resistance embedded state institutions, such as the Chico Mendes Institute for Biodiversity Conservation, an official environmental institute of the federal state. The Chico Mendes Institute for Biodiversity Conservation was a key player in the struggle: as a progressive but not radical institution, it had its own discussions with Vale, offering a minor parcel of the area the company wanted in order to resolve the conflict, while the institute itself wanted the largest part of the area to be turned into a natural park that it would govern. http://www.mining.com/vales-4-billionapolo-iron-ore-project-in-brazil-jeopardized/ (accessed July 30, 2015).

20. Progressive state institution powerholders, together with civil society resistance (these two embedding each other) created several specific-purpose working groups that invited all stakeholders (including Vale) to join in discussions on whether mining would be allowed inside the park. The result of these interactions was that only the small existing mines were given permits to continue mining. http://rioacima.com/ noticias/15/Uni\%C3\%A3o-decidir\%C3\%A1-futuro-de-projeto-Apolo-da-Vale.html (accessed July 30, 2015).

21. http://diariodocomercio.com.br/noticia.php?tit=projeto_apolo_mais_perto_ de_sair_do_papel\&id=142993 (accessed July 30, 2015).

22. http://www.aguasdogandarela.org/notes/PARQUE_NACIONAL_ CRIADO_N\%C3\%83O_PROTEGE_A_SERRA_E_AS_\%C3\%81GUAS_DO_ GANDARELA (accessed July 30, 2015).

23. This makes it partially more understandable why the Capão Xavier mine, established by Vale in the early 2000s just next to the city of Belo Horizonte before Gandarela and also located on hills providing water, was resisted only after the mine was constructed. This resistance was low level, with no visible protests, and mostly consisted of neighborhood people, so there were many weaknesses in mobilization that are causally related to the nonstoppage outcome. For a basic overview of the case, see http://ejatlas.org/conflict/capao-xavier-mine-brazil (accessed August 13, 2015). With the Apolo project, people could rely on incorporated experience from Capáo Xavier.

24. Yet in many ways this is a very special case, as it involved an urban middle class with many technical skills and connections who realized that the targeted area would be the last remaining water source for the millions of people living in the state capital. It is therefore difficult in this case to claim that specific resistance strategies alone explain the outcomes.

25. For a fuller list of the entities involved in this movement, see http://conflitosambientaismg.lcc.ufmg.br/conflito/?id=237 (accessed August 12, 2015).

26. Santos, who is a key expert on Brazilian iron ore mining, and deeply involved in trying to pressure the government to make better mining policies, considers the 
relocation outcome an interactive property of the company-resistance relation, which has different impacts on resistance depending on the sector; relocation can either empower the resistance group or make it subject to criticism.

27. Dinius (2010) notes that the CSN workers had the power to challenge and even undermine the post-World War II developmentalism of large Latin American countries already between the 1940s and 1960s and build labor regimes that benefited workers. These historical roots can be seen as partly explaining the new contentiousness (trade union environmentalism) visible in the CSN mining resistance groups of today. There's a particular kind of resistance agency linked to CSNs corporate agency, and their interaction, including conflicts, which breeds a particular dynamics of contention, where the resistance has a stronger compounded agency to start with than in some other cases. A somewhat similar case, to be discussed later, existed in India between the Dalli Rajhara iron ore mine and its labor union. It is important to identify such contextual factors that help to build up resistance, so that the differing roots of mobilization can be linked to possibly differing outcomes.

28. Investors do not seem to be aware of the politics that explain investment outcomes, as this news article intended for investors portrays, "A survey from consultancy Wood Mackenzie points to twenty iron ore projects in Brazil with a combined capacity for 250 million metric tons per year, all pending the solving of infrastructure bottlenecks. CSN is to postpone the expansion of Casa de Pedra mine; the Itabiritos reserves of Brazilian mining company MMX are not feasible under the current prices scenario" ("Brazil: Iron Mining Investments on Hold," SABI-News, April 9, 2015). This investor view lacks a more complete understanding of the politics at the point of production, whereby many of the projects mentioned above were already curbed and stalled well before the price decline, and whose opening would not be politically easy or feasible even in high-price scenarios. It is more investor friendly to say that your company is postponing a project due to a bad market situation rather than due to resistance making the expansion hard or impossible. In many cases there is no knowledge of the politics of resistance behind investments, for which reason they need to be opened up.

29. http://marianaviva.blogspot.fi/p/informe-se.html (accessed May 23, 2015)

30. Available online: http://revistadoispontos.com/trilha-do-minerio/uma-cidadefeita-de-minerio/ (accessed July 30, 2015).

31. http://www.folhamarianense.com.br/web2/?id=artigo\&artigo=5 (accessed July 30, 2015).

32. http://al-mg.jusbrasil.com.br/noticias/2746972/mariana-resiste-ao-projetode-reativacao-da-mina-del-rey (accessed July 30, 2015; author's translation).

33. http://ejatlas.org/conflict/impacts-of-iron-ore-mining-in-conceicao-do-matodentro-mg-brazil (accessed July 30, 2015).

34. See also http://conflitosambientaismg.lcc.ufmg.br/conflito/?id=253 (accessed July 30, 2015).

35. http://www.conflitoambiental.icict.fiocruz.br/index.php?pag=ficha\&cod=229 (accessed July 30, 2015).

36. https://acervo.racismoambiental.net.br/2010/06/02/morre-assassinado-umdos-moradores-mais-querido-da-comunidade-da-mumbuca-conceicao-do-mato-den tro/ (accessed July 30, 2019). 
37. The difference between Bellary and the Minas Gerais cases, however, is while in the latter the resistance was waged before major physical space changes took place, the resistance largely managed to avoid rampant land destruction through creation of new open-pit mines. In Bellary the resistance had to operate on top of an already ravaged landscape - that is, on a physical arena whose key game rules had already been set to favor the continuation of mining, accruing all kinds of capital to miners (as the physical change was largely irreversible).

38. During this pre-1996 era, there was a much greater degree of violence and police repression than after the nationally acknowledged massacre of nineteen MST protestors in 1996, who were killed by police during a peaceful march in Eldorado dos Carajás, close to the Vale mine, and linked to the land conflicts caused by the project, bringing international shame upon the government.

39. March 8 is not just any day; it is the day chosen by La Via Campesina and MST for the most radical of acts, those that seek to directly confront capital by sabotage and other means, and, not coincidentally, it is also International Women's Day (Kröger 2010, 2011, 2013a). Women's protests are central, and acts on this day are chosen, organized, and implemented exclusively by women, in order to link the powerful potential that instigating protests has for turning typically less politically active people into critical activists. By this, they mean activating women in many rural areas of Brazil, as they have less capital (in its gendered social divisions) and potentially would not normally be involved in political protest. When I first arrived at the Palmares settlement on March 8, 2011, it was carnival time and "everybody else except the MST were on holiday" as the activists explained to me. I witnessed a large women's protest march the same day.

40. The Pastoral land Commission is linked to the Catholic Church and the theology of liberation, which inspires important civil society networks and supports a variety of land justice initiatives, by issuing, for example, a yearly report about violence in the countryside.

41. The general goal of the protests by the MST and its allies has been a transformation in Brazil's mining policy, which includes the elimination of tax incentives, the fortification of regulatory state agencies supervising mining, new mining taxes, higher royalties, and greater environmental control over Vale (Alvares da Silva, Costa, and Veiga 2011). Vale has exploited a lack of information, by dealing with individuals rather than with communities (Gerbode 2011), and battles over knowledge are central to the conflict.

42. Unfortunately for the resistance in Carajás, the economically stronger opposition in Minas Gerais may have driven Vale's decision to focus all its attention on their new expansion project in the Carajás complex, called S11D.

43. These moves have brought important economic outcomes: Vale was ordered by a court on August 14, 2015 to close down its Puma nickel mine and pay an equivalent in Brazilian reais to $\$ \mathrm{US} 287,000$ to each indigenous village in the area and conduct environmental impact assessments before resuming any operations. Such outcomes show that, like in India, the resistance has gained by adopting the protesting tactics of direct land control and blocking the physical entrance. This tactic seems to be particularly useful against greenfield mines. The public interest in litigation in the Puma case was based on successful judicial embedding by the indigenous and their anti-Vale allies such as the MST. 
44. The same applies to the Goan, Karnatakan, Odishan, and Tamil Nadu cases of peaceful resistance in India, although in these the political outcome fostering the creation of larger resistance coalitions or deeper local willingness and capacity for mobilizations in the future was less explicit; the main aim being economic - to close the mines or projects.

\section{Chapter 4}

1. The mining sector in India is less focused on serving China than the sector in Brazil, and more on creating its own industry. India already produces more than three times as much steel as Brazil and has a much larger metal industry. India also has also had export-oriented projects, such as POSCO (which will be talked about at length in a forthcoming chapter) that would feed the massive steel capacity of South Korea. I mention this here to highlight that there are important differences between these contexts.

2. The resistance agencies here had particular qualities. One important particularity of the armed Indian resistance is that a large number of the Maoists are women, and most of them are Adivasi (Chandroke 2015). There's more leeway for political economic agency among Adivasi women than among some other comparable groups. In India, Adivasi women typically have more control over their earnings than Hindu women. Basu (1992) found that this increased access and control over economic gains has made Adivasi women more apt protagonists in protesting than their Hindu peers.

3. The Salwa Judum in the Gondi tribal language means a "purification hunt"; in English these paramilitaries are called "Peace March." According to Kalshian (2007, 6), "a Chhattisgarh state government-sponsored campaign to mobilise Adivasi youth against the Naxal 'menace' as well as, as some allege, popular resistance to mining in the state ... threatens to fracture and destroy the indigenous communities caught in the crossfire between the state and the Naxalites. . . . [In May 2007,] 55 ill-equipped Salwa Judum troopers were mowed down by their Naxalite brethren in Dantewada." A survey by Zemp and Mohapatra ("Child Soldiers in Chhattisgarh: Issues, Challenges and FFDA's Response," no date) revealed that in the Dantewada district alone, 12,000 minors were recruited by the Salwa Judum as soldiers. The state also recruited thousands of Adivasi boys and girls as police officers, and such recruitments were also very common among the Maoist cadres. 2015).

4. http://www.epw.in/editorials/salwa-judum-version-20.html (accessed June 5,

5. http://in.reuters.com/article/2013/06/04/ironore-india-chhattisgarh-idINL3N0EG1U320130604 (accessed August 4, 2015).

6. Several national mining activists saw this as a tragedy. One wondered "why militants have to call themselves after Mao," as "nobody has imposed mining as ruthlessly as Mao himself."

7. The FRA has provided strong de jure ethnic-territorial rights in India but failed to offer de facto rights. According to $\operatorname{Nayak}(2015,262)$, the act will save Adivasis and forest dwellers "from being treated as encroachers and evicted from their land for development purposes without compensation" and "is designed to prevent the use 
of forestland for development projects ... without the consent of the Gram Sabhas (village assemblies). However, the implementation of this law has failed on various grounds."

8. Panchayats are village-level statutory institutions of local self-government. These village governments are headed by a sarpanch, who links the village community to the central and state governments, and also has judicial powers in some states. According to police officers, sarpanchs who have been elected without Maoist acceptance of them as candidates are sometimes killed in civil war areas in India (http://www. thehindu.com/news/national/other-states/maoists-kill-sarpanch-deputy-sarpanchin-bastar/article7534609.ece?ref=sliderNews accessed August 13, 2015). Besides the sarpanch, the Gram Panchayat is constituted by elected panchas (members). Activists against land acquisitions have used panchayats to get movement members elected as sarpanchs, which has been helpful (National Center for Advocacy Studies 2011).

9. Some politicians, such as Centre minister Jairam Ramesh, according to an National Adivasi Alliance activist, had been strengthening the FRA in the early 2010s, which meant that Adivasis could declare their areas Adivasi areas. However, the current drive of Narendra Modi's government is exactly the opposite, to cut Gram Sabha power. Until now, most Gram Sabha, FRA, and other pro-local land control "political opportunity" power has been curtailed by the contradictory Land Acquisition Act of 1894 under which "the government has the right to acquire any private land as long as it's in the public interest to do so" (Hinmon 2007, 130).

10. I am referring in this book to the pre-2012 district separation, before the splintering of the three southern Chhattisgarh districts of Bastar, Kanker, and Dantewada into several smaller districts. In 1999, Bastar was divided into these three districts. The Bastar Division refers to all of the three districts together. This overlapping of names explains why many texts refer to Bailadila iron ore deposits being in Bastar, for example, although they are in the Dantewada district. Dalli Rajhara deposits are now in the Balod district, while before 2012 they were in Durg. The proposed Rowghat mines close to the city of Narayanpur were before 2012 located in the Kanker district. The Bastar district proper has no known large iron ore deposits or projects, but it has several steel plant projects.

11. Please see Map 1, in the introduction, for the locations and the rough size of the case areas being discussed in this chapter.

12. Godawari acknowledges that it has not been able to open up the Boria Tippu mine due to Naxal presence (http://articles.economictimes.indiatimes.com/2013-1002/news/42617578_1_iron-ore-ari-dongri-2-4-mtpa, accessed August 7, 2015).

13. Recently Sarda has resumed operations on a small-scale mine, which it argues has reserves of $20 \mathrm{mt}$ (http://www.seml.co.in/mining.php, accessed July 2, 2015).

14. http://Naxalrevolution.blogspot.fi/2010/11/interview-with-com-ganapathygeneral.html (accessed August 7, 2015).

15. https://southasiarev.wordpress.com/2010/01/15/peoples-liberation-guerilla-army-stages-daring-ambushes-in-chhattisgarh/ (accessed August 7, 2015).

16. http://Naxalrevolution.blogspot.fi/2012/06/oppose-army-deployment-inbastar.html (accessed August 7, 2015).

17. http://www.thehindu.com/news/national/article2117812.ece (accessed July 2, 2015). 
18. This also partly explains why there has been a strong Communist trade union in the plant, and why the historically Soviet Union-leaning Communist Parties of India (CPI and CPI-M) are at odds with the China-leaning Communist Parties (Maoist and Marxist-Leninist). There has been for decades a rupture in the internal politics of the Left in India flowing from the international schism between the Soviet Union and China. Officially India has been on good terms with the first and at times at war with the latter (Banerjee 2013).

19. http://www.business-standard.com/article/economy-policy/rowghat-iron-oreproject-gets-home-ministry-s-push-115021001610_1.html (accessed July 1, 2015).

20. CMM has "successfully resisted mechanization" since the late 1970s according to a national mining activist. The movement's founder was assassinated by industrialists in 1991, but the movement has left a strong statist and nonmechanizing legacy to the Chhattisgarh steel and iron industry to push for an alternative industrialization (but not resistance to it) (Krishnan 2014). CMM has also been centrally involved in resisting genetically modified crops and defending the rights of peasants against land grabbers. It has mobilized small and marginal farmers, some of whom are part-time laborers in the mines, to resist the destruction of cultivable land and fresh water sources by mining (Baviskar 2005). Krishnan (2014) argues that the CMM's success in affecting technology development and usage in mining is a globally important example. The combination of outside movements in concert with an in-mine labor union is indeed a promising example, and the movement's ability to secure MLA positions suggests that it is one of the most notable and most nuanced place-based mining-critical contentious agents in the world — not an easy feat when one embeds a movement in an industry.

21. http://www.epw.in/authors/chhattisgarh-mukti-morcha (accessed July 12, 2015).

22. http://www.tehelka.com/who-is-the-mines-ministry-trying-to-save/ (accessed July 12, 2015).

23. I received and found diverging claims on whether the current mines, mainly Dalli Rajhara, are actually depleting as fast as claimed, and whether there is a real "necessity" to open the Rowghat mines to avoid closing down the Bhilai plant. In 2011 the government of Chhattisgarh's Mineral Resources Department (http://chhattisgarhmines.gov.in/iron-ore.htm, accessed July 2, 2015) estimated there were approximately $165 \mathrm{mt}$ of iron ore reserves in Dalli Rajhara. On average, 1.6 tons of iron ore are needed to produce a ton of steel (https://www.oecd.org/sti/ind/50494260.pdf, accessed July 2, 2015), but the Bhilai Steel Plant consumes about 2 tons, claimed the president of the iron miners' union in Chhattisgarh. With its current 4.7 million tons per annum hot metal capacity, the captive Dalli Rajhara deposits would last the BSP plant about eighteen years. If the plant capacity increases to the proposed 7.5 million tons per annum, they will last for eleven years. In the official public statistics, referenced above, Rowghat had a deposit of $732 \mathrm{mt}$, but my expert informants claimed that this is an underestimation and that the best information is not public; the big private players have much more information than the state on the deposits. Rowghat hills were argued by some to have at least as much reserves as the hills in Dantewada, which had 1,343 $\mathrm{mt}$ in 2011.

24. http://www.thehindu.com/todays-paper/tp-national/new-iron-ore-mine-tobe-developed/article4063401.ece (accessed July 2, 2015) 
25. http://chhattisgarhmines.gov.in/iron-ore.htm (accessed June 10, 2015).

26. Although Eklama seems to have far fewer reserves than Rowghat, the authorities argue that there is enough iron ore to start a new independent steel mill for the deposit, suggesting that there might be more than the announced $200 \mathrm{mt}$.

27. See http://scroll.in/article/802590/in-chhattisgarh-mining-interests-andtribal-rights-on-a-collision-course (accessed March 31, 2016).

28. It has 66 percent pure ore and the minerals extracted were valued at about 40 billion rupees or 815 million US dollars in 2010-11.

29. In the official statistics 80 percent of the people in this region were considered to be tribal even by the Indian government. However, the actual number is higher, as the Adivasi group also includes people who are not considered by the Indian state to be members of "Scheduled Tribes." For example, there are officially no such Scheduled Tribes in Goa, but the locals see themselves as Adivasis and indigenous.

30. A large part of the ore is still exported to Japan, and such international dimensions typically deepen corporate agency. Estimates of the percentage exported to Japan varied wildly among my informants. One journalist and a bureaucrat argued that it was about half. This was disputed by NMDCs Bailadila trade union leader and the CPI secretary for Chhattisgarh who claimed in an interview that only 10 percent of the Bailadila mine production was exported, with 70 percent going to Andra Pradesh to a government steel plant, and 20 percent to Chhattisgarh sponge iron plants and other local uses.

31. http://www.newindianexpress.com/business/news/Naxal-Problem-HitsNMDC-Bailadila-Mine-Expansion/2014/09/05/article2414586.ece (accessed July 7, 2015).

32. These two Communist parties split into two, mostly because the Maoists wanted to opt for an armed revolution, backed up by China, while the traditional CPI was aligned with the Soviet Union, and wants to seek change via parliamentary politics.

33. Unskilled laborers earn 15,000 rupees per month there, while in private companies the rate is 4,000-5,000 rupees. Private operations are also unconcerned about the environment, according to this informant.

34. NMDC's Bailadila trade union leader and the CPI secretary for Chhattisgarh shared the argument that the relations with Adivasis were "good," with many of them employed. At the same time, he acknowledged that there is pollution in loading places and water pollution going to the villages; losses for which the Adivasis are "compensated," according to him. Sundar (2006), by contrast, claims that Bailadila does not provide employment to the locals. A CPI-affiliated Bhilai Steel Plant and iron ore mine trade unionist asserted to me that Adivasis get only "sweeping jobs" as they are the "most illiterate, backward, poor, distressed people." He also emphasized that the Rowghat mine must be opened at any cost.

35. I do not compare these steel plant cases systematically, but discuss many of them (such as CNS in Congonhas, the Mangalore plant that used Kudremukh ore, and several steel plants and projects in Chhattisgarh and Jharkhand Odisha), as they help to explain iron ore extraction politics. As stated by two Adivasi leaders, as well as journalists I interviewed, the Naxals have been central in blocking the private companies Essar and Tata in Dantewada, in the Bastar and Kanker districts, whose steel 
projects were in the middle of Naxal areas. A journalist claimed that "Essar would have opened a big steel plant in Dantewada, if not for the Maoists." The Tata steel plant case in Bastar demonstrates similar stoppage dynamics, but in Bastar further pressure has come from peaceful resistance building.

A non-Adivasi mining activist explained to me that there is a petition in court against the Tata steel project in Lohandiguda, and as of 2013 Tata had not gotten the required permits. The petition was submitted by Manish Kunjam, a former MLA and the president of the Adivasi Mahasabha, a political party and Adivasi movement; Kunjam also led the peaceful mobilization. So in this case there was simultaneously both armed revolutionary agency and peaceful litigation by organized social movements at play in the resistance to the privatization of the Bastar mines/forests. A lawyer familiar with the petition said that, despite it being in a High Court, and despite strong peaceful local mobilization, Tata went ahead with the project in 2007. At this point, the Maoists stepped in and stopped the project by force. According to the lawyer, there were over 150,000 Naxalite and peaceful resistance movement members all agitating against the Tata project in that area. In practice, the Naxalites killed two strong local politicians, which led to a stoppage of the Tata steel project, which as of 2015 still had not advanced. A bit later, the Maoists also burned a trial Tata mining operation in Dantewada, thus stopping it. This was shared with me in 2013 by a Tehelka journalist knowledgeable about the area. In these Tata steel plant and mine project stoppages, a mix of armed and nonarmed resistance is clearly visible as well.

36. Essar came to own the waste iron dust created by the public NMDC company's mining, converting the dust to pellets and transporting it via slurry pipelines for that purpose. Naxals have bombed the pipeline. BJP was in power when the MOUs were signed, and not even the opposition Congress Party could see these agreements in order to check them, and they were later found to be "signed with scant regard to all rules and regulations" (Putul 2007, 50).

37. This suggests that the media is not a good source of information when examining resistance in Eastern India (or elsewhere for that matter), and that field research is needed. A journalist exclaimed that "rallies do not matter" as the government in Chhattisgarh "can easily ignore" them. A lawyer observed that a general feature of Indian democracy is that it is not very responsive to its people. This sentiment specifically referred to the 1980s dam movement, which was, according to the lawyer, well supported and organized but "gained nothing." My comparative analysis does not, however, support this dam-movement claim-the 1980s dam movement had several weaknesses in comparison to the successful peaceful social movements in mining conflicts in India, which are studied herein.

38. One possible cause for this, mentioned by the advocate, is that this resistence has no informed intellectual class, even in the capital. This situation is unlike the capitals of Odisha and Jharkhand, and is a state of affairs dating back to the very late arrival of British education to this part of India.

39. Dayamani Barla, a Munda tribal, Adivasi leader, journalist, and an Aam Aadmi Party Lok Sabha MP candidate in the 2014 elections (inspired by her sixty-nine day imprisonment in 2012) spearheaded a land occupation movement. This movement peacefully stopped ArcelorMittal from investing 8.8 billion USD to build a giant steel 
plant, only thirty kilometers away from Ranchi, the state capital. The steel plant would had been fed by West Singhbhum iron ore.

40. After the events described above transpired, the Shah Commission report had an impact on Jharkhand. On September 4, 2014, the Jharkhand government was ordered by the central government to close the operation of twelve of its seventeen working iron ore mines, all in the West Singhbhum district. This closure was done in response to the May 15, 2014, direction of the Supreme Court demanding that companies without leases should be acted against. West Singhbhum has had strong resistance against greenfield mining, but not much activism around the existing mines, where populations are mostly promining. However, the Shah Commission also forced existing mines to close, bringing almost all iron mining in the state to a halt. The closed mines were operating illegally as their leases had expired, so this was an imposition of the rule of law. According to an interview with the state mines and geology department secretary, Arun Kumar, reported in the Telegraph, his institution "had served notices to mines and in some cases started hearings in the wake of the Shah Commission report tabled in Parliament this August [2014]. 'The report mentioned illegal mining in tune of over Rs 20,000 crore alone in Jharkhand by companies'." http://www.telegraphindia.com/1140904/jsp/frontpage/story_18798968.jsp\#.ValFQ2PtN4k (accessed July 17, 2015). According to the website Down to Earth, this closure of mines "triggered panic among major steel makers in the area." The chief minister blamed the capitalists: "the closure is a result of inability of mining giants to follow the rules." This minister also blamed the mining companies for their inability to set a corporate social responsibility policy and maintain the environment and forests. http://www.downtoearth.org.in/news/ panic-hunger-and-loss-of-livelihood-follow-closure-of-12-mines-in-jharkhandswest-singhbhum-46280 (accessed July 17, 2015).

41. Dalli Rajhara resistance was spearheaded by an alternative trade union movement, not armed resistance, but the threat of armed resistance lingered in the air, as the Maoists made it clear they could intervene there as well.

42. Max Bearak, "Indian Villagers Cut Down Hills in Quest for Mining Wealth," New York Times, March 24, 2014, B2.

43. Armed conflicts often hide the actions taken while they are happening. Coltan from Congo is an example of how a civil war context allows the dubious background of minerals used transnationally to be hidden (Nest 2011). In Nigeria, the creation and maintenance of "economies of violence" by petro-capitalism (the key agency of change in that context, according to Michael Watts [2004]) has been essential not only for oil extractivism to continue but also for several national, ethnic, and community minorities and underdogs to be able to get at least something out of the extractive revenues (through the use of arms) for themselves.

44. Banerjee $(2013,390)$ argues that, since independence, armed revolutionary agency has always returned to India, and more strongly after being repressed, while the places where Naxalism has not resurfaced have been those where land reform has been carried out, rural minimum wages increased, and Gram Sabhas have been given power. It is this power that "the demand for which initially drove the rural poor to join the Naxalites." Therefore, Hinmon (2007) argues that instead of the extractivist projects' 
resulting in less armed resistance, as the Hindutva movement and the BJP assume, a deeper armed conflict is likely to ensue.

\section{Chapter 5}

1. In Kudremukh, the ore was not of very high quality, but this weakness was partly compensated by the uphill location of the mine, which meant the ore could be sent downhill by pipelines, thereby cutting logistical costs. However, the mine did not turn a profit during the thirty years of its life. This was partly because it was a public operation whose key goal initially had been to help increase India's exports to ease the balance of payment crisis during Indira Gandhi's rule, and to establish diplomatic ties with Iran, which bought the ore (see Sridhar 2010). In the wave of liberalization in the 2000s, the threat of privatizing the mine and selling to the Japanese would have meant greater environmental and social costs for the people and workers as the private owners would obviously have wanted to make the mine profitable, argued Saldanha.

2. http:/www.thehindubusinessline.com/news/jindals-quest-for-iron-ore-in-tnenters-the-final-phase/article5735945.ece (accessed July 29, 2015).

\section{Chapter 6}

1. Another claim that I heard constantly from informants who had studied the project in detail was that the POSCO project design involves many very curious and worrisome features from the viewpoint of potential corruption. For example, 30 percent of the iron ore of the captive mine could be swapped with ore coming from abroad-one informant asked, "why is there such a scheme?" Another informant argued that foreign direct investment such as POSCO is not in fact even foreign direct investment, but principally Indian billionaires' black money from abroad, which they want to bring back to India, laundered, under the guise of foreign direct investment.

2. Replicative networking is typically a temporal process, whereby the methods of successful movement organizations spread, often through conscious efforts by activists. Such networking can be very effective in spreading the ability and willingness to resist. This type of expansion, however, is quite strongly defined by the span of a specific moral economy, as forms of protesting or organizing may be resisted by the inertia of other local moral economies. The example of MST's (few) failed expansions of the "MST model" from southern to Northeast Brazil illustrate the centrality of moral economy (Wolford 2010) in placing barriers to replicating networks. Odisha seems to have a shared moral economy among the resistance-the horizontal organizing typical to the movements mentioned above is an illustration.

3. The different local struggles in Odisha present very interesting and differing dynamics between the strategies used and the outcomes, which is why their analysis is fruitful for testing the hypothesis. The rich local variation across cases demonstrates that not all mining politics are about resistance. In my database there are also cases where the locals have not used many of the five key strategies, such as in Sundargarh. A 
comparison between neighboring Sundargarh and Keonjhar, where all of the five were used (successfully), is therefore highly useful to highlight how particular strategies create activism, which then leads to particular investment outcomes.

4. Sundargarh has been an important feeder of iron ore, not only to the Rourkela state-owned SAIL plant but also, among many others, to the private Jindal Company's three million tons per annum steel plant in Raigarh, in the neighboring state of Chhattisgarh. Activists in Raigarh explained to me that there had been fierce and long-term resistance by the locals to the installation of the steel plant, which still continues, as the violently displaced people have not received compensation. The difficult situation for the resistance against the Raigarh steel project, which failed, coincided with an absence of networking with the Adivasis affected by mining in Tensa in eastern Sundargarh where Jindal gets its iron ore. Conversely, the absence of resistance in Tensa meant that these people could not hold back Jindal's steel plant installation in Raigarh.

5. This activist also said the state-level Adivasi leaders are building some electoral alliances with politicians, but that this task is "complex." Thirty-five percent of the electorate is Adivasi, and political parties are keen to get their votes. They have also had Adivasi politicians in power (three members of the Legislative Assembly), but they have been co-opted, so this is not a path they would like to continue to pursue. In comparison to the MST in Brazil, which also has its own politicians (who were not co-opted to favor corporate investments at the cost of locals), a key difference lies in organizational identity, which is weak for the Adivasis in Odisha's old iron mine areas. In contrast, Adivasis who are still forest dwellers in areas adjacent to old mines seem to be better organized in this sense. In Keonjhar (apart from Joda), locals deployed targeted voting, and managed to use this tactic to help block mine expansion.

6. Indian districts are divided into several smaller administrative units, called blocks. My prior analysis has focused on the district or state levels, but here I will do a more fine-tuned analysis across blocks, as this is essential to understand the drastic differences in the use and nonuse of resistance strategies in the different parts of the Keonjhar district. In the discussion below, focusing on resistance to mining in the Keonjhar district, I talk mostly about the Banspal, Harichandanpur, and Telkoi blocks, where the resistance was strongest. I also discuss the Joda block, where resistance was not so common at all, as this is an old and established mining area. This is important to bear in mind in instances where Joda is discussed.

7. By nonmodernist lines, I mean that one does not put a monetary value on nature and nature is understood in ways that are not solely anthropocentric. These are cases in which the mountain is a god, or holy, or the place of spiritual worship, or some kind of being, or otherwise beyond the scales of valuation in monetary or other modern terms, which do not give such supernatural, agentive, or place-specific uniqueness to mountains, for example. These holy and even agentive mountains cannot be compensated by saving a piece of nature elsewhere, or by giving money. They are beyond and outside modernity's project of rendering everything ontologically flat, so that it can be managed and governed, and calculated. Moore (2014) also talks about this "modern" thinking that flattens everything as something that was born in Enlightenment thinking and is behind the capitalist way of organizing things.

8. Particularly if people with different experiences are mixed in rallies, including 
villagers who have suffered from repression and others whose lands and lives have been ravaged by mining, "everybody learns from each other."

9. In India, district collectors, also called district magistrates, are the most senior officials responsible for administrating a district. They are appointed by the state government, and their duties generally include maintaining law and order, coordinating the police, supervising jails, being arbitrators of land acquisition, collecting land revenue, registering property documents, as well as other related duties as they arise. Thereafter, the collector of the district was the key powerholder to be blamed for the irregularities in these matters concerning the mining projects in question.

10. Khandadhar is not just any place, a coordinator from the Bhubaneswar-based National Center for Advocacy Studies explained to me in February 2013. It is a "religious area" where "even the British did not dare to enter" in fear of an "emotional backlash." It hosts one of India's largest waterfalls, an important elephant corridor, and is an ecological hotspot with high biodiversity and extremely rare species such as the golden gecko.

11. The Khandadhar region has many corporate takers. Among the corporations in court still disputing over rights to the lease are POSCO and KIOCL, the stateowned Kudremukh mining company whose mine was closed in Karnataka. KIOCL argues that the Odisha government gave overlapping extraction MOUs for the site, first to KIOCL and later to POSCO (CSE 2008).

12. This NGO seemed to prefer more of a conciliatory stance than contention, noting, for example, that mine sites could be revegetated by returning the "overburden" (layers of soil and rock covering a deposit) to the open pits after closures, giving examples of where this had been done. Their organization, among other entities, had found by analyzing transport registries that mines were "typically double legal size," but they did not describe their work to me as having played a role in the closures. They explained that the illegal looting has been "going on for long, but not monitored well," because forest officials shared the proceeds and thus have stayed quiet.

13. http://odishanewsonline.blogspot.fi/2014/08/odisha-unrest-in-koira-regionas-locals.html (accessed August 3, 2015).

14. http://timesofindia.indiatimes.com/city/bhubaneswar/HC-notice-to-Centrestate-for-delay-in-collecting-NPV-from-miners/articleshow/47281128.cms (accessed August 13, 2015).

15. See, for example, http://www.deccanherald.com/content/195087/fromtourists-paradise-mining-mafias.html and http://www.hindustantimes.com/indianews/goa-anti-mining-activist-battles-defamation-suit/article1-372997.aspx for their actions. See also http://www.minesandcommunities.org/article.php?a=9069.

16. To read the whole poem, please visit http://mandgoa.blogspot.in/2008/04/ilove-pissurlem.html (accessed May 16, 2015).

17. See, e.g., http://www.dnaindia.com/mumbai/report-mining-ruined-goa-swater-says-activist-1596232 (accessed March 31, 2016).

18. One reason for this has been that all parties have had to take into consideration minorities such as Muslims as key swing voters, as the rising number of caste-based parties has increased the competition for non-upper-caste support. 


\section{Chapter 7}

1. Liberation theology was born in Latin America and has been a particularly impactful ideology and practice in inspiring and organizing the rural poor who are facing situations of oppression. Its preachers guide the members of rural communities to reflect on their economic and political oppression and understand their situation as being similar to how God liberated his people in the Exodus and elsewhere and could do the same for them (Kröger 2010, 103).

2. http://www.justicanostrilhos.org/nota/849 (accessed May 16, 2016)

3. The privatization of Vale in 1997 changed the playing field significantly. As a public company, Vale had to invest 8 percent of its profits in municipalities; this money was passed onward via Caixa, a Brazilian state bank, to municipalities that then decided what to do with the money. After privatization, the development fund became the Vale Foundation, which independently decides what it will finance. This moved a significant political game from state remediation to private politics. Such a change in the structure of available political alternatives has worked to push movements outside of state-based rights and into company-based private negotiations of interests, not backed by laws. According to Father Antonio, "there was also corruption in the previous scheme," but now that the company decides, the problem is that it "listens very little to civil society."

4. It is worth noting, however, that these notes on CSE's work apply only to their mining advocacy. I interviewed a few people working at their pulp and paper industry section and looked through their publications. The paper industry work of the CSE seemed to differ dramatically from their mining advocacy; it was characterized by close engagement in private politics with corporations, which were small mill companies with relatively small tree plantations in the global context.

5. In India, La Via Campesina is not actively involved in mining politics, its secretary told me in interviews. Other activists suggested that La Via Campesina India is not as radical or as tightly small-peasant based as the movement is in Brazil (gleaned from several interviews with Brazilian, Indian, and global La Via Campesina insiders since 2003).

6. I talked to Jurutí mobilizers while conducting participant observation among the rainforest movements for six months around Santarém between 2005 and 2011. The Jurutí case is exemplary and should be studied in detail-it belongs to the category of bauxite mine expansion, which appears to have been easier to resist than iron ore mining. However, based on my field research in the area in 2018, Alcoa is trying to expand to multiple-use conservation areas there, such as Lago Grande.

7. These causalities became more obvious and clearer when I exposed the political ethnographic accounts to a crisp-set Qualitative Comparative Analysis, whereby the resistance strategies identified across all the cases were rendered as causal conditions, and the causal condition complexes formed by these were analyzed in relation to their causal outcomes. While the political ethnographic accounts presented here exposed the richness of different cases, the QCA analysis I performed systemized that data, enabling me to grasp the key lessons needed to draw conclusions and unite and systematically compare the lessons from the different political ethnographies. 


\section{Conclusion}

1. Later, quite a few progressive state actors also became involved, due to massive mobilizations and state embedding by civil society, which made them see the dangers of wanton extractivist expansion or forced them to act to retain power. A wide range of civil society actors can resist extractivism: it was not necessary to have a popular social movement, created via grassroots mass mobilization, to counter project expansion. A professional NGO could do the same, provided it used all the other key strategies and abstained from private politics with companies. However, based on the data, such an outcome may also depend on the targets' underestimation of the resistance potential.

2. As these are large countries with major internal differences, there are also exceptions, such as the armed revolutionary/secessionary conflicts in India.

3. http://ejatlas.org/ (accessed August 5, 2019)

4. A more detailed and systematic study of conflicts and resistance in these areas that is based on the outline proposed herein should verify the extent of my findings.

5. In fact, Nayak (2015) argues that the best known Indian mining conflictNiamgiri's bauxite project by Vedanta — was successfully resisted due to its affiliation with opposition parties. Some movements critical of iron ore extraction were also political parties, for example, CMM in Dalli Rajhara and the CPI-Maoist Naxalite resistance in Chhattisgarh and West Singhbhum. The key movement activists or the movements in Goa, Salem, Tiruvannamalai, Keonjhar, and Khandadhar were also strongly party affiliated.

6. See, e.g., http://upsidedownworld.org/main/international-archives60/5409-extractivism-creates-a-society-without-subjects-raul-zibechi-on-latinamerican-social-movements, and https://www.youtube.com/watch? $\mathrm{v}=\mathrm{Rdb} 3 \mathrm{xdIzcCg}$ (accessed March 30, 2016).

7. These were the places where the welfare-state-based oil extraction model, and the modern mining industry, respectively, were created — where it was even possible to create such models, due to their first world position.

\section{Appendix}

1. See http://conflitosambientaismg.lcc.ufmg.br/observatorio-de-conflitos-ambientais/mapa-dos-conflitos-ambientais/ (accessed August 15, 2015).

2. Carlos Bittencourt from IBASE argued during his interview with me in 2011 (that is, before the massive tailings dam catastrophe) that the Alegria mine had the world's largest tailings pond, whose water use is very badly supervised.

3. http://www.mining-technology.com/features/featurethe-worlds-11-biggestiron-ore-mines-4180663/ (accessed August 15, 2015).

4. For the grievances, see http://www.ifch.unicamp.br/profseva/SEVA_texto $\% 20$ analiticoR_MapeamentoGESTA_junho2011.pdf (accessed August 15, 2015).

5. See http://conflitosambientaismg.lcc.ufmg.br/conflito/?id=241 (accessed August 15, 2015). 


\section{Abbreviation List}

\begin{tabular}{|c|c|}
\hline BJP & Bharatiya Janata Party \\
\hline BSP & Bhilai Steel Plant \\
\hline MM & Chhattisgarh Mukti Morcha (Chhattisgarh Liberation Front) \\
\hline CPI & Communist Party of India \\
\hline $\mathrm{CPI}(\mathrm{M}-\mathrm{L})$ & Communist Party of India (Marxist-Leninist) \\
\hline CPI-M & Communist Party of India \\
\hline CSD & Campaign for Survival and Dignity \\
\hline CSE & Centre for Science and Environment \\
\hline CSN & Companhia Siderúrgica Nacional (National Steel Company) \\
\hline FAO & Food and Agriculture Organization of the United Nations \\
\hline FRA & $\begin{array}{l}\text { Scheduled Tribes and Other Traditional Forest Dwellers Forest } \\
\text { Rights Act } 2006\end{array}$ \\
\hline BASE & Brazilian Institute for Social and Economic Analysis \\
\hline ICMBio & Chico Mendes Institute for Biodiversity Conservation \\
\hline INCRA & Brazil's Land Reform Institute \\
\hline JoR & Justice on the Rails \\
\hline KIOCL & KIOCL Limited (Kudremukh Iron Ore Company Limited) \\
\hline MAM & $\begin{array}{l}\text { Movimento dos Atingidos pelo Mineração (as of 20I4 Movi- } \\
\text { mento Nacional pela Soberania Popular frente à Mineração) } \\
\text { (Movement for Popular Sovereignty in Mining) }\end{array}$ \\
\hline MLA & Member of the Legislative Assembly \\
\hline MMP & Mines, Minerals and People \\
\hline MMX & $\begin{array}{l}\text { MMX Mineração e Metálicos S.A. (Minerals and Metals } \\
\text { Company) }\end{array}$ \\
\hline OU & memorandum of understanding \\
\hline I & Member of Parliament \\
\hline MST & Landless Workers' Movement \\
\hline
\end{tabular}


NGO nongovernmental organization

NMDC National Mineral Development Corporation

PESA Indian Extension to Scheduled Areas Act of 1996

POSCO POSCO Group (formerly Pohang Iron and Steel Company)

PPSS POSCO Pratirodh Sangram Samiti (Anti-POSCO People's Movement)

PT Partido dos Trabalhadores (Workers' Party)

QCA Qualitative Comparative Analysis

SAIL Steel Authority of India Limited Company

SPS Samaj Parivartan Samudaya (Social Change Community) 


\section{References}

Ahmad, Nesar. 2014. "Colonial Legislation in Postcolonial Times." In The Coal Nation: Histories, Ecologies and the Politics of Coal in India, edited by Kuntala Lahiri-Dutt, 257-76. Aldershot: Ashgate.

Alvares da Silva, Ana Carolina, Silvana Costa, and Marcello M. Veiga. 2011. "Drivers of Conflict around Large-Scale Mining Activity in Latin America: The Case of the Carajás Iron Ore Complex in the Brazilian Amazon.” In Governance Ecosystems: CSR in the Latin American Mining Sector, edited by Julia Sagebien and Nicole Marie Lindsay, 154-69. London: Palgrave.

Amenta, Edwin, Neal Caren, Elizabeth Chiarello, and Yang Su. 2010. "The Political Consequences of Social Movements." Annual Review of Sociology 36: 287-307.

Arce, Moisés. 2014. Resource Extraction and Protest in Peru. Pittsburgh: University of Pittsburgh Press.

Arrighi, Giovanni. 1994. The Long Twentieth Century: Money, Power, and the Origins of Our Times. London: Verso Books.

Arsel, Murat, Barbara Hogenboom, and Lorenzo Pellegrini. 2016. “The Extractive Imperative and the Boom in Environmental Conflicts at the End of the Progressive Cycle in Latin America." Extractive Industries and Society 3: 877-79.

Asselin, Victor. 2009. Grilagem: Corrupção e violência em terras do Carajás. 2nd ed. Imperatriz: Ética.

Auyero, Javier. 2007. Routine Politics and Violence in Argentina: The Gray Zone of State Power. Cambridge: Cambridge University Press.

Auyero, Javier, and Débora Alejandra Swistun. 2009. Flammable: Environmental Suffering in an Argentine Shantytown. New York: Oxford University Press.

Banerjee, Subhabrata Bobby. 2000. "Whose Land Is It Anyway? National Interest, Indigenous Stakeholders, and Colonial Discourses." Organization \& Environment 13 (1): 3-38.

Banerjee, Subhabrata Bobby. 2013. "Radical and Violent Political Movements." In Routledge Handbook of South Asian Politics, edited by Paul R. Brass, 382-98. London: Routledge.

Basu, Amrita. 1992. Two Faces of Protest: Contrasting Modes of Women's Activism in India. Berkeley: University of California Press. 
Basu, Amrita. 2015. Violent Conjunctures in Democratic India. New York: Cambridge University Press.

Basu, Rahul. 2014. "Implementing Intergenerational Equity in Goa." Economic \& Political Weekly 49 (51): 33-37.

Baviskar, Amita. 2001. "Written on the Body, Written on The Land: Violence and Environmental Struggles in Central India." In Violent Environments, edited by Nancy Peluso and Michael Watts, 354-79. Ithaca: Cornell University Press.

Baviskar, Amita. 2005. "Red in Tooth and Claw? Looking for Class in Struggles over Nature." In Social Movements in India: Poverty, Power, and Politics, edited by Raka Ray and Mary Fainsod Katzenstein, 161-78. Lanham, MD: Rowman and Littlefield.

Baviskar, Amita. 2014. "Ecology and Development in India: A Field and Its Future." In Sociology of Environment, edited by S. Chaudhury, 42-55. London: Sage.

Bebbington, Anthony, and Jeffery Bury, eds. 2013. Subterranean Struggles: New Dynamics of Mining, Oil, and Gas in Latin America. Austin: University of Texas Press.

Bebbington, Anthony, Leonith Hinojosa, Denise Humphreys Bebbington, Maria Luisa Burneo, and Ximena Warnaars. 2008. "Contention and Ambiguity: Mining and the Possibilities of Development." Development and Change 39 (6): 887-914.

Bedi, Heather P. 2013a. "Environmental Mis-Assessment, Development and Mining in Orissa, India." Development and Change 44 (1): 101-23.

Bedi, Heather P. 2013b. "Special Economic Zones: National Land Challenges, Localized Protest." Contemporary South Asia 21 (1): 38-51.

Benson, Michelle, and Thomas R. Rochon. 2004. "Interpersonal Trust and the Magnitude of Protest: A Micro and Macro Level Approach.” Comparative Political Studies 37: 435-57.

Benson, Peter, and Stuart Kirsch. 2010. "Capitalism and the Politics of Resignation." Current Anthropology 51 (4): 459-86.

Bisht, Arpita, and Julien-Francois Gerber. 2017. "Ecological distribution conflicts (EDCs) over mineral extractivism in India: An overview." Extractive Industries and Societies 4 (3): 548-63.

Blaser, Mario. 2009. "Political Ontology." Cultural Studies 23: 873-96.

Blaser, Mario. 2013. "Ontological Conflicts and the Stories of Peoples in Spite of Europe." Current Anthropology 54 (5): 547-68.

Borras, Saturnino M., Jr., and Jennifer C. Franco. 2013. "Global Land Grabbing and Political Reactions 'from Below'. Third World Quarterly 34 (9): 1723-47.

Bosi, Lorenzo, and Marco Giugni. 2012. "The Study of the Consequences of Armed Groups: Lessons from the Social Movement Literature." Mobilization 17 (1): 85-98.

Bosi, Lorenzo, Marco Giugni, and Katrin Uba, eds. 2016. The Consequences of Social Movements. Cambridge: Cambridge University Press.

Bourdieu, Pierre. 1986. "The Forms of Capital." In Handbook of Theory and Research for the Sociology of Education, edited by J. G. Richardson, 241-58. New York: Greenwood.

Bourdieu, Pierre. 1991. Language and Symbolic Power. Cambridge: Polity Press.

Bourdieu, Pierre. 1998. Practical Reason: On the Theory of Action. Cambridge: Polity Press. 
Bridge, Gavin. 2010. "Resource Geographies 1: Making Carbon Economies, Old and New." Progress in Human Geography 35 (6): 820-34.

Broad, Robin, and John Cavanagh. 2015. "Poorer Countries and the Environment: Friends or Foes?” World Development 72: 419-31.

Bunce, Valerie J., and Sharon L. Wolchik. 2011. Defeating Authoritarian Leaders in Postcommunist Countries. Cambridge: Cambridge University Press.

Bunker, Stephen. 1985. Underdeveloping the Amazon: Extraction, Unequal Exchange, and the Failure of the Modern State. Chicago: University of Chicago Press.

Bunker, Stephen. 2003. "Matter, Space, Energy, and Political Economy: The Amazon in the World-System.” Journal of World-Systems Research 9 (2): 219-58.

Bunker, Stephen, and Paul Ciccantell. 2005. Globalization and the Race for Natural Resources. Baltimore: John Hopkins University Press.

Burchardt, Hans-Jürgen, and Kristina Dietz. 2014. "(Neo-) Extractivism-a New Challenge for Development Theory from Latin America." Third World Quarterly 35 (3): 468-86.

Carney, Judith, and Michael Watts. 1990. "Manufacturing Dissent: Work, Gender and the Politics of Meaning in a Peasant Society." Africa 60: 207-41.

Carter, Miguel, ed. 2015. Challenging Social Inequality: The Landless Rural Worker's Movement and Agrarian Reform in Brazil. London: Duke University Press.

Carvalho, Pedro Sérgio Landim de, Marcelo Machado da Silva, Marco Aurélio Ramalho Rocio, and Jacques Moszkowicz. 2014. "Minério de ferro.” Insumos Básicos. BNDES Setorial 39: 197-234.

Castree, Noel. 2003. "Commodifying What Nature?" Progress in Human Geography 27 (3): 273-97.

Centre for Science and the Environment. 2008. Rich Lands, Poor People: Is 'Sustainable' Mining Possible? New Delhi: CSE.

Centre for Science and the Environment. 2011. Sharing the Wealth of Minerals. Centre for Science and Environment. New Delhi: CSE.

Chandhoke, Neera. 2015. Democracy and Revolutionary Politics. New Delhi: Bloomsbury.

Chenoweth, Erica, and Maria J. Stephan. 2011. Why Civil Resistance Works: The Strategic Logic of Nonviolent Conflict. Columbia University Press.

Chenoy, Anuradha M., and Kamal A. Mitra Chenoy. 2010. Maoist and Other Armed Conflicts. New Delhi: Penguin.

Chhattisgarh Bachao Andolan. 2014. "Bhilai Steel Plant, State and Central Governments Collaborating on Criminal, Illegal Loot in Rowghat-Another Scam in the Making." Press release, February 18.

Chomsky, Aviva. 2016. "Social Impacts of Resource Extraction." Latin American Research Review 51: 243-54.

Choudhary, Shubhranshu. 2012. Let's Call Him Vasu: With the Maoists in Chhattisgarh. New Delhi: Penguin.

Coelho, Tádzio. 2012. "Mineração e dependência no quadrilátero ferrífero" [Mining and dependency in the iron quadrangle]. Intratextos 3: 128-46.

Coelho-De-Souza, Carolina Herrmann. 2015. "O 'espaço da resistência' na Serra do Gandarela: Instrumentos, contraposiçôes e a necessária utopia.” PhD thesis, Universidade Federal de Minas Gerais. 
Conde, Marta. 2017. "Resistance to Mining: A Review.” Ecological Economics 132: 80-90.

Dalton, Russell J., Steve Recchia, and Robert Rohrschneider. 2003. "The Environmental Movement and the Modes of Political Action." Comparative Political Studies 36 (7): 743-71.

Das, Amarendra. 2005. "POSCO Deal: Natural Resource Implications." Economic and Political Weekly (October 29): 4678-80.

Davenport, Christian, and Priyamvada Trivedi. 2013. "Activism and Awareness: Resistance, Cognitive Activation, and 'Seeing' Untouchability among 98,316 Dalits." Journal of Peace Research 50 (3): 369-83.

de la Cadena, Marisol. 2014. "The Politics of Modern Politics Meets Ethnographies of Excess through Ontological Openings." Cultural Anthropology Online, January 13. de la Cadena, Marisol. 2015. Earth Beings. Durham, NC: Duke University Press.

Deonandan, Kalowatie, and Michael L. Dougherty, eds. 2017. Mining in Latin America: Critical Approaches to the New Extraction. London: Routledge.

Dinius, Oliver. 2010. Brazil's Steel City: Developmentalism, Strategic Power, and Industrial Relations in Volta Redonda, 1941-1964. Stanford: Stanford University Press.

Dougherty, Michael L., and Tricia D. Olsen. 2014. “'They Have Good Devices': Trust, Mining, and the Microsociology of Environmental Decision-Making." Journal of Cleaner Production 84: 183-92.

Downey, Liam, Eric Bonds, and Katherine Clark. 2010. "Natural Resource Extraction, Armed Violence, and Environmental Degradation." Organization \& Environment 23 (4): 417-45.

Dryzek, John S., David Downes, Christian Hunold, and David Schlosberg. 2003. Green States and Social Movements: Environmentalism in the United States, United Kingdom, Germany, and Norway. New York: Oxford University Press.

Duit, Andreas, ed. 2014. State and Environment: The Comparative Study of Environmental Governance. Cambridge, MA: MIT Press.

Edelman, Marc, Carlos Oya, and Saturnino M. Borras Jr. 2013. "Global Land Grabs: Historical Processes, Theoretical and Methodological Implications and Current Trajectories." Third World Quarterly 34: 1517-31.

EMIS. 2014a. Insight_India Mining Sector Report. July.

EMIS. 2014b. Insight_Brazil Mining Sector Report. December.

Ernst \& Young. 2013. "Business Risks Facing Mining and Metals 2012-2013." Ernst \& Young, accessed June 17, 2015. http://www.zurichna.com/internet/zna/ SiteCollectionDocuments/en/Products/energy/Ernst_Young_Mining_Risk_Sur vey.pdf

Escobar, Arturo. 2008. Territories of Difference: Place, Movements, Life, Redes. Durham, NC: Duke University Press.

Escobar, Arturo. 2011. Encountering Development: The Making and Unmaking of the Third World. 2nd ed. Princeton: Princeton University Press.

Evans, Geoffrey Russell, James Goodman, and Nina Lansbury, eds. 2002. Moving Mountains: Communities Confront Mining and Globalization. London: Zed Books.

Evans, Peter. 1995. Embedded Autonomy: States and Industrial Transformation. Princeton: Princeton University Press.

Evans, Peter. 2010. “Constructing the 21st Century Developmental State: Potentialities 
and Pitfalls." In Constructing a Democratic Developmental State in South Africa: Potentials and Challenges, edited by Omano Edigheji, 37-58. Capetown: HSRC Press.

Evans, Peter. 2014. "Reconstructing Polanyi in the Late Neoliberal Era: A Critical but Optimistic Perspective." Paper presented at Social Movement Seminar, Tokyo, July 20 .

Evans, Peter, and Patrick Heller. 2015. "Human Development, State Transformation and the Politics of the Developmental State." In The Oxford Handbook of Transformations of the State, 691-713. Oxford: Oxford University Press.

Fox, Jefferson, Yayoi Fujita, Dimbab Ngidang, Nancy Peluso, Lesley Potter, Niken Sakuntaladewi, Janet Sturgeon, and David Thomas. 2009. "Policies, PoliticalEconomy, and Swidden in Southeast Asia." Human Ecology 37 (3): 305-22.

Frank, Andre, and Barry Gills, eds. 1993. The World System: Five Hundred Years or Five Thousand? London: Routledge.

Freire, Paulo. 2000. Pedagogia da indignação: Cartas pedagógicas e outros escritos. São Paulo: São Paulo State University.

Fuentes-George, Kemi. 2016. Between Preservation and Exploitation: Transnational Advocacy Networks and Conservation in Developing Countries. Cambridge, MA: MIT Press.

Ganguly, Debjani. 2015. "The Subaltern after Subaltern Studies: Genealogies and Transformations." South Asia: Journal of South Asian Studies 38 (1): 1-9.

Gerbode, Christine. 2011. "The Role of Information in Enabling Community Response to Mining Threats in Palmares II." ISP Collection, Paper No. 1212.

Giugni, Marco. 2004. Social Protest and Policy Change: Ecology, Antinuclear, and Peace Movements in Comparative Perspective. Lanham, MD: Rowman and Littlefield.

Giugni, Marco, Lorenzo Bosi, and Katrin Uba. 2013. "Outcomes of Social Movements and Protest Activities." In Oxford Bibliographies in "Political Science," edited by L. Sandy Meisel. Oxford: Oxford University Press.

Giugni, Marco G., and Maria T. Grasso. 2015. "Environmental Movements: Heterogeneity, Transformation, and Institutionalization." Annual Review of Environment and Resources 40.

Golub, Alex. 2014. Leviathans at the Gold Mine: Creating Indigenous and Corporate Actors in Papua New Guinea. Durham, NC: Duke University Press.

Gudynas, Eduardo. 2009. "La ecología política del giro biocéntrico en la nueva Constitución de Ecuador." Revista de estudios sociales 32: 34-47.

Gudynas, Eduardo. 2011. "Buen Vivir: Today's Tomorrow.” Development 54: 441-47.

Gudynas, Eduardo. 2012. "Estado compensador e nuevos extractivismos: Las ambivalencias del progresismo sudamericano." Nueva Sociedad 237: 128-46.

Gudynas, Eduardo. 2015. Extractivismos: Ecología, economía y politica de un modo de entender el desarrollo y la naturaleza. Cochabamba: CEDIB.

Gudynas, Eduardo. 2016. "Beyond Varieties of Development: Disputes and Alternatives." Third World Quarterly 37 (4): 721-32.

Guha, Ramachandra, and Joan Martinez-Alier. 1997. Varieties of Environmentalism: Essays North and South. London: Earthscan.

Guha, Ranajit. 1989. "Dominance without Hegemony and Its Historiography." In Subaltern Studies VI: Writings on South Asian History, edited by Ranajit Guha. Delhi: Oxford University Press. 
Gunderson, Ryan. 2015. "Environmental Sociology and the Frankfurt School 1: Reason and Capital." Environmental Sociology 13: 224-35.

Hadden, Jennifer. 2015. Networks in Contention: The Divisive Politics of Climate Change. New York: Cambridge University Press.

Hall, Peter A., and Rosemary C. R. Taylor. 1996. "Political Science and the Three New Institutionalisms." Political Studies 44: 936-57.

Haslam, Paul Alexander, and Nasser Ary Tanimoune. 2016. "The Determinants of Social Conflict in the Latin American Mining Sector: New Evidence with Quantitative Data." World Development 78: 401-19.

Hecht, Susanna B. 2011. "From Eco-Catastrophe to Zero Deforestation? Interdisciplinarities, Politics, Environmentalisms and Reduced Clearing in Amazonia." Environmental Conservation 39 (1): 4-19.

Hellman, J. A. 1992. "The Study of New Social Movements in Latin America and the Question of Autonomy." In The Making of Social Movements in Latin America: Identity, Strategy and Democracy, edited by Arturo Escobar and Sonia E. Alvarez, 52-61. San Francisco: Westview Press.

Hinmon, Ashly. 2007. "Forgeries in Steel: We Also Make Poverty." In Caterpillar and the Mahua Flower: Tremors in India's Mining Fields, edited by Rakesh Kalshian, 124-39.

Hochstetler, Kathryn. and Margret E. Keck. 2007. Greening Brazil: Environmental Activism in State and Society. Durham, NC: Duke University Press.

Human Rights Watch. 2012. "Out of Control: Mining, Regulatory Failure, and Human Rights in India." Human Rights Watch. Posted June 14. https://www. hrw.org/report/2012/06/14/out-control/mining-regulatory-failure-and-humanrights-india

Ingold, Tim. 2000. The Perception of the Environment: Essays in Livelihood, Dwelling and Skill. London: Routledge.

International Council on Mining and Metals. 2013. "Mining: Partnerships for Development. The Mining Sector in Brazil: Building Institutions for Sustainable Development." London: ICMM. https://www.icmm.com/document/5423

Jalbert, Kirk, Anna Willow, David Casagrande, and Stephanie Paladino, eds. 2017. ExtrACTION: Impacts, Engagements, and Alternative Futures. London: Routledge.

Kalshian, Rakesh, ed. 2007. Caterpillar and the Mahua Flower: Tremors in India's Mining Fields. Kathmandu, Nepal: Panos South Asia.

Karlsson, Bengt G. 2011. Unruly Hills: Nature and Nation in India's Northeast. New Delhi: Orient BlackSwan.

Khagram, Sanjeev. 2004. Dams and Development: Transnational Struggles for Water and Power. Ithaca: Cornell University Press.

King, Brayden G. 2008. "A Political Mediation Model of Corporate Response to Social Movement Activism.” Administrative Science Quarterly 53: 395-421.

King, Brayden G., and Sarah A. Soule. 2007. "Social Movements as Extra-institutional Entrepreneurs: The Effect of Protests on Stock Price Returns." Administrative Science Quarterly 52: 413-42.

Kirsch, Stuart. 2013. Mining Capitalism: The Relationship between Corporations and Their Critics. Berkeley: University of California Press.

Klein, Naomi. 2014. This Changes Everything: Capitalism vs, the Climate. New York: Alfred A. Knopf. 
Kohli, Atul. 2012. Poverty amid Plenty in the New India. New York: Cambridge University Press.

Korten, David. 2002. "Predatory Corporations." In Moving Mountains: Communities Confront Mining and Globalization, edited by Geoff Evans, James Goodman, and Nina Lansbury, 1-18. London: Zed Books.

Krishnan, Radhika. 2014. "Rethinking Technological Choices and Knowledge Production in the Mines and on the Factory Floor: Chhattisgarh Mukti Morcha's Experiences in Central India." African Journal of Science, Technology, Innovation and Development 6 (3): 213-21.

Kröger, Markus. 2010. "The Politics of Pulp Investment and the Brazilian Landless Movement (MST).” PhD diss., Political Science, University of Helsinki.

Kröger, Markus. 2011. "Promotion of Contentious Agency as a Rewarding Movement Strategy: Evidence from the MST-Paper Industry Conflicts in Brazil." Journal of Peasant Studies 38 (2): 435-58.

Kröger, Markus. 2012. "Neo-Mercantilist Capitalism and Post-2008 Cleavages in Economic Decision-Making Power in Brazil." Third World Quarterly 33 (5): 887901.

Kröger, Markus. 2013a. Contentious Agency and Natural Resource Politics. London: Routledge.

Kröger, Markus. 2013b. "Grievances, Agency and the Absence of Conflict: The New Suzano Pulp Investment in the Eastern Amazon." Forest Policy and Economics 33: $28-35$.

Kröger, Markus. 2013c. “Globalization as the 'Pulping' of Landscapes: Forestry Capitalism's North-South Territorial Accumulation.” Globalizations 10 (6): 837-53.

Kröger, Markus. 2014. "The Political Economy of Global Tree Plantation Expansion: A Review." Journal of Peasant Studies 41 (2): 235-61.

Kröger, Markus. 2015a. "Spatial Causalities in Resource Rushes: Notes from the Finnish Mining Boom.” Journal of Agrarian Change 16 (4): 543-70.

Kröger, Markus. 2015b. "O papel do estado brasileiro na criação de fronteira capitalista e novas naturezas no passado e futuro." In Estado, burocracia e controle democrático, edited by Carlos Santana and W. Iglecias, 171-96. São Paulo: Alameda.

Kröger, Markus. 2017. "Inter-sectoral Determinants of Forest Policy: The Power of Deforesting Actors in Post-2012 Brazil.” Forest Policy and Economics 77 (April): 24-32; https://doi.org/10.1016/j.forpol.2016.06.003

Kröger, Markus. 2019. "O crescimento acelerado e o colapso do extrativismo do minério de ferro: O nexo Brasil-Índia-China.” In Desenvolvimento e transformaçôes agrárias: BRICS, competição e cooperação no sul global, edited by Sérgio Sauer, 30724. São Paulo: Outras Expressóes.

Kröger, Markus, and Rickard Lalander. 2016. "Ethnic-Territorial Rights and the Resource Extraction Boom in Latin America: Do Constitutions Matter?" Third World Quarterly 37 (4): 682-702.

Kumar, Kundan, and John M. Kerr. 2012. "Democratic Assertions: The Making of India's Recognition of Forest Rights Act." Development and Change 43 (3): 75171.

Lahiri-Dutt, Kuntala, ed. 2011. Gendering the Field: Towards Sustainable Livelihoods for Mining Communities. Canberra: Australian National University E Press. 
Lahiri-Dutt, Kuntala, ed. 2014. The Coal Nation: Histories, Ecologies and the Politics of Coal in India. Aldershot: Ashgate.

Lahiri-Dutt, Kuntala, Radhika Krishnan, and Nesar Ahmad. 2014. "'Captive' Coal Mining in Jharkhand: Taking Land from Indigenous Communities." In The Coal Nation: Histories, Ecologies and the Politics of Coal in India, edited by Kuntala Lahiri-Dutt, 165-82. Aldershot: Ashgate.

Lang, Miriam, and Dunia Mokrani, eds. 2013. Beyond Development Alternative Visions from Latin America. Amsterdam: Rosa Luxemburg Foundation and Transnational Institute.

Lesbirel, Sidney Hayden, and Daigee Shaw, eds. 2005. Managing Conflict in Facility Siting: An International Comparison. Cheltenham, UK: Edward Elgar.

Levien, Michael. 2011. "Special Economic Zones and Accumulation by Dispossession in India." Journal of Agrarian Change 11 (4): 454-83.

Levien, Michael. 2012. "The Land Question: Special Economic Zones and the Political Economy of Dispossession in India." Journal of Peasant Studies 39 (3-4): 93369.

Levien, Michael. 2013a. "The Politics of Dispossession: Theorizing India's 'Land Wars.” Politics \& Society 41 (3): 351-94.

Levien, Michael. 2013b. "Regimes of Dispossession: From Steel Towns to Special Economic Zones." Development and Change 44 (2): 381-407.

Levien, Michael. 2015. "From Primitive Accumulation to Regimes of Dispossession: Six Theses on India's Land Question.” Economic \& Political Weekly 50 (22): 14657.

Levien, Michael. 2018. Dispossession without Development: Land Grabs in Neoliberal India. Oxford: Oxford University Press.

Li, Fabiana. 2015. Unearthing Conflict: Corporate Mining, Activism, and Expertise in Peru. Durham, NC: Duke University Press.

Ludden, David, ed. 2001. Reading Subaltern Studies: Perspectives on History, Society, and Culture in South Asia. New Delhi: Permanent Black.

Luders, Joseph E. 2010. The Civil Rights Movement and the Logic of Social Change. Cambridge: Cambridge University Press.

MacKay, Joseph, and Jamie Levin. 2015. "Hanging Out in International Politics: Two Kinds of Explanatory Political Ethnography for IR.” International Studies Review 17: 163-88.

Maher, Rajiv. 2014. "What Influences Community Positions towards Nearby Mining Projects: Eight Cases from Brazil and Chile.” PhD diss., Cranfield University.

Marcus, George E. 1995. "Ethnography in/of the World System: The Emergence of Multi-Sited Ethnography." Annual Review of Anthropology 24: 95-117.

Marques, Gilberto. 2007. Estado e desenvolvimento na Amazônia: A inclusáo amazônica na reprodução capitalista brasileira. Rio de Janeiro: UFRRJ/CPDA.

Marques, Gilberto. 2012. "Amazônia: Uma moderna colônia energético mineral." Ciência \& Tecnologia 49: 32-45.

Martinez-Alier, Joan. 2016. "Social/Climate/Agrarian/Environmental Justice, Social Movements and Alternatives." Keynote in plenary panel at Interational Critical Agrarian Studies (ICAS) Colloquium, The Hague, Netherlands, February 5.

Martinez-Alier, Joan, Leah Temper, Daniela Del Bene, and Daniela Scheidel. 2016. "Is 
There a Global Environmental Justice Movement?" Journal of Peasant Studies. doi: 10.1080/03066150.2016.1141198.

Marx, Karl. 1887. Capital: A Critique of Political Economy. Volume I. Book One: The Process of Production of Capital.

McAdam, Doug. 1999. Political Process and the Development of Black Insurgency, 1930 1970. Chicago: University of Chicago Press.

McAdam, Doug, and Hilary Boudet. 2012. Putting Social Movements in Their Place: Explaining Opposition to Energy Projects in the United States, 2000-2005. New York: Cambridge University Press.

McAdam, Doug, Sidney Tarrow, and Charles Tilly. 2001. Dynamics of Contention. Cambridge: Cambridge University Press.

McAdam, Doug, Sidney Tarrow, and Charles Tilly. 2008. "Methods for Measuring Mechanisms of Contention." Qualitative Sociology 31: 307-31.

McAllister, Lesley. 2008. Making Law Matter: Environmental Protection and Legal Institutions in Brazil. Stanford: Stanford University Press.

McKay, Ben M. 2017. "Agrarian Extractivism in Bolivia." World Development 97: 199-211.

Meher, Rajkishor. 2009. "Globalization, Displacement and the Livelihood Issues of Tribal and Agriculture Dependent Poor People: The Case of Mineral-Based Industries in India." Journal of Developing Societies 25 (4): 457-80.

Meher, Rajkishor. 2011. "Development or Deprivation of the Ecosystem People? A Study of Displaced Families by Three Public Sector Steel Plants in India." Journal of Humanities and Social Studies 2 (July-December).

Mies, Maria, Veronika Bennholdt-Thomsen, and Claudia von Werlhof. 1988. Women, the Last Colony. London: Zed Books.

Mies, Maria, and Vandana Shiva. 2014. Ecofeminism (Critique, Influence, Change). London: Zed Books.

Ministry of Mines and Energy. 2010. "Plano nacional de mineração 2030 (PNM2030)" [National Plan of Mining 2030]. Ministry of Mines and Energy (Brazil), accessed August 8, 2013, http://www.mme.gov.br/sgm/galerias/arquivos/plano_ duo_decenal/Plano_Nacional_de_Mineraxo_2030__Consulta_Publica_10_ NOV.pdf

Mishra, Banikanta. 2010. "Agriculture, Industry and Mining in Orissa in the PostLiberalisation Era: An Inter-District and Inter-State Panel Analysis." Economic \& Political Weekly 45 (20): 49-68.

Mitchell, Timothy. 2011. Carbon Democracy: Political Power in the Age of Oil. London: Verso.

Mohapatra, Subash. 2007. "Conflict-Induced Displacement in Chhattisgarh: Analysis and Situation Report on the Displacement Camps in Dantewada." Kolkata: Mahanirban Calcutta Research Group, accessed June 4, 2015, http://www.mcrg. ac.in/pp15.pdf

Moody, Roger. 2007. Rocks and Hard Places: The Globalisation of Mining. London: Zed Books.

Moore, Jason W. 2014. "The Capitalocene, Part II: Abstract Social Nature and the Limits to Capital.” Binghamton, NY: Fernand Braudel Center and Department of Sociology, Binghamton University, accessed July 15, 2015, https:/www.aca 
demia.edu/7257990/The_Capitalocene_Part_II_Abstract_Social_Nature_and_ the_Limits_to_Capital

Moore, Jason W. 2015. Capitalism in the Web of Life: Ecology and the Accumulation of Capital. London: Verso Books.

National Center for Advocacy Studies. 2011. Organising and Mobilising in People Centred Advocacy in South Asia: A Resource Book. Pune, Maharashtra, India: National Center for Advocacy Studies.

Nayak, Arun Kumar. 2015. "Environmental Movements in India." Journal of Developing Societies 31 (2): 249-80.

Nest, Michael. 2011. Coltan. Cambridge: Polity Press.

Nilsen, Alf Gunvald. 2012. "Adivasis in and against the State: Subaltern Politics and State Power in Contemporary India." Critical Asian Studies 44 (2): 251-82.

Nilsen, Alf Gunvald, and Srila Roy, eds. 2015. New Subaltern Politics: Reconceptualizing Hegemony and Resistance in Contemporary India. Oxford: Oxford University Press.

Nugent, Jeffrey B., and James A. Robinson. 2010. "Are Factor Endowments Fate?" Revista de Historia EconomicalJournal of Iberian and Latin American Economic History 28: 45-82.

Omvedt, Gail. 1993. Reinventing Revolution: New Social Movements and the Socialist Tradition in India. London: Routledge.

O’Neill, Kate. 2012. “The Comparative Study of Environmental Movements.” In Comparative Environmental Politics: Theory, Practice, and Prospects, edited by Paul F. Steinberg and Stacy D. VanDeveer, 115-42. Cambridge, MA: MIT Press.

Özkaynak, Begüm, Beatriz Rodríguez-Labajos, Murat Arsel, Duygu Avci, María Helena Carbonell, Bruno Chareyron, G. Chicaiza, et al. 2012. "Mining Conflicts around the World: Common Grounds from Environmental Justice Perspective." EJOLT Report No. 7.

Özkaynak, Begüm, Beatriz Rodríguez-Labajos, Cem İskender Aydın, Ivonne Yanez, and Claudio Garibay. 2015. "Towards Environmental Justice Success in Mining Conflicts: An Empirical Investigation.” EJOLT Report No. 14.

Padel, Felix, and Samarendra Das. 2007. "Agya, What Do You Mean by Development?" In Caterpillar and the Mahua Flower: Tremors in India's Mining Fields, edited by Rakesh Kalshian, 24-46. Kathmandu, Nepal: Panos South Asia.

Padel, Felix, and Samarendra Das. 2010a. Out of This Earth: East India Adivasis and the Aluminium Cartel. New Delhi: Orient BlackSwan.

Padel, Felix, and Samarendra Das. 2010b. "Cultural Genocide and the Rhetoric of Sustainable Mining in East India.” Contemporary South Asia 18 (3): 333-41.

Paul, Santosh. ed. 2013. The Maoist Movement in India: Perspectives and Counterperspectives. New Delhi: Routledge.

Pedlowski, Marcos A. 2013. "When the State Becomes the Land Grabber: Violence and Dispossession in the Name of 'Development' in Brazil." Journal of Latin American Geography (January 1): 91-111.

Pellow, David Naguib. 2007. Resisting Global Toxics. Cambridge, MA: MIT Press.

Peluso, Nancy Lee, and Michael Watts. 2001. "Violent Environments." In Violent Environments, edited by Nancy Lee Peluso and Michael Watts, 3-38. Ithaca: Cornell University Press. 
Petras, James, and Henry Veltmeyer. 2014. The New Extractivism: A Post-Neoliberal Development Model or Imperialism of the Twenty-First Century? London: Zed Books.

Polanyi, Karl. 2001. The Great Transformation: The Political and Economic Origins of Our Time. 2nd ed. Boston: Beacon Press.

Poteete, Amy R. 2009. "Is Development Path Dependent or Political? A Reinterpretation of Mineral-Dependent Development in Botswana." Journal of Development Studies 45 (4): 544-71.

Putul, Alok Orakash. 2007. "No Man's Land." In Caterpillar and the Mahua Flower: Tremors in India's Mining Fields, edited by Rakesh Kalshian, 47-64. Kathmandu, Nepal: Panos South Asia.

Ramalho, José Ricardo, Rodrigo Salles Pereora Santos, and Raphael Jonasthas da Costa Lima. 2013. "Estratégias de desenvolvimento industrial e dinâmicas territoriais de contestação social" [Strategies of industrial development and territorial dynamics of social contestation].” Sociologia \& Antropologia 3 (5): 175-200.

Ray, Raka. 1999. Fields of Protest: Women's Movements in India. Minneapolis: University of Minnesota Press.

Ray, Raka, and Mary Fainsod Katzenstein, eds. 2005. Social Movements in India: Poverty, Power, and Politics. Lanham, MD: Rowman and Littlefield.

Rihoux, Benoît. 2008. "Case-Oriented Configurational Research: Qualitative Comparative Analysis (QCA), Fuzzy Sets, and Related Techniques." In The Oxford Handbook of Political Methodology, edited by Janet M. Box-Steffensmeier, Henry E. Brady, and David Collier, 722-36. Oxford: Oxford University Press.

Rodrigues, Maria Guadalupe Moog. 2003. Global Environmentalism and Local Politics: Transnational Advocacy Networks in Brazil, Ecuador, and India. New York: SUNY Press.

Rodrigues, Sebastiao. 2014. A Status of Adivasis/Indigenous Peoples Mining Series 1: Goa-Land, Mining and Indigenous Peoples; an Overview. New Delhi: Aakar Books.

Romero, José Antonio Lapa. 2017. Lo que los ojos no ven: Capital minero, hegemonia, represión estatal y movimiento social en el Valle de Tambo de marzo a mayo del 2015. Lima: Arteidea.

Roy, Arundhati. 2010. "Foreword.” In Out of This Earth: East India Adivasis and the Aluminium Cartel, edited by Felix Padel and Samarendra Das, xi-xii. New Delhi: Orient BlackSwan.

Rycroft, Daniel J., and Sangeeta Dasgupta, eds. 2011. Indigenous Pasts and the Politics of Belonging in India: Becoming Adivasi. London: Routledge.

Saes, Beatriz Macchione. 2018. Comércio ecologicamente desigual no século XXI : Evidências a partir da inserção brasileira no mercado internacional de minério de ferro. Rio de Janeiro: Garamond.

Sampat, Preeti. 2015. “The 'Goan Impasse': Land Rights and Resistance to SEZs in Goa, India." Journal of Peasant Studies 42 (3-4): 765-90.

Santos, Rodrigo Salles Pereira. 2015. "Da estratégia corporativa à ação economicamente relevante: A CSN e a contestação social na mineração de ferro.” Revista Pós Ciências Sociais 12 (24): 143-66.

Santos, Rodrigo Salles Pereira, and Bruno Milanez. 2015. "The Global Production Network for Iron Ore: Material, Corporate Strategies, and Social Contestation in Brazil." Extractive Industries and Society 2 (4): 756-65. 
Sawyer, Suzana. 2004. Crude Chronicles: Indigenous Politics, Multinational Oil, and Neoliberalism in Ecuador. Durham, NC: Duke University Press.

Schatz, Edward, ed. 2009. Political Ethnography: What Immersion Contributes to the Study of Power. Chicago: University of Chicago Press.

Schmidt, D. 1991. Citizen Lawmakers: The Ballot Initiative Revolution. Temple University Press.

Schreurs, Miranda A. 2003. Environmental Politics in Japan, Germany, and the United States. Cambridge: Cambridge University Press.

Scott, James. 1998. Seeing Like a State. New Haven: Yale University Press.

Scott, James. 2009. The Art of Not Being Governed. New Haven: Yale University Press.

Shah, Alpa. 2010. In the Shadows of the State: Indigenous Politics, Environmentalism, and Insurgency in Jharkhand, India. Durham, NC: Duke University Press.

Shah, Ghanshyam. 2004. Social Movements in India: A Review of Literature. New Delhi: Sage Publications.

Sherman, Daniel. 2011. "Critical Mechanisms for Critical Masses: Exploring Variation in Opposition to Low-Level Radioactive Waste Site Proposals." Mobilization 16 (1): 81-100.

Shiva, Vandana. 1991. Ecology and the Politics of Survival: Conflicts over Natural Resources in India. New Delhi: Sage.

Sisodia, Yatindra Singh, and Tapas Kumar Dalapati, eds. 2015. Development and Discontent in Tribal India. Jaipur, Rajasthan, India: Rawat Publications.

Snow, David, Robert Benford, Holly McCammon, Lyndi Hewitt, and Scott Fitzgerald. 2014. "The Emergence, Development, and Future of the Framing Perspective: 25+ Years since 'Frame Alignment.” Mobilization 19 (1): 23-45.

Soule, Sarah A. 2009. Contention and Corporate Social Responsibility. Cambridge: Cambridge University Press.

Sowers, Jeannie. 2013. Environmental Politics in Egypt: Activists, Experts and the State. London: Routledge.

Svampa, Maristella. 2019. Neo-extractivism in Latin America: Socio-Environmental Conflicts, the Territorial Turn, and New Political Narratives. Cambridge: Cambridge University Press.

Spivak, Gayatri Chakravorty. 2004. "Righting Wrongs.” South Atlantic Quarterly 103 (2): 523-81.

Sridhar, V. K. 2010. "Political Ecology and Social Movements with Reference to Kudremukh Environment Movement.” Social Change 40 (3): 371-85.

Steinberg, Paul F., and Stacy D. VanDeveer, eds. 2012. Comparative Environmental Politics: Theory, Practice, and Prospects. Cambridge, MA: MIT Press.

Sundar, Nandini. 2006. "Bastar, Maoism and Salwa Judum." Economic and Political Weekly 41 (29): 3187-92.

Sundar, Nandini. 2008. Subalterns and Sovereigns: An Anthropological History of Bastar (1854-2006). 2nd ed. New Delhi: Oxford University Press India.

Tarrow, Sidney. 2005. The New Transnational Activism. Cambridge: Cambridge University Press.

Tarrow, Sidney. 2011. Power in Movement: Social Movements and Contentious Politics. 3rd ed. Cambridge: Cambridge University Press. 
Taylor, Marcus. 2015. The Political Ecology of Climate Change Adaptation: Livelihoods, Agrarian Change and the Conflicts of Development. London: Routledge.

Teets, Jessica C. 2014. Civil Society under Authoritarianism: The China Model. Cambridge: Cambridge University Press.

Temper, Leah. 2014. "Environmentalism of the Dispossessed: Mapping Ecologies of Resistance." PhD diss., Universitat Autònoma de Barcelona.

Tiwari, Nupur, ed. 2016. Tribal Self-Governance: PESA and Its Implementation. Jaipur, Rajasthan, India: Rawat Publications.

Triner, Gail. 2011. Mining and the State in Brazilian Development. London: Pickering $\&$ Chatto Publishers.

Tsing, Anna Lowenhaupt. 2005. Friction: An Ethnography of Global Connection. Princeton: Princeton University Press.

United Nations Conference on Trade and Development/World Trade Organization. 2012. "Iron Ore Concentrates by Country." International Trade Centre, assessed May 21, 2012, http://www.NationMaster.com/graph/eco_wor_tra_exp_iro_ore_ con-trade-exports-iron-ore-concentrates

U.S. Geological Survey. 2011. "Mineral Commodity Summaries, Iron Ore.” United States Geological Survey, accessed May 21, 2012, http://minerals.usgs.gov/minerals/pubs/commodity/iron_ore/mcs-2011-feore.pdf

Valdivia, Gabriela. 2015. "The Sacrificial Zones of 'Progressive' Extraction in Andean Latin America." Latin American Research Review 50: 245-53.

Vale. 2012. "Annual Report 2011." Vale S.A., accessed May 24, 2012, http://www. vale.com.br/en-us/investidores/relatorios-anuais-e-de-sustentabilidade/2011/ Documents/20F_2011_i.pdf

Vasi, Ion. 2009. "Social Movements and Industry Development: The Environmental Movement's Impact on the Wind Energy Industry." Mobilization 14 (3): 315-36.

Verma, Meenakshie. 2004. Aftermath: An Oral History of Violence. New Delhi: Penguin Books.

Walker, Richard A. 2001. "California’s Golden Road to Riches: Natural Resources and Regional Capitalism, 1848-1940." Annals of the Association of American Geographers 91 (1): 167-99.

Walsh, Edward J., Rex H. Warland, and D. Clayton Smith. 1997. Don't Burn It Here: Grassroots Challenges to Trash Incinerators. University Park: Pennsylvania State University Press.

Watts, Michael. 2004. "Resource Curse? Governmentality, Oil and Power in the Niger Delta, Nigeria.” Geopolitics 9 (1): 50-80.

Weber, Max. 1968. Economy and Society: An Outline of Interpretive Sociology, Volume 2. Edited by Guenter Roth and Claus Wittich. New York: Bedminster.

Wilkinson, Steven I. 2013. "Communal and Caste Politics and Conflicts in India." In Routledge Handbook of South Asian Politics: India, Pakistan, Bangladesh, Sri Lanka, and Nepal, edited by Paul R. Brass, 262-73. London: Routledge.

Willow, Anna J. 2018. Understanding ExtrACTIVISM: Culture and Power in Nature Resource Disputes. London: Routledge.

Wolford, Wendy. 2010. This Land Is Ours Now: Social Mobilization and the Meanings of Land in Brazil. Durham, NC: Duke University Press.

Wolford, Wendy, and Sara Keene. 2015. "Social Movements." In The Routledge 
Handbook of Political Ecology, edited by Tom Perreault, Gavin Bridge, and James McCarthy, 573-84. London: Routledge.

Ye, Jingzhong, Jan Douwe van der Ploeg, Sergio Schneider, and Teodor Shanin. 2020. "The Incursions of Extractivism: Moving from Dispersed Places to Global Capitalism." Journal of Peasant Studies 47 (1): 155-83.

Young, Kevin, and Michael Schwartz. 2014. "A Neglected Mechanism of Social Movement Political Influence: The Role of Anticorporate and Anti-Institutional Protest in Changing Government Policy." Mobilization 19 (3): 239-60.

Zhouri, Andréa. 2010. "'Adverse Forces' in the Brazilian Amazon: Developmentalism versus Environmentalism and Indigenous Rights." Journal of Environment \& Development 19 (3): 252-73.

Zhouri, Andréa, Paola Bolados, and Edna Castro. 2016. Mineração na América do Sul: Neoextrativismo e lutas territoriais [Mining in South America: Neoextractivism and territorial struggles]. São Paulo: Annablume Editora.

Zhouri, Andréa, and Klemenas Laschefski, eds. 2017. Desenvolvimento e conflitos ambientais [Development and environmental conflicts]. Belo Horizonte: Editora UFMG.

Zhouri, Andréa, and Norma Felicidade Lopes da Silva Valencio, eds. 2014. Formas de matar, de morrer e de resistir: Limites da resolução negociada de conflitos ambientais [Forms to kill, to die, and to resist: Limits of negotiated resolution of environmental conflicts]. Belo Horizonte: Editora UFMG.

Zonta, Márcio, and Charles Trocate. 2016. "A questão mineral no Brasil—vol. 2: Antes fosse mais leve a carga: Reflexóes sobre o desastre da Samarco/Vale/BHP Billiton.” Marabá: Editorial iGuana.

Zysman, John. 1994. "How Institutions Create Historically Rooted Trajectories of Growth." Industrial and Corporate Change 3: 243-83. 


\section{Index}

1988 Brazilian Constitution, 59, $253 \mathrm{n} 10$

Aam Aadmi Party Lok Sabha, 264n39

Adivasi, 61, 123, 135, 260n2, 263n34; access, 57-58; displacement, 10713, 143-45, 161-63, 168-69, 252n2; dwelling, 33, 261n9; holy sites, 37; indigenous peoples, 31, 248n1, 249n4, 263n29; leaders, 56, 105-6, 127; mines, 61, 128, 175, 177; movement, 55, 120-22, 12526, 186, 220, 260n3, 263-64n35, 264-65n39; networking, 172, 199, 267nn4-5; political games, 65, 174-75, 216; resistance, 94, 114-16, 123-25, 129-30, 147, 154, 179, 182, 185; symbolic acts, 159; tribal culture, 111; violence against, 118, 126, 166, 197. See also Gram Sabhas; indigenous peoples

Adivasi Mahasabha, 55, 253n5, 264n35 Afro-Brazilian quilombolas, 91 agency, 32, 34, 49, 68, 135, 207, 226, 229, 250n6, 260n2, 264n43; activist, $75,195,216,253 \mathrm{n} 9$; armed revolutionary, 20, 28, 101, 107, 114, 115, 126, 134, 136, 215-16, 264n35, 265n44; armed resistance, 22, 115; armed secessionary, 134; corporate, 51, 73, 91-94, 108-10, 118-20,
149, 158, 213-14, 217, 263n30; corporate-government, 128, 129; extractivist, 110, 215; nature, 37; peaceful, 118, 133, 228; resistance, $70,75,85,92,101,115,125,139$, 161, 228, 258n27; revolutionary, 35, 52-54, 112, 129, 215; society, 45; state-corporate, 133, 159, 163, 21214; willingness, xii All-India Adivasi Mahasabha, 55 Alvares, Claude, 180 Amazon rainforest, 13, 94, 233 Amnesty International, 171 Anaconda Operation, 130 Andean, 209, 229

Anglo American, 91-92 anthropocentric, 18, 37, 267n7; nonanthropocentric, 5, 38, 250n7 appropriation, 200, 225; extractivist 116; natural resources, 95, 109, 118; over, 226

armed conflict, 22, 48, 52-56, 68, 101, 105-7, 152, 205, 215-16, 229, 265n43-44; Chhattisgarh, 107-16, 147; context, 17, 19, 104; Dalli Rajhara, 116-18; Dantewada, 122-28; Eastern India, 133-37, 217; Jharkhand, 129-32; Kawardha, 11618; Manupur, 116-18; one-sided, 92, 104, 205; two-sided, 67, 127, 205;

Rowghat, 118-22 
armed revolution, $7,125,216,263 \mathrm{n} 32$; agency, 28, 101, 126-28, 134, 136, 215-16, 263-64n35, 265n44; conflicts, 54; groups, 7, 114-15; politics, 49, 52-55; resistance, 19, 49, 122, 139 armed secession, 54, 65, 106, 110, 13435,220

Ausangate, 37

Australia, 15, 134, 225, 246n10 authoritarian: authoritarianism, 45 , 228-29, 252n14; politicians, 217, 228; politics, 246n8; power, 228; regimes, 42, 45, 228

autonomy, 134-35, 163, 167, 211, 250n9; defense of, 5, 42; embedded, 51, 55, 60, 104, 164; financial, 167; increase, 78; movement, 18, 42, 210; political games, 56-58; resistance, 206; retaining, 16, 18-19, 42-43, 104, 193, 203, 216, 251nn11-12; state, $251 \mathrm{n} 13$; strong, 165

Bailadila, 123-25, 261n10, 263n30, $263 n 34$

Balco aluminum company, 159

Bangalore, 141, 184; Environmental Support Group 144-45

Banspal, 154, 163, 267n6

Bastar Division/region, 55, 107, 10916, 126, 130, 216, 261n10, 263n35

Baú mine, 84

bauxite mining, 8, 32, 65-66, 120, 155, 196, 200, 212, 222, 229, 269n6, 270n5

Bellary: case, 103, 259n37; district/ region, 14, 51, 71, 73-74, 206, 238, 255n5; Mafia, 15, 247n17; mine, 70; resistance, 75-82; republic of, 76

Belo Horizonte, 83, 191, 200, 206, 249, 257n23

Belo Monte dam, 56

Bharatiya Janata Party (BJP), 15, 74, 112, 119, 247n16, 249n4, 264n36, 266n 44

Bhilai Steel Plant (BSP), 116, 118-21, 125-26, 262n23, 263n 34
Bhubaneshwar, 153, 156, 163, 171, 176

Bicholim, ix, xii, 179, 183

Biodiversity, xi, 70, 142, 157, 222, 268n 10

Bittencourt, Carlos, 200, 270n2

Bolsonaro, Jair, 50, 217-18, 228

Bougainville, Papua New Guinea, 134

Bourdieu, Pierre, 5, 64; capital, 94, 254n13; theory of field, 48, 62, 135

Brahmani, river, 157

Brazilian Institute for Social and Economic Analysis (IBASE), 197, 270n2

Brazilian Landless Workers' Movement (MST), 17, 29, 36, 55, 150, 239, 259n43; autonomy, 198-99; 251n12; leadership, 96-98; massacre, 259n38; model, 266n2; movement, 85, 96102, 190-91, 194, 200, 207, 253n10, 256n13, 267n5; protests, 259n41; Woman's Day, 259n39

Brazilian MMX Mineraçáo company, 92, 258n28

BRICs countries, 9

British: rule, 59; education, 264n38; people, $268 \mathrm{n} 10$

brownfield, 30, 122, 130, 174

buen vivir, $85,250 \mathrm{n} 7,255 \mathrm{n} 7$

Cajamarca: Yanacocha project, 209

Cameron, James, 84

Campaign for Survival and Dignity (CSD), 199-200

campaigning, 169; antimodernist, 85; electoral politics, 77; Keonjhar, 169, 172; key strategy, 16-17, 36-37, 164, 203; local, 151, 181; nonmodernist, $86,146,154,167,180,203$; peaceful, 123; resistance, 75, 206, 253n6, 253n9; vertical, 185. See also five key strategies

Canada, 193-94, 202-3, 207; United Steel Workers of Canada, 193

Capanema mine, 84 capital, 29, 116, 152, 195, 217, 229, 251n11, 259n37; accumulation, 28, $82,90,109,227$; extractive, 5, 8; eco- 
nomic, 63, 80, 98, 175; expansion, 4, 72; government, 130; physical, 35, 63, 74; private, $110,126,133$; regulation, 35; social/cultural, 57, 63, 65, 93-94, 99, 103, 159, 219, 254n13, 259n39; symbolic, 63-66, 80, 8588, 93-94, 103, 160, 175, 220-21, $254 \mathrm{n} 13$

capitalism, 11, 38, 66, 130, 199, 218, 225, 255n7, 265n43; anticapitalist, 220; Brazilian, 102; challenges to, 85; expansion of, 71, 95, 218, 226, 249nn3-4; global, 3, 30, 52, 223; predatory, 29. See also world-ecology Carajás, 99-100; Eldorado dos Carajás, 98, 259n38; export orientation, 108; frontier 135; 212; Great Project; 95; mine, xiii, 13, 29-30, 94-96, 98-99, 102, 239, 256nn15-16; National Forest, 96; peasants 96; protest/resistance, 98-99, 101-2, 182, 190-91, 194, 213, 259n42

Casa de Pedra, 83, 87-88, 94, 258n28 caste, $248 \mathrm{n} 2$; anti-upper caste; $185-86$; backwards, 159; Brahmin, 147, 186; cleavages, 154, 185, 187, 246n8; cross-caste, 149, 178-88; Dalit, 36, 151, 159, 186, 252n2; 256n10; depressed, 53; discrimination, 147; lower-caste, 31, 159, 185; noncaste, 185, 216, 252n2, (see Dalit); politics, 185; Scheduled; 159, 186; trader, 115; untouchable, 159; upper-caste, 33, 53, 108, 147, 179, 185-86, 213

Catholic Church, 89, 259n40

Central America, 209

Central Empowered Committee (CEC), 148

Central India, 52, 107

Centre for Science and Environment, 56, 73, 197-200, 268n11, 269n4

Centre, the, 58, 119, 177, 257n17, $253 n 7,261 n 9$. See also New Delhi

Chhattisgarh, 37, 53, 55, 95, 123, 12829, 133, 247n13, 262n23, 263nn3435, 267n4; armed conflict, 105-16,
147, 156, 187, 260n3, 262n20, 264n37, 270n5; Bachao Andolan, 14, 121; export; 263n30; High Court, 113; mine closure, 125; Mukti Morcha (Chhattisgarh Liberation Front, or CMM), 118-20, 262n20, 270n5; PUCL (People's Union for Civil Liberties), 121; union, 126

Chiapas, Mexico, 28

Chico Mendes Institute for Biodiversity Conservation (ICMBio), 84, 257n19

China, 9, 11, 14, 45, 246n10, 260n1, $262 \mathrm{n} 18,263 \mathrm{n} 32$

civil war, 52-53, 55, 101-2, 107, 133-35, 204, 216, 236, 238, 261n8; context, 111, 126-29, 265n43; Eastern Indian, 110, 136, 147, 199; manufactured, 109, 215

clientelism, 18, 236, 254n11, 257n18. See also proextractivist

climate: change, 8, 11, 35-35, 219, 225; crises xi, 203, 217; negotiation, 186; strikes, 233

coalition, 102; building, 22; global, 194, 228; national, 194-95; resistance, 85, 140, 222, 228, 260n44; transnational, 29, 190, 194, 207, 222, 245n4; working-class, 135 commodity paradigm, 2, 4, 10, 256n12 communist: radical movements, 52; ideology 54; party 107, 119; trade union, 118, 122, 262n18

Communist Party of India (CPI), 119, 262n18, 263n32; Maoist, 252n4, 262n18, 263n32; Marxist, 157; (Marxist-Leninist) (CPI (M-L)), 53, 262n 18

Companhia Siderúrgica Nacional (CSN), 87-88, 258nn27-28

Conceição de Mato Dentro region, 91 conflict: avoidance, 5, 154; dynamics, 8, 33, 35-36, 91, 94, 160, 180, 221, 224, 264n37, 270n5; environmental, $21,34,50,62,147,211,229$; internal, 185-87; iron ore, 142, 147, 152, 154, 173; local level, 7, 49; mining, 
conflict (continued)

10-13, 32-33, 78, 95-97, 154-55, 178, 253n11, 255-56n9; ontological, 229-31, 259n41; outcomes, 7, 140, 154, 245n6; physical, 21821 ; resolution, $30,145,257 \mathrm{n} 18$; social, 218-21; symbolic, 218-21. See also armed conflict; nonarmed resistance

Congonhas, 30, 39, 87-93, 100, 214, 219, 263n35

Congress Party India, 74, 119, 247n16, $264 n 36$

contentious politics, 21, 34, 43, 49-50, 53, 89, 103, 175, 229; investment outcomes, 204-8; peaceful, 110; protesting 135, 193; non-violent, 156; scholarship, 62; specialists, 100; state-mediated, 40; study of, 204 coproduction: civil society, 44, 210; institutional, 41-42, 199, 253n10; key strategy, 16; opportunity structures, 58; politics, 39, 206; steps of, 60-62; strategy, 19, 52, 58, 68, 79, 103-4, 184, 198, 255n5; targeted voting, 174, 253-54n11. See also five key strategies corporate countertactics, 183 corporate social responsibility, 19, 50, $85,99,103,165,194,213,265 \mathrm{n} 40$

Corumbá, 206, 248n22

Council on Mines and Energy, 89 countermovement, 1435 80, 82, 183, 211-12. See also Polanyian countermovement

crises, 38; global, 1, 11, 64, 217, 224, 233; modern, 228; socioenvironmental, xi, 203; sustainability, 1

crisp-set (csQCA), 236, 269n7

Cusco, 37, 229

da Silva, Luiz Inácio, 50

Dalli Rajhara, 270n5; mine, 30, 11619, 133, 258n27, 261n10, 262n23; resistance, $265 \mathrm{n} 41$
Dantewada, 108-10, 112-13, 115-16, 122-28, 133, 238, 260n3, 261n10, 262n23, 263n35

Das, Samarendra, 180

Dayamani Barla, 265-65n39

de jure rights, 41, 113, 115, 210

de Sousa, Hartman, 180

de Souza, Delfino (Delzinho), 91

de Souza, Geraldo Sales, 89

deforestation, 50

democracy, 30, 55, 59, 79, 128, 175, 187; consolidating, 21, 45, 70-82, 103, 120, 135, 183, 185, 217, 246n8; deep, 7, 134, 185, 254n12; Indian, 72, 253n7, 264n37; local, 75; promotion, 246n8, 255n7

democratization, Brazilian, 59; Indian, 59,70

development, 35-36, 62, 215, 249nn45, 250n7, 250n9, 258n27; agendas, 13; anti-, 115; failure, 30; fund, 194, 269n3; global capitalist, 3; local, 87, 119; positive, 4; misguided, 3; mal-, 12; negative, 4; neo-, 95; policies, 101; project, 95, 107, 150, 172, 226; resource based, 65, 227; rural 131, 260n7; state, 43, 178, 211, 251nn1011; under-, 224

Development Initiative, 161, 176 direct action 29, 182; nonviolent, 4950, 52-53, 55, 72, 164, 215; violent, 159, 179

Direction of Mines, 148

Durg district, 116-17

earth-being , 37, 229

Eastern Amazon, 13, 21, 83, 94-95, 102, 106, 109, 189-91, 206, 212, $247 \mathrm{n} 13$

Eastern India, 14, 79, 101, 109-11, 120, 133-34, 140, 171, 183, 213, 247n13; armed resistance, 107, 217; civil war, 110, 136, 147, 199; iron ore, 102, 133, 206; guerrilla, 68, 159; mining resistance, 106, 134, 140, 264n37; resource frontier, 95, 128 
economic outcomes, 20-21; conflicts, 21; key strategy, 67, 137, 140, 200201, 214; political, 32; resistance, 85-86, 104, 134-35, 187-88, 190, 194-95, 206-8, 256n16, 259n43; state, 60; study of, 5, 17, 36, 214

EJOLT (Environmental Justice Atlas), 209, 239, 248n 22

Eklama area, 120, 263n26

embedding, civil society, 41-42, 59, 61, 76-77, 84, 251nn10-11, 254n12, 257n20, 270n1; corporate, 152, 194; electoral, 56, 60, 77, 100, 172-73, 198-99, 206; encompassing, 135-36; failure, 177; institutional, 56, 58, 73, 90, 128, 172, 198; judicial, 78, 104, 123, 136, 196, 206-7, 259n43; key strategy, 16-19, 36, 165, 203; lack of, 124, 127, 133, 144, 151, 162, 172; process, 42-45, 59-61, 104; strategy, 51-52, 75-80, 89, 114-15, 123, 146, 154, 173, 195, 216, 252n16; transnational, 62, 227. See also five key strategies

environmental justice, ix, 31; local, 222; in-, 192; movement, 223

environmentalism, 30, 118; indigeneity, 65; studies on, 31 ; trade union, 258

environmentalist, 33, 121, 144-45, 166; coalitions, 245n4; politicians, 87; stances, 30

Espírito Santo, 97

Essar, 109, 124, 126-27, 130, 176, 263n35, 264n36

ethnography: multisited, 236, 238, 249n3; multisited political, 7, 187, 224; political, 236 extraction zones, 6, 16, 213 extractivism: agroextractivism, 4; extrahere, 4; forestry, 4, 20; global, 5, 22, 29, 70, 136, 139, 203-4, 228, 250n9; (extractivist) expansion, 47, 63, 68, 79, 90, 104, 123, 133, 270n1; hyperextractivism, 217; (neo-)extractivism, 218, 224, 228; postextractivist, 85-
$86,135,218,223,231$; proextractivist, 18, 43, 219 (see clientelism) extrahuman, 37, 39, 227

FAO (Food and Agriculture Organization of the United Nations), 62, 254n 12

Father Antonio, 191-94, 269n3

feminist, 34, 151

Finland, 27, 47, 105-6, 203, 227, 250-51n9

five key strategies, 19, 36, 67, 102, 122, $167,205,222$; building on, 102, 165 , 194; hypothesis, 16-17, 90, 153-54; simultaneous, 145-46, 178, 183, 185-87, 205-6, 207-9; in use, 1-2, 20-23, 80, 180, 195-96, 201, 203, 229, 248n22, 266n3

Fomento Company, 72

food sovereignty, 17, 62, 254n 12

FRA 2006 (Scheduled Tribes and Other Traditional Forest Dwellers (Recognition of Forest Rights), 41, 112-14, $124,129,163,182,260 \mathrm{n} 7,261 \mathrm{n} 9$

Frankfurt school, 34

Gadchiroli district, 117

Gandarela: aquifer, 83; blog, 84; hills 84, 257n23; movement, 86, 256n16; region, 85

Gandhi, Mahatma, 27; Gandhian, 26, 53; social movement, 59, 187, 255n7, 266n1

Gandhi, Sonia, 74

Ganjamale hill, 148

Gauns, Ramesh, ix, xi, 179, 183-84

Global North, xii, 22, 42, 47, 190, 250-51n9

Global South, xii, 7, 22, 31, 34, 42, 47, 77, 184, 190, 221

global warming, 8

globalization, 13, 30, 102, 221, 227

Goa, 14, 61, 69-73, 79, 81, 103, 109, 247n13, 263n29; High Court, 184; key strategy, 153, 186; mining, ix-xii, 57, 212-13, 248n20; NGOs, 39; outcomes, 1, 143, 152, 176, 178, 203, 
Goa (continued)

206, 208, 212-14, 218-19; resistance, 62, 67, 140, 154, 158, 177-87, 196, 230-31, 260n44, 270n5

Goa Federation of Mine Affected People, 181-82

Goa Foundation, 15, 73, 78, 180

Goa, Goa, Gone, 180

Goa-net, 179

Godawari Power \& Ispat, 117

Goenka, S.N., 27

Gomez, Ednalva Moreira, 98-99, 191

governance, 1, 56, 98, 132, 205, 227,

254n12; context, 9; environmental, 7, 40-42, 45, 195, 204, 207, 221, 225, 245n5, 255n5; global, 11, 222; mining, 16; mechanisms of, 51, 76, 196, 202; radical, 113; top down, 75

Gram Panchayats, 113, 129

Gram Sabhas, 113, 127-28, 261n7, $265 n 44$

grassroots actions, 11

Green Hunt Operation, 130, 252n4 greenfield, 90; Apolo, 83; expansion, 90, 116, 239; Kawardha, 118-22; politics, 132; projects, 21, 123, 125, 130, 132, 174, 176, 203; resistance, 17, 259n43, 265n40; state-owned, 176

Harichandanpur, 163, 267n6

Hindu, 186, 248-49n2, 249n4, 260n2

The Hindu, 118

historic natures, 32, 249n3

Ho people, 130, 132

Humala, Ollanta, 209

identity: Adivasi, 163; building, 163; ethnic, 177; organizational, 267n5; political, 7

ideology, 225; Adivasi, 134; building, 52, 54; extractivist, 5-6; free-market, 72; liberation theology, 192, 269n1; leftist, 134, 216; state, 249n4 impacts: civil-society, 40; dynamics, 54, 108, 191; global, 3, 16, 195; investment, 115; key strategy, 178; metapolitics, 230; mining, 123, 126, $158,161,164,168,189,197,225-$ 27, 247n11; resistance, $15,21,37$, 127, 140, 150, 214-15, 217, 257n26; social movement, 6,140

Imperatriz, 97

Indian Administrative Service of Andhra Pradesh, 127

India's Supreme, Court Green Tribunal 77, 156, 207

indigeneity: framing, 249n4; politics, 33; symbolic capital, 65

indigenous peoples, 14, 69, 213; Adivasi, 31, 248n1; uprising, 123, 248n22; world view, 66

Indonesia, 11, 116, 247n17

injustice, 36, 160; class, 134, 222; environmental, 192; ethnic, 92, 95, 223; study of, 55

institutionalization, $251 \mathrm{n} 10$; physical position, 64-65

International Articulation of People Affected by Vale, 191

investment outcomes: agency, 53, 133, 135; class dynamics, 99; key strategy, 67, 205, 266n3; politics, 258n28; resistance, 19, 37, 60, 122, 133, 152, 207, 217; study of, 11-13, 245n6

Jagdalpur, 113

Japan, 123, 145, 246-47n10, 263n30, 266n 1

Jharkhand, 22, 95, 106, 120, 128, 133, 151, 154, 247n13, 264n38; activists, 177, 221, 253n6; Adivasis, 172, 216, 220; armed conflict, 129-32; illegal mining, 125; Mukti Morcha, 129; resistance, 156, 220, 265n40; steel, 197, 263n35

Jindal, 151; Steel \& Power company, $146,151,196,267 \mathrm{n} 4$

Joda, 61, 154-55, 168, 177, 223, 237, 267nn5-6

Judges for Democracy, 193

Jurutí, 200, 269n6 
Justice on the Rails (JoR), 85, 99, 102, 190-95, 200, 207

Kanker, 115-17, 261n10, 263n25

Karma, Mahendra, 109, 112, 124, 127

Karnataka, 61, 71, 74, 77, 152, 176, 178, 206, 247n13, 255n5; BJP, 74; High Court, 143; mafia, 15, 72, 149; mining, 70, 179, 247n16, 248n20, 268n11; nonarmed conflict, 21 , 260n44; Rajya Raitha Sangha, 144; SPS, 51, 103

Kawardha district, 120, 133, greenfield project, 116, 118-22

Keonjhar, 163-75; Banspal, 154, 163, 267n6; Harichandanpur, 163, 267n6; Telkoi blocks, 163, 267n6

Kerala, 43, 153, 208, 247n13, 251n11

Khandadhar, 154, 156, 158, 162-63, 268nn10-11; forests, 163; mobilization, 175; movement, 164, 270n5; Surakhya Sangram Samiti, 157; waterfall, 157

Koida block (Koira), 154-55, 161-63, 177

Kolham village, 179

Kond people, 66, 229

Kudremukh, 141-42, 152, 206, 214, 219, 222; closure, 146, 268n11;

KIOCL Iron Ore Company Limited, 176, 268n11; mines, 70; ore, 263n35, 266n1; resistance movements, 140 , 142-45; Tiruvannamalai, 158

Kunjam, Manish, 264n35

Kushalnagar, 144

labor unions, 30, 90, 258n27, 262n20

land grabbing, 92, 108; government, 127; study of, 34, 211, 237; resistance, 211

landscape: physical, 79-80, 95, 175, 202; transformation, $47,79,82,160$, 254n13, 259n37

Latin America: civil-society, 18; extractivism, 3, 224, 228; mining, 12,
99, 192, 209, 217; movements, 66, 99, 101, 218, 235, 250n7, 253n11; (neo-)extractivism, 3, 209; study of, 3, 31, 38, 230, 258n27, 268n 1

La Via Campesina, 62, 85, 144, 199, 254n12, 256n13, 259n39, 269n5 lived environments, 32-33, 35, 121, 135, 137, 153, 189, 226, 233, 249n3; Eastern Amazon, 95; indigenous, 84, 109, 230; loss, 39; nonanthropocentric, 5, 66; sustainable, 152, 230; transformation, 1, 82, 94, 167

Lokayukta, 75-77, 255n5

Maharashtra, 27, 117

MAM (Movimento dos Atingidos pelo Mineração [Movement for Popular Sovereignty in Mining]), 86, 96, 101, 196, 199, 256n13, 256n16; Movimento Nacional pela Soberania Popular frente à Mineração, 191, 195, 256n13

Manacas, Ulisses, 96, 98

Manmohan Singh central government, 198

Manpur mine, 116-18, 133, 238

Manush, Piyush, 147

Maoist, 110-18, 126, 129-31, 155, 165, 170-72, 260n3, 261n8; armed resistance, 55; guerrilla, 46, 52, 54, 110-12, 118-19, 127, 133-34, 126,216 ; insurgency, 52, 54, 65, 102, 108, 116; politics, 55, 252n4, 262n18, 270n5; resistance, 120, 134, 156, 160, 260n2, 263n35; revolution(aires), 28, 107, 129, 133, 263n32; Sanghams, 54

Maoist cases: Bastar, 112; Dalli Rajhara, 116-18, Dantewada, 122-28, 265n41; Kwardha, 118-22; Manpur, 116-18; Rowghat, 118-22

Maranhão, 15, 30, 97, 182, 189, 192, 206-7, 239, 247n13

Mariana, 15, 30, 39, 88-90, 100, 214, 219

Mariana Viva, 89 
Marx, Karl, 218; Marxist theories, 34; class, 22; labor, 205; neo-Marxist, 13; post-Marxist, 34; primitive accumulation, 28

mass social movements: absence of, 81 , 83, 86, 239; Goa, xi; grassroots, 17; key strategy, 16, 22, 140, 203; politicizing, 146, 164, 167, 209; radical, 196, 200; resistance strategy, 91, 117, 142-43, 146, 151-52, 196-97. See also five key strategies

Mayurbhanj district, 161

Mina Del Rey, 83, 88-90, 93-94

Minas Gerais: resistance, 60, 82-94, 136, 191, 239-40, 249-50n5, 259n37, 259n42; state, 21, 30, 193, 206, 214, 226, 230, 246n10, 256n12 Minas-Rio Mineduct Project, 90-94 Minerals (Regulation and Development) Act of 1957, 15, 253n8; amendments 2015, 15

mining: Arctic, 47, 227; booms, 11-16, 63, 155, 207, 225, 250n9; illegal, 14-16, 73-74, 76, 114, 119, 125-26, 175-77, 247n16, 248n20, 253n8, 265n40; legal, 16, 175; mining mafia, 15, 61, 72-76, 80-81, 149, 156, 173, 176-77, 198, 247n17; scams, 43, 71, 186, 257n16; selfish, 74; terrorism, 180,185

mining expansion, 12-13, 55, 84, 90, $96,106,129,162,179,203,212$; resistance, 88, 123, 156, 161, 16364, 190, 215, 219; state-led, 129; violent, 108, 120, 136

Ministério Público, 44, 57

Ministry for Agrarian Development, 198 Ministry of Agriculture, 198

Mittal, 164, 176; ArcelorMittal, 197, 220, 264n39; family, 108; Lakshmi Mittal, 220

MMP (Mines, Minerals and Peoples), 41, 114, 155, 176, 195-97, 199, 200, 253n7

MMX-Anglo Ferrous, 91

modernics, 37, 250 modernity, 66, 84, 109, 221, 226, 228, 230, 233, 267n7

Modi, Narendra, 217; government, 56, 218, 261n9

Mohapatra, Subash, 107, 177

Moore, Jason, 4, 11, 32, 38, 66, 95, 225-26, 249n3, 255n7, 267n7. See also world-ecology

MOU (Memorandum of Understanding), 108, 120, 124, 126, 129, 15556, 173-74, 206, 264n36, 268n 11

movement: building, 17, 123, 151; transnational, 191-92. See also five key strategies

Mulnivasi, 186

Mumbuca, 91

Munda tribal, 264-65n39

Nagarnar, 113

National Adivasi Alliance, 113, 261n9

National Centre for Advocacy Studies, $157,160,261 \mathrm{n} 8,268 \mathrm{n} 10$

The National Human Rights Commission, 183

National Mineral Development Corporation (NMDC), 37, 113, 119, 12325, 263n30, 263n34, 264n36

nature, 4-5; appropriation, 4 "cheap nature," 4, 11; historic, 32, 249. See also Moore, Jason

Naxalite, 55, 107, 112, 115, 120-21, 145, 147, 252n4, 265-66n44; armed, 53, 123-24, 264-64n35; guerrilla, 114; Naxalbari village, 107; Naxalism, 107, 265n44; resistance, 270n5

networking: Adivasi, 163, 172; civil society, 62; events, xiii; inter-movement, 29, 142-43, 157, 180, 193-94, 207, 222, 228; key strategies, 16-18, 36, 39, 165, 203, 206; lack of, 123, 151, 162, 267n4; mass movement, 162; national, 146, 200; replicative, 158 , 266n2; resistance, 129, 133, 182-83, 193, 245n6; violence, 170; virtual, 179; weakened, 164, 185, 187. See also five key strategies 
New Delhi, 78, 109, 189, 196; government, 119

New York Times, 135

NGOs (non-governmental organizations), 17, 83, 165, 249n5, 207-8, 219, 222

Niamgiri, 37; bauxite, 155, 270n5; Hills, 65, 229; litigation, 197; mining, 37; struggle, 66

nonarmed resistance, $17,21-22,52,63$, 68, 70, 106, 109-110, 114-15, 136, 263n35; Apolo, 83-86; Carajás, 94104; Casa de Pedra, 87-88; Mina Del Rey, 88-90; Minas Gerais, 82-83; Minas-Rio, 90-94; Rowghat, 121; Western India, 70-82

nonmodernist framing, 37, 65-66; campaigning, 86, 180. See also five key strategies

Northeast India, 33, 54, 134

objectification: social position, 64-65, 80, 159; symbolic power, 169

Observatorio de Conflictos Mineros de América Latina, 193

Odisha, 44, 59, 61, 114-15, 209, 213, 216, 223, 229-30, 247n13, 266n3; cases, 153-62; outcomes, 175-78

organic society, 255nn5, 7; building, 72, 81, 103, 147; established, 106; Goa, 78-79, 81-82, 152, 176, 179; theory, 29, 35, 43, 71, 217

Ouro Preto, 89

outcomes: movement, 5, 81, 122, 178, 206; negative, 4; positive, 36, 94, 97, 180; residual, 177; resistance, 68, 79, $82,217,221,240,248 \mathrm{n} 2$. See also economic outcomes; political outcomes

Paikray, Prashant, 157

Pallamad mines, 117

Palmares Settlements 29, 96, 98, 239, 259n39

Panchayats (Extension to Scheduled Areas) Act of 1996 (PESA), 112-14

Pará, 83, 95-97, 99-101, 182, 190,
200, 206-7, 246n10, 247n13,

256n16; Parauebebas municipality, 29, 96, 239

paramilitary forces, 111, 126, 130-31, 215

participant observation, 85, 100, 124, 235-38, 249n3, 269n6

Particularly Vulnerable Tribal Groups (PVTG), 157. See also FRA

Pastoral Land Commission (CPT), 97, 259n40

Paudi Bhunya, 157

peasant, 52, 91, 96, 111, 159, 230; Adivasi, 108; landless, 53; middle-class, 31; movements, 27, 101, 144, 269n5; rights, 262n20; uprising 107

Pequiá, 191-93

peripheral territory, 70. See also resource frontier

pig-iron, 96, 189, 192-93, 239

Polanyi, Karl: analysis, 103; countermovement, 30, 35, 71-72; theory, 28-29, $43,79,217$. See also organic society political ecology, 21-22, 30-31, 62, 66, 238, 245n1

political economy, 10, 38; agrarian, 21, 28; global, 4, 6-7, 202, 206, 226-27, 246n10; theories, 5, 224

political games, 47-52, 56, 58, 77, 92, 127, 175, 223; Adivasis, 65; agencies, 132, 139; armed conflict, 52-56, 128-29, 135; key, 39; opportunity, 41; policy-making, 205; resistance, 44, 102-3, 109-10, 128; routine, 111, 129; state embedding, 59, 86; state mediated, 39-40, 45, 58-59, 104, 110, 129, 152, 202, 208, 216; theory, 7, 206, 219, 252n1

political ontology, 33, 39, 230, 245n1, $254 \mathrm{n} 14$

political outcomes 19-20, 30, 48, 81, 89, 106, 127, 162, 187, 190, 194, 200, 215; global, 188, 195, 207; important, 85, 223; influences, 145; investment politics, 135; lack of, 163; study of, 5 
Pollution Control Board, 173, 184

POSCO, 154-57, 159-61, 164, 175-

76, 213, 260n1, 266n1, 268n11

POSCO Pratirodh Sangram Samiti (the Anti-POSCO People's Movement, or PPSS), 157, 160

post-Cartesian, 32-33

protesting: Adivasi, 260n2; local, 182,

266n2; lack of, 197; key strategy,

16-18, 36, 39, 140, 164, 172, 196,

203; outcomes, 217; peaceful, 123,

142, 158-59, 163, 193, 207, 210;

physical, 81, 122, 193, 222, 256n11;

resistance strategy, 75, 96, 99, 133,

135, 145-47, 151-52, 162, 169, 206, 253n9; tactic, 259n43. See also five

key strategies

Public Prosecutor's Office (Ministério

Público), 44, 92

Quadrilátero Ferrífero (Iron Quadrangle), 83, 88, 206

Qualitative Comparative Analysis, 235; crisp-set (csQCA), 236, 269n7

Raipur: Alloys 117; area, 105, 117-18 Rajnandgaon district, 117

Ramesh, Jairam, 131, 199, 261n9

Ranchi, 197, 220, 264n39

Reddy brothers, 74, 76, 247n17

resource frontier, 103, 200, 213,

219, 254n13; commoditizing, 95;

expansion, 31, 52, 94-104, 116, 245n2; global, 83, 94, 213, 223; key, 99, 101-2, 104; militarized, 215; national, 22, 70, 94-95, 223, 212; new, 14; primary, 95, 106, 128; social spaces, 103; violent 97, 101. See also peripheral territory

resource nationalism, 6

Rio de Janeiro, 91-92, 97, 99, 189, 193, $247 \mathrm{n} 12$

Rodrigues, Sebastian, ix, xi-xii, 27, 69, 179-80, 182, 186, 245n4; poem, 180-81

Rourkela Steel Plant, 161, 163, 267n4
Roussef, Dilma, 57, 84, 95

Rowghat, 116, 118-22, 124-26, 133, 213, 238, 261n10, 262n23, 263n26, $263 n 34$

Roy, Arundhati, 66

Russia, 9, 11

Saldanha, Leo, 144-45, 266n1

Salem, 22, 141-42, 146-51, 206, 214, 270n5

Salwa Judum, 108-110, 112, 124, 127, 260n3

Samaj Parivartan Samudaya (SPS), 51, 71-78, 81

Samta Manch movement, 114

Santos, Rodrigo, 92, 101, 256n13

Sarda Energy \& Minerals Limited, 117

Sarda mines, 117, 261n13. See also

Raipur: Alloys

satyagraha, 36, 53, 81, 256n11

Scheduled Tribes, 41, 112, 123, 136, $263 n 29$

Serra do Gandarela, 84, 256-57n16

Serra Pelada, 97, 191

Shah Commission, 114, 119, 131-32, 175-77, 183, 198, 217; creation, 58, 61, 76, 198, 253n8; dismantling, 114; report, $14,265 \mathrm{n} 40$

South Africa, 11

South Asia, 31, 46; east, 111

South Korea, 155, 260n1

Southern India, 134, 147, 206, 247n13, $25 \ln 11$

Soviet Union, 118, 262n18, 263n32

stakeholder, 47, 84, 257n20; compensation, 165; dialogues, 20, 92, 202, 207; relations, 50, 195

Steel Authority of India Limited [SAIL] Company, 108, 119-20, 125, 176, $267 \mathrm{n} 4$

steel towns, $\mathrm{x}$, xiii, 153

Sundar, Nandini, 109

Sundargarh district, 154, 158, 161-63, 165-67, 175-77, 266nn3-4

"supercycle": commodity, x, xiii, 4; iron, 108; mining, 3 
Supreme Federal Court, 44

sustainability, 71, 99, 192; challenges, 3, 22-23, 224; global, 1

symbolic acts of merit, 64, 79, 81, 159-

61,180

Tamil Nadu, 43, 141, 247n13; activists, 22; cases, 142, 145, 152, 206; hills,

37; religious tourism, 214; resistance movements, 140, 230, 260n44; state embedding, 146-52

Tata Steel Plant, 113, 159, 263-64n35

Tehelka, 124, 176, 263-64n35

Telkoi blocks, 163, 267n6

Times of India, 177

Tiruvannamalai, 142, 146, 148, 151, $158,206,214,238,270 \mathrm{n} 5$

trade unions, 30, 82, 89, 100, 118, 125,

135, 248n2; mining, 90, 119, 190,

219; networks 30; power, 120

Traditional Leaders Forum, 129

trust, 36, 64, 167, 240

Udub, 141

upstream struggles, 16, 190-95, 212, 222,225

Vale, 83, 89, 96-98; anti-, 30, 89, 9697; Apolo, 83-88, 90, 93-94, 100, 200, 249n5, 256nn14-16, 257n19, 257n23; Carajás, 95, 98; Corporation, 29; directors, 99; executives, 100; headquarters, xiii, 99; trade union, 97, 99; workers, 100

Vale do Aço (Valley of Steel), 83

Vedanta, 15, 65, 155, 164-66, 176, 179, 196-97, 270n5

Velip village, 179

violence: symbolic, 5, 103, 159-60, $254 \mathrm{n} 13$

VKG Steel and Energy Company, 148

web of life, 5, 65-66, 226, 245n2

Western: worldview, democracy, 45, 226; experiences, 59; modernity, 221, 250n7; understanding, 5, 34, 37; way of life, 18

Western Ghats, ix, xi, 69-70, 141-42, 144-45

West Singhbhum, 111, 128-33, 156, 216, 220-21, 223, 238, 264nn3940, 270n5

Workers' Party (Partido dos Trabalhadores), 50, 89, 95

World Bank, 8

world-ecology, 5, 22, 33-34, 102, 22526, 249n3

World Social Forum, 191

Zapatistas, 28, 215 
